University of Nebraska - Lincoln

DigitalCommons@University of Nebraska - Lincoln

Papers in the Earth and Atmospheric Sciences

Earth and Atmospheric Sciences, Department

2011

\title{
Late Pleistocene dune activity in the central Great Plains, USA
}

Joseph A. Mason

University of Wisconsin, Madison, mason@geography.wisc.edu

James B. Swinehart

University of Nebraska-Lincoln, jswinehart1@unl.edu

Paul R. Hanson

University of Nebraska-Lincoln, phanson2@unl.edu

David Loope

University of Nebraska-Lincoln, dloope1@unl.edu

Ronald J. Goble

University of Nebraska-Lincoln, rgoble2@unl.edu

See next page for additional authors

Follow this and additional works at: https://digitalcommons.unl.edu/geosciencefacpub

Part of the Earth Sciences Commons

Mason, Joseph A.; Swinehart, James B.; Hanson, Paul R.; Loope, David; Goble, Ronald J.; Miao, Xiaodong; and Schmeisser, Rebecca L, "Late Pleistocene dune activity in the central Great Plains, USA" (2011). Papers in the Earth and Atmospheric Sciences. 316.

https://digitalcommons.unl.edu/geosciencefacpub/316

This Article is brought to you for free and open access by the Earth and Atmospheric Sciences, Department of at DigitalCommons@University of Nebraska - Lincoln. It has been accepted for inclusion in Papers in the Earth and Atmospheric Sciences by an authorized administrator of DigitalCommons@University of Nebraska - Lincoln. 


\section{Authors}

Joseph A. Mason, James B. Swinehart, Paul R. Hanson, David Loope, Ronald J. Goble, Xiaodong Miao, and Rebecca L Schmeisser 


\title{
Late Pleistocene dune activity in the central Great Plains, USA
}

\author{
J. A. Mason, ${ }^{1}$ J. B. Swinehart, ${ }^{2}$ P. R. Hanson, ${ }^{2}$ D. B. Loope, ${ }^{3}$ R. J. Goble, ${ }^{3}$ \\ X. Miao, ${ }^{4}$ and R. L. Schmeisser ${ }^{5}$
}

\author{
1. Department of Geography, University of Wisconsin Madison, 160 Science Hall, 550 N. Park St., Madison, WI 53706, USA \\ 2. School of Natural Resources, University of Nebraska-Lincoln, Lincoln, NE 68588-0517, USA \\ 3. Department of Geosciences, University of Nebraska-Lincoln, Lincoln, NE 68588, USA \\ 4. Illinois State Geological Survey, Champaign, IL 61820-6964, USA \\ 5. St. Norbert College, De Pere, WI 54115, USA \\ Corresponding author — J. A. Mason, tel 608 262-6316, email mason@geography.wisc.edu
}

\begin{abstract}
Stabilized dunes of the central Great Plains, especially the megabarchans and large barchanoid ridges of the Nebraska Sand Hills, provide dramatic evidence of late Quaternary environmental change. Episodic Holocene dune activity in this region is now well-documented, but Late Pleistocene dune mobility has remained poorly documented, despite early interpretations of the Sand Hills dunes as Pleistocene relicts. New optically stimulated luminescence (OSL) ages from drill cores and outcrops provide evidence of Late Pleistocene dune activity at sites distributed across the central Great Plains. In addition, Late Pleistocene eolian sands deposited at 20-25 ka are interbedded with loess south of the Sand Hills. Several of the large dunes sampled in the Sand Hills clearly contain a substantial core of Late Pleistocene sand; thus, they had developed by the Late Pleistocene and were fully mobile at that time, although substantial sand deposition and extensive longitudinal dune construction occurred during the Holocene. Many of the Late Pleistocene OSL ages fall between 17 and $14 \mathrm{ka}$, but it is likely that these ages represent only the later part of a longer period of dune construction and migration. At several sites, significant Late Pleistocene or Holocene large-dune migration also probably occurred after the time represented by the Pleistocene OSL ages. Sedimentary structures in Late Pleistocene eolian sand and the forms of large dunes potentially constructed in the Late Pleistocene both indicate sand transport dominated by northerly to westerly winds, consistent with Late Pleistocene loess transport directions. Numerical modeling of the climate of the Last Glacial Maximum has often yielded mean monthly surface winds southwest of the Laurentide Ice Sheet that are consistent with this geologic evidence, despite strengthened anticyclonic circulation over the ice sheet. Mobility of large dunes during the Late Pleistocene on the central Great Plains may have been the result of cold, short growing seasons with relatively low precipitation and low atmospheric $\mathrm{CO}_{2}$ that increased plant moisture stress, limiting the ability of vegetation to stabilize active dune sand. The apparent coexistence of large mobile dunes with boreal forest taxa suggests a Late Pleistocene environment with few modern analogs.
\end{abstract}

Keywords: Eolian activity, Dunefield, Great Plains, Nebraska Sand Hills, Late Pleistocene, OSL dating

\section{Introduction}

The Nebraska Sand Hills form the largest dunefield in North America, covering at least $50,000 \mathrm{~km}^{2}$ of the central Great Plains. Dunes of the Sand Hills include forms found mainly in warm desert environments, including barchanoid ridges more than one hundred meters high and tens of kilometers long (Swinehart, 1990; Loope and Swinehart, 2000). Despite this impressive evidence of past eolian activity, the Sand Hills are almost entirely stabilized by native grassland vegetation under the modern climate. Other stabilized dunefields on the central Great Plains are individually smaller in area than the Sand Hills, but together cover a large area (Forman et al., 2001; Muhs and Zarate, 2001) and can include large compound parabolic dunes several kilometers long (Muhs et al., 1996, 1999b).

The Sand Hills and other Great Plains dunes have drawn the attention of geomorphologists and Quaternary scientists for more than 75 years, often focused on the timing of dune activity and the nature of the paleoenvironments that allowed it to occur. Lugn (1935, pp. 16o-161) interpreted the Sand Hills dunes and the thick Peoria Loess deposits to the southeast as coarse and fine facies of eolian sediment dispersed across the region during the Late Pleistocene. In the first major work on the geomorphology of the Sand Hills, H.T.U. Smith (1965) defined three series of dunes. Smith's first series includes megabarchans and large barchanoid ridges, and the second is primarily made up of 
smaller longitudinal dunes, often superimposed on larger dunes of the first series. The third series mainly consists of small parabolic dunes associated with blowouts (deflation hollows). Smith concluded that the dunes of the first and second series developed mainly under relatively cold and dry conditions of the Late Pleistocene, although he correlated the second series with the Bignell Loess, now known to be of Holocene age (Johnson and Willey, 2000; Mason et al., 2003). Warren (1976) also assumed the large Sand Hills dunes were of Pleistocene age in his interpretation of paleowind directions. Wright et al. (1985) argued that the basal ages of interdune peats and lacustrine sediment imply a Pleistocene age for the large dunes.

By the 1980s, however, new radiocarbon dating clearly demonstrated substantial Holocene dune activity in the Sand Hills; in fact, more than $40 \mathrm{~m}$ of eolian sand was deposited in the middle to late Holocene at several sites (Ahlbrandt et al., 1983; Swinehart and Diffendal, 1990; Loope et al., 1995). Holocene activity has also been documented in other dunefields across the central Great Plains of Nebraska, Kansas, and Colorado (Muhs, 1985; Forman and Maat, 1990; Madole, 1994, 1995; Forman et al., 1995, 2001; Muhs and Holliday, 1995; Muhs et al., 1996; Arbogast and Johnson, 1998; Hanson et al., 2010). Optically stimulated luminescence (OSL) dating, which determines the time since deposition of eolian sand, has provided important new insights on the timing of Holocene dune activity (Stokes and Swinehart, 1997; Miao et al., 2007; Hanson et al., 2010). In the Sand Hills, OSL dating at multiple sites consistently indicates that the longitudinal dunes of Smith's second series formed in the late Holocene (Goble et al., 2004; Mason et al., 2004; Sridhar et al., 2006; Schmeisser, 2009).

In contrast, evidence of Late Pleistocene dune or sand sheet activity in the Sand Hills has remained quite limited. Goble et al. (2004) reported a single Late Pleistocene OSL age from a deep blowout in the northern Sand Hills (Kroeger Blowout, discussed below). At Gudmundsen Ranch in the central Sand Hills, peat that formed at 13,160 $\pm 450{ }^{14} \mathrm{C}$ yr BP $(14,195-16,995$ cal yr BP; Reimer et al., 2009), was subsequently buried by a large dune, possibly in the Late Pleistocene (Swinehart, 1990; Swinehart and Diffendal, 1990). Late Pleistocene environmental conditions on the central Great Plains clearly did favor at least one form of eolian activity: Peoria Loess accumulated at very high rates near the Sand Hills during that time period, at sites such as Bignell Hill, discussed below (Roberts et al., 2003). Furthermore, Late Pleistocene eolian sands have been identified in northeastern Colorado, based on radiocarbon and luminescence dating, pedologic evidence, and stratigraphic relations with archaeological artifacts (Forman et al., 1995; Muhs et al., 1996). Muhs et al. (1997) noted that the mineralogical maturity of Sand Hills dune sand probably reflects a long history of eolian activity over more than one glacial-interglacial cycle. One explanation for the limited evidence of Pleistocene dune activity in Nebraska dunefields is that Late Pleistocene eolian sand is often deeply buried by Holocene sediment, especially in areas where late Holocene longitudinal dunes developed. Stokes et al. (1999) reported initial results of OSL dating using core samples from deep within dunes of the Sand Hills, and noted evidence for both Pleistocene and Holocene dune construction. The final results of that study have not been published, and it was based on early, now superceded OSL methodology.

In this paper we report new OSL dating results that demonstrate Late Pleistocene eolian sand activity at numerous localities in the central Great Plains, not only within the Nebraska Sand Hills and other dunefields, but also where eolian sand was subsequently covered with thick, Late Pleistocene loess. While some evidence reported here is from outcrops, much of it is based on core samples collected from large dunes of the Sand Hills (not the same cores sampled by Stokes et al., 1999). We also discuss the environmental factors that allowed dune activity during the Late Pleistocene.

\section{Study sites and methods}

\subsection{Study sites}

The new OSL ages reported here are from fifteen localities, including ten in the Nebraska Sand Hills, three in smaller dunefields of Nebraska and Colorado, and two in the loess-mantled region south of the Sand Hills (Figure 1, Table 1). Cores were collected at eight sites, by drilling either on the dune crest to sample the greatest possible thickness of eolian sand, or somewhat below the crest on the north or northwest slope of the dune. The latter location was used in some cases where the dune form recorded migration toward the south or southeast, to increase the likelihood of sampling the oldest sand within the dune. The other five localities are outcrops where the presence of Late Pleistocene eolian sand was identified by OSL dating, carried out as part of recent research projects on eolian sediments of the central Great Plains. The Hwy 97 Milepost 81 roadcut and Vinton Blowout are two of only three sites in the Sand Hills where Pleistocene eolian sand has been identified in outcrop using OSL dating; the third site, Kroeger Blowout, was reported by Goble et al. (2004). The Wach site is an outcrop in a small unnamed dunefield of southwestern Nebraska. Bignell Hill and Moran Canyon are primarily loess sections, but contain eolian sand interbedded with or buried by Late Pleistocene loess.

\subsection{Field methods}

Cores were collected using either a hollow-stem auger technique or direct push with a Geoprobe (Table 1 includes method used at each site). The 5-cm diameter hollow-stem auger cores were collected in a split-barrel that travels downward inside the lead auger. The stack of augers acts as a casing that prevents contamination of the core sample with material from higher in the section. The core was extracted after each $1.5 \mathrm{~m}$ of drilling, with core recovery usually representing 30-60\% of that depth increment, typical for eolian sand, because friction prevents the core from sliding all the way up the barrel and eventually sand is

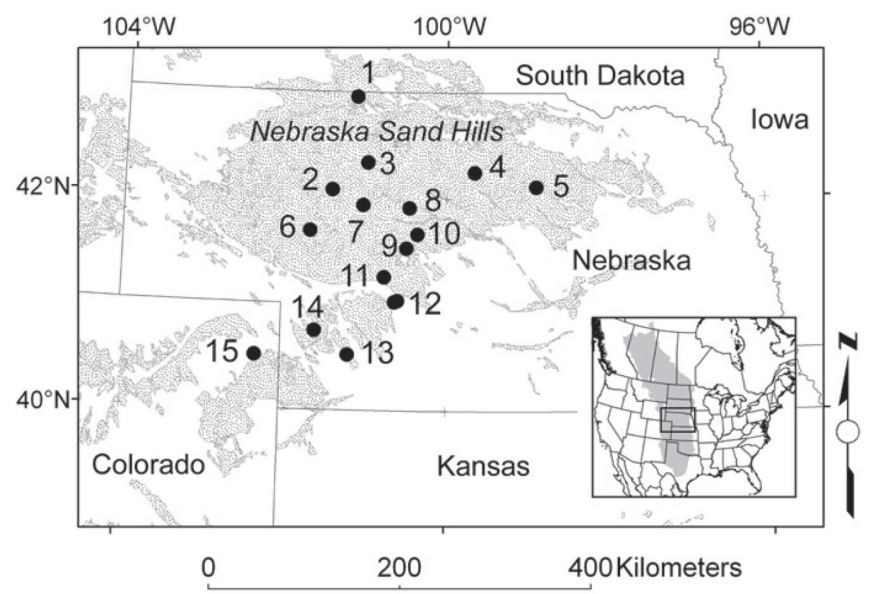

Figure 1. Dunefields of the central Great Plains (stippled) and sites discussed in text: 1. Kroeger Blowout, 2. Gudmundsen Ranch, 3. Highway 97 Milepost 81, 4. Barta Brothers Dune, 5. Haake Dune, 6. Schmidt Ranch, 7. Vinton Blowout, 8. Nebraska National Forest, 9. Diamond Bar Ranch, 10. Wild horse Creek Ranch, 11. Hansen Ranch, 12. Moran Canyon and Bignell Hill, 13. Wach, 14. Cornelius Dune, 15. Hamm Dune. Inset shows study area location (box) within the Great Plains region of the U.S.A. and Canada (gray shade). 
Table 1. OSL age estimates referred to in this paper, with equivalent dose and dose rate data. Ages are grouped by study site, with geographic location and sampling method indicated.

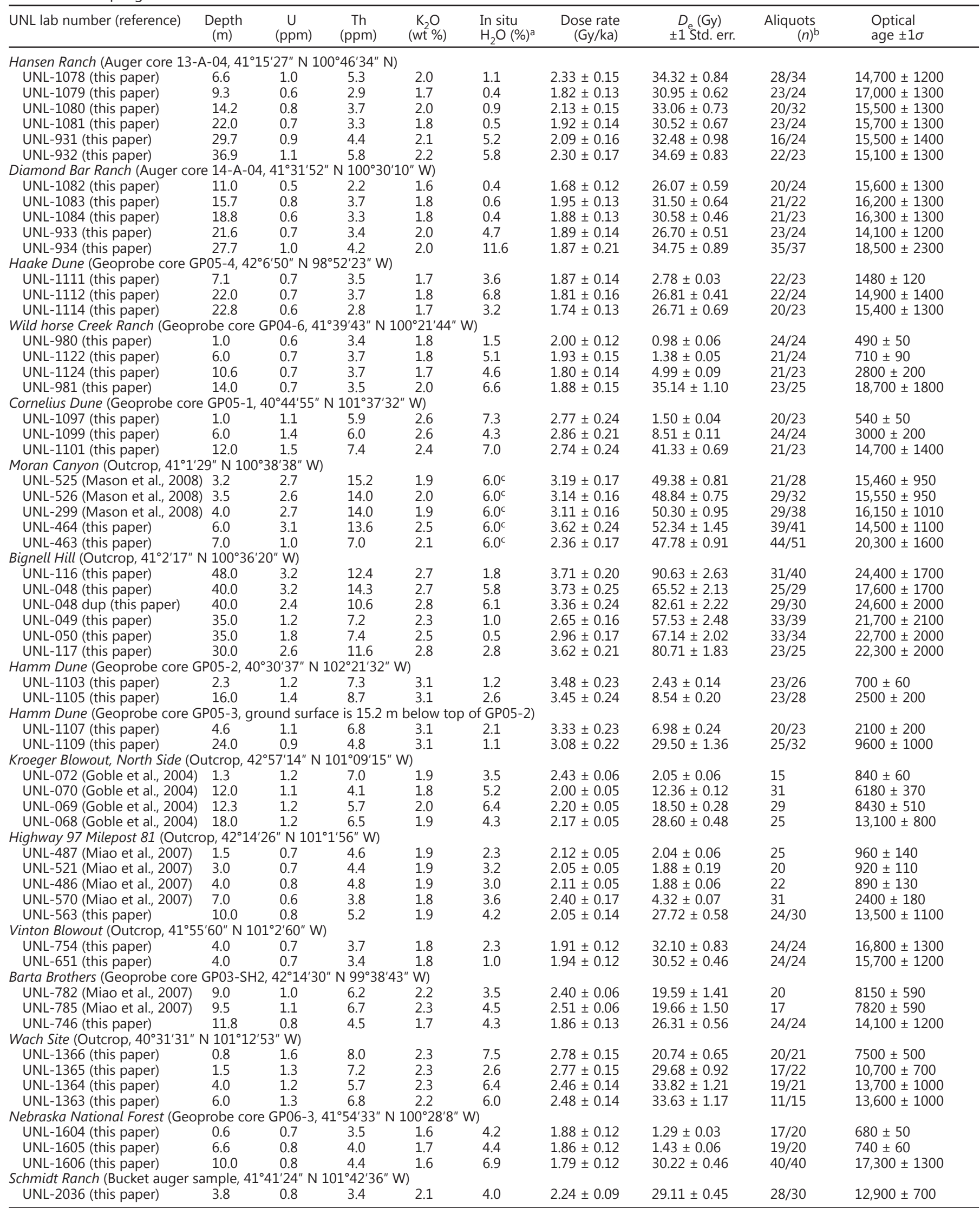

a. Assumes $100 \%$ error in measurement.

b. Where ratio is given, it represents accepted disks/all disks.

c. Estimated from similar samples. 
pushed aside rather than entering the core. Sedimentary structures were often preserved within the cores with minimal deformation (Figure 2a), however, so we assume the recovered core represents only the upper part of the cored interval and assigned depths accordingly. Samples for OSL dating were collected by pushing steel or brass tubes into sand in the lower end of the core before the split-barrel was opened. The Geoprobe uses percussion to drive $1.2 \mathrm{~m}$-long, 3 -cm inside-diameter core barrels with plastic liners, with typical recovery of $75 \%$ or more. Cores in opaque liners were sampled in the lab for OSL dating, while clear liners were split in the field to describe sedimentary structures, which were usually well-preserved (Figure $2 \mathrm{~b}$ ). Outcrops were sampled for OSL dating by pushing metal tubes into freshly excavated faces. One OSL sample was collected by pushing a metal tube into sand brought to the surface in a bucket auger, without light exposure.

Outcrops and cores were described in detail, including observations of sedimentary structures (Figure 2), paleosols, trace fossils, and sediment grain size. The broad geomorphic setting of each study site was assessed using 10-m digital elevation data, aerial photographs, and regional mapping and interpretation of Sand Hills dune forms by Swinehart (1990).

a

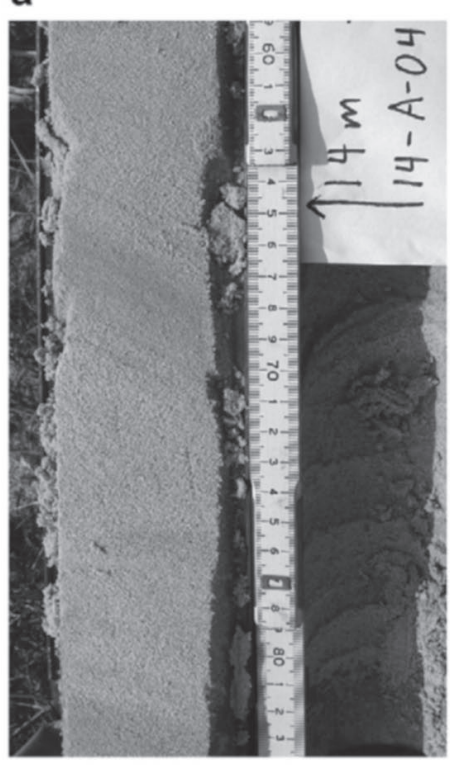

b
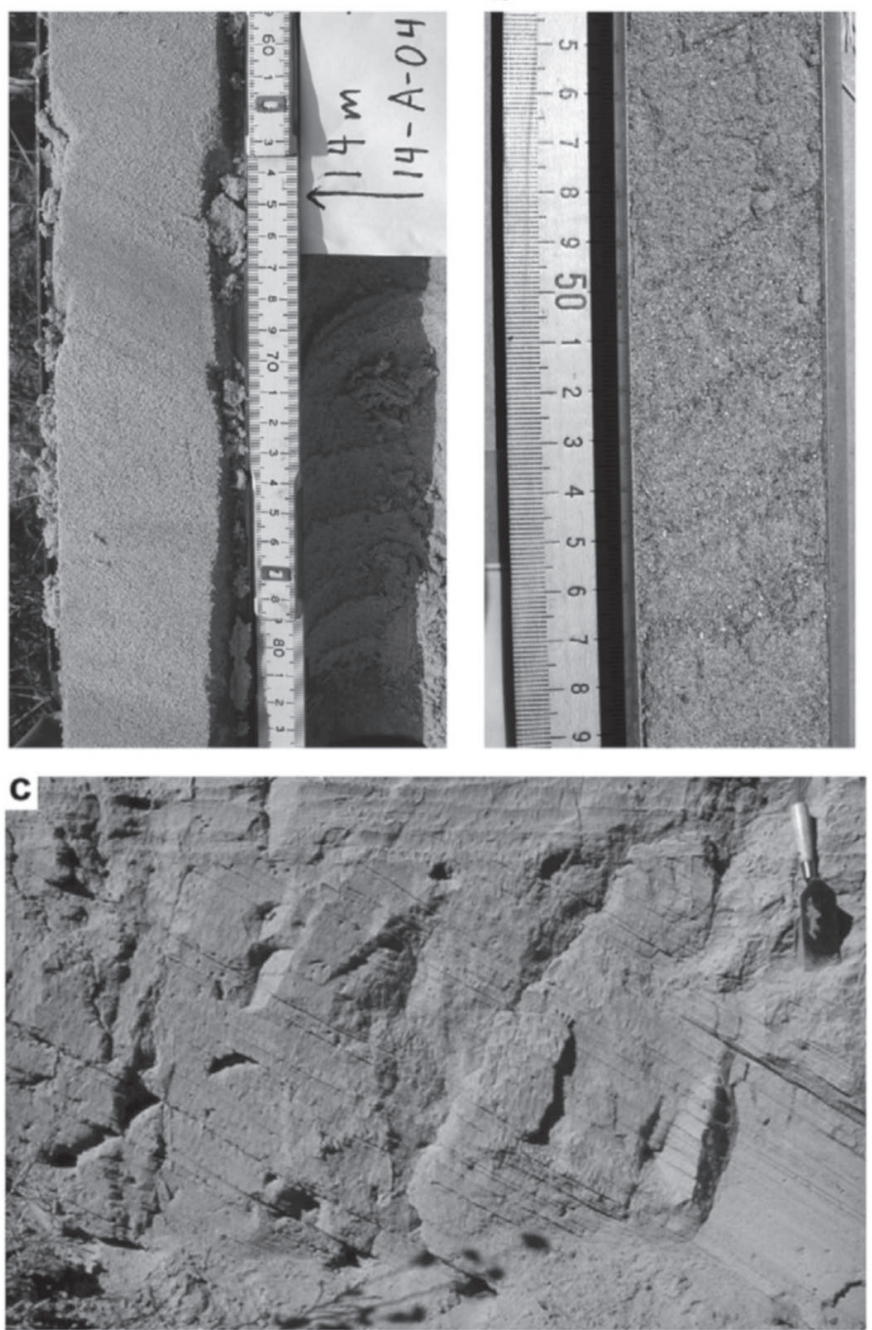

Figure 2. Cross-bedded eolian sand at study sites, typical of material with well-preserved sedimentary structures used for most OSL ages: a. hollow-stem auger core at Diamond Bar Ranch (13.95-14.2 m depth); b. Geoprobe core at Hamm Dune (10.3-10.45 m depth); c. outcrop at Moran Canyon (eolian sand overlain by Peoria Loess, east is to the right, trowel is ca $25 \mathrm{~cm}$ long). In a and b, up is toward ground surface, scale is in $\mathrm{cm}$.

\subsection{OSL dating methods}

OSL dating analyses were conducted at the University of Nebraska's Luminescence Geochronology Laboratory. The methodology used was similar to numerous other studies that used OSL in the Nebraska Sand Hills (Goble et al., 2004; Mason et al., 2004; Miao et al., 2007) and adjacent loess hills (Mason et al., 2003., 2008). Samples were sieved to isolate 90-150 $\mu \mathrm{m}$ grains, treated with $1 \mathrm{~N} \mathrm{HCl}$ to remove carbonates, and floated in $2.7 \mathrm{~g}$ / $\mathrm{cm}^{3}$ sodium polytungstate to remove heavy minerals. The remaining sample was then treated with $48 \%$ hydrofluoric acid for $\sim 75$ min to remove feldspars and etch quartz grains, followed by a treatment in $47 \% \mathrm{HCl}$ for $\sim 30 \mathrm{~min}$. The samples were then resieved to remove grains finer than $90 \mu \mathrm{m}$. Equivalent dose $\left(D_{\mathrm{e}}\right)$ values were determined on the $90-150 \mu \mathrm{m}$ quartz grains using the single aliquot regenerative (SAR) method (Murray and Wintle, 2000). OSL dating analyses were carried out on both Daybreak and Risø TL/OSL readers. Individual aliquots were rejected if their recycling ratios were $> \pm 10 \%$. Aliquots were also monitored for contamination with feldspars, the presence of which typically results in ages that are younger than expected. Therefore, aliquots were rejected if they were suspected of containing feldspars based on their shinedown curves and/or their response when stimulated with infrared diodes. Equivalent dose distributions including histograms are given for each sample in the Supplementary material.

Dose rate estimates were based on elemental concentrations of $\mathrm{K}, \mathrm{U}$, Th, and $\mathrm{Rb}$ from bulk sediment samples using ICP-MS and ICP-AES. The cosmogenic component of the dose rate was calculated using equations from Prescott and Hutton (1994), and the final dose rate values calculated following equations from Aitken (1998). All optical ages are presented in ka, thousands of calendar years ago. New ages reported in this paper that were older than 1.5 ka were rounded to the nearest hundred years, and the younger ages were rounded to the nearest ten years; other ages are listed as originally published.

\section{Results \\ 3.1. OSL ages}

All OSL ages discussed in this paper are listed with associated data in Table 1, including some previously published ages that are important for stratigraphic interpretation. Other less relevant published ages from the study sites are noted below but are not included in Table 1. New ages are also plotted in Figure 3 along with all of the Holocene ages from central Great Plains dunefields reported by Miao et al. (2007). Following standard practice, we present OSL ages with $\pm 1 \sigma$ errors throughout this paper; however, the $\pm 2 \sigma$ error range ( $95 \%$ probability) should be considered when assessing the significance of age inversions, age trends, or differences between ages. For example, while there are apparent age inversions in some of the cores and outcrops we do not consider these to be significant if the $\pm \mathbf{2} \sigma$ error ranges of the ages involved include values that would allow all ages to be in stratigraphic order. Similar to other Nebraska Sand Hills samples (e.g. Goble et al., 2004; Mason et al., 2004; Miao et al., 2007), none of the samples displayed anomalous behavior that would call their validity into question. Variability in equivalent dose values is fairly low for these samples. In addition, very few aliquots were rejected (Table 1), and there was little difference in the age calculated using all of the disks run compared with the age calculated using the final weighted disks (see equivalent dose distributions in Supplementary material). We interpret all of our ages as indicating the time since the sediments were 


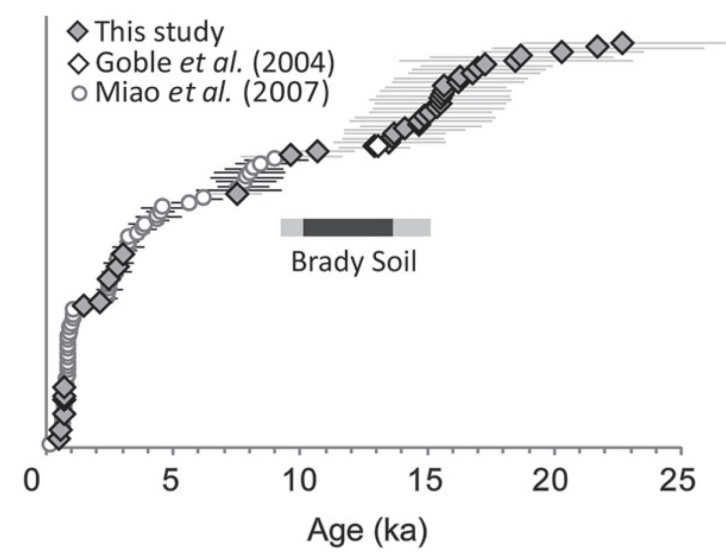

Figure 3. OSL ages from this study and Miao et al. (2007), arrayed vertically from youngest (bottom) to oldest (top). Time intervals with abundant OSL ages where the plot rises steeply indicate widespread dune activity, intervening plateaus with few ages presumably indicate dunefield stability. Time represented by Brady Soil is shown with shaded bar, based on dating described in Mason et al. (2008). Darker tone indicates time during which Brady Soil was forming at almost all sites (13.5-10 ka); lighter tone includes additional time of soil formation suggested by dating at some sites (15-13.5 ka and 10-9 ka).

deposited, because there was minimal evidence for bioturbation or other soil processes that would have acted to reset the luminescence clock in the cores and outcrops sampled for dating (e.g. Figure 2).

\subsection{Subsurface samples from dunefields}

The Barta Brothers core (Figure 4a) was collected on the crest of a "dome-like" dune with superimposed longitudinal dunes in the northern Sand Hills. Much of the core penetrated Holocene sand, based on ages reported by Miao et al. (2007). Early Holocene sand was identified at 9.0-9.5 $\mathrm{m}$ depth, and at $12 \mathrm{~m}$ (only about $3 \mathrm{~m}$ above local interdune elevations), eolian cross-strata with a dip of about $20^{\circ}$ yielded a Pleistocene age of $14.1 \pm 1.2 \mathrm{ka}$ (Figure $4 \mathrm{a}$ ). The direction of maximum dip cannot be determined because of core rotation during extraction, and the dune is too poorly defined to infer direction of migration. At the Wild Horse Creek Ranch (Figure 4b), a core was collected on a poorly defined large dune with superimposed longitudinal dunes in the southcentral Sand Hills. The upper $10.6 \mathrm{~m}$ of this core yielded Late Holocene OSL ages, but a sample at $14 \mathrm{~m}$ depth, in eolian cross-strata dipping at $25^{-30^{\circ}}$, produced a Pleistocene age of $18.7 \pm 1.8 \mathrm{ka}$. This sample was $>10 \mathrm{~m}$ above local interdunes; thus, the dune contains a substantial body of Late Pleistocene eolian sand.

The Diamond Bar Ranch and Hansen Ranch core sites (Figure $4 \mathrm{C}$ and d) are in similar settings on the north or northwest slope of moderately large dunes in the southern Sand Hills. Holocene ages obtained from shallow depths in these cores were reported by Miao et al. (2007). Both cores reached the elevation of adjacent interdunes, and much of the dune sand in both cores is Late Pleistocene, with ages between $14 \mathrm{ka}$ and $19 \mathrm{ka}$. There are OSL ages out of stratigraphic sequence at both sites; however, we do not consider these inversions to be significant because the $2 \sigma$ error estimate for all of the Pleistocene ages overlap substantially. All of the Pleistocene ages are from fine sand typical of Sand Hills dunes, generally containing eolian sedimentary structures. The dune cored at Diamond Bar Ranch is poorly defined, but fairly distinct steep lee slopes are preserved on the cored dune and its neighbors at the Hansen Ranch, indicating migration toward the south-southeast. At the Nebraska National Forest site (Figure 4e), a core was collected on the crest of a longitu- dinal dune, located on the north slope of a poorly defined larger dune. Two OSL ages within the longitudinal dune are late Holocene, but an age of $17.3 \pm 1.3$ ka was obtained from sand at $10 \mathrm{~m}$ depth, just into the underlying larger dune form. At the Schmidt Ranch in the western Sand Hills (location in Figure 1), a single Late Pleistocene age of $12.9 \pm 0.7 \mathrm{ka}$ was obtained from a bucket auger sample at a depth of $3.8 \mathrm{~m}$ on the northern slope of a large dune, well above interdune elevation.

Two other core sites provided evidence of Late Pleistocene eolian sand deposition that was not clearly related to construction of the present dunes, and the latter may have been built largely or entirely during the Holocene. At the Haake site (Figure $4 \mathrm{f}$ ), a core was collected on the northwest slope of a large dune located in the transition zone where dunes give way to the low-relief sand sheets that dominate the easternmost part of the Sand Hills. The upper $7 \mathrm{~m}$ of this core is late Holocene eolian sand, overlying a zone with pedogenic lamellae that may represent a truncated paleosol. Ages of $14.9 \pm 1.4$ and $15.4 \pm 1.3$ ka were obtained from laminated fine-medium sand well below the lamellae at depths of 22.0 and $22.8 \mathrm{~m}$, respectively, near the elevation of adjacent interdunes. The Cornelius dune (Figure $4 \mathrm{~g}$ ) is located in a small dunefield north of Imperial, Nebraska, southwest of the Sand Hills. At least the upper $6 \mathrm{~m}$ of a core taken on the crest of this dune is late Holocene, and we obtained one additional age of $14.9 \pm 1.4 \mathrm{ka}$, in laminated fine-medium sand at a depth of $12 \mathrm{~m}$, just above Miocene bedrock.

Cores drilled on a large compound parabolic dune at the Hamm site (Figure 4h), in the Wray dunefield of northeastern Colorado yielded only Holocene ages. The entire upper $16 \mathrm{~m}$ of the core collected on the dune crest at this site is younger than $2.5 \pm 0.2 \mathrm{ka}$. An age of $9.6 \pm 0.9 \mathrm{ka}$ was obtained from laminated fine and medium sand near interdune level, in a second core that started partway down the dune flank.

\subsection{Outcrops in dunefields}

The Vinton Blowout (Figure 5a) exposes eolian sand on the lower stoss slope of a large barchan dune, one of several similar dunes with forms clearly indicating migration toward the southeast. Two OSL ages of $15.7 \pm 1.2$ and $16.8 \pm 1.3$ ka were obtained from large-scale eolian cross-strata dipping $30^{\circ}$ toward the southeast $\left(120^{\circ}\right.$ azimuth), recording sedimentation on the slip face of a dune migrating in that direction. The Hwy 97 Milepost 81 section (Figure $5 \mathrm{~b}$ ) is a roadcut through a longitudinal dune that was sampled when newly excavated. While sand forming the longitudinal dune is Late Holocene, based on OSL ages previously reported by Miao et al. (2007), it rests at least in part on wind-ripple laminated eolian sand dated to $13.5 \pm 1.1 \mathrm{ka}$ (some Late Holocene sand is also present below the base of the longitudinal dune near the south end of the exposure; Figure $5 \mathrm{~b}$ ). The Kroeger Blowout (Figure $5 \mathrm{c}$ ) is a deep deflation hollow near the crest of a large dune. As reported by Goble et al. (2004), most of the eolian sand exposed at this site is Holocene, but an age of $13.1 \pm 0.8$ ka was obtained $18 \mathrm{~m}$ below the top of the blowout face, just below a truncation surface. This sample was collected at least $20 \mathrm{~m}$ above the level of the nearest interdunes, so there is a substantial core of Pleistocene sand within the large dune at this locality. The form of the dune is poorly defined, but it is steepest on its south-southeast face, as are adjacent large dunes, indicating migration toward the south-southeast.

The Wach site (Figure $5 \mathrm{~d}$ ) is a blowout in a small unnamed field of parabolic dunes in southwestern Nebraska. These dunes are distinctive in several respects, based on field observations and the county soil survey (Scheinost, 1982). Compared to the Sand Hills, they have smoother surfaces and surface soils that often have more silt and thicker A horizons, all consistent with 
a Barta Brothers
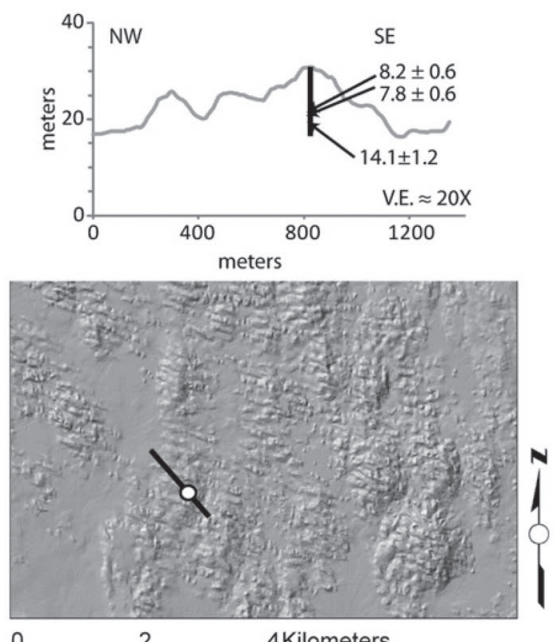

b Wildhorse Creek Ranch
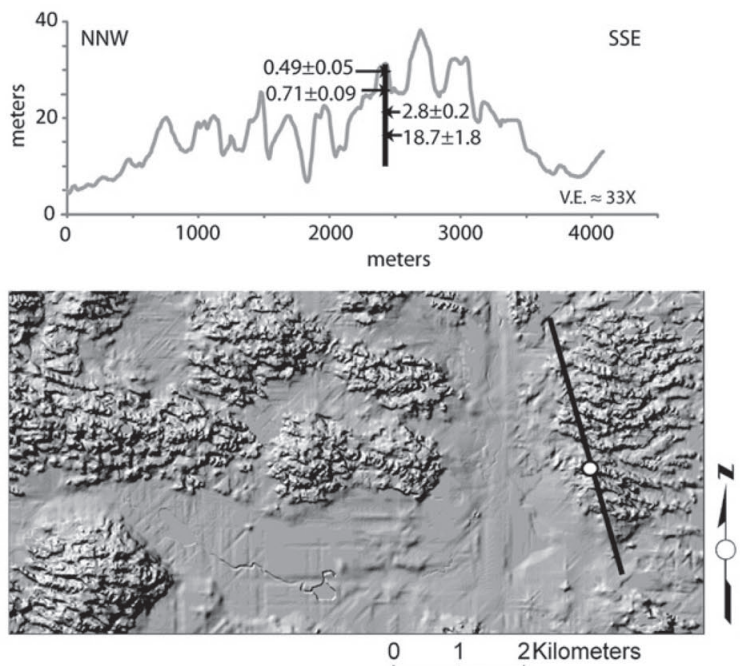

C Diamond Bar Ranch

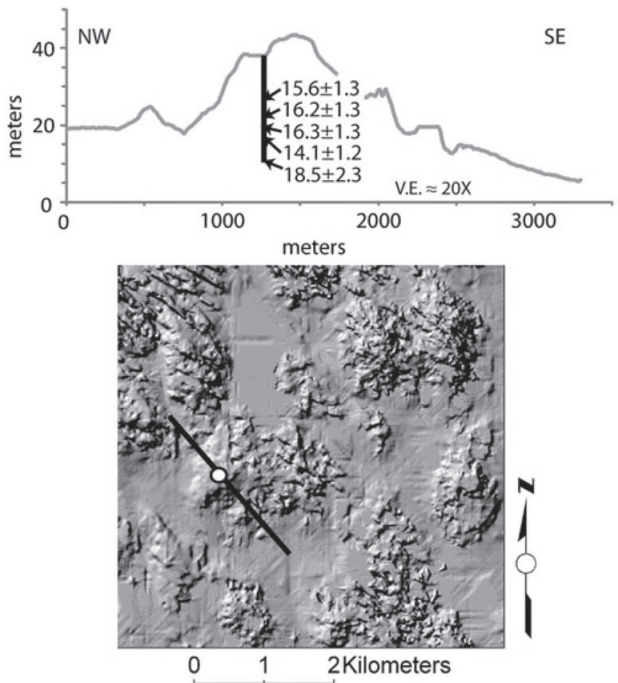

d Hansen Ranch
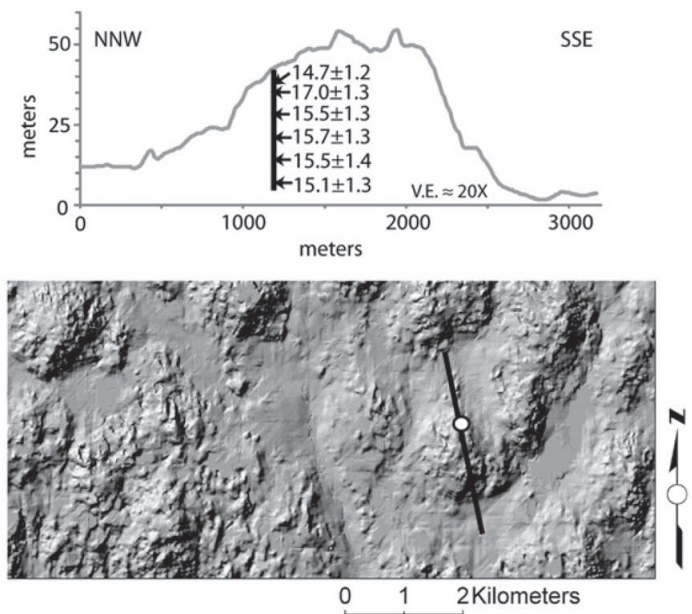

e Nebraska National Forest
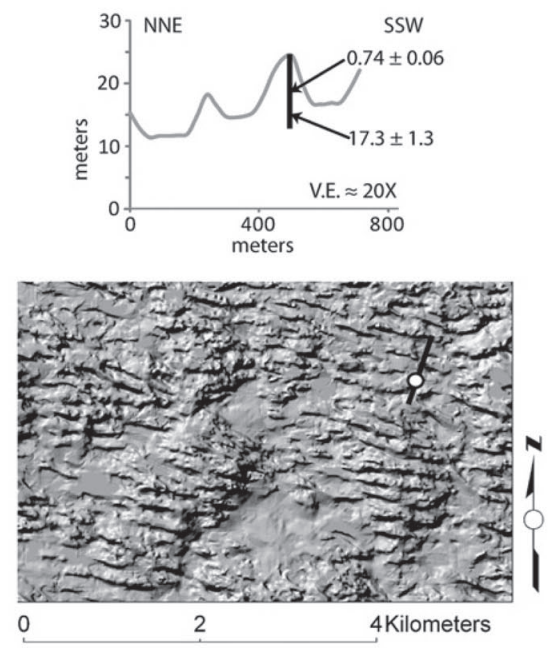

f Haake Dune
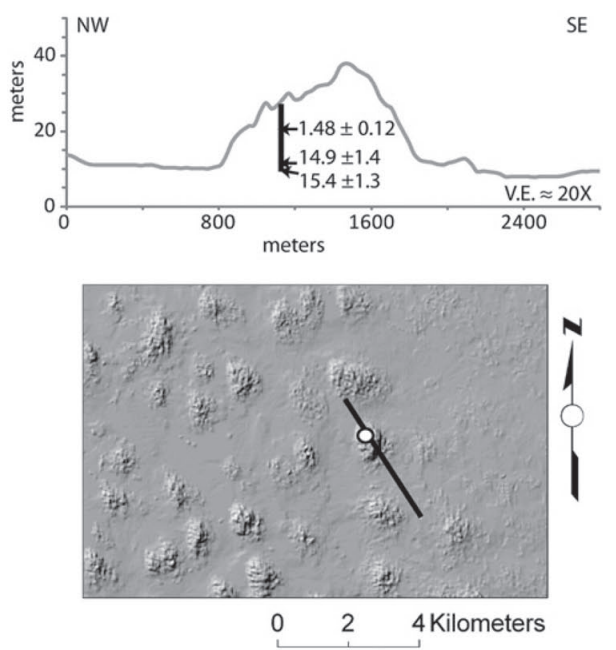

Figure 4. Local landscape setting of coring sites. Topographic profiles show ground surface (gray line), cored location and total depth (vertical black line), and OSL sample ages and depths. Shaded relief images from USGS digital elevation models show locations of cores (white dot) and topographic profiles (black line). 
g Cornelius Dune
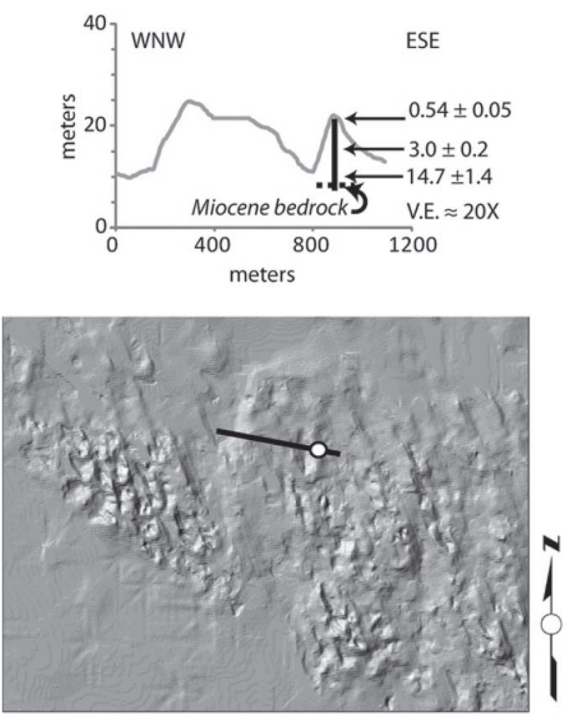

h Hamm Dune
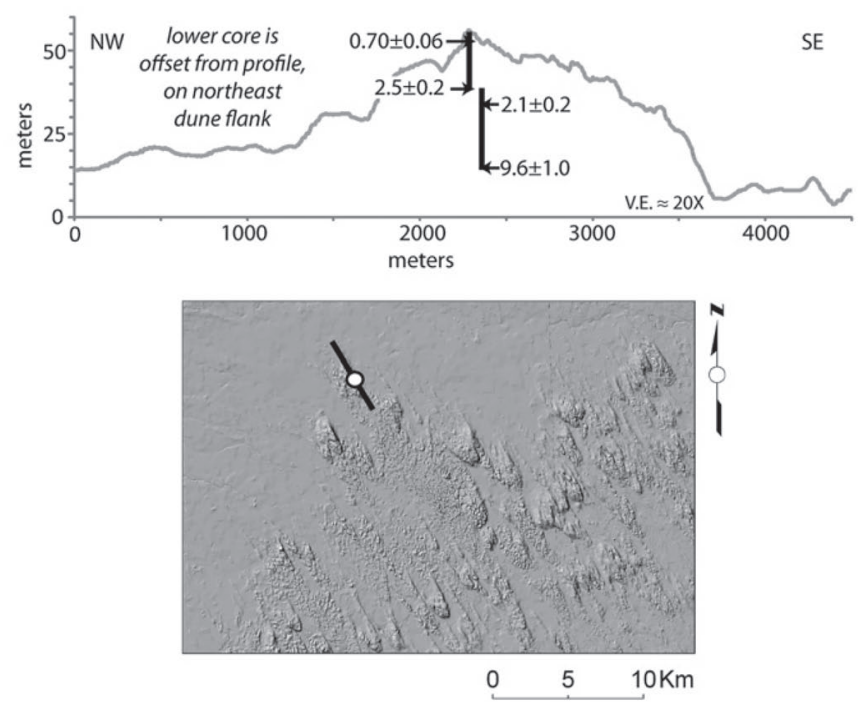

Figure 4. (continued)

more limited reactivation in the Holocene. The outcrop sampled for OSL dating at the Wach site exposes massive lightbrown sand overlying a thick buried soil with an Ab-Bwb-Bkb$\mathrm{BCb}$ profile. This soil is morphologically similar to the Brady Soil, a regional marker of the Pleistocene-Holocene boundary (Mason et al., 2008); however, the two OSL ages bracketing the soil $(7.5 \pm 0.5$ ka just above the Ab horizon, $10.7 \pm 0.7$ ka below it) suggest it is somewhat younger than most Brady Soil profiles (typical age range shown in Figure 3, see Mason et al., 2008, for more details). Below the $\mathrm{BCb}$ horizon, we obtained an OSL age of $13.7 \pm 1.0$ ka from $2-m$ thick horizontally stratified very fine sand, and a very similar age of $13.6 \pm 1.0 \mathrm{ka}$ from underlying high angle cross-stratified fine sand. These ages suggest that the dune may contain a substantial body of Late Pleistocene sand. The a
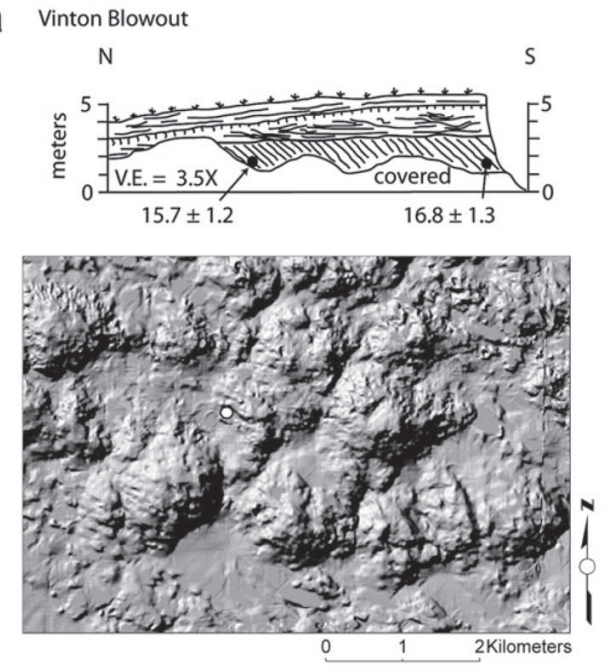

b Highway 97 Milepost 81

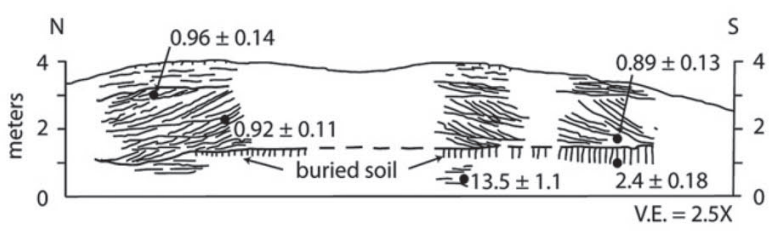

C Kroeger Blowout
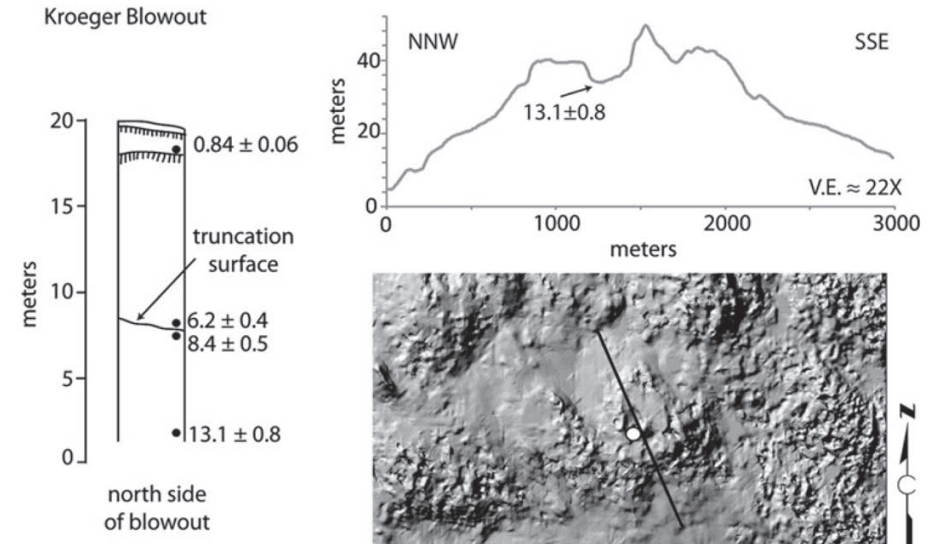

d Wach

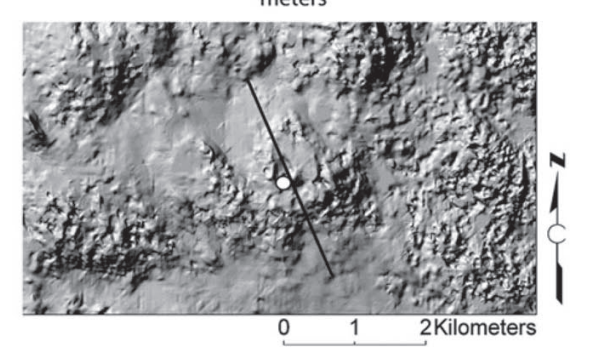

recent blowout
deposits
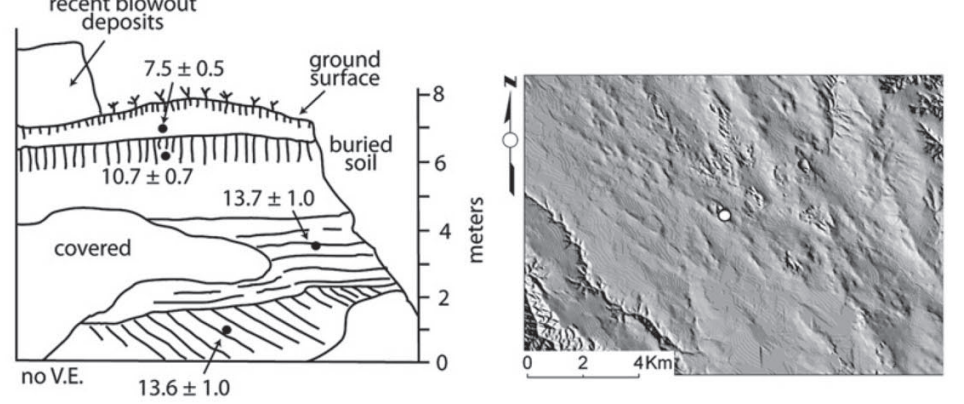

Figure 5. Stratigraphic diagrams of dunefield outcrops, with OSL ages in ka. For three outcrops, shaded relief maps from USGS digital elevation models also show landscape setting. Topographic profile (as in Figure 4) is included for Kroeger Blowout, but because of DEM resolution it does not capture true height of blowout rim above OSL sample location. 
cross-strata at the base of the section dip toward the southeast, and all of the parabolic dunes in the vicinity indicate a similar southeastward direction of migration.

\subsection{Outcrops in the thick loess region}

Lugn (1935), Smith (1965), and Ahlbrandt et al. (1983) all noted that eolian sand overlies Peoria Loess at the southeast margin of the Sand Hills, but there are also localities where sand beds occur within or at the base of Peoria Loess. We sampled two of these localities for OSL dating (Figure 6). We previously reported OSL ages from Bignell Loess and upper Peoria Loess in the roadcut section at Bignell Hill and a core adjacent to the roadcut at Moran Canyon (Mason et al., 2003, 2008), and a variety of other luminescence and radiocarbon ages and have been obtained from these localities (Maat and Johnson, 1996; Muhs et al., 1999b, 2008; Roberts et al., 2003). At Moran Canyon, a roadcut exposes Holocene Bignell Loess and about $4.5 \mathrm{~m}$ of Peoria Loess overlying more than $2.5 \mathrm{~m}$ of medium sand. Within the sand, a set of cross-strata more than $2 \mathrm{~m}$ thick record eastward migration of a dune that was subsequently buried by Peoria Loess (Figure 2c). An OSL age of $20.3 \pm 1.6$ ka was obtained from about $0.4 \mathrm{~m}$ below the top of the sand (Figure 6).

Bignell Hill (Figure 6) is one of the best-known loess sections in the central Great Plains (Feng et al., 1994; Maat and Johnson, 1996; Muhs et al., 1999b, 2008; Mason et al., 2003; Roberts et al., 2003), comprising several disjunct exposures along a steep road at the margin of a loess table. The upper and lower boundaries of Peoria Loess are well-exposed and separated by a vertical distance of $51 \mathrm{~m}$ (Bettis et al., 2003). Fine-medium sand about $5.5 \mathrm{~m}$ thick is exposed about $10 \mathrm{~m}$ above the base of the Peoria Loess, but has not been included in most published sections, probably because the investigators were not certain of the stratigraphic relations between this sand and the loess exposed in other roadcut segments. A geologic test hole drilled near the top of the roadcut encountered sand interbedded with Peoria Loess at approximately the same elevation as the sand in the roadcut (Bettis et al., 2003), however. We also identified subhorizontal upper and lower contacts between the sand and loess in the roadcut, and observed wind-ripple lamination and fine calcite rhizoliths and insect burrows within the sand. Based on those observations, we interpret the sand in the roadcut as an eolian sand sheet that migrated over the basal increment of Peoria Loess and was then buried by renewed loess accumulation. Ages of $21.7 \pm 2.1$ and $22.7 \pm 2.0$ ka were obtained from the sand (Figure 6). These ages overlap at $1 \sigma$ with the age from dune sand at Moran Canyon, and with an age of $22.3 \pm 2.0$ from loess immediately overlying the sand. Two duplicate samples from loess just below the sand in the same outcrop yielded two very different ages, $17.6 \pm 1.7 \mathrm{ka}$ and $24.6 \pm 2.0 \mathrm{ka}$. Although the latter age is more consistent with ages in the overlying sand, we have no other reason for assuming it is the more accurate of the two. Roberts et al. (2003) reported an OSL age of $18.9 \pm 0.9$ from loess just below the elevation of the sand, but apparently not in the same roadcut segment. This age overlaps at $2 \sigma$ with our two ages from the sand.

\section{Discussion}

\subsection{Geomorphological interpretation of the OSL ages}

At the most basic level, the OSL ages reported here document Late Pleistocene eolian sand activity at sites distributed across a large area of the central Great Plains. At several study sites (Barta Brothers, Kroeger Blowout, Wild Horse
Creek Ranch, Diamond Bar Ranch, Hansen Ranch, Wach, Nebraska National Forest, and possibly Schmidt Ranch), the present dunes were partly constructed in the Late Pleistocene. At the same time, data from many of the new cores confirm the importance of Holocene sand dune activity. The Sand Hills are not entirely products of Holocene aridity, nor are they simply relict Pleistocene dunes, as once supposed.

The new Late Pleistocene ages extend the close correspondence in time between episodes of eolian sand activity and rapid loess deposition in the central Great Plains, previously noted for the Holocene (Miao et al., 2007). Most of the Late Pleistocene eolian sand ages coincide with OSL ages recording Peoria Loess deposition in western Nebraska (Roberts et al., 2003; Mason et al., 2008). The youngest Late Pleistocene sand ages may overlap with the early stages of Brady Soil formation (Figure 3), which marks a minimum of loess accumulation in the central and northern Great Plains (Mason et al., 2008). To our knowledge, the $10.7 \mathrm{ka}$ age from the Wach site is the only OSL date indicating eolian sand deposition in the central Great Plains within the later part of Brady Soil development, between about 12.5 and $10 \mathrm{ka}$.

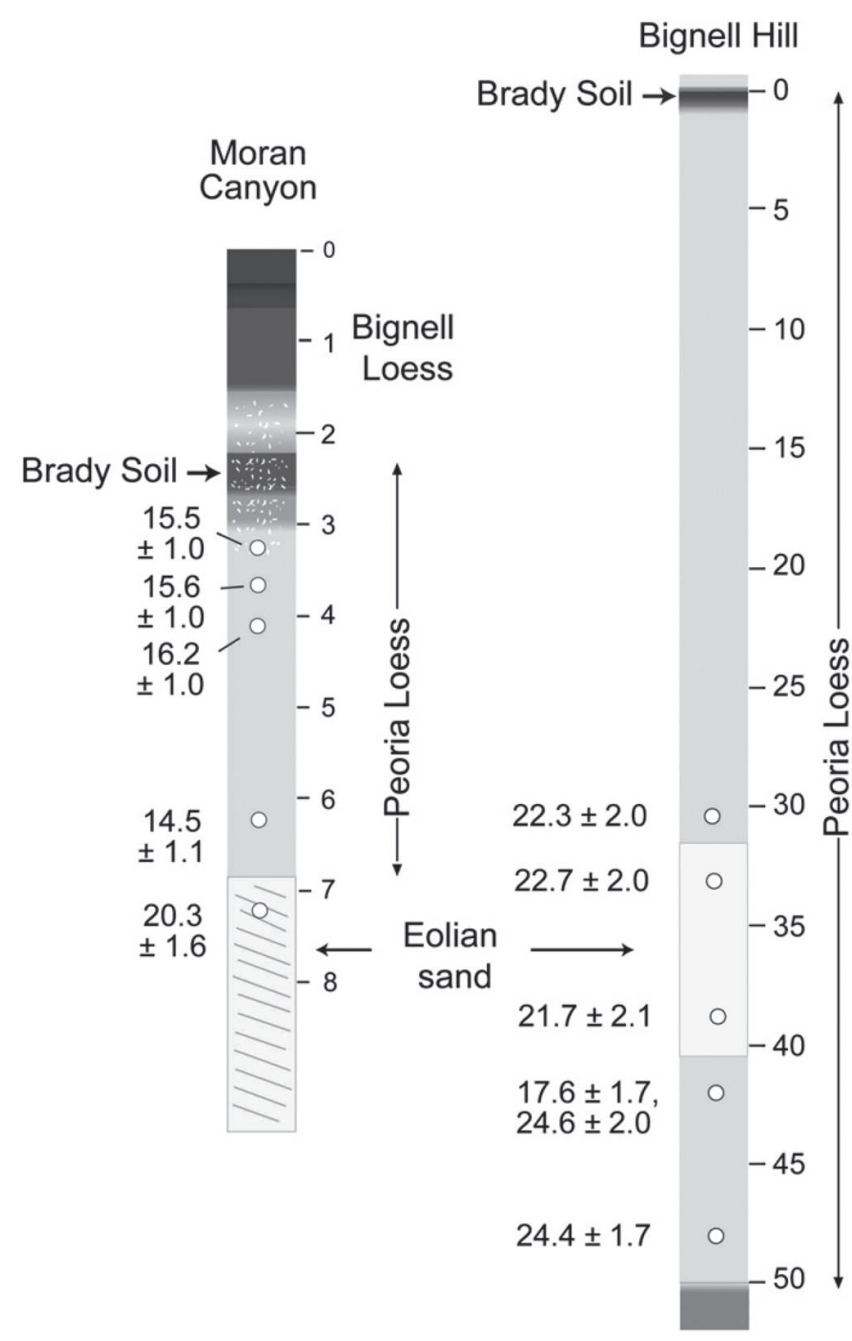

Figure 6. Stratigraphy at two sites where eolian sand is interbedded with Peoria Loess, with OSL ages from this study (for additional ages from these sites, not shown, see Maat and Johnson, 1996; Muhs et al., 1999b; Roberts et al., 2003; Mason et al., 2008). Bignell Hill shown as vertical section based on both roadcut exposures and test hole from top of section (Bettis et al., 2003). See text for discussion of anomalous ages below eolian sand bed. 
Our ability to reconstruct the three-dimensional geometry of Late Pleistocene sands within the large Sand Hills dunes is limited. Muhs et al. (1999a) documented spatial variation in the geochemistry and mineralogy of eolian sands across the Sand Hills, but we have not identified temporal changes in sand composition allowing differentiation of Pleistocene and Holocene deposits without OSL dating. Our cores seldom contained paleosols or other potential stratigraphic markers, probably because of frequent erosional truncation, and efforts to use ground-penetrating radar to characterize the stratigraphy within the large dunes have been unsuccessful so far. Thus, in the rest of this section we focus on what can be inferred from the OSL ages and their position relative to the present dune morphology.

Many of the Late Pleistocene ages from eolian sands within large Sand Hills dunes range between $14 \mathrm{ka}$ and $17 \mathrm{ka}$, with all ages older than 19 ka coming from eolian sands interbedded with loess (Figures 3-6). These results could be interpreted as indicating a fairly short interval of major dune activity, but there are good reasons to treat this apparent cluster of ages with caution. First, the OSL ages should be interpreted as relatively broad probability distributions, often with $\pm 2 \sigma$ ranges spanning $>4000$ yr. Second, OSL ages from many dunefield settings are inherently biased toward the later part of an extended period of dune activity, because much of the record of such activity is eroded through ongoing dune migration. Certainly, our dating of sand high within large dunes is unlikely to have captured the initial construction of the dunes.

Third, there is good reason to believe that the OSL ages do not adequately record the final phase of Late Pleistocene activity, either. The simplest interpretation of the ages clustered around 1517 ka at Diamond Bar Ranch and Hansen Ranch is that they represent sedimentation on leeward slopes of the large dunes that are still present today, in an earlier stage of their migration toward the south or southeast. If so, substantial Late Pleistocene dune migration could have occurred after deposition of the sand that was dated, because the cores were taken $300-1000 \mathrm{~m}$ from the present southeast slopes of these dunes. The individual Late Pleistocene ages from Kroeger Blowout and Wild Horse Creek Ranch, located high in the modern dunes but some distance from modern leeward slopes, are also consistent with this interpretation. The cross-strata dated at Vinton Blowout could record an earlier position of the large barchan dune extending southeast from that site, implying very substantial migration after $15^{-17} \mathrm{ka}$. In all of these cases, it is possible that some of the large-scale dune migration post-dating our OSL ages occurred not only in the Late Pleistocene, but also during the Early to Middle Holocene, a period of sustained aridity, eolian sand activity, and dust production across the central Great Plains (Miao et al., 2007).

The Wach site is near the downwind end of a fairly small parabolic dune; thus, OSL ages there are more likely to record the last major period of dune migration, than the ages from large Sand Hills dunes. The smooth topography and silt-rich surface soils of this dune and its neighbors would be expected if it had been largely stabilized by dust-trapping vegetation since the Late Pleistocene or Early Holocene. Although one age indicates some Early Holocene sand deposition at the Wach site, the preservation of Late Pleistocene sand deeper in the section suggests limited dune migration in the Holocene. Late Pleistocene eolian sand at the Barta Brothers, Haake, and Cornelius sites is not far above interdune level, and the morphology of the dunes or sand sheets in which this sand was deposited is uncertain. Ages from Bignell Hill and Moran Canyon indicate that sand sheet and dune activity occurred locally southeast of the present Sand Hills dunefield around the time of the Last Glacial Maximum (LGM), before stabilization of the sand surface allowed loess accumulation. The broader geomorphic or paleoenvironmental significance of these events is uncertain.

\subsection{Late Pleistocene wind regimes}

The net direction of potential sand transport by modern winds in the Sand Hills and northeastern Colorado is toward the southeast, and the overall pattern of sand transport should produce dune crests oriented southwest-northeast (Schmeisser et al., 2010). The orientations of large barchanoid ridge, barchan, and compound parabolic dunes across the region are broadly consistent with these predictions from modern wind observations (Smith, 1965; Warren, 1976; Swinehart, 1990; Muhs et al., 1996), although the east-west oriented barchanoid ridge crests of the central Sand Hills indicate a stronger northerly component than at present. A strong component of southwesterly winds is recorded by longitudinal dunes superimposed on larger bedforms of the Sand Hills (Smith's second series), and other dunes of the central and southern Great Plains, but those winds are believed to have occurred mainly during Late Holocene dry periods (Sridhar et al., 2006; Schmeisser et al., 2010).

The results reported here suggest that the regional pattern of large dune orientation could have initially developed in the Late Pleistocene, with prevailing wind directions similar to those observed today. Many of the dunes found to have cores of Late Pleistocene sand have fairly well-defined, steep leeward slopes facing south or southeast, indicating northerly to northwesterly winds, similar to winds that formed Late Pleistocene eolian cross-strata in outcrops at the Vinton Blowout, Wach, and Moran Canyon sites.

While this evidence on the Late Pleistocene wind regime is limited, it is important, given issues raised by general circulation model simulations of climate during the Last Glacial Maximum (LGM), particularly the early modeling studies of the COHMAP Group. Papers describing those studies (Kutzbach and Guetter, 1986; COHMAP, 1988) emphasized the development of anticyclonic circulation over the Laurentide Ice Sheet, suggesting the possibility of easterly surface winds south of the ice margin. Prevalence of easterly winds at the LGM would conflict not only with the evidence on paleowinds reported here, but also with most paleowinds inferred from other Late Pleistocene dunefields of the North American midcontinent (Wolfe et al., 2004; Miao et al., 2010) and with Late Pleistocene loess transport directions (Muhs and Bettis, 200o).

Closer examination shows that the initial COHMAP study and later modeling projects actually produced results that are consistent with the eolian record on the central Great Plains, however. Surface winds simulated for the LGM and the modern control in the original COHMAP study are illustrated in Figure 7 (Kutzbach and Guetter, 1986; Wright et al., 1993; Kutzbach, 1994). Southwest of the ice sheet margin on the central Great Plains, the mean LGM winter winds are from the west to northwest, with a larger northerly component than in the modern control (Figure 7). Winter winds in the modern control are very similar to the mean January winds in the NCEP reanalysis of modern observations (Kalnay et al., 1996). Summer winds are southerly to easterly in both LGM and modern control simulations, but are weaker than the winter winds, so winter winds dominate the annual mean. The anticyclonic winds often emphasized in discussions of climate modeling results occur mainly over the ice sheet itself, with northeasterly to northerly wind flow down the southern ice sheet margin (Figure 7).

More recent modeling studies have produced similar results. Table 2 lists published examples of surface wind plots. Monthly wind vectors from numerous other studies are available through archives such as those maintained by NOAA Paleoclimatology [ http://www.ncdc.noaa.gov/paleo/data.html ] and the University of Wisconsin-Madison Center for Climatic Research [ http://ccr.aos.wisc.edu/ ]. Northeasterly downslope winds at the ice margin are especially well-developed in the regional model 

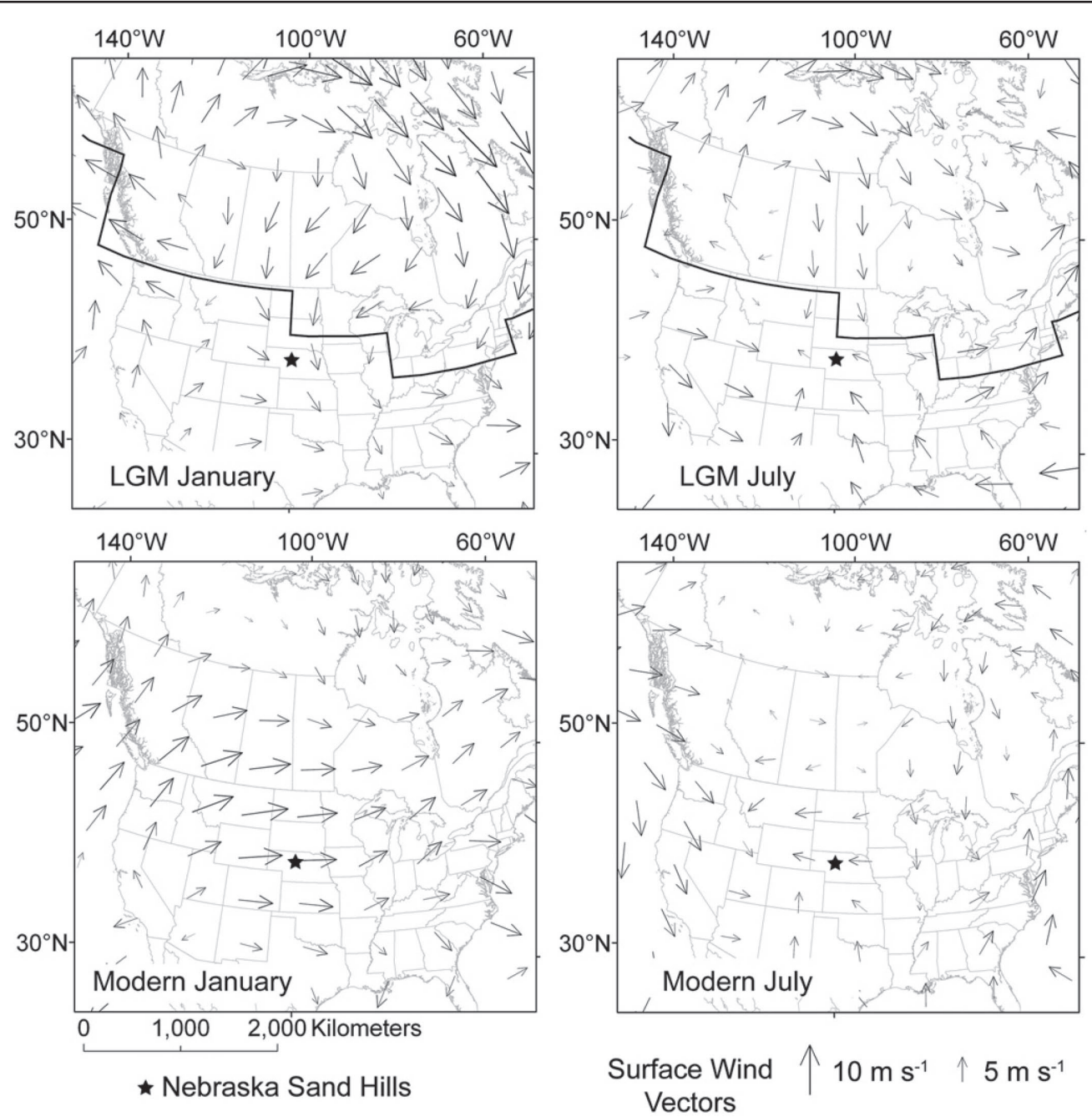

Figure 7. Surface wind vectors in January and July, simulated by the general circulation model initially used by the COHMAP Group (CCM0), with boundary conditions appropriate for the LGM (originally assigned an age of 18K by COHMAP) and the modern pre-industrial control. Vectors plotted in ArcGIS using gridded monthly mean data obtained from NOAA NCDC Paleoclimatology data archive (Kutzbach, 1994); same vectors are shown with a different projection in Kutzbach and Guetter (1986, Figs. 7 and 12). Heavy line in LGM maps shows southern margin of ice sheet as represented in the model.

Table 2. Examples of near-surface wind vectors at the Last Glacial Maximum simulated by global or regional models (published maps showing monthly or seasonal means).

\begin{tabular}{ll}
\hline Reference & Figures illustrating wind vectors \\
\hline Kutzbach and Guetter (1986) & Figs. 7 (July) and 12 (January) \\
Bartlein et al. (1998) & Figure 2 (January and July) \\
Dong and Valdes (1998) & Figure 5 (DJF) and Figure 6 (JJA) \\
Whitlock et al. (2001) & Figure 10 (January and July) \\
Shin et al. (2003) & Figure 16 (DJF and JJA) \\
Bromwich et al. (2004) & Figure 2 (January) and Figure 3 (July) \\
\hline
\end{tabular}

a. $850 \mathrm{hPa}$ winds, shown as anomalies for the LGM; direction can be inferred by comparison with modern control.

of Bromwich et al. (2004); however, the simplified ice margin used in that model is apparently much farther south in the central Great Plains than the actual outermost Late Pleistocene ice margin, which was $200-500 \mathrm{~km}$ northeast of most Sand Hills dunes. Dunes in western Canada that formed within $200 \mathrm{~km}$ of a contemporaneous ice margin record southeasterly winds (Wolfe et al., 2004), which may be comparable to ice marginal downslope winds in the model results of Bromwich et al. (2004).

Northwesterly winds simulated for the LGM on the central Great Plains by the COHMAP project and later modeling studies are consistent with results of this study and with loess transport directions and provenance in the same region (Mason, 2001; Aleinikoff et al., 2008). Comparison of winds in modern control runs (Figure 7) with the resultant drift direction for eolian sand, calculated from modern observations (Schmeisser et al., 2010), raises an important issue, however. Resultant drift direction probably has a stronger northerly component than the mean monthly modern winds because it is heavily influenced by strong northerly and northwesterly winds associated with well-developed cold fronts in mid-latitude cyclones. Such cyclones would still have played an important role in the Great Plains wind regime during the Late Pleistocene (Muhs and Bettis, 200o), even though cyclone tracks were probably affected by changes in upper-level flow induced by the ice sheet (Bromwich et al., 2004, 2005); therefore, the change in dominant sand transport directions between the LGM and the modern climate may have been even less than implied by modeling results shown in Figure 7.

\subsection{Implications for Late Pleistocene environments}

Sediment supply is a basic requirement for dunefield development (Kocurek and Lancaster, 1999), and in the central Great Plains, broad channel belts of major streams are an obvious potential source of eolian sand. Episodes of Late Pleistocene dune 
activity near those channel belts could have occurred at times when extensive areas of fluvial sand were frequently exposed to the wind, either because of high sediment loads and variable discharge related to glaciation in the Rocky Mountains, or because of broader effects of climate change on the fluvial system. Similar sediment supply effects have been proposed for Holocene dune activity on the Great Plains (Muhs and Holliday, 1995; Muhs et al., 1996; Muhs and Zarate, 2001) and Late Pleistocene dune development elsewhere in the midcontinent (Rawling et al., 2008; Miao et al., 2010). While this conceptual model could apply to sand interbedded with loess near the Platte River at Moran Canyon and Bignell Hill, it is difficult to apply to other occurrences of Late Pleistocene eolian sand, which are relatively far from any major fluvial sediment source. A direct effect of fluvial sediment supply on Late Pleistocene dune activity in the Sand Hills seems particularly unlikely, given the mineralogical maturity of dune sand there compared to potential fluvial sources and the availability of sand from underlying Pliocene eolian sand sheets (Muhs et al., 1997).

Besides sediment supply, major variables influencing eolian system state include the transport capacity of the wind and sediment availability for wind entrainment, often controlled by the extent of stabilizing vegetation cover (Kocurek and Lancaster, 1999). The importance of wind power has been emphasized in research on dunes in other regions (e.g. Tsoar, 2005), but increased transport capacity has generally not been considered the primary explanation for initiation of Holocene dune activity on the Great Plains, because the dunefields there are largely stable today despite winds with very high transport capacity (Muhs and Maat, 1993; Muhs and Holliday, 1995; Muhs and Wolfe, 1999). There is no compelling evidence that winds even stronger than those on the Great Plains today could have enhanced dune mobility in the Late Pleistocene, although this issue merits further investigation. As noted above, strong downslope winds simulated in a regional modeling study of the LGM (Bromwich et al., 2004) are confined to areas near the ice margin and are not consistent with the field evidence of Late Pleistocene sand- and loess-transporting wind directions (Muhs and Bettis, 2000; Mason, 2001).

With that background, the key factors allowing Late Pleistocene dune activity were probably those limiting dune-stabilizing vegetation growth. For the Holocene, most researchers have focused on effective moisture as the critical control of dunefield vegetation, a view supported by the similar timing of eolian activity and independent evidence for a dry climate (Madole, 1994; Forman et al., 1995, 2001; Muhs et al., 1996; Arbogast and Johnson, 1998; Mason et al., 2004; Miao et al., 2007). For example, significant dune activity occurred in the central Great Plains during the Medieval Climatic Anomaly, when severe drought across the western U.S. is well-documented by other evidence (Cook et al., 2004; Mason et al., 2004; Daniels and Knox, 2005; Miao et al., 2007). In the Canadian Prairies, however, growing-season length and temperature have been identified as additional important factors limiting dune stabilization (Muhs and Wolfe, 1999). In that region, the coldest part of the Great Plains, short growing seasons may allow dune mobility despite effective moisture high enough to sustain fully stabilized dunes in warmer areas; furthermore, dune stabilization has occurred as the climate of the Canadian Prairies warmed during the historical period (Wolfe and Hugenholtz, 2009).

Drawing on that insight, we propose that growing-season length and temperature played important roles in allowing Late Pleistocene dune activity, in combination with lower than modern precipitation and low atmospheric $\mathrm{CO}_{2}$. This explanation is at least partially consistent with paleoecological data, and is more plausible than attributing Late Pleistocene dune activity to aridity alone, although paleoclimatic modeling does provide a basis for assuming that precipitation was lower than modern under full-glacial conditions (Forman et al., 1995). Most paleoclimatic research has focused on the LGM $(\sim 21 \mathrm{ka})$, earlier than most of our eolian sand ages, but the insight provided on glacial climates is still valuable. Numerical modeling of the LGM climate using global and regional models of widely varying complexity and resolution consistently indicates much colder winter and summer temperatures than at present south of the ice margin in central North America (e.g. Kutzbach and Guetter, 1986; Bartlein et al., 1998; Shin et al., 2003; Bromwich et al., 2004; Kim et al., 2008). These climate simulations often also indicate substantially less summer precipitation in the Great Plains region at the LGM than in the modern climate (e.g. Bartlein et al., 1998; Shin et al., 2003; Kim et al., 2008), but the regional model used by Bromwich et al. (2005) indicated episodic heavy rainfall related to cyclones tracking over the southern part of the ice sheet.

Jackson et al. (2000) reconstructed the LGM climate of eastern North America using pollen and plant macrofossil assemblages, and concluded that July temperatures were $14-18{ }^{\circ} \mathrm{C}$ lower than modern and annual precipitation was $40-60 \%$ less than modern in the region just east of the central Great Plains. These estimates suggest more extreme contrasts between the LGM and modern conditions than is indicated by numerical modeling; however, Jackson et al. (200o) did not take into account the effects of much lower atmospheric $\mathrm{CO}_{2}$ on plant physiology during the last glaciation. These are the subject of ongoing discussion, but it appears that lower water use efficiency and other effects of lower $\mathrm{CO}_{2}$ contributed to the open vegetation and relatively low tree cover evident in Late Pleistocene pollen data, which would otherwise be attributed to aridity and possibly low temperatures (Cowling and Sykes, 1999; Williams et al., 2000; Williams, 2002; Loehle, 2007; Prentice and Harrison, 2009). More open vegetation and lower primary productivity would probably favor eolian sand mobility, regardless of the relative contributions of climate and low $\mathrm{CO}_{2}$ to these conditions.

Within the central Great Plains, Late Pleistocene paleoecological evidence clearly indicates a cold climate, and strongly suggests an open mosaic of vegetation including both grasses and trees. Muhs et al. (1999b) concluded that the environment of Peoria Loess deposition in northeastern Colorado was predominantly a cool-season grassland, based on mammal and insect fossil assemblages described by Graham (1981) and Elias and Toolin (1990), also noting the interpretation of a cold steppe environment from fossil gastropods in Peoria Loess of western $\mathrm{Ne}$ braska (Rousseau and Kukla, 1994; Rossignol et al., 2004). On the other hand, Late Pleistocene pollen and plant macrofossils confirm the local presence of spruce (Picea glauca, white spruce, where species-level identification is possible) in Kansas and Nebraska, including the Sand Hills (Watts and Wright, 1966; Grüger, 1973; Wells and Stewart, 1987; Loope and Swinehart, 200o). Fredlund and Tieszen (1997) interpreted pollen and phytoliths from Late Pleistocene sediments in Nebraska and Kansas as indicating an environment with some trees and abundant grass-covered openings, at about the same time as many of our dunefield OSL ages. Small mammals represented by Late Pleistocene fossils in western Kansas and Nebraska are found today in boreal forest, Rocky Mountain conifer forest, and cool grassland or parkland (Wells and Stewart, 1987; Corner and Voorhies, 1994). Assuming that moisture stress related to low $\mathrm{CO}_{2}$ had an important role in favoring open vegetation rather than closed forest, it is possible that patches of forest occurred mainly in landscape settings with greater soil moisture availability, such as interdune valleys in the Sand Hills.

Regardless of the specific nature of the vegetation mosaic during the Late Pleistocene on the central Great Plains, it must have been a very different environment from the deserts 
in which most large fully mobile dunes similar to those of the Sand Hills occur at present. It should be noted, however, that active inland dunes surrounded by boreal forest do occur today in Alaska and northern Alberta, where a cold, short growing season occurs together with relatively low precipitation (David, 1977; Mann et al., 2002). We suggest that during the Late Pleistocene on the central Great Plains, short, cool, dry growing seasons, with increased moisture stress related to low $\mathrm{CO}_{2}$ levels, severely limited the ability of vegetation to colonize bare dune sand with low moisture retention. Thus, even though soil moisture was sufficient to sustain spruce and other boreal forest species in certain parts of the landscape, and grassland vegetation in many areas, large areas of bare sand remained mobile.

\section{Conclusions}

Research over the last several decades has conclusively demonstrated that substantial dune activity occurred during the Holocene in the central Great Plains. The results of this study represent an important step toward understanding the earlier, Late Pleistocene history of the Nebraska Sand Hills and neighboring dunefields. While these results comprise a very small sample from the thousands of dunes across this region, they clearly suggest that many of the large dunes still present today may have been constructed in the Pleistocene. Late Pleistocene OSL ages of eolian sand sampled in this study cluster between 17 and $14 \mathrm{ka}$, but it is likely that dune construction and migration began well before that time, and the OSL ages also do not capture the final phases of large-dune migration at several sites. Late Pleistocene dune activity occurred in a very different environment than Holocene activity, with cold, short growing seasons and low atmospheric $\mathrm{CO}_{2}$. In this setting, fully mobile dunes were juxtaposed with boreal forest biota in a landscape with few modern analogs.

Acknowledgments - This work was funded by the National Science Foundation (EAR-9709742, BCS-0352683, BCS-0352748, DEB-0322067) and the Conservation and Survey Division, Institute of Agriculture and Natural Resources, University of $\mathrm{Ne}-$ braska. We thank numerous landowners for study site access, drillers Jim Roberts, Mark Burbach, and Matt Marxsen, field assistants Derek Geise, Aaron Feggestad, Corey Werner, Henry Loope, and Hannah Loope, and two anonymous reviewers for their comments.

\section{References}

Ahlbrandt, T. S., Swinehart, J. B., Maroney, D. G., 1983. The dynamic Holocene dune fields of the Great Plains and Rocky Mountain basins, U. S. A. In: Brookfield, M. E., Ahlbrandt, T. S. (eds.), Eolian Sediments and Processes/11th International Association of Sedimentologists Congress. Elsevier Sci. Publ. Co, Amsterdam, Netherlands, pp. 379-406.

Aitken, M. J., 1998. An Introduction to Optical Dating: The Dating of Quaternary Sediments by the Use of Photon-Stimulated Luminescence, 1st ed. Oxford University Press, Oxford.

Aleinikoff, J. N., Muhs, D. R., Bettis, E. A., Johnson, W. C., Fanning, C. M., Benton, R., 2008. Isotopic evidence for the diversity of late Quaternary loess in Nebraska: Glaciogenic and nonglaciogenic sources. Geological Society of America Bulletin 120, 1362-1377.

Arbogast, A. F., Johnson, W. C., 1998. Late-Quaternary landscape response to environmental change in south-central Kansas. Annals of the Association of American Geographers 88, 126-145.

Bartlein, P. J., Anderson, K. H., Anderson, P. M., Edwards, M. E., Mock, C. J., Thompson, R. S., Webb, R. S., Whitlock, C., 1998. Paleoclimate simulations for North America over the past 21,000 years: Features of the simulated climate and comparisons with paleoenvironmental data. Quaternary Science Reviews 17, 549-585.

Bettis III, E. A., Mason, J. A., Swinehart, J. B., Miao, X. D., Hanson, P. R., Goble, R. J., Loope, D. B., Jacobs, P. M., Roberts, H. M., 2003. Cenozoic eolian sedimentary systems of the USA midcontinent. In: Easterbrook, D. J. (ed.), Quaternary Geology of the United States. Desert Research Institute, Reno, Nevada, pp. 195-218.

Bromwich, D. H., Toracinta, E. R., Oglesby, R. J., Fastook, J. L., Hughes, T. J., 2005. LGM summer climate on the southern margin of the Laurentide ice sheet: Wet or dry? Journal of Climate 18, 3317-3338.

Bromwich, D. H., Toracinta, E. R., Wei, H., Oglesby, R. J., Fastook, J. L., Hughes, T. J., 2004. Polar MM5 simulations of the winter climate of the Laurentide Ice Sheet at the LGM. Journal of Climate 17, 3415-3433.

COHMAP, 1988. Climatic changes of the last 18,000 years - Observations and model simulations. Science 241, 1043-1052.

Cook, E. R., Woodhouse, C. A., Eakin, C. M., Meko, D. M., Stahle, D. W., 2004. Long-term aridity changes in the western United States. Science 306, 1015-1018.

Corner, R. G., Voorhies, M. R., 1994. Late Quaternary records of the heather vole (Phenacomys intermedius) in Nebraska: Paleoenvironmental implications. In: Dort Jr., W. (ed.), Institute for Tertiary-Quaternary Studies-TER-QUA Symposium Series. Nebraska Academy of Sciences, Lincoln, Nebraska.

Cowling, S. A., Sykes, M. T., 1999. Physiological significance of low atmospheric $\mathrm{CO}_{2}$ for plant-climate interactions. Quaternary Research $52,237-242$.

Daniels, J. M., Knox, J. C., 2005. Alluvial stratigraphic evidence for channel incision during the Mediaeval Warm Period on the central Great Plains, USA. The Holocene 15, 736-747.

David, P. P., 1977. Sand Dune Occurrences of Canada. A Theme and Resource Inventory Study of Eolian Landforms of Canada. Indian and Northern Affairs National Parks Branch, Montreal, Canada. Contract No. 74-230.

Dong, B., Valdes, P. J., 1998. Simulations of the Last Glacial Maximum climates using a general circulation model: Prescribed versus computed sea surface temperatures. Climate Dynamics 14, 571-591.

Elias, S. A., Toolin, L. J., 1990. Accelerator dating of a mixed assemblage of late Pleistocene insect fossils from the Lamb Spring site, Colorado. Quaternary Research 33, 122-126.

Feng, Z. D., Johnson, W. C., Diffendal Jr., R. F., 1994. Environments of aeolian deposition in south-central Nebraska during the last glacial maximum. Physical Geography 15, 249-261.

Forman, S. L., Maat, P., 1990. Stratigraphic evidence for late Quaternary dune activity near Hudson on the Piedmont of northern Colorado. Geology 18, 745-748.

Forman, S. L., Oglesby, R., Markgraf, V., Stafford, T., 1995. Paleoclimatic significance of late Quaternary eolian deposition on the Piedmont and High Plains, Central United States. Global and Planetary Change 11, 35-55.

Forman, S. L., Oglesby, R., Webb, R. S., 2001. Temporal and spatial patterns of Holocene dune activity on the Great Plains of North America; megadroughts and climate links. Global and Planetary Change $29,1-29$.

Fredlund, G. G., Tieszen, L. L., 1997. Calibrating grass phytolith assemblages in climatic terms; application to late Pleistocene assemblages from Kansas and Nebraska. Palaeogeography, Palaeoclimatology, Palaeoecology 136, 199-211.

Goble, R. J., Mason, J. A., Loope, D. B., Swinehart, J. B., 2004. Optical and radiocarbon ages of stacked paleosols and dune sands in the Nebraska Sand Hills, USA. Quaternary Science Reviews 23, 1173-1182.

Graham, R. W., 1981. Preliminary report on late Pleistocene vertebrates from the Selby and Dutton archeological/paleontological sites, Yuma County, Colorado. University of Wyoming Contributions to Geology 20, 33-56.

Grüger, J., 1973. Studies on the Late-Quaternary vegetation history of northeastern Kansas. Geological Society of America Bulletin 84, 239-250. 
Hanson, P. R., Arbogast, A. F., Johnson, W. C., Joeckel, R., Young, A., 2010. Megadroughts and late Holocene dune activation at the eastern margin of the Great Plains, north-central Kansas, USA. Aeolian Research 1, 101-110.

Jackson, S. T., Webb, R. S., Anderson, K. H., Overpeck, J. T., Webb, T., Williams, J. W., Hansen, B. C. S., 2000. Vegetation and environment in Eastern North America during the Last Glacial Maximum. Quaternary Science Reviews 19, 489-508.

Johnson, W. C., Willey, K. L., 2000. Isotopic and rock magnetic expression of environmental changes at the Pleistocene-Holocene transition in the central Great Plains. Quaternary International 67, 89-106.

Kalnay, E., Kanamitsu, M., Kistler, R., Collins, W., Deaven, D., Gandin, L., Iredell, M., Saha, S., White, G., Woollen, J., Zhu, Y., Chelliah, M., Ebisuzaki, W., Higgins, W., Janowiak, J., Mo, K. C., Ropelewski, C., Wang, J., Leetmaa, A., Reynolds, R., Jenne, R., Joseph, D., 1996. The NCEP/NCAR 40-year reanalysis project. Bulletin of the American Meteorological Society 77, 437-471.

Kim, S.-J., Crowley, T. J., Erickson, D. J., Govindasamy, B., Duffy, P. B., Lee, B. Y., 2008. High-resolution climate simulation of the last glacial maximum. Climate Dynamics 31, 1-16.

Kocurek, G., Lancaster, N., 1999. Aeolian system sediment state; theory and Mojave Desert Kelso dune field example. Sedimentology 46, 505-515.

Kutzbach, J., 1994. CCMO General Circulation Model Output Data Set. IGBP PAGES/ World Data Center-A for Paleoclimatology Data Contribution Series \# 94-025. NOAA/NGDC Paleoclimatology Program, Boulder CO, USA.

Kutzbach, J. E., Guetter, P. J., 1986. The influence of changing orbital parameters and surface boundary-conditions on climate simulations for the past 18,000 years. Journal of the Atmospheric Sciences 43, $1726-1759$.

Loehle, C., 2007. Predicting Pleistocene climate from vegetation in North America. Climate of the Past 3, 109-118.

Loope, D. B., Swinehart, J. B., 2000. Thinking like a dune field: Geologic history in the Nebraska Sand Hills. Great Plains Research 10, 5-35.

Loope, D. B., Swinehart, J. B., Mason, J. P., 1995. Dune-dammed paleovalleys of the Nebraska Sand Hills; intrinsic versus climatic controls on the accumulation of lake and marsh sediments. Geological Society of America Bulletin 107, 396-406.

Lugn, A. L., 1935. The Pleistocene Geology of Nebraska. Nebraska Geological Survey, Lincoln, NE, United States.

Maat, P. B., Johnson, W. C., 1996. Thermoluminescence and new (super 14) $C$ age estimates for late Quaternary loesses in southwestern Nebraska. Geomorphology 17, 115-128.

Madole, R. F., 1994. Stratigraphic evidence of desertification in the west-central Great Plains within the past 1000 yr. Geology 22, 483-486.

Madole, R. F., 1995. Spatial and temporal patterns of late Quaternary eolian deposition, eastern Colorado, U. S. A. Quaternary Science Reviews 14, 155-177.

Mann, D. H., Heiser, P. A., Finney, B. P., 2002. Holocene history of the Great Kobuk Sand Dunes, Northwestern Alaska. Quaternary Science Reviews 21, 709-731.

Mason, J. A., 2001. Transport direction of Peoria Loess in Nebraska and implications for loess sources on the central Great Plains. Quaternary Research 56, 79-86.

Mason, J. A., Jacobs, P. M., Hanson, P. R., Miao, X. D., Goble, R. J., 2003. Sources and paleoclimatic significance of Holocene Bignell Loess, Central Great Plains, USA. Quaternary Research 60, 330-339.

Mason, J. A., Miao, X. D., Hanson, P. R., Johnson, W. C., Jacobs, P. M., Goble, R. J., 2008. Loess record of the Pleistocene-Holocene transition on the northern and central Great Plains, USA. Quaternary Science Reviews 27, 1772-1783.

Mason, J. A., Swinehart, J. B., Goble, R. J., Loope, D. B., 2004. Late-Holocene dune activity linked to hydrological drought, Nebraska Sand Hills, USA. Holocene 14, 209-217.

Miao, X. D., Hanson, P. R., Wang, H., Young, A., 2010. Timing and origin for sand dunes in the Green River Lowland of Illinois, upper Mississippi River Valley, USA. Quaternary Science Reviews 29, 763-773.
Miao, X. D., Mason, J. A., Swinehart, J. B., Loope, D. B., Hanson, P. R., Goble, R. J., Liu, X. D., 2007. A 10,000 year record of dune activity, dust storms, and severe drought in the central Great Plains. Geology $35,119-122$.

Muhs, D. R., 1985. Age and paleoclimatic significance of Holocene sand dunes in northeastern Colorado. Annals of the Association of American Geographers 75, 566-582.

Muhs, D. R., Bettis III, E. A., 2000. Geochemical variations in Peoria Loess of western Iowa indicate paleowinds of midcontinental North America during last glaciation. Quaternary Research 53, 49-61.

Muhs, D. R., Bettis III, E. A., Aleinikoff, J. N., McGeehin, J. P., Beann, J, Skipp, G., Marshall, B. D., Roberts, H. M., Johnson, W. C., Benton, R., 2008. Origin and paleoclimatic significance of late Quaternary loess in Nebraska: Evidence from stratigraphy, chronology, sedimentology, and geochemistry. Geological Society of America Bulletin 120, 1378-1407.

Muhs, D. R., Holliday, V. T., 1995. Evidence of active dune sand on the Great Plains in the 19th century from accounts of early explorers. Quaternary Research 43, 198-208.

Muhs, D. R., Maat, P. B., 1993. The potential response of eolian sands to greenhouse warming and precipitation reduction on the Great Plains of the U. S. A. Journal of Arid Environments 25, 351-361.

Muhs, D. R., Stafford, T. W., Cowherd, S. D., Mahan, S. A., Kihl, R., Maat, P. B., Bush, C. A., Nehring, J., 1996. Origin of the late Quaternary dune fields of northeastern Colorado. Geomorphology 17, 129-149.

Muhs, D. R., Stafford Jr., T. W., Swinehart, J. B., Cowherd, S. D., Mahan, S. A., Bush, C. A., Madole, R. F., Maat, P. B., 1997. Late Holocene eolian activity in the mineralogically mature Nebraska Sand Hills. Quaternary Research 48, 162-176.

Muhs, D. R., Aleinikoff, J. N., Stafford Jr., T. W., Kihl, R., Been, J., Mahan, S. A., Cowherd, S., 1999a. Late Quaternary loess in northeastern Colorado; Part I, Age and paleoclimatic significance. Geological Society of America Bulletin 111, 1861-1875.

Muhs, D. R., Swinehart, J. B., Loope, D. B., Aleinikoff, J. N., Been, J., 1999b. 200,000 years of climate change recorded in eolian sediments of the High Plains of eastern Colorado and western Nebraska. In: Lageson David, R., Lester Alan, P., Trudgill Bruce, D. (eds.), Colorado and Adjacent Areas. Geological Society of America, Boulder, CO, United States, pp. 71-91.

Muhs, D. R., Wolfe, S. A., 1999. Sand dunes of the Northern Great Plains of Canada and the United States. In: Lemmen, D. S., Vance, R. E. (eds.), Holocene Climate and Environmental Change in the Palliser Triangle; A Geoscientific Context for Evaluation of the Impacts of Climate Change on the Southern Canadian Prairies. Geological Survey of Canada, Ottawa, ON, Canada, pp. 183-197.

Muhs, D. R., Zarate, M., 2001. Late Quaternary eolian records of the Americas and their paleoclimatic significance. In: Markgraf, V. (ed.) Interhemispheric Climate Linkages. Academic Press, San Diego, pp. 183-216.

Murray, A. S., Wintle, A. G., 2000. Luminescence dating of quartz using an improved single-aliquot regenerative-dose protocol. Radiation Measurements 32, 57-73.

Prentice, I. C., Harrison, S. P., 2009. Ecosystem effects of $\mathrm{CO}_{2}$ concentration: Evidence from past climates. Climate of the Past 5, 297-307.

Prescott, J. R., Hutton, J. T., 1994. Cosmic ray contributions to dose rates for luminescence and ESR dating: Large depths and long-term time variations. Radiation Measurements 23, 497-500.

Rawling III, J. E., Hanson, P. R., Young, A., Attig, J. W., 2008. Late Pleistocene dune construction in the Central Sand Plain of Wisconsin, USA. Geomorphology 100, 494-505.

Reimer, P. J., Baillie, M. G. L., Bard, E., Bayliss, A., Beck, J. W., Blackwell, P. G., Ramsey, C. B., Buck, C. E., Burr, G. S., Edwards, R. L., Friedrich, M., Grootes, P. M., Guilderson, T. P., Hajdas, I., Heaton, T. J., Hogg, A. G., Hughen, K. A., Kaiser, K. F., Kromer, B., McCormac, F. G., Manning, S. W., Reimer, R. W., Richards, D. A., Southon, J. R., Talamo, S., Turney, C. S. M., van der Plicht, J., Weyhenmeye, C. E., 2009. INTCAL09 and Marine09 radiocarbon age calibration curves, $0-50,000$ years cal BP. Radiocarbon 51, 1111-1150. 
Roberts, H. M., Muhs, D. R., Wintle, A. G., Duller, G. A. T., Bettis III, E. A., 2003. Unprecedented last-glacial mass accumulation rates determined by luminescence dating of loess from western Nebraska. Quaternary Research 59, 411-419.

Rossignol, J., Moine, O., Rousseau, D. D., 2004. The Buzzard's Roost and Eustis mollusc sequences: Comparison between the paleoenvironments of two sites in the Wisconsinan loess of Nebraska, USA. Boreas 33, 145-154.

Rousseau, D. D., Kukla, G., 1994. Late Pleistocene climate record in the Eustis loess section, Nebraska, based on land snail assemblages and magnetic susceptibility. Quaternary Research 42, 176-187.

Scheinost, S. A., 1982. Soil Survey of Hayes County, Nebraska. U. S. Department of Agriculture, Washington, D. C.

Schmeisser, R., 2009. Reconstruction of Paleoclimatic Conditions and Timing of the Last Dune Reactivation in the Nebraska Sand Hills. Ph. D. dissertation. University of Nebraska, Lincoln, Nebraska, p. 121.

Schmeisser, R., Loope, D. B., Mason, J. A., 2010. Modern and late Holocene wind regimes over the Great Plains (central U. S. A.). Quaternary Science Reviews 29, 554-566.

Shin, S. I., Liu, Z., Otto-Bliesner, B., Brady, E. C., Kutzbach, J. E., Harrison, S. P., 2003. A simulation of the last glacial maximum climate using the NCAR-CCSM. Climate Dynamics 20, 127-151.

Smith, H. T. U., 1965. Dune morphology and chronology in central and western Nebraska. Journal of Geology 73, 557-578.

Sridhar, V., Loope, D. B., Swinehart, J. B., Mason, J. A., Oglesby, R. J., Rowe, C. M., 2006. Large wind shift on the Great Plains during the Medieval Warm Period. Science 313, 345-347.

Stokes, S., Rich, J., Swinehart, J. B., Loope, D. B., 1999. Holocene timing of megabarchan dune construction in the Nebraska Sand Hills. Geological Society of America Abstracts with Programs 31, A231.

Stokes, S., Swinehart, J. B., 1997. Middle- and late-Holocene dune reactivation in the Nebraska Sand Hills, USA. The Holocene 7, 263-272.

Swinehart, J. B., 1990. Wind-blown deposits. In: Bleed, A., Flowerday, C. (eds.), An Atlas of the Sand Hills. Conservation and Survey Division. University of Nebraska, Lincoln, Nebraska, pp. 43-56.

Swinehart, J. B., Diffendal Jr., R. F., 1990. Geology of the pre-dune strata. In: Bleed, A., Flowerday, C. (eds.), An Atlas of the Sand Hills. Conservation and Survey Division. University of Nebraska, Lincoln, Nebraska, pp. 29-42.
Tsoar, H., 2005. Sand dunes mobility and stability in relation to climate. Physica A 357, 50-56.

Warren, A., 1976. Morphology and sediments of the Nebraska Sand Hills in relation to Pleistocene winds and the development of aeolian bedforms. Journal of Geology 84, 685-700.

Watts, W., Wright, H. J., 1966. Late-Wisconsin pollen and seed analysis from the Nebraska Sandhills. Ecology 47, 202-210.

Wells, P., Stewart, J., 1987. Spruce charcoal, conifer macrofossils, and landsnail and small-vertebrate faunas in Wisconsinan sediments on the High Plains of Kansas. In: Johnson, W. C. (ed.), Quaternary Environments of Kansas. Kansas Geological Survey Guidebook Series, vol. 5 Lawrence, Kansas.

Whitlock, C., Bartlein, P. J., Markgraf, V., Ashworth, A., 2001. The midlatitudes of North and South America during the Last Glacial Maximum and early Holocene: Similar paleoclimatic sequences despite differing large-scale controls. In: Markgraf, V. (ed.), Interhemispheric Climate Linkages. Academic Press, San Diego, pp. 391-416.

Williams, J., 2002. Variations in tree cover in North America since the last glacial maximum. Global and Planetary Change 35, 1-23.

Williams, J. W., Webb, T., Shurman, B. N., Bartlein, P. J., 2000. Do low $\mathrm{CO}_{2}$ concentrations affect pollen-based reconstructions of LGM climates? A response to "Physiological significance of low atmospheric $\mathrm{CO}_{2}$ for plant-climate interactions" by Cowling and Sykes. Quaternary Research 53, 402-404.

Wolfe, S. A., Hugenholtz, C. H., 2009. Barchan dunes stabilized under recent climate warming on the northern Great Plains. Geology 37 1039-1042.

Wolfe, S. A., Huntley, D. J., Ollerhead, J., 2004. Relict late Wisconsinan dune fields of the northern Great Plains, Canada. Geographie Physique et Quaternaire 58, 323-336.

Wright Jr., H. E., Almendinger, J. C., Gruger, J., 1985. Pollen diagram from the Nebraska Sandhills and the age of the dunes. Quaternary Research 24, 115-120.

Wright, H. E., Kutzbach, J. E., Webb III, T., Ruddiman, W. F., Street-Perrott, F. A., Bartlein, P. J. (eds.), 1993. Global Climates Since the Last Glacial Maximum. University of Minnesota Press, Minneapolis, MN, p. 569. 


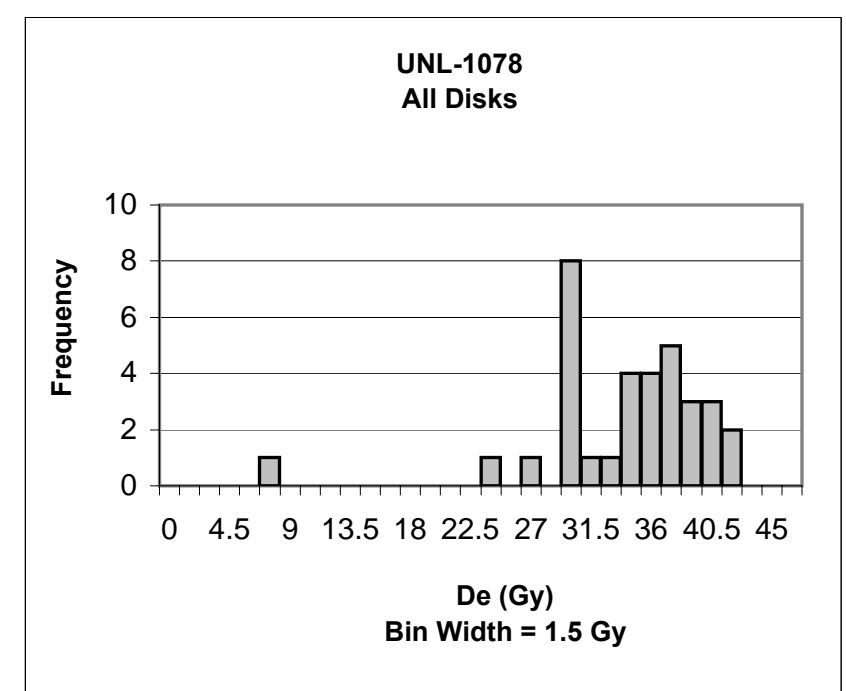

$\begin{array}{lcll}\text { All Disks } & & & \\ & \text { De }(G y) & & \\ \text { Mean }= & 33.30 & \text { S.D. }(\mathbf{1 \sigma})= & 6.39 \\ \text { Median }= & 34.53 & \text { Std. Err }= & 1.10 \\ \text { Min }= & 7.36 & \text { Disks }(\mathbf{n})= & 34 \\ \text { Max }= & 41.26 & & \end{array}$

\begin{tabular}{|c|c|c|c|c|c|}
\hline Disk & $\mathrm{De}$ & Err & Disc & $\mathrm{De}$ & Err \\
\hline 1 & 7.36 & 30.00 & 28 & 37.97 & 0.12 \\
\hline 2 & 23.50 & 1.43 & 29 & 38.00 & 0.17 \\
\hline 3 & 26.14 & 0.73 & 30 & 39.04 & 0.06 \\
\hline 4 & 29.09 & 1.15 & 31 & 39.60 & 0.02 \\
\hline 5 & 29.11 & 1.44 & 32 & 40.39 & 0.43 \\
\hline 6 & 29.26 & 0.82 & 33 & 40.72 & 0.12 \\
\hline 7 & 29.38 & 0.29 & 34 & 41.26 & 0.29 \\
\hline 8 & 29.39 & 0.28 & 35 & & \\
\hline 9 & 29.51 & 0.76 & 36 & & \\
\hline 10 & 29.88 & 0.07 & 37 & & \\
\hline 11 & 29.94 & 0.61 & 38 & & \\
\hline 12 & 30.08 & 0.35 & 39 & & \\
\hline 13 & 32.68 & 0.75 & 40 & & \\
\hline 14 & 33.00 & 0.14 & 41 & & \\
\hline 15 & 33.27 & 0.11 & 42 & & \\
\hline 16 & 34.28 & 0.57 & 43 & & \\
\hline 17 & 34.38 & 0.04 & 44 & & \\
\hline 18 & 34.68 & 0.36 & 45 & & \\
\hline 19 & 35.40 & 0.32 & 46 & & \\
\hline 20 & 35.86 & 0.45 & 47 & & \\
\hline 21 & 35.98 & 0.23 & 48 & & \\
\hline 22 & 36.47 & 0.15 & 49 & & \\
\hline 23 & 37.18 & 0.02 & 50 & & \\
\hline 24 & 37.19 & 0.16 & 51 & & \\
\hline 25 & 37.39 & 0.04 & 52 & & \\
\hline 26 & 37.42 & 0.01 & 53 & & \\
\hline 27 & 37.53 & 0.23 & 54 & & \\
\hline
\end{tabular}

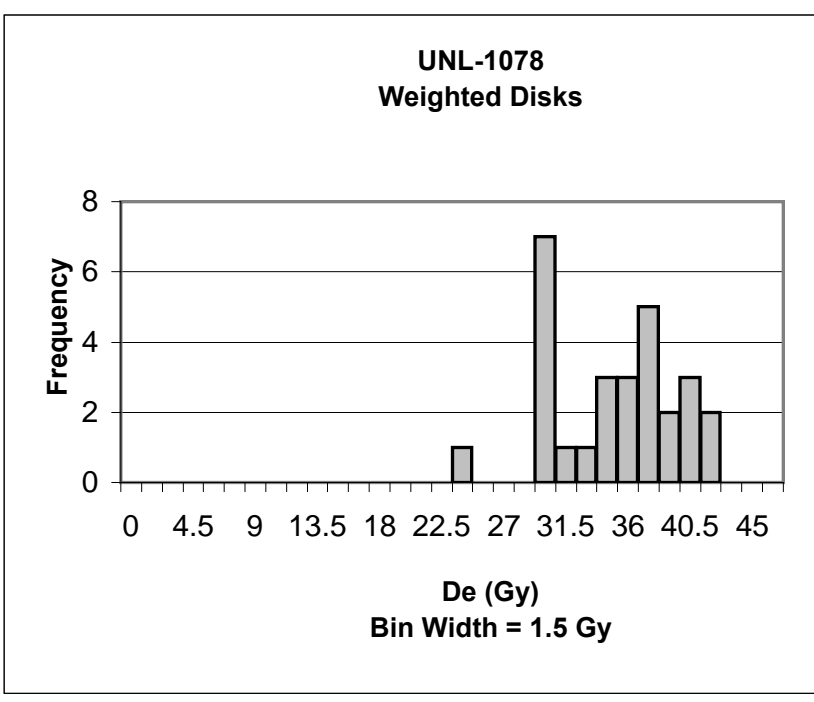

Weighted Disks

De (Gy)

Mean $=\quad 34.32$

Median $=\quad 35.04$

Min $=\quad 23.50$

Max $=\quad 41.26$

$\begin{array}{cccccc}\text { Disk } & \text { De } & \text { Err } & \text { Disc } & \text { De } & \text { Err } \\ \mathbf{1} & 23.50 & 1.43 & \mathbf{2 8} & 41.26 & 0.29 \\ \mathbf{2} & 29.09 & 1.15 & \mathbf{2 9} & & \\ \mathbf{3} & 29.11 & 1.44 & \mathbf{3 0} & & \\ \mathbf{4} & 29.26 & 0.82 & \mathbf{3 1} & & \\ \mathbf{5} & 29.38 & 0.29 & \mathbf{3 2} & & \\ \mathbf{6} & 29.39 & 0.28 & \mathbf{3 3} & & \\ \mathbf{7} & 29.51 & 0.76 & \mathbf{3 4} & & \\ \mathbf{8} & 29.94 & 0.61 & \mathbf{3 5} & & \\ \mathbf{9} & 30.08 & 0.35 & \mathbf{3 6} & & \\ \mathbf{1 0} & 32.68 & 0.75 & \mathbf{3 7} & & \\ \mathbf{1 1} & 33.00 & 0.14 & \mathbf{3 8} & & \\ \mathbf{1 2} & 33.27 & 0.11 & \mathbf{3 9} & & \\ \mathbf{1 3} & 34.38 & 0.04 & \mathbf{4 0} & & \\ \mathbf{1 4} & 34.68 & 0.36 & \mathbf{4 1} & & \\ \mathbf{1 5} & 35.40 & 0.32 & \mathbf{4 2} & & \\ \mathbf{1 6} & 35.98 & 0.23 & \mathbf{4 3} & & \\ \mathbf{1 7} & 36.47 & 0.15 & \mathbf{4 4} & & \\ \mathbf{1 8} & 37.18 & 0.02 & \mathbf{4 5} & & \\ \mathbf{1 9} & 37.19 & 0.16 & \mathbf{4 6} & & \\ \mathbf{2 0} & 37.39 & 0.04 & \mathbf{4 7} & \\ \mathbf{2 1} & 37.42 & 0.01 & \mathbf{4 8} & \\ \mathbf{2 2} & 37.53 & 0.23 & \mathbf{4 9} & \\ \mathbf{2 3} & 37.97 & 0.12 & \mathbf{5 0} & \\ \mathbf{2 4} & 39.04 & 0.06 & \mathbf{5 1} & \\ \mathbf{2 5} & 39.60 & 0.02 & \mathbf{5 2} & \\ \mathbf{2 6} & \mathbf{4 0 . 3 9} & 0.43 & \mathbf{5 3} & \\ \mathbf{2 7} & \mathbf{4 0 . 7 2} & 0.12 & \mathbf{5 4} & & \end{array}$

$\begin{array}{ll}\text { S.D. }(\mathbf{1} \sigma)= & 4.54 \\ \text { Std. } \text { Err }= & 0.84\end{array}$

Disks $(n)=28$ 


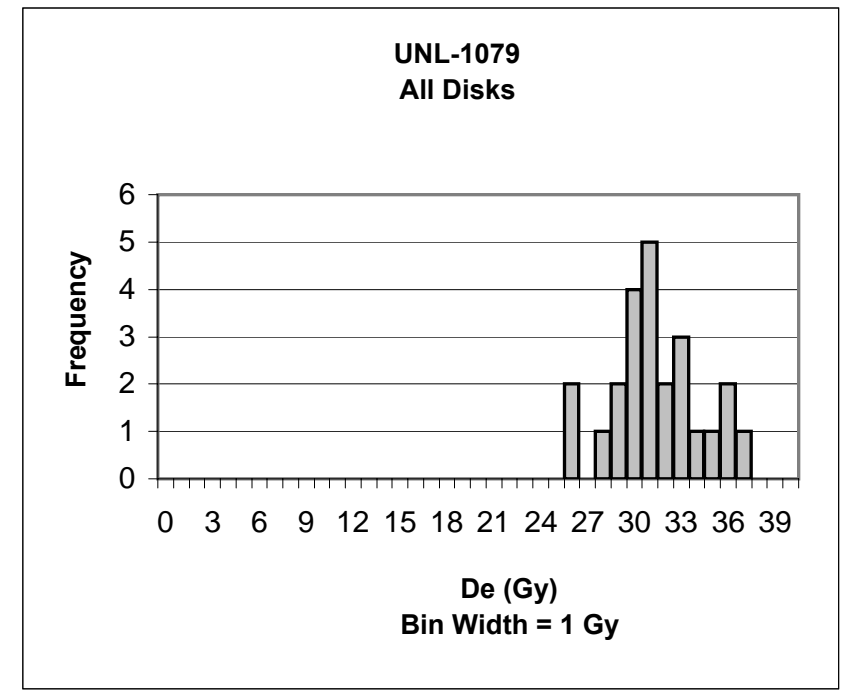

$\begin{array}{lc}\text { All Disks } & \\ & \text { De }(\mathbf{G y}) \\ \text { Mean }= & \mathbf{3 0 . 8 6} \\ \text { Median = } & 30.73 \\ \text { Min = } & 25.13 \\ \text { Max }= & 36.42\end{array}$

\begin{tabular}{|c|c|c|c|c|}
\hline Disk & $\mathrm{De}$ & Err & Disc & De \\
\hline 1 & 25.13 & 0.05 & 28 & \\
\hline 2 & 25.49 & 0.35 & 29 & \\
\hline 3 & 27.59 & 0.56 & 30 & \\
\hline 4 & 28.66 & 0.36 & 31 & \\
\hline 5 & 28.70 & 0.21 & 32 & \\
\hline 6 & 29.16 & 0.34 & 33 & \\
\hline 7 & 29.36 & 0.42 & 34 & \\
\hline 8 & 29.47 & 0.13 & 35 & \\
\hline 9 & 29.51 & 0.07 & 36 & \\
\hline 10 & 30.05 & 0.17 & 37 & \\
\hline 11 & 30.11 & 0.27 & 38 & \\
\hline 12 & 30.64 & 0.14 & 39 & \\
\hline 13 & 30.82 & 0.24 & 40 & \\
\hline 14 & 30.87 & 0.33 & 41 & \\
\hline 15 & 31.05 & 0.32 & 42 & \\
\hline 16 & 31.54 & 0.33 & 43 & \\
\hline 17 & 32.12 & 0.20 & 44 & \\
\hline 18 & 32.13 & 0.40 & 45 & \\
\hline 19 & 32.20 & 0.46 & 46 & \\
\hline 20 & 33.07 & 0.25 & 47 & \\
\hline 21 & 34.97 & 0.01 & 48 & \\
\hline 22 & 35.69 & 0.20 & 49 & \\
\hline 23 & 35.82 & 0.24 & 50 & \\
\hline 24 & 36.42 & 0.10 & 51 & \\
\hline 25 & & & 52 & \\
\hline 26 & & & 53 & \\
\hline 27 & & & 54 & \\
\hline
\end{tabular}

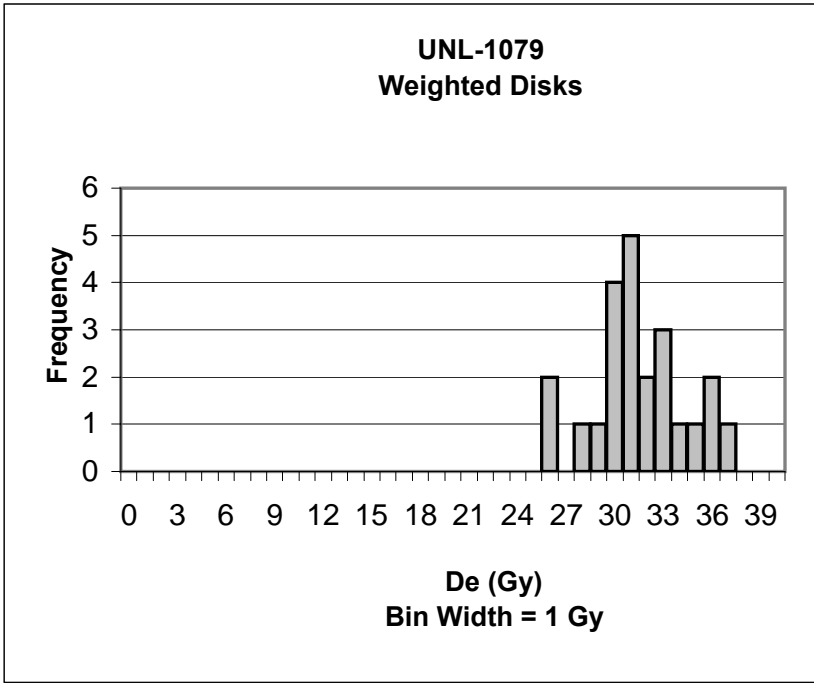

Weighted Disks

S.D. $(1 \sigma)=2.94$

Std. Err $=\quad 0.60$

Disks $(n)=24$
De (Gy)

Mean $=\quad 30.95$

Median $=\quad 30.82$

Min $=\quad 25.13$

Max $=\quad 36.42$
S.D. $(1 \sigma)=2.96$

Std. Err $=\quad 0.62$

Disks $(n)=23$

$\begin{array}{ccccc}\text { Disk } & \text { De } & \text { Err } & \text { Disc } & \text { De } \\ \mathbf{1} & 25.13 & 0.05 & \mathbf{2 8} & \\ \mathbf{2} & 25.49 & 0.35 & \mathbf{2 9} \\ \mathbf{3} & 27.59 & 0.56 & \mathbf{3 0} \\ \mathbf{4} & 28.70 & 0.21 & \mathbf{3 1} \\ \mathbf{5} & 29.16 & 0.34 & \mathbf{3 2} \\ \mathbf{6} & 29.36 & 0.42 & \mathbf{3 3} \\ \mathbf{7} & 29.47 & 0.13 & \mathbf{3 4} \\ \mathbf{8} & 29.51 & 0.07 & \mathbf{3 5} \\ \mathbf{9} & 30.05 & 0.17 & \mathbf{3 6} \\ \mathbf{1 0} & 30.11 & 0.27 & \mathbf{3 7} \\ \mathbf{1 1} & 30.64 & 0.14 & \mathbf{3 8} \\ \mathbf{1 2} & 30.82 & 0.24 & \mathbf{3 9} \\ \mathbf{1 3} & 30.87 & 0.33 & \mathbf{4 0} \\ \mathbf{1 4} & 31.05 & 0.32 & \mathbf{4 1} \\ \mathbf{1 5} & 31.54 & 0.33 & \mathbf{4 2} \\ \mathbf{1 6} & 32.12 & 0.20 & \mathbf{4 3} \\ \mathbf{1 7} & 32.13 & 0.40 & \mathbf{4 4} \\ \mathbf{1 8} & 32.20 & 0.46 & \mathbf{4 5} \\ \mathbf{1 9} & 33.07 & 0.25 & \mathbf{4 6} \\ \mathbf{2 0} & 34.97 & 0.01 & \mathbf{4 7} \\ \mathbf{2 1} & 35.69 & 0.20 & \mathbf{4 8} \\ \mathbf{2 2} & 35.82 & 0.24 & \mathbf{4 9} \\ \mathbf{2 3} & 36.42 & 0.10 & \mathbf{5 0} \\ \mathbf{2 4} & & & \mathbf{5 1} \\ \mathbf{2 5} & & & \mathbf{5 2} \\ \mathbf{2 6} & & & \mathbf{5 3} \\ \mathbf{2 7} & & & \mathbf{5 4}\end{array}$




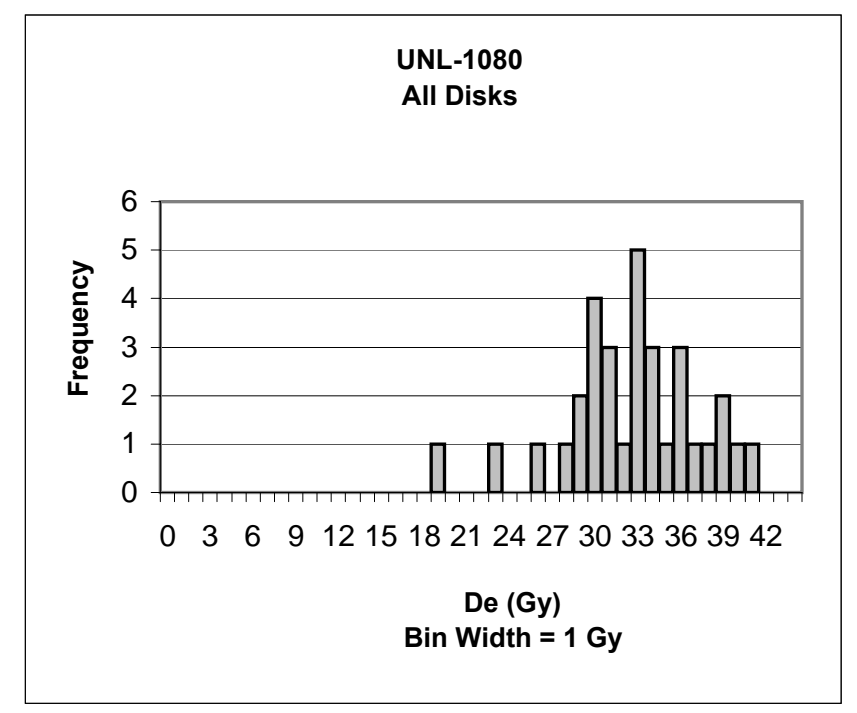

$\begin{array}{lcll}\text { All Disks } & & & \\ & \text { De }(G y) & & \\ \text { Mean }= & \mathbf{3 2 . 1 2} & \text { S.D. }(\mathbf{1} \boldsymbol{\sigma})= & 4.78 \\ \text { Median }= & 32.68 & \text { Std. Err }= & 0.85 \\ \text { Min }= & 18.16 & \text { Disks }(\mathbf{n})= & 32 \\ \text { Max }= & 40.81 & & \end{array}$

\begin{tabular}{|c|c|c|c|c|c|}
\hline Disk & De & Err & Disc & $\mathrm{De}$ & Err \\
\hline 1 & 18.16 & 1.40 & 28 & 37.70 & 0.23 \\
\hline 2 & 22.47 & 0.12 & 29 & 38.42 & 0.51 \\
\hline 3 & 25.89 & 0.60 & 30 & 38.79 & 1.38 \\
\hline 4 & 27.60 & 1.40 & 31 & 39.18 & 0.24 \\
\hline 5 & 28.04 & 0.84 & 32 & 40.81 & 0.08 \\
\hline 6 & 28.90 & 0.16 & 33 & & \\
\hline 7 & 29.63 & 0.58 & 34 & & \\
\hline 8 & 29.63 & 0.63 & 35 & & \\
\hline 9 & 29.73 & 0.74 & 36 & & \\
\hline 10 & 29.99 & 0.84 & 37 & & \\
\hline 11 & 30.26 & 0.38 & 38 & & \\
\hline 12 & 30.46 & 0.07 & 39 & & \\
\hline 13 & 30.71 & 0.00 & 40 & & \\
\hline 14 & 31.11 & 0.33 & 41 & & \\
\hline 15 & 32.51 & 0.70 & 42 & & \\
\hline 16 & 32.65 & 0.80 & 43 & & \\
\hline 17 & 32.71 & 0.24 & 44 & & \\
\hline 18 & 32.88 & 0.09 & 45 & & \\
\hline 19 & 32.92 & 0.62 & 46 & & \\
\hline 20 & 33.03 & 0.43 & 47 & & \\
\hline 21 & 33.60 & 0.55 & 48 & & \\
\hline 22 & 33.69 & 0.25 & 49 & & \\
\hline 23 & 34.09 & 0.20 & 50 & & \\
\hline 24 & 35.01 & 0.12 & 51 & & \\
\hline 25 & 35.02 & 0.04 & 52 & & \\
\hline 26 & 35.28 & 0.09 & 53 & & \\
\hline 27 & 36.97 & 0.28 & 54 & & \\
\hline
\end{tabular}

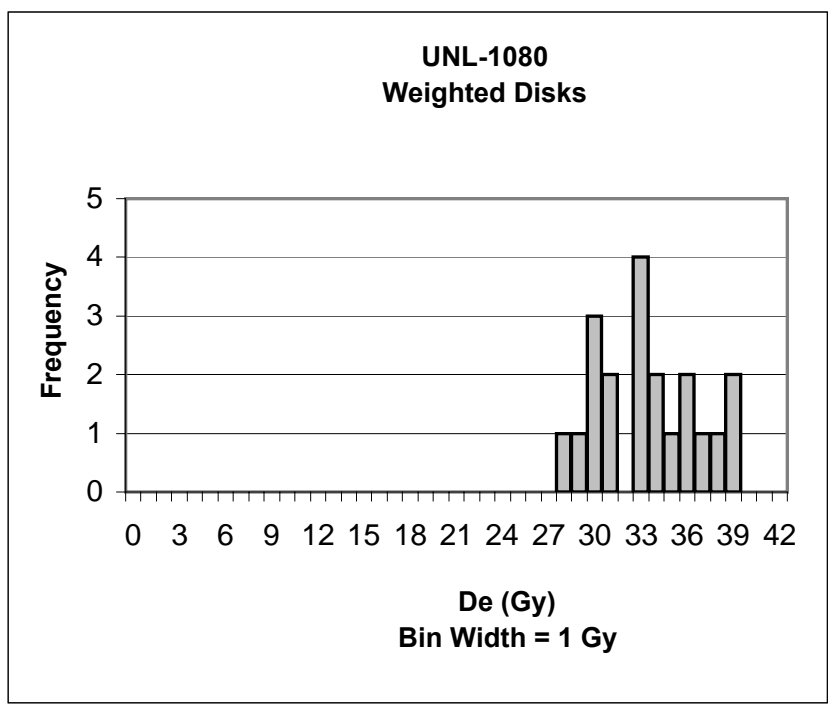

$\begin{array}{lcll}\text { Weighted Disks } & & \\ & \text { De (Gy) } & & \\ \text { Mean }= & \mathbf{3 3 . 0 6} & \text { S.D. }(\mathbf{1} \sigma)= & 3.27 \\ \text { Median }= & 32.90 & \text { Std. Err }= & 0.73 \\ \text { Min }= & 27.60 & \text { Disks }(\mathbf{n})= & 20 \\ \text { Max }= & 38.79 & & \end{array}$

$\begin{array}{cccccc}\text { Disk } & \text { De } & \text { Err } & \text { Disc } & \text { De } & \text { Err } \\ \mathbf{1} & 27.60 & 1.40 & \mathbf{2 8} & & \\ \mathbf{2} & 28.90 & 0.16 & \mathbf{2 9} & \\ \mathbf{3} & 29.63 & 0.63 & \mathbf{3 0} & \\ \mathbf{4} & 29.73 & 0.74 & \mathbf{3 1} & \\ \mathbf{5} & 29.99 & 0.84 & \mathbf{3 2} & \\ \mathbf{6} & 30.26 & 0.38 & \mathbf{3 3} & \\ \mathbf{7} & 30.46 & 0.07 & \mathbf{3 4} & \\ \mathbf{8} & 32.65 & 0.80 & \mathbf{3 5} & \\ \mathbf{9} & 32.71 & 0.24 & \mathbf{3 6} & \\ \mathbf{1 0} & 32.88 & 0.09 & \mathbf{3 7} & \\ \mathbf{1 1} & 32.92 & 0.62 & \mathbf{3 8} & \\ \mathbf{1 2} & 33.60 & 0.55 & \mathbf{3 9} & \\ \mathbf{1 3} & 33.69 & 0.25 & \mathbf{4 0} & \\ \mathbf{1 4} & 34.09 & 0.20 & \mathbf{4 1} & \\ \mathbf{1 5} & 35.01 & 0.12 & \mathbf{4 2} & \\ \mathbf{1 6} & 35.28 & 0.09 & \mathbf{4 3} & \\ \mathbf{1 7} & 36.97 & 0.28 & \mathbf{4 4} & \\ \mathbf{1 8} & 37.70 & 0.23 & \mathbf{4 5} & \\ \mathbf{1 9} & 38.42 & 0.51 & \mathbf{4 6} & \\ \mathbf{2 0} & 38.79 & 1.38 & \mathbf{4 7} \\ \mathbf{2 1} & & & \mathbf{4 8} & \\ \mathbf{2 2} & & & \mathbf{4 9} \\ \mathbf{2 3} & & & \mathbf{5 0} \\ \mathbf{2 4} & & & \mathbf{5 1} \\ \mathbf{2 5} & & & \mathbf{5 2} \\ \mathbf{2 6} & & & \mathbf{5 3} \\ \mathbf{2 7} & & & \mathbf{5 4}\end{array}$




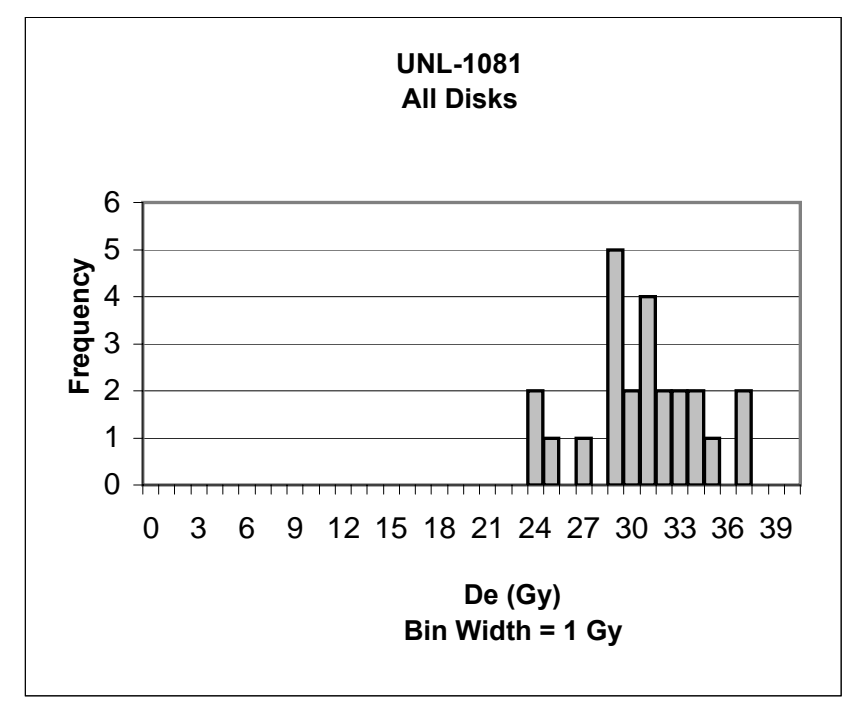

$\begin{array}{lcll}\text { All Disks } & & & \\ & \text { De }(G y) & & \\ \text { Mean }= & \mathbf{3 0 . 2 5} & \text { S.D. }(\mathbf{1 \sigma})= & 3.43 \\ \text { Median }= & 30.38 & \text { Std. Err }= & 0.70 \\ \text { Min }= & 23.43 & \text { Disks }(\mathbf{n})= & 24 \\ \text { Max }= & 36.66 & & \end{array}$

\begin{tabular}{|c|c|c|c|c|}
\hline Disk & De & Err & Disc & De \\
\hline 1 & 23.43 & 0.19 & 28 & \\
\hline 2 & 23.97 & 0.14 & 29 & \\
\hline 3 & 24.80 & 0.25 & 30 & \\
\hline 4 & 26.98 & 0.00 & 31 & \\
\hline 5 & 28.25 & 0.48 & 32 & \\
\hline 6 & 28.26 & 0.40 & 33 & \\
\hline 7 & 28.34 & 0.38 & 34 & \\
\hline 8 & 28.74 & 0.21 & 35 & \\
\hline 9 & 28.85 & 0.40 & 36 & \\
\hline 10 & 29.95 & 0.26 & 37 & \\
\hline 11 & 29.96 & 0.33 & 38 & \\
\hline 12 & 30.28 & 0.51 & 39 & \\
\hline 13 & 30.49 & 0.03 & 40 & \\
\hline 14 & 30.78 & 0.06 & 41 & \\
\hline 15 & 30.78 & 0.14 & 42 & \\
\hline 16 & 31.36 & 0.20 & 43 & \\
\hline 17 & 31.89 & 0.64 & 44 & \\
\hline 18 & 32.16 & 0.18 & 45 & \\
\hline 19 & 32.56 & 0.06 & 46 & \\
\hline 20 & 33.08 & 0.34 & 47 & \\
\hline 21 & 33.83 & 0.46 & 48 & \\
\hline 22 & 34.05 & 0.14 & 49 & \\
\hline 23 & 36.46 & 0.28 & 50 & \\
\hline 24 & 36.66 & 0.42 & 51 & \\
\hline 25 & & & 52 & \\
\hline 26 & & & 53 & \\
\hline 27 & & & 54 & \\
\hline
\end{tabular}

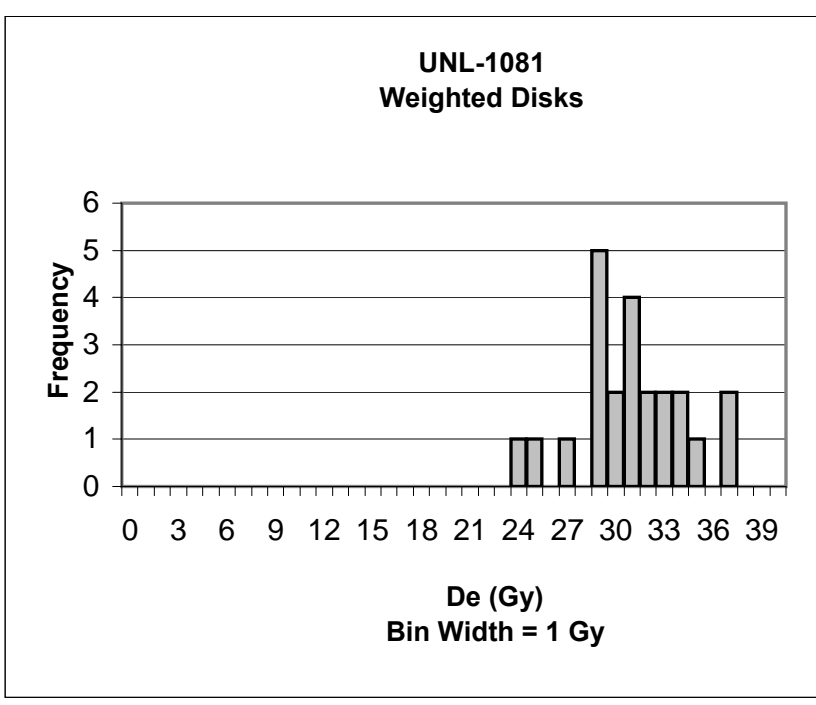

Weighted Disks De (Gy)

Mean $=\quad 30.52$

Median $=\quad 30.49$

Min $=\quad 23.43$

Max $=\quad 36.66$

$\begin{array}{cccccc}\text { Disk } & \text { De } & \text { Err } & \text { Disc } & \text { De } & \text { Err } \\ \mathbf{1} & 23.43 & 0.19 & \mathbf{2 8} & & \\ \mathbf{2} & 24.80 & 0.25 & \mathbf{2 9} & \\ \mathbf{3} & 26.98 & 0.00 & \mathbf{3 0} & \\ \mathbf{4} & 28.25 & 0.48 & \mathbf{3 1} & \\ \mathbf{5} & 28.26 & 0.40 & \mathbf{3 2} & \\ \mathbf{6} & 28.34 & 0.38 & \mathbf{3 3} & \\ \mathbf{7} & 28.74 & 0.21 & \mathbf{3 4} & \\ \mathbf{8} & 28.85 & 0.40 & \mathbf{3 5} & \\ \mathbf{9} & 29.95 & 0.26 & \mathbf{3 6} & \\ \mathbf{1 0} & 29.96 & 0.33 & \mathbf{3 7} & \\ \mathbf{1 1} & 30.28 & 0.51 & \mathbf{3 8} & \\ \mathbf{1 2} & 30.49 & 0.03 & \mathbf{3 9} & \\ \mathbf{1 3} & 30.78 & 0.06 & \mathbf{4 0} & \\ \mathbf{1 4} & 30.78 & 0.14 & \mathbf{4 1} & \\ \mathbf{1 5} & 31.36 & 0.20 & \mathbf{4 2} & \\ \mathbf{1 6} & 31.89 & 0.64 & \mathbf{4 3} \\ \mathbf{1 7} & 32.16 & 0.18 & \mathbf{4 4} & \\ \mathbf{1 8} & 32.56 & 0.06 & \mathbf{4 5} & \\ \mathbf{1 9} & 33.08 & 0.34 & \mathbf{4 6} & \\ \mathbf{2 0} & 33.83 & 0.46 & \mathbf{4 7} \\ \mathbf{2 1} & 34.05 & 0.14 & \mathbf{4 8} \\ \mathbf{2 2} & 36.46 & 0.28 & \mathbf{4 9} \\ \mathbf{2 3} & 36.66 & 0.42 & \mathbf{5 0} \\ \mathbf{2 4} & & & \mathbf{5 1} \\ \mathbf{2 5} & & & \mathbf{5 2} \\ \mathbf{2 6} & & & \mathbf{5 3} \\ \mathbf{2 7} & & & \mathbf{5 4}\end{array}$




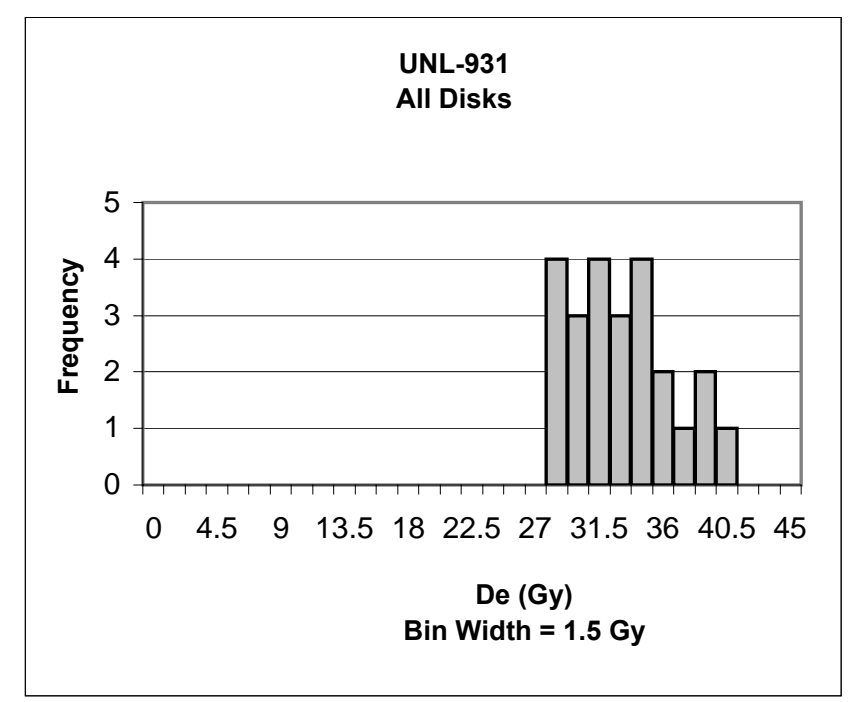

$\begin{array}{lcll}\text { All Disks } & & & \\ & \text { De (Gy) } & & \\ \text { Mean }= & \mathbf{3 2 . 3 6} & \text { S.D. }(\mathbf{1 \sigma})= & 3.57 \\ \text { Median }= & 31.63 & \text { Std. Err }= & 0.73 \\ \text { Min }= & 27.43 & \text { Disks }(\mathbf{n})= & 24 \\ \text { Max }= & 39.91 & & \end{array}$

\begin{tabular}{|c|c|c|c|c|}
\hline Disk & De & Err & Disc & De \\
\hline 1 & 39.91 & 0.07 & 28 & \\
\hline 2 & 32.13 & 0.70 & 29 & \\
\hline 3 & 31.34 & 1.17 & 30 & \\
\hline 4 & 31.51 & 0.62 & 31 & \\
\hline 5 & 30.80 & 1.93 & 32 & \\
\hline 6 & 28.18 & 1.41 & 33 & \\
\hline 7 & 34.12 & 2.02 & 34 & \\
\hline 8 & 28.08 & 0.81 & 35 & \\
\hline 9 & 33.81 & 0.39 & 36 & \\
\hline 10 & 34.63 & 1.14 & 37 & \\
\hline 11 & 27.43 & 0.62 & 38 & \\
\hline 12 & 36.79 & 0.13 & 39 & \\
\hline 13 & 28.84 & 1.50 & 40 & \\
\hline 14 & 30.48 & 0.08 & 41 & \\
\hline 15 & 31.17 & 1.14 & 42 & \\
\hline 16 & 31.74 & 0.73 & 43 & \\
\hline 17 & 38.51 & 0.06 & 44 & \\
\hline 18 & 28.05 & 1.21 & 45 & \\
\hline 19 & 34.97 & 0.62 & 46 & \\
\hline 20 & 33.06 & 0.25 & 47 & \\
\hline 21 & 38.36 & 0.78 & 48 & \\
\hline 22 & 29.37 & 0.42 & 49 & \\
\hline 23 & 34.26 & 0.94 & 50 & \\
\hline 24 & 29.01 & 0.53 & 51 & \\
\hline 25 & & & 52 & \\
\hline 26 & & & 53 & \\
\hline 27 & & & 54 & \\
\hline
\end{tabular}

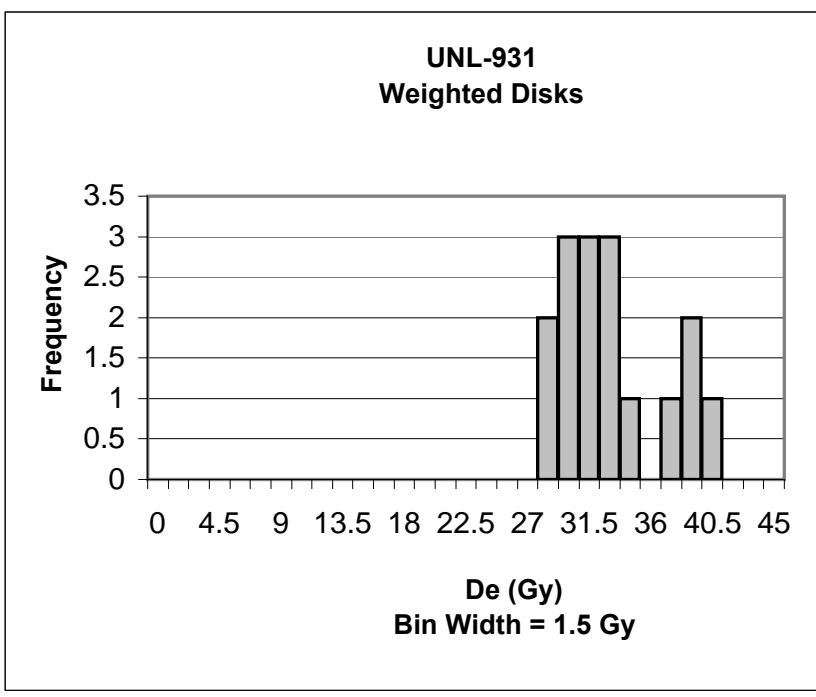

Weighted Disks

$\begin{array}{lc}\text { Mean }= & \mathbf{D e}(\mathbf{G y}) \\ \text { Median }= & 31.48 \\ \text { Min }= & 28.05 \\ \text { Max }= & 39.91\end{array}$

S.D. $(1 \sigma)=3.91$

Std. Err $=0.98$

$\operatorname{Disks}(\mathbf{n})=16$

$\begin{array}{cccccc}\text { Disk } & \text { De } & \text { Err } & \text { Disc } & \text { De } & \text { Err } \\ \mathbf{1} & 39.91 & 0.07 & \mathbf{2 8} & & \\ \mathbf{2} & 32.13 & 0.70 & \mathbf{2 9} & \\ \mathbf{3} & 31.34 & 1.17 & \mathbf{3 0} & \\ \mathbf{4} & 31.51 & 0.62 & \mathbf{3 1} & \\ \mathbf{5} & 28.18 & 1.41 & \mathbf{3 2} & \\ \mathbf{6} & 36.79 & 0.13 & \mathbf{3 3} & \\ \mathbf{7} & 28.84 & 1.50 & \mathbf{3 4} & \\ \mathbf{8} & 30.48 & 0.08 & \mathbf{3 5} & \\ \mathbf{9} & 31.17 & 1.14 & \mathbf{3 6} & \\ \mathbf{1 0} & 31.74 & 0.73 & \mathbf{3 7} & \\ \mathbf{1 1} & 38.51 & 0.06 & \mathbf{3 8} & \\ \mathbf{1 2} & 28.05 & 1.21 & \mathbf{3 9} & \\ \mathbf{1 3} & 38.36 & 0.78 & \mathbf{4 0} & \\ \mathbf{1 4} & 29.37 & 0.42 & \mathbf{4 1} & \\ \mathbf{1 5} & 34.26 & 0.94 & \mathbf{4 2} & \\ \mathbf{1 6} & 29.01 & 0.53 & \mathbf{4 3} \\ \mathbf{1 7} & & & \mathbf{4 4} & \\ \mathbf{1 8} & & & \mathbf{4 5} & \\ \mathbf{1 9} & & & \mathbf{4 6} & \\ \mathbf{2 0} & & & \mathbf{4 7} \\ \mathbf{2 1} & & & \mathbf{4 8} \\ \mathbf{2 2} & & & \mathbf{4 9} \\ \mathbf{2 3} & & & \mathbf{5 0} \\ \mathbf{2 4} & & & \mathbf{5 1} \\ \mathbf{2 5} & & & \mathbf{5 2} \\ \mathbf{2 6} & & & \mathbf{5 3} \\ \mathbf{2 7} & & & \mathbf{5 4}\end{array}$




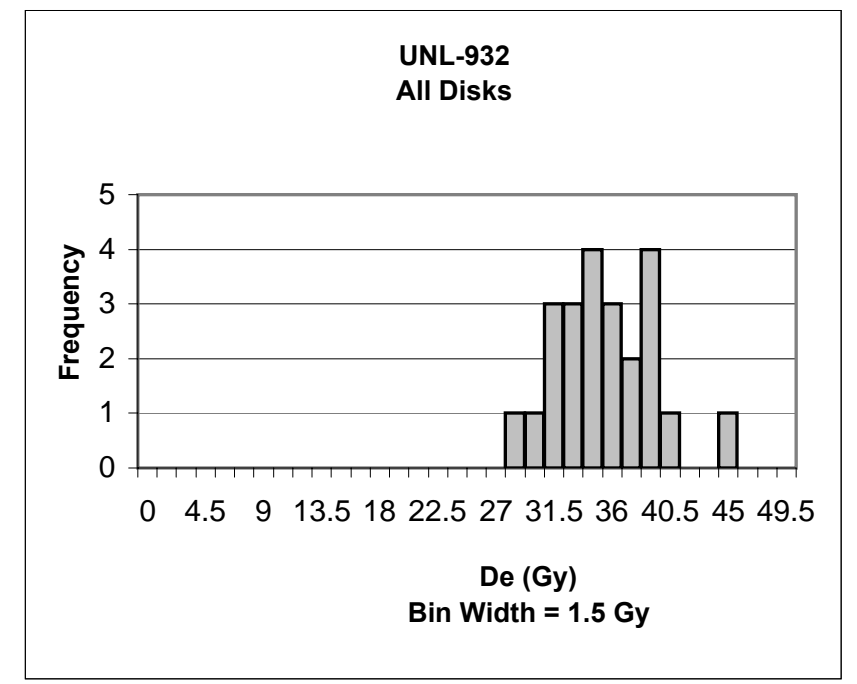

$\begin{array}{lcll}\text { All Disks } & & & \\ & \text { De (Gy) } & & \\ \text { Mean }= & 34.57 & \text { S.D. }(\mathbf{1 \sigma})= & 3.85 \\ \text { Median }= & 34.29 & \text { Std. Err }= & 0.80 \\ \text { Min }= & 27.26 & \text { Disks }(\mathbf{n})= & 23 \\ \text { Max }= & 43.79 & & \end{array}$

\begin{tabular}{|c|c|c|c|c|}
\hline Disk & De & Err & Disc & De \\
\hline 1 & 30.73 & 0.09 & 28 & \\
\hline 2 & 27.26 & 0.30 & 29 & \\
\hline 3 & 31.94 & 0.14 & 30 & \\
\hline 4 & 29.03 & 0.08 & 31 & \\
\hline 5 & 32.20 & 1.25 & 32 & \\
\hline 6 & 38.27 & 0.31 & 33 & \\
\hline 7 & 34.61 & 0.25 & 34 & \\
\hline 8 & 38.53 & 22.33 & 35 & \\
\hline 9 & 33.93 & 0.47 & 36 & \\
\hline 10 & 35.52 & 1.42 & 37 & \\
\hline 11 & 32.15 & 0.26 & 38 & \\
\hline 12 & 33.35 & 1.63 & 39 & \\
\hline 13 & 37.90 & 0.85 & 40 & \\
\hline 14 & 34.29 & 1.39 & 41 & \\
\hline 15 & 37.03 & 0.13 & 42 & \\
\hline 16 & 36.31 & 0.07 & 43 & \\
\hline 17 & 31.23 & 0.52 & 44 & \\
\hline 18 & 34.58 & 0.30 & 45 & \\
\hline 19 & 30.73 & 1.76 & 46 & \\
\hline 20 & 33.47 & 0.29 & 47 & \\
\hline 21 & 38.11 & 1.93 & 48 & \\
\hline 22 & 43.79 & 0.54 & 49 & \\
\hline 23 & 40.15 & 2.25 & 50 & \\
\hline 24 & & & 51 & \\
\hline 25 & & & 52 & \\
\hline 26 & & & 53 & \\
\hline 27 & & & 54 & \\
\hline
\end{tabular}

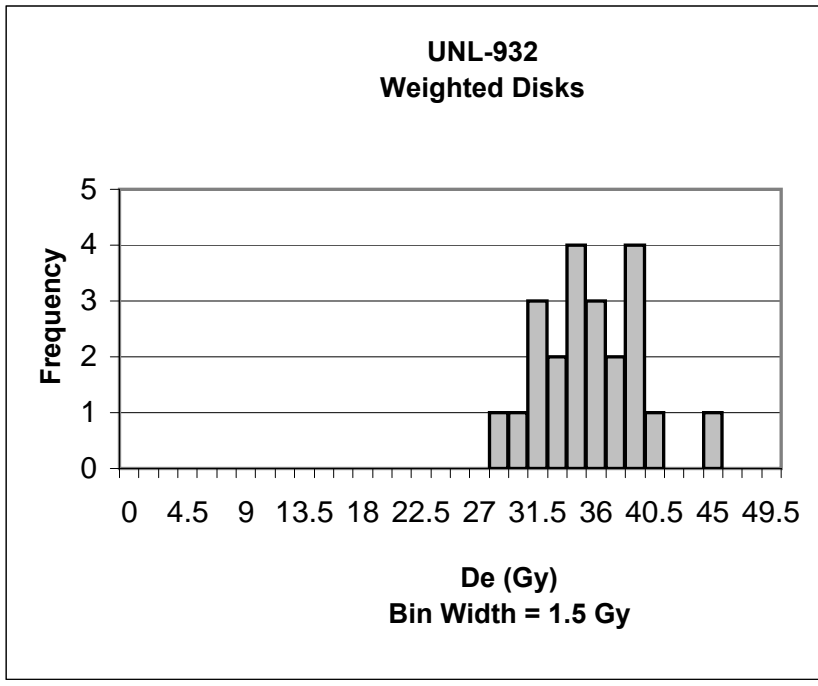

Weighted Disks De (Gy)

Mean $=\quad 34.69$

Median $=\quad 34.44$

Min $=\quad 27.26$

Max $=\quad 43.79$
UNL-932

Weighted Disks

$\begin{array}{ccccc}\text { Disk } & \text { De } & \text { Err } & \text { Disc } & \text { De } \\ \mathbf{1} & 30.73 & 0.09 & \mathbf{2 8} \\ \mathbf{2} & 27.26 & 0.30 & \mathbf{2 9} \\ \mathbf{3} & 29.03 & 0.08 & \mathbf{3 0} \\ \mathbf{4} & 32.20 & 1.25 & \mathbf{3 1} \\ \mathbf{5} & 38.27 & 0.31 & \mathbf{3 2} \\ \mathbf{6} & 34.61 & 0.25 & \mathbf{3 3} \\ \mathbf{7} & 38.53 & 22.33 & \mathbf{3 4} \\ \mathbf{8} & 33.93 & 0.47 & \mathbf{3 5} \\ \mathbf{9} & 35.52 & 1.42 & \mathbf{3 6} \\ \mathbf{1 0} & 32.15 & 0.26 & \mathbf{3 7} \\ \mathbf{1 1} & 33.35 & 1.63 & \mathbf{3 8} \\ \mathbf{1 2} & 37.90 & 0.85 & \mathbf{3 9} \\ \mathbf{1 3} & 34.29 & 1.39 & \mathbf{4 0} \\ \mathbf{1 4} & 37.03 & 0.13 & \mathbf{4 1} \\ \mathbf{1 5} & 36.31 & 0.07 & \mathbf{4 2} \\ \mathbf{1 6} & 31.23 & 0.52 & \mathbf{4 3} \\ \mathbf{1 7} & 34.58 & 0.30 & \mathbf{4 4} \\ \mathbf{1 8} & 30.73 & 1.76 & \mathbf{4 5} \\ \mathbf{1 9} & 33.47 & 0.29 & \mathbf{4 6} \\ \mathbf{2 0} & 38.11 & 1.93 & \mathbf{4 7} \\ \mathbf{2 1} & 43.79 & 0.54 & \mathbf{4 8} \\ \mathbf{2 2} & 40.15 & 2.25 & \mathbf{4 9} \\ \mathbf{2 3} & & & \mathbf{5 0} \\ \mathbf{2 4} & & & \mathbf{5 1} \\ \mathbf{2 5} & & & \mathbf{5 2} \\ \mathbf{2 6} & & & \mathbf{5 3} \\ \mathbf{2 7} & & & \mathbf{5 4}\end{array}$




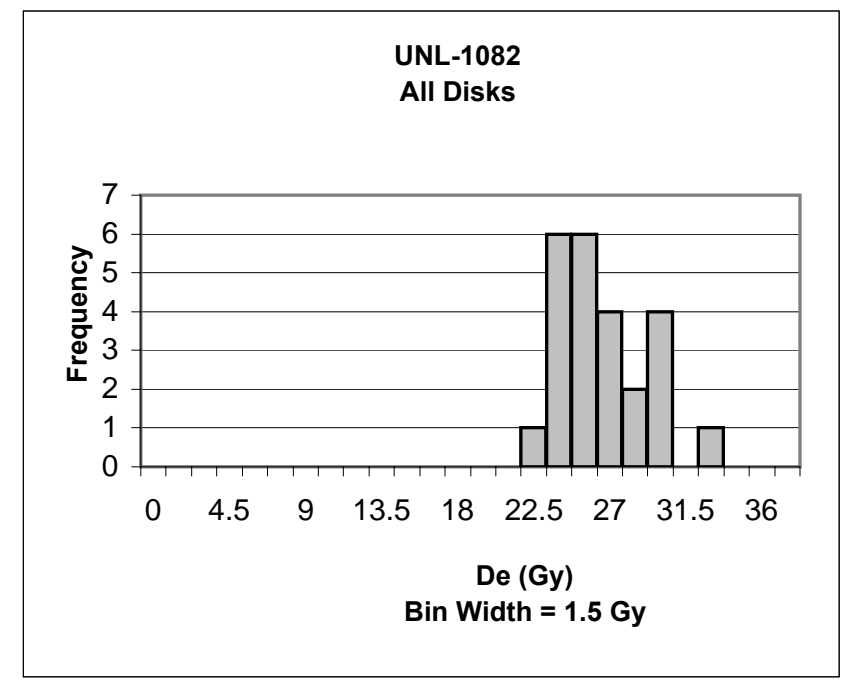

$\begin{array}{lcll}\text { All Disks } & & & \\ & \text { De (Gy) } & & \\ \text { Mean }= & \mathbf{2 5 . 7 8} & \text { S.D. }(\mathbf{1} \sigma)= & 2.54 \\ \text { Median }= & 25.32 & \text { Std. Err }= & 0.52 \\ \text { Min }= & 22.49 & \text { Disks }(\mathbf{n})= & 24 \\ \text { Max }= & 32.53 & & \end{array}$

\begin{tabular}{|c|c|c|c|c|}
\hline Disk & De & Err & Disc & De \\
\hline 1 & 22.49 & 1.23 & 28 & \\
\hline 2 & 22.51 & 0.12 & 29 & \\
\hline 3 & 22.78 & 0.51 & 30 & \\
\hline 4 & 22.79 & 0.32 & 31 & \\
\hline 5 & 23.26 & 0.39 & 32 & \\
\hline 6 & 23.42 & 1.01 & 33 & \\
\hline 7 & 23.80 & 0.19 & 34 & \\
\hline 8 & 24.14 & 0.88 & 35 & \\
\hline 9 & 24.94 & 0.53 & 36 & \\
\hline 10 & 25.06 & 0.73 & 37 & \\
\hline 11 & 25.20 & 0.18 & 38 & \\
\hline 12 & 25.22 & 0.13 & 39 & \\
\hline 13 & 25.41 & 0.65 & 40 & \\
\hline 14 & 26.02 & 0.90 & 41 & \\
\hline 15 & 26.12 & 0.17 & 42 & \\
\hline 16 & 26.22 & 0.14 & 43 & \\
\hline 17 & 26.56 & 0.35 & 44 & \\
\hline 18 & 27.59 & 0.67 & 45 & \\
\hline 19 & 27.84 & 0.27 & 46 & \\
\hline 20 & 28.57 & 0.10 & 47 & \\
\hline 21 & 28.61 & 0.10 & 48 & \\
\hline 22 & 28.67 & 0.34 & 49 & \\
\hline 23 & 28.97 & 0.06 & 50 & \\
\hline 24 & 32.53 & 0.11 & 51 & \\
\hline 25 & & & 52 & \\
\hline 26 & & & 53 & \\
\hline 27 & & & 54 & \\
\hline
\end{tabular}

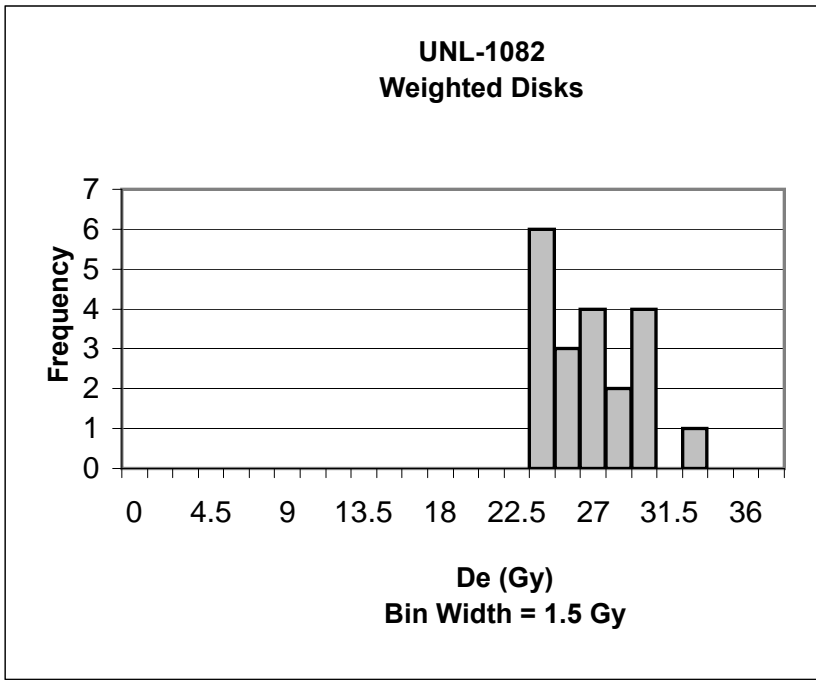

Weighted Disks

$\begin{array}{lc} & \text { De }(\text { Gy }) \\ \text { Mean }= & \mathbf{2 6 . 0 7} \\ \text { Median }= & 26.07 \\ \text { Min }= & 22.51 \\ \text { Max }= & 32.53\end{array}$

$\begin{array}{cccccc}\text { Disk } & \text { De } & \text { Err } & \text { Disc } & \text { De } & \text { Err } \\ \mathbf{1} & 22.51 & 0.12 & \mathbf{2 8} & & \\ \mathbf{2} & 22.78 & 0.51 & \mathbf{2 9} & \\ \mathbf{3} & 22.79 & 0.32 & \mathbf{3 0} & \\ \mathbf{4} & 23.26 & 0.39 & \mathbf{3 1} & \\ \mathbf{5} & 23.42 & 1.01 & \mathbf{3 2} & \\ \mathbf{6} & 23.80 & 0.19 & \mathbf{3 3} & \\ \mathbf{7} & 24.94 & 0.53 & \mathbf{3 4} & \\ \mathbf{8} & 25.06 & 0.73 & \mathbf{3 5} & \\ \mathbf{9} & 25.22 & 0.13 & \mathbf{3 6} & \\ \mathbf{1 0} & 26.02 & 0.90 & \mathbf{3 7} & \\ \mathbf{1 1} & 26.12 & 0.17 & \mathbf{3 8} & \\ \mathbf{1 2} & 26.22 & 0.14 & \mathbf{3 9} & \\ \mathbf{1 3} & 26.56 & 0.35 & \mathbf{4 0} & \\ \mathbf{1 4} & 27.59 & 0.67 & \mathbf{4 1} & \\ \mathbf{1 5} & 27.84 & 0.27 & \mathbf{4 2} & \\ \mathbf{1 6} & 28.57 & 0.10 & \mathbf{4 3} \\ \mathbf{1 7} & 28.61 & 0.10 & \mathbf{4 4} & \\ \mathbf{1 8} & 28.67 & 0.34 & \mathbf{4 5} & \\ \mathbf{1 9} & 28.97 & 0.06 & \mathbf{4 6} & \\ \mathbf{2 0} & 32.53 & 0.11 & \mathbf{4 7} \\ \mathbf{2 1} & & & \mathbf{4 8} \\ \mathbf{2 2} & & & \mathbf{4 9} \\ \mathbf{2 3} & & & \mathbf{5 0} \\ \mathbf{2 4} & & & \mathbf{5 1} \\ \mathbf{2 5} & & & \mathbf{5 2} \\ \mathbf{2 6} & & & \mathbf{5 3} \\ \mathbf{2 7} & & & \mathbf{5 4}\end{array}$




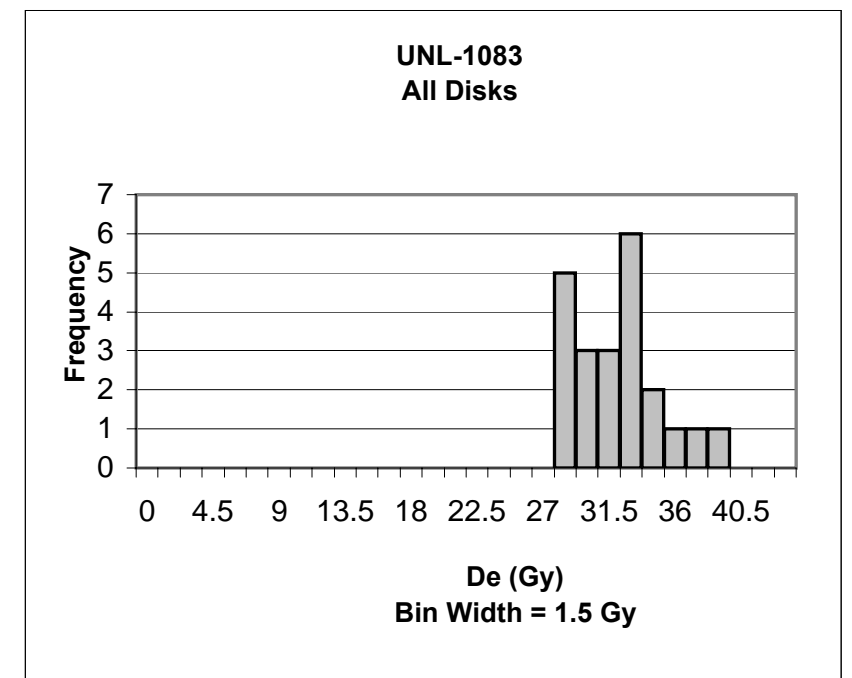

$\begin{array}{lcll}\text { All Disks } & & & \\ & \text { De }(G y) & & \\ \text { Mean }= & \mathbf{3 1 . 3 2} & \text { S.D. }(\mathbf{1 \sigma})= & 3.04 \\ \text { Median }= & 31.46 & \text { Std. Err }= & 0.65 \\ \text { Min }= & 27.17 & \text { Disks }(\mathbf{n})= & 22 \\ \text { Max }= & 38.06 & & \end{array}$

\begin{tabular}{|c|c|c|c|c|}
\hline Disk & De & Err & Disc & De \\
\hline 1 & 27.17 & 0.01 & 28 & \\
\hline 2 & 27.34 & 0.22 & 29 & \\
\hline 3 & 27.61 & 0.28 & 30 & \\
\hline 4 & 27.65 & 0.59 & 31 & \\
\hline 5 & 27.71 & 0.10 & 32 & \\
\hline 6 & 29.30 & 0.03 & 33 & \\
\hline 7 & 29.47 & 0.11 & 34 & \\
\hline 8 & 29.77 & 1.03 & 35 & \\
\hline 9 & 30.38 & 0.24 & 36 & \\
\hline 10 & 30.70 & 0.20 & 37 & \\
\hline 11 & 30.97 & 0.09 & 38 & \\
\hline 12 & 31.95 & 0.20 & 39 & \\
\hline 13 & 32.06 & 0.03 & 40 & \\
\hline 14 & 32.12 & 0.32 & 41 & \\
\hline 15 & 32.30 & 0.01 & 42 & \\
\hline 16 & 32.41 & 0.16 & 43 & \\
\hline 17 & 32.76 & 0.82 & 44 & \\
\hline 18 & 33.38 & 0.00 & 45 & \\
\hline 19 & 33.40 & 0.24 & 46 & \\
\hline 20 & 35.64 & 0.22 & 47 & \\
\hline 21 & 36.91 & 0.01 & 48 & \\
\hline 22 & 38.06 & 0.10 & 49 & \\
\hline 23 & & & 50 & \\
\hline 24 & & & 51 & \\
\hline 25 & & & 52 & \\
\hline 26 & & & 53 & \\
\hline 27 & & & 54 & \\
\hline
\end{tabular}

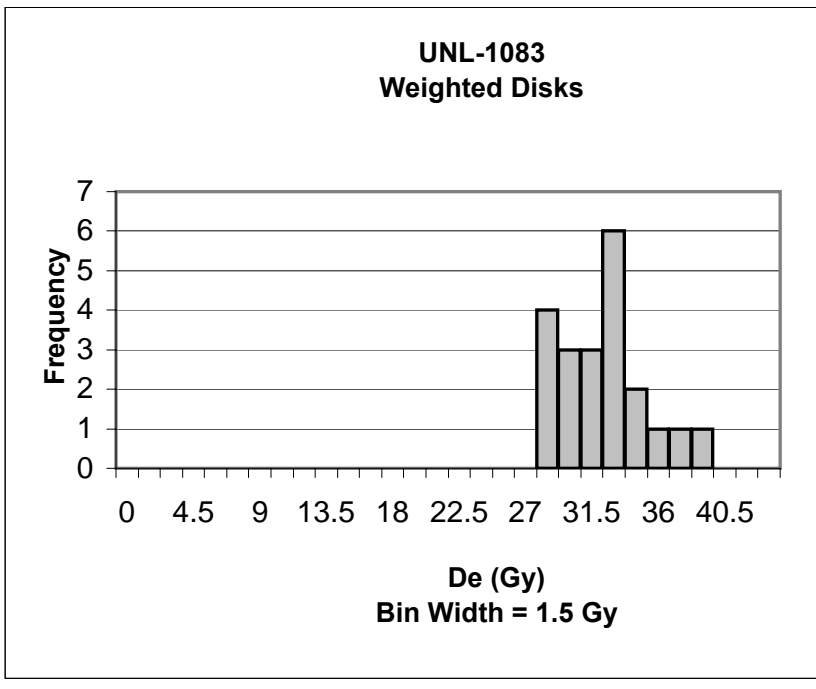

Weighted Disks

De (Gy)

Mean $=\quad 31.50$

Median $=\quad 31.95$

Min $=\quad 27.17$

Max $=\quad 38.06$

$\begin{array}{cccccc}\text { Disk } & \text { De } & \text { Err } & \text { Disc } & \text { De } & \text { Err } \\ \mathbf{1} & 27.17 & 0.01 & \mathbf{2 8} & & \\ \mathbf{2} & 27.34 & 0.22 & \mathbf{2 9} & \\ \mathbf{3} & 27.65 & 0.59 & \mathbf{3 0} & \\ \mathbf{4} & 27.71 & 0.10 & \mathbf{3 1} & \\ \mathbf{5} & 29.30 & 0.03 & \mathbf{3 2} & \\ \mathbf{6} & 29.47 & 0.11 & \mathbf{3 3} & \\ \mathbf{7} & 29.77 & 1.03 & \mathbf{3 4} & \\ \mathbf{8} & 30.38 & 0.24 & \mathbf{3 5} & \\ \mathbf{9} & 30.70 & 0.20 & \mathbf{3 6} & \\ \mathbf{1 0} & 30.97 & 0.09 & \mathbf{3 7} & \\ \mathbf{1 1} & 31.95 & 0.20 & \mathbf{3 8} & \\ \mathbf{1 2} & 32.06 & 0.03 & \mathbf{3 9} & \\ \mathbf{1 3} & 32.12 & 0.32 & \mathbf{4 0} & \\ \mathbf{1 4} & 32.30 & 0.01 & \mathbf{4 1} & \\ \mathbf{1 5} & 32.41 & 0.16 & \mathbf{4 2} & \\ \mathbf{1 6} & 32.76 & 0.82 & \mathbf{4 3} & \\ \mathbf{1 7} & 33.38 & 0.00 & \mathbf{4 4} & \\ \mathbf{1 8} & 33.40 & 0.24 & \mathbf{4 5} & \\ \mathbf{1 9} & 35.64 & 0.22 & \mathbf{4 6} & \\ \mathbf{2 0} & 36.91 & 0.01 & \mathbf{4 7} & \\ \mathbf{2 1} & 38.06 & 0.10 & \mathbf{4 8} & \\ \mathbf{2 2} & & & \mathbf{4 9} \\ \mathbf{2 3} & & & \mathbf{5 0} \\ \mathbf{2 4} & & & \mathbf{5 1} \\ \mathbf{2 5} & & & \mathbf{5 2} \\ \mathbf{2 6} & & & \mathbf{5 3} \\ \mathbf{2 7} & & & \mathbf{5 4} & \end{array}$




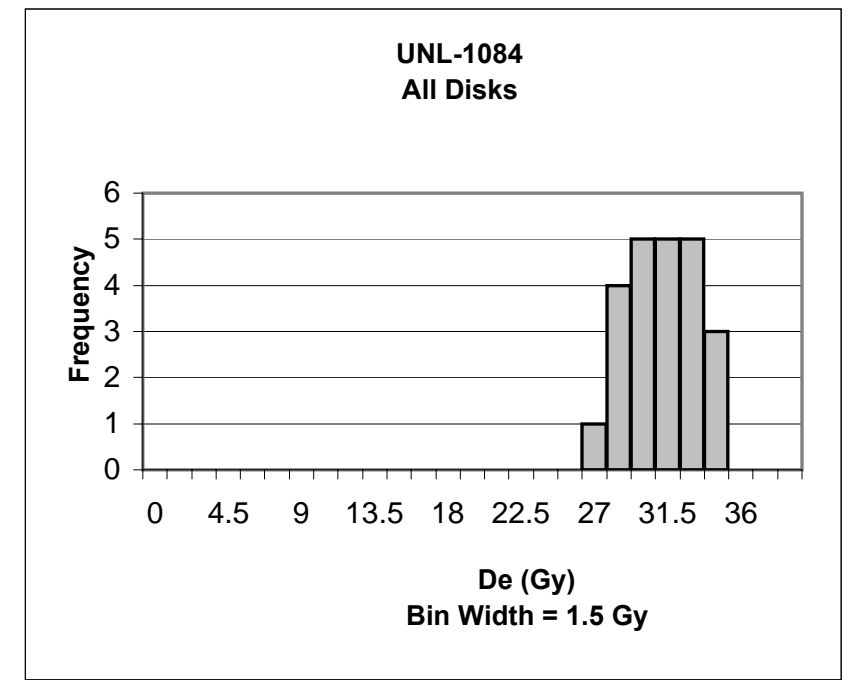

$\begin{array}{lcll}\text { All Disks } & & & \\ & \text { De (Gy) } & & \\ \text { Mean }= & \mathbf{3 0 . 4 4} & \text { S.D. }(\mathbf{1 \sigma})= & 2.07 \\ \text { Median }= & 30.34 & \text { Std. Err }= & 0.43 \\ \text { Min }= & 26.93 & \text { Disks }(\mathbf{n})= & 23 \\ \text { Max }= & 33.92 & & \end{array}$

\begin{tabular}{|c|c|c|c|c|}
\hline Disk & De & Err & Disc & De \\
\hline 1 & 26.93 & 0.12 & 28 & \\
\hline 2 & 27.64 & 0.22 & 29 & \\
\hline 3 & 28.03 & 0.22 & 30 & \\
\hline 4 & 28.06 & 0.17 & 31 & \\
\hline 5 & 28.19 & 0.32 & 32 & \\
\hline 6 & 28.58 & 0.08 & 33 & \\
\hline 7 & 28.74 & 0.64 & 34 & \\
\hline 8 & 29.23 & 0.28 & 35 & \\
\hline 9 & 29.40 & 0.75 & 36 & \\
\hline 10 & 29.94 & 0.91 & 37 & \\
\hline 11 & 30.10 & 0.85 & 38 & \\
\hline 12 & 30.34 & 0.19 & 39 & \\
\hline 13 & 30.68 & 0.11 & 40 & \\
\hline 14 & 31.12 & 0.36 & 41 & \\
\hline 15 & 31.37 & 0.63 & 42 & \\
\hline 16 & 31.69 & 0.02 & 43 & \\
\hline 17 & 31.78 & 0.09 & 44 & \\
\hline 18 & 32.31 & 0.45 & 45 & \\
\hline 19 & 32.39 & 0.13 & 46 & \\
\hline 20 & 32.77 & 0.07 & 47 & \\
\hline 21 & 33.32 & 0.42 & 48 & \\
\hline 22 & 33.68 & 0.06 & 49 & \\
\hline 23 & 33.92 & 0.09 & 50 & \\
\hline 24 & & & 51 & \\
\hline 25 & & & 52 & \\
\hline 26 & & & 53 & \\
\hline 27 & & & 54 & \\
\hline
\end{tabular}

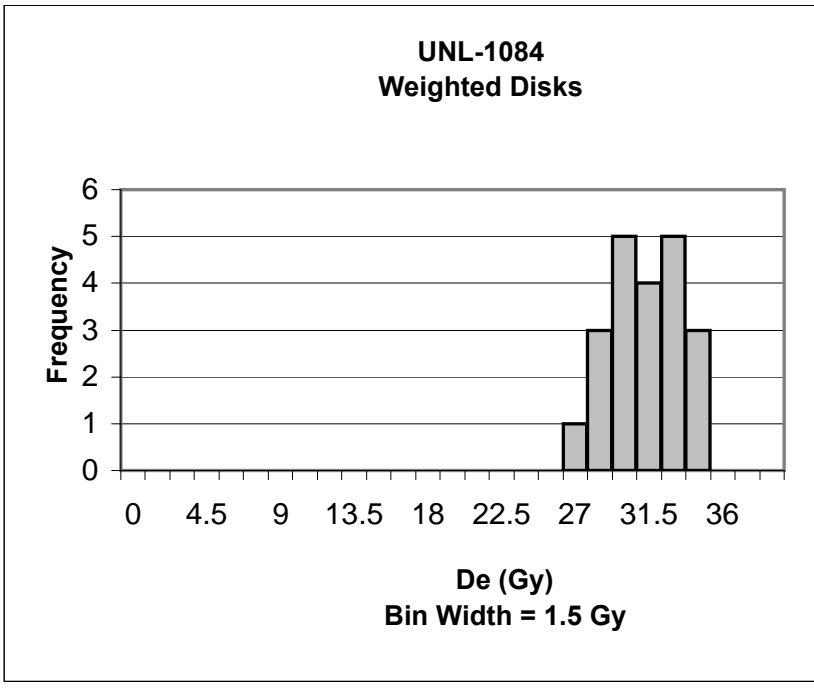

Weighted Disks De (Gy)

Mean $=\quad 30.58$

Median $=\quad 30.68$

Min $=\quad 26.93$

Max $=\quad 33.92$

$\begin{array}{cccccc}\text { Disk } & \text { De } & \text { Err } & \text { Disc } & \text { De } & \text { Err } \\ \mathbf{1} & 26.93 & 0.12 & \mathbf{2 8} & & \\ \mathbf{2} & 27.64 & 0.22 & \mathbf{2 9} & \\ \mathbf{3} & 28.06 & 0.17 & \mathbf{3 0} & \\ \mathbf{4} & 28.19 & 0.32 & \mathbf{3 1} & \\ \mathbf{5} & 28.58 & 0.08 & \mathbf{3 2} & \\ \mathbf{6} & 28.74 & 0.64 & \mathbf{3 3} & \\ \mathbf{7} & 29.23 & 0.28 & \mathbf{3 4} & \\ \mathbf{8} & 29.40 & 0.75 & \mathbf{3 5} & \\ \mathbf{9} & 29.94 & 0.91 & \mathbf{3 6} & \\ \mathbf{1 0} & 30.34 & 0.19 & \mathbf{3 7} & \\ \mathbf{1 1} & 30.68 & 0.11 & \mathbf{3 8} & \\ \mathbf{1 2} & 31.12 & 0.36 & \mathbf{3 9} & \\ \mathbf{1 3} & 31.37 & 0.63 & \mathbf{4 0} & \\ \mathbf{1 4} & 31.69 & 0.02 & \mathbf{4 1} & \\ \mathbf{1 5} & 31.78 & 0.09 & \mathbf{4 2} & \\ \mathbf{1 6} & 32.31 & 0.45 & \mathbf{4 3} & \\ \mathbf{1 7} & 32.39 & 0.13 & \mathbf{4 4} & \\ \mathbf{1 8} & 32.77 & 0.07 & \mathbf{4 5} & \\ \mathbf{1 9} & 33.32 & 0.42 & \mathbf{4 6} & \\ \mathbf{2 0} & 33.68 & 0.06 & \mathbf{4 7} \\ \mathbf{2 1} & 33.92 & 0.09 & \mathbf{4 8} \\ \mathbf{2 2} & & & \mathbf{4 9} \\ \mathbf{2 3} & & & \mathbf{5 0} \\ \mathbf{2 4} & & & \mathbf{5 1} \\ \mathbf{2 5} & & & \mathbf{5 2} \\ \mathbf{2 6} & & & \mathbf{5 3} \\ \mathbf{2 7} & & & \mathbf{5 4}\end{array}$




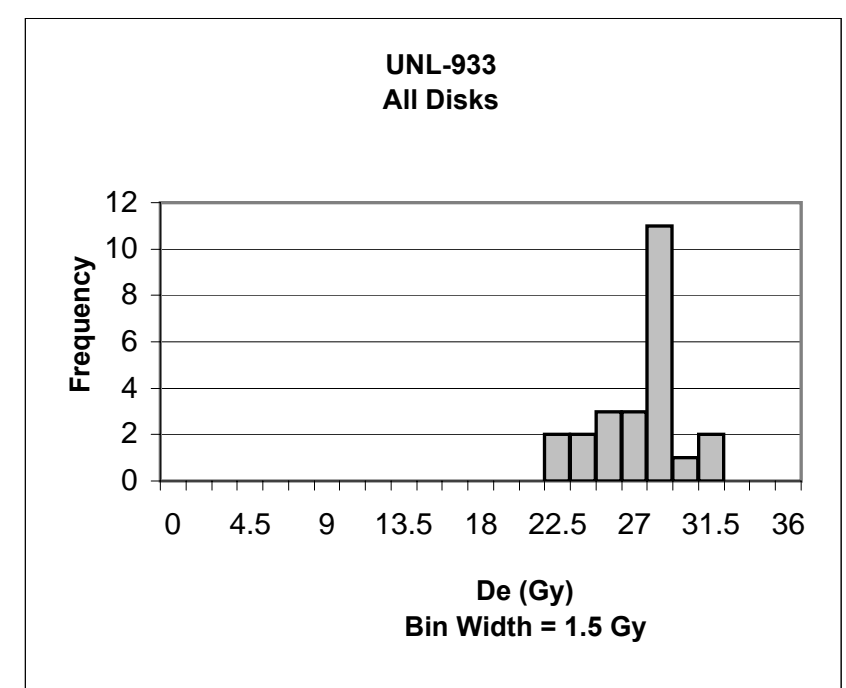

$\begin{array}{lc}\text { All Disks } & \\ & \text { De (Gy) } \\ \text { Mean }= & \mathbf{2 6 . 7 5} \\ \text { Median }= & 27.35 \\ \text { Min }= & 22.19 \\ \text { Max }= & 31.38\end{array}$

\begin{tabular}{|c|c|c|c|c|}
\hline Disk & De & Err & Disc & De \\
\hline 1 & 27.58 & 0.02 & 28 & \\
\hline 2 & 26.50 & 0.15 & 29 & \\
\hline 3 & 24.01 & 0.20 & 30 & \\
\hline 4 & 27.73 & 0.73 & 31 & \\
\hline 5 & 27.48 & 0.19 & 32 & \\
\hline 6 & 27.29 & 0.09 & 33 & \\
\hline 7 & 23.45 & 1.47 & 34 & \\
\hline 8 & 25.08 & 0.92 & 35 & \\
\hline 9 & 25.87 & 0.75 & 36 & \\
\hline 10 & 24.98 & 1.63 & 37 & \\
\hline 11 & 30.46 & 0.21 & 38 & \\
\hline 12 & 27.42 & 1.31 & 39 & \\
\hline 13 & 26.89 & 0.18 & 40 & \\
\hline 14 & 29.91 & 0.42 & 41 & \\
\hline 15 & 28.00 & 0.06 & 42 & \\
\hline 16 & 28.12 & 1.76 & 43 & \\
\hline 17 & 28.48 & 0.82 & 44 & \\
\hline 18 & 27.14 & 1.10 & 45 & \\
\hline 19 & 23.74 & 1.79 & 46 & \\
\hline 20 & 28.04 & 0.61 & 47 & \\
\hline 21 & 22.22 & 2.23 & 48 & \\
\hline 22 & 22.19 & 1.18 & 49 & \\
\hline 23 & 27.95 & 0.52 & 50 & \\
\hline 24 & 31.38 & 0.71 & 51 & \\
\hline 25 & & & 52 & \\
\hline 26 & & & 53 & \\
\hline 27 & & & 54 & \\
\hline
\end{tabular}

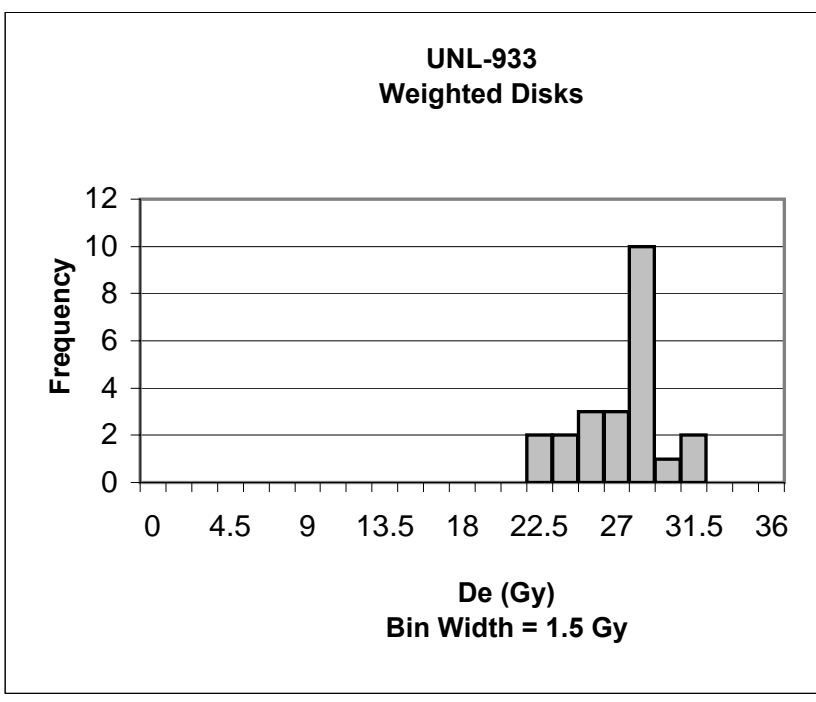

Weighted Disks

S.D. $(1 \sigma)=\quad 2.41$

Std. Err $=\quad 0.49$

Disks $(n)=\quad 24$
De (Gy)

Mean $=\quad 26.70$

Median $=\quad 27.29$

Max $=\quad 31.38$
Min $=\quad 22.19$
S.D. $(1 \sigma)=2.45$

Std. Err $=\quad 0.51$

Disks $(\mathbf{n})=23$

$\begin{array}{ccccc}\text { Disk } & \text { De } & \text { Err } & \text { Disc } & \text { De } \\ 1 & 27.58 & 0.02 & \mathbf{2 8} & \\ 2 & 26.50 & 0.15 & \mathbf{2 9} & \\ \mathbf{3} & 24.01 & 0.20 & \mathbf{3 0} \\ \mathbf{4} & 27.48 & 0.19 & \mathbf{3 1} \\ \mathbf{5} & 27.29 & 0.09 & \mathbf{3 2} \\ \mathbf{6} & 23.45 & 1.47 & \mathbf{3 3} \\ \mathbf{7} & 25.08 & 0.92 & \mathbf{3 4} \\ \mathbf{8} & 25.87 & 0.75 & \mathbf{3 5} \\ \mathbf{9} & 24.98 & 1.63 & \mathbf{3 6} \\ \mathbf{1 0} & 30.46 & 0.21 & \mathbf{3 7} \\ \mathbf{1 1} & 27.42 & 1.31 & \mathbf{3 8} \\ \mathbf{1 2} & 26.89 & 0.18 & \mathbf{3 9} \\ \mathbf{1 3} & 29.91 & 0.42 & \mathbf{4 0} \\ \mathbf{1 4} & 28.00 & 0.06 & \mathbf{4 1} \\ \mathbf{1 5} & 28.12 & 1.76 & \mathbf{4 2} \\ \mathbf{1 6} & 28.48 & 0.82 & \mathbf{4 3} \\ \mathbf{1 7} & 27.14 & 1.10 & \mathbf{4 4} \\ \mathbf{1 8} & 23.74 & 1.79 & \mathbf{4 5} \\ \mathbf{1 9} & 28.04 & 0.61 & \mathbf{4 6} \\ \mathbf{2 0} & 22.22 & 2.23 & \mathbf{4 7} \\ \mathbf{2 1} & 22.19 & 1.18 & \mathbf{4 8} \\ \mathbf{2 2} & 27.95 & 0.52 & \mathbf{4 9} \\ \mathbf{2 3} & 31.38 & 0.71 & \mathbf{5 0} \\ \mathbf{2 4} & & & \mathbf{5 1} \\ \mathbf{2 5} & & & \mathbf{5 2} \\ \mathbf{2 6} & & & \mathbf{5 3} \\ \mathbf{2 7} & & & \mathbf{5 4}\end{array}$




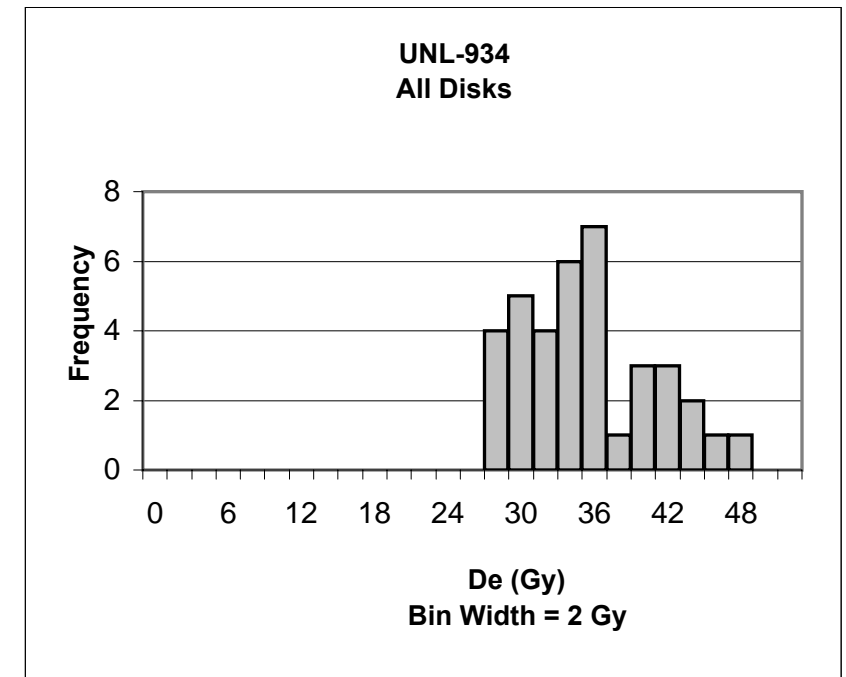

$\begin{array}{lcll}\text { All Disks } & & & \\ & \text { De }(G y) & & \\ \text { Mean }= & \mathbf{3 4 . 4 0} & \text { S.D. }(\mathbf{1 \sigma})= & 5.40 \\ \text { Median = } & 33.64 & \text { Std. Err }= & 0.89 \\ \text { Min }= & 26.59 & \text { Disks }(\mathbf{n})= & 37 \\ \text { Max }= & 46.30 & & \end{array}$

$\begin{array}{cccccc}\text { Disk } & \text { De } & \text { Err } & \text { Disc } & \text { De } & \text { Err } \\ \mathbf{1} & 34.38 & 3.25 & \mathbf{2 8} & 34.05 & 0.33 \\ \mathbf{2} & 41.31 & 1.64 & \mathbf{2 9} & 31.16 & 3.51 \\ \mathbf{3} & 41.79 & 0.71 & \mathbf{3 0} & 32.09 & 1.04 \\ \mathbf{4} & 43.21 & 1.34 & \mathbf{3 1} & 31.42 & 0.10 \\ \mathbf{5} & 46.30 & 1.28 & \mathbf{3 2} & 39.27 & 1.53 \\ \mathbf{6} & 34.38 & 0.68 & \mathbf{3 3} & 35.15 & 0.41 \\ \mathbf{7} & 33.64 & 0.76 & \mathbf{3 4} & 31.19 & 0.17 \\ \mathbf{8} & 32.86 & 0.47 & \mathbf{3 5} & 27.26 & 0.50 \\ \mathbf{9} & 27.09 & 30.72 & \mathbf{3 6} & 26.59 & 0.44 \\ 10 & 34.62 & 1.38 & \mathbf{3 7} & 29.45 & 0.18 \\ 11 & 37.53 & 0.36 & \mathbf{3 8} & & \\ 12 & 38.85 & 0.83 & \mathbf{3 9} & & \\ 13 & 42.44 & 2.06 & \mathbf{4 0} & & \\ 14 & 39.15 & 1.08 & \mathbf{4 1} & & \\ 15 & 44.38 & 0.75 & \mathbf{4 2} & & \\ 16 & 35.01 & 0.40 & \mathbf{4 3} & & \\ 17 & 41.66 & 0.98 & \mathbf{4 4} & & \\ 18 & 32.58 & 0.65 & \mathbf{4 5} & & \\ 19 & 27.59 & 1.48 & \mathbf{4 6} & & \\ \mathbf{2 0} & 28.02 & 1.37 & \mathbf{4 7} & & \\ \mathbf{2 1} & 32.41 & 0.33 & \mathbf{4 8} & & \\ \mathbf{2 2} & 35.62 & 0.42 & \mathbf{4 9} & & \\ \mathbf{2 3} & 29.77 & 1.28 & \mathbf{5 0} & & \\ \mathbf{2 4} & 31.87 & 0.28 & \mathbf{5 1} & & \\ \mathbf{2 5} & 28.17 & 1.24 & \mathbf{5 2} & & \\ \mathbf{2 6} & 28.19 & 0.80 & \mathbf{5 3} & & \\ \mathbf{2 7} & 32.29 & 0.45 & \mathbf{5 4} & & \\ & & & & & \end{array}$

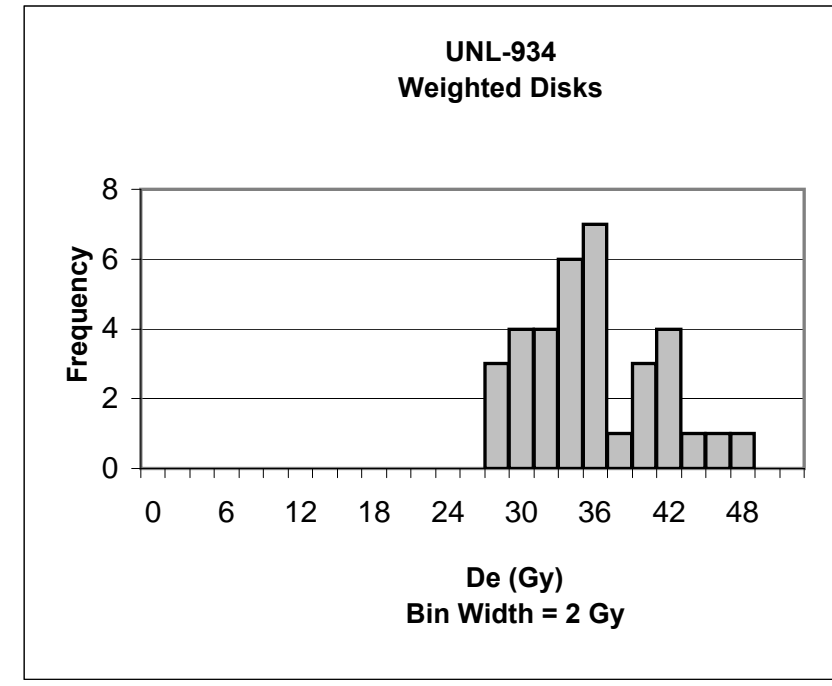

\section{Weighted Disks}

De (Gy)

Mean $=\quad 34.75$

Median $=\quad 34.05$

Min $=\quad 26.59$

Max $=\quad 46.30$
S.D. $(1 \sigma)=\quad 5.24$

Std. Err $=\quad 0.89$

Disks $(\mathbf{n})=35$

\begin{tabular}{|c|c|c|c|c|c|}
\hline Disk & $\mathrm{De}$ & Err & Disc & De & Err \\
\hline 1 & 34.38 & 3.25 & 28 & 31.42 & 0.10 \\
\hline 2 & 41.31 & 1.64 & 29 & 39.27 & 1.53 \\
\hline 3 & 41.79 & 0.71 & 30 & 35.15 & 0.41 \\
\hline 4 & 43.21 & 1.34 & 31 & 31.19 & 0.17 \\
\hline 5 & 46.30 & 1.28 & 32 & 27.26 & 0.50 \\
\hline 6 & 34.38 & 0.68 & 33 & 26.59 & 0.44 \\
\hline 7 & 33.64 & 0.76 & 34 & 29.45 & 0.18 \\
\hline 8 & 32.86 & 0.47 & 35 & 41.20 & 0.96 \\
\hline 9 & 34.62 & 1.38 & 36 & & \\
\hline 10 & 37.53 & 0.36 & 37 & & \\
\hline 11 & 38.85 & 0.83 & 38 & & \\
\hline 12 & 39.15 & 1.08 & 39 & & \\
\hline 13 & 44.38 & 0.75 & 40 & & \\
\hline 14 & 35.01 & 0.40 & 41 & & \\
\hline 15 & 41.66 & 0.98 & 42 & & \\
\hline 16 & 32.58 & 0.65 & 43 & & \\
\hline 17 & 27.59 & 1.48 & 44 & & \\
\hline 18 & 28.02 & 1.37 & 45 & & \\
\hline 19 & 32.41 & 0.33 & 46 & & \\
\hline 20 & 35.62 & 0.42 & 47 & & \\
\hline 21 & 29.77 & 1.28 & 48 & & \\
\hline 22 & 31.87 & 0.28 & 49 & & \\
\hline 23 & 28.19 & 0.80 & 50 & & \\
\hline 24 & 32.29 & 0.45 & 51 & & \\
\hline 25 & 34.05 & 0.33 & 52 & & \\
\hline 26 & 31.16 & 3.51 & 53 & & \\
\hline 27 & 32.09 & 1.04 & 54 & & \\
\hline
\end{tabular}




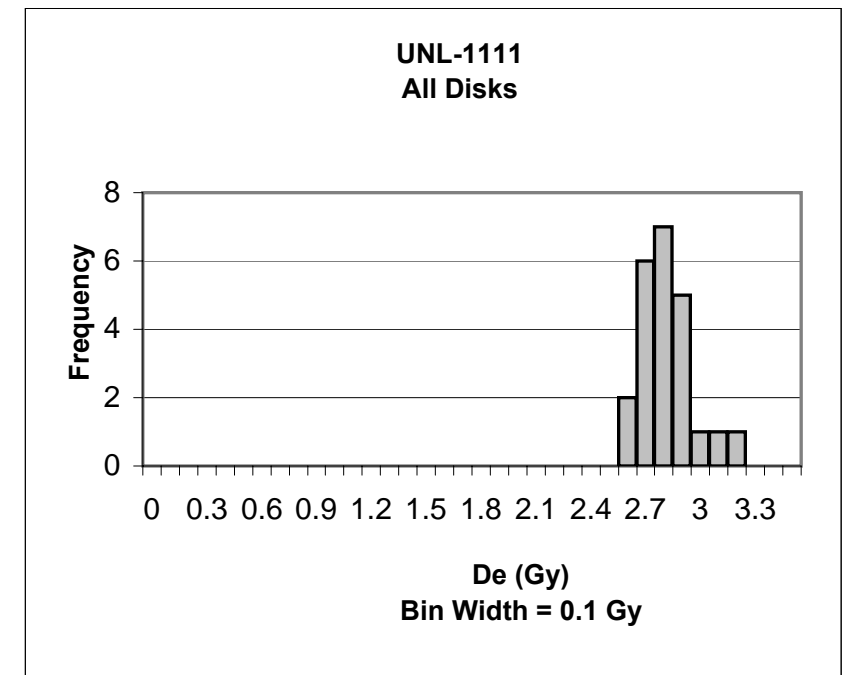

\section{All Disks}

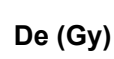

$\begin{array}{ll}\text { Mean }= & \mathbf{2 . 7 7} \\ \text { Median }= & 2.76 \\ \text { Min }= & 2.51 \\ \text { Max }= & 3.19\end{array}$

$\begin{array}{cccccc}\text { Disk } & \text { De } & \text { Err } & \text { Disc } & \text { De } & \text { Err } \\ 1 & 2.51 & 0.08 & 28 & & \\ 2 & 2.56 & 0.05 & 29 & & \\ 3 & 2.63 & 0.05 & 30 & & \end{array}$

S.D. $(1 \sigma)=0.16$

Std. Err $=\quad 0.03$

Disks $(n)=23$

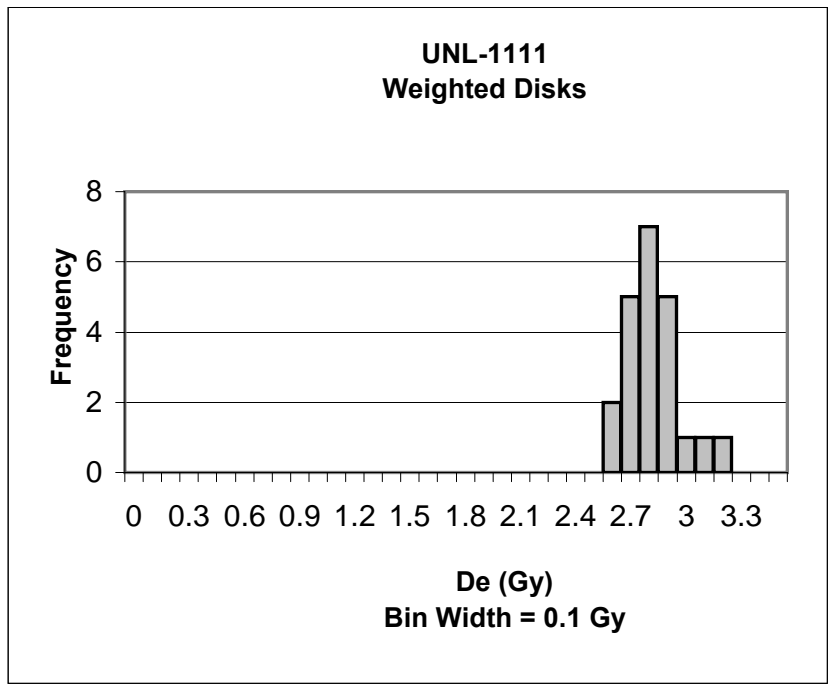

Weighted Disks

30

31

32

33

34

35

36

37

38

39

40

41

42

43

44

45

46

47

48

49

50

51

52

53

54
De (Gy)

$\begin{array}{lllc}\text { Mean }= & \mathbf{2 . 7 8} & \text { S.D. }(\mathbf{1} \sigma)= & 0.16 \\ \text { Median }= & 2.76 & \text { Std. } \text { Err }= & 0.03 \\ \text { Min }= & 2.51 & \text { Disks }(\mathbf{n})= & 22\end{array}$

Max $=\quad 3.19$

$\begin{array}{ccccc}\text { Disk } & \text { De } & \text { Err } & \text { Disc } & \text { De } \\ 1 & 2.51 & 0.08 & \mathbf{2 8} \\ 2 & 2.56 & 0.05 & \mathbf{2 9} & \\ \mathbf{3} & 2.63 & 0.05 & \mathbf{3 0} \\ \mathbf{4} & 2.65 & 0.09 & \mathbf{3 1} \\ \mathbf{5} & 2.66 & 0.11 & \mathbf{3 2} \\ \mathbf{6} & 2.67 & 0.10 & \mathbf{3 3} \\ \mathbf{7} & 2.68 & 0.04 & \mathbf{3 4} \\ \mathbf{8} & 2.71 & 0.01 & \mathbf{3 5} \\ \mathbf{9} & 2.71 & 0.07 & \mathbf{3 6} \\ \mathbf{1 0} & 2.75 & 0.04 & \mathbf{3 7} \\ \mathbf{1 1} & 2.76 & 0.03 & \mathbf{3 8} \\ \mathbf{1 2} & 2.76 & 0.02 & \mathbf{3 9} \\ \mathbf{1 3} & 2.78 & 0.05 & \mathbf{4 0} \\ \mathbf{1 4} & 2.79 & 0.03 & \mathbf{4 1} \\ \mathbf{1 5} & 2.85 & 0.11 & \mathbf{4 2} \\ \mathbf{1 6} & 2.86 & 0.10 & \mathbf{4 3} \\ \mathbf{1 7} & 2.87 & 0.08 & \mathbf{4 4} \\ \mathbf{1 8} & 2.89 & 0.06 & \mathbf{4 5} \\ \mathbf{1 9} & 2.90 & 0.05 & \mathbf{4 6} \\ \mathbf{2 0} & 2.93 & 0.04 & \mathbf{4 7} \\ \mathbf{2 1} & 3.07 & 0.02 & \mathbf{4 8} \\ \mathbf{2 2} & 3.19 & 0.08 & \mathbf{4 9} \\ \mathbf{2 3} & & & \mathbf{5 0} \\ \mathbf{2 4} & & & \mathbf{5 1} \\ \mathbf{2 5} & & & \mathbf{5 2} \\ \mathbf{2 6} & & & \mathbf{5 3} \\ \mathbf{2 7} & & & \mathbf{5 4}\end{array}$




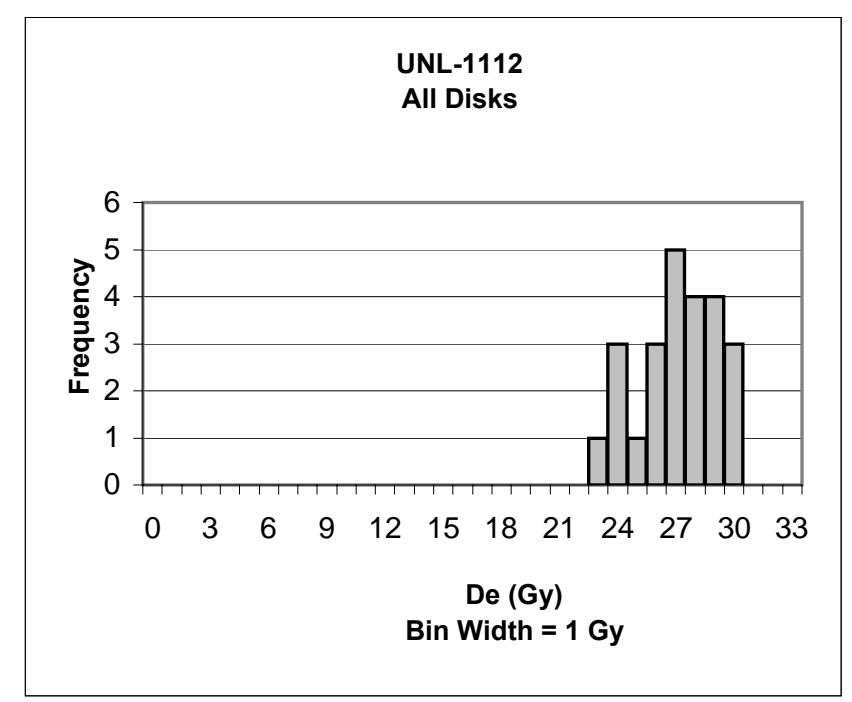

$\begin{array}{lcll}\text { All Disks } & & & \\ & \text { De (Gy) } & & \\ \text { Mean }= & \mathbf{2 6 . 5 5} & \text { S.D. }(\mathbf{1 \sigma})= & 2.03 \\ \text { Median }= & 26.61 & \text { Std. Err }= & 0.41 \\ \text { Min }= & 22.31 & \text { Disks }(\mathbf{n})= & 24 \\ \text { Max }= & 29.85 & & \end{array}$

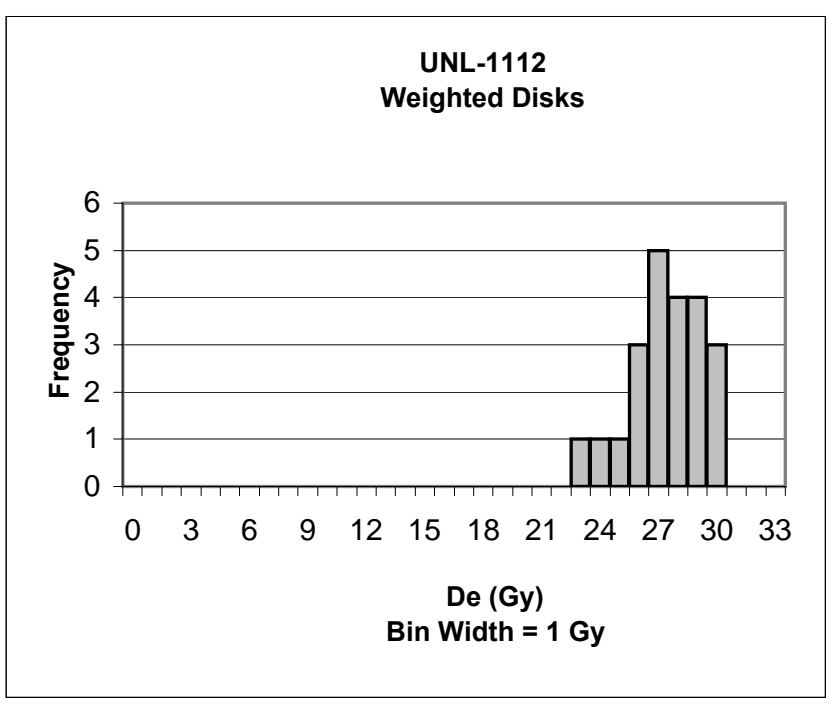

Weighted Disks De (Gy)

$\begin{array}{cccccc}\text { Disk } & \text { De } & \text { Err } & \text { Disc } & \text { De } & \text { Err } \\ \mathbf{1} & 22.31 & 0.48 & \mathbf{2 8} & & \\ \mathbf{2} & 23.59 & 0.35 & \mathbf{2 9} & & \\ \mathbf{3} & 24.70 & 0.43 & \mathbf{3 0} & & \\ \mathbf{4} & 25.12 & 0.06 & \mathbf{3 1} & & \\ \mathbf{5} & 25.36 & 0.04 & \mathbf{3 2} & \\ \mathbf{6} & 25.53 & 0.39 & \mathbf{3 3} & \\ \mathbf{7} & 26.04 & 0.20 & \mathbf{3 4} & \\ \mathbf{8} & 26.08 & 0.22 & \mathbf{3 5} & \\ \mathbf{9} & 26.22 & 0.11 & \mathbf{3 6} & \\ \mathbf{1 0} & 26.58 & 0.25 & \mathbf{3 7} & \\ \mathbf{1 1} & 26.65 & 0.10 & \mathbf{3 8} & \\ \mathbf{1 2} & 27.11 & 0.23 & \mathbf{3 9} & \\ \mathbf{1 3} & 27.40 & 0.30 & \mathbf{4 0} & \\ \mathbf{1 4} & 27.48 & 0.21 & \mathbf{4 1} & \\ \mathbf{1 5} & 27.76 & 0.09 & \mathbf{4 2} & \\ \mathbf{1 6} & 28.04 & 0.22 & \mathbf{4 3} & \\ \mathbf{1 7} & 28.12 & 0.24 & \mathbf{4 4} & \\ \mathbf{1 8} & 28.36 & 0.15 & \mathbf{4 5} & \\ \mathbf{1 9} & 28.95 & 0.05 & \mathbf{4 6} & \\ \mathbf{2 0} & 29.02 & 0.20 & \mathbf{4 7} & \\ \mathbf{2 1} & 29.53 & 0.03 & \mathbf{4 8} & \\ \mathbf{2 2} & 29.85 & 0.05 & \mathbf{4 9} & \\ \mathbf{2 3} & & & \mathbf{5 0} & \\ \mathbf{2 4} & & & \mathbf{5 1} \\ \mathbf{2 5} & & & \mathbf{5 2} & \\ \mathbf{2 6} & & & \mathbf{5 3} & \\ \mathbf{2 7} & & & \mathbf{5 4} & \end{array}$

Mean $=\quad 26.81$

Median $=26.88$

Min $=\quad 22.31$

Max $=29.85$

De Err

$\begin{array}{cccccc}\text { Disk } & \text { De } & \text { Err } & \text { Disc } & \text { De } & \text { Err } \\ \mathbf{1} & 22.31 & 0.48 & \mathbf{2 8} & \\ \mathbf{2} & 23.48 & 0.19 & \mathbf{2 9} & \\ \mathbf{3} & 23.59 & 0.35 & \mathbf{3 0} & \\ \mathbf{4} & 23.94 & 0.42 & \mathbf{3 1} & \\ \mathbf{5} & 24.70 & 0.43 & \mathbf{3 2} & \\ \mathbf{6} & 25.12 & 0.06 & \mathbf{3 3} & \\ \mathbf{7} & 25.36 & 0.04 & \mathbf{3 4} & \\ \mathbf{8} & 25.53 & 0.39 & \mathbf{3 5} & \\ \mathbf{9} & 26.04 & 0.20 & \mathbf{3 6} & \\ \mathbf{1 0} & 26.08 & 0.22 & \mathbf{3 7} & \\ \mathbf{1 1} & 26.22 & 0.11 & \mathbf{3 8} & \\ \mathbf{1 2} & 26.58 & 0.25 & \mathbf{3 9} & \\ \mathbf{1 3} & 26.65 & 0.10 & \mathbf{4 0} & \\ \mathbf{1 4} & 27.11 & 0.23 & \mathbf{4 1} & \\ \mathbf{1 5} & 27.40 & 0.30 & \mathbf{4 2} & \\ \mathbf{1 6} & 27.48 & 0.21 & \mathbf{4 3} \\ \mathbf{1 7} & 27.76 & 0.09 & \mathbf{4 4} \\ \mathbf{1 8} & 28.04 & 0.22 & \mathbf{4 5} \\ \mathbf{1 9} & 28.12 & 0.24 & \mathbf{4 6} \\ \mathbf{2 0} & 28.36 & 0.15 & \mathbf{4 7} \\ \mathbf{2 1} & 28.95 & 0.05 & \mathbf{4 8} \\ \mathbf{2 2} & 29.02 & 0.20 & \mathbf{4 9} \\ \mathbf{2 3} & 29.53 & 0.03 & \mathbf{5 0} \\ \mathbf{2 4} & 29.85 & 0.05 & \mathbf{5 1} \\ \mathbf{2 5} & & & \mathbf{5 2} \\ \mathbf{2 6} & & & \mathbf{5 3} \\ \mathbf{2 7} & & & \mathbf{5 4}\end{array}$

S.D. $(\mathbf{1 \sigma})=1.91$

Std. Err $=\quad 0.41$

Disks $(\mathrm{n})=22$ 


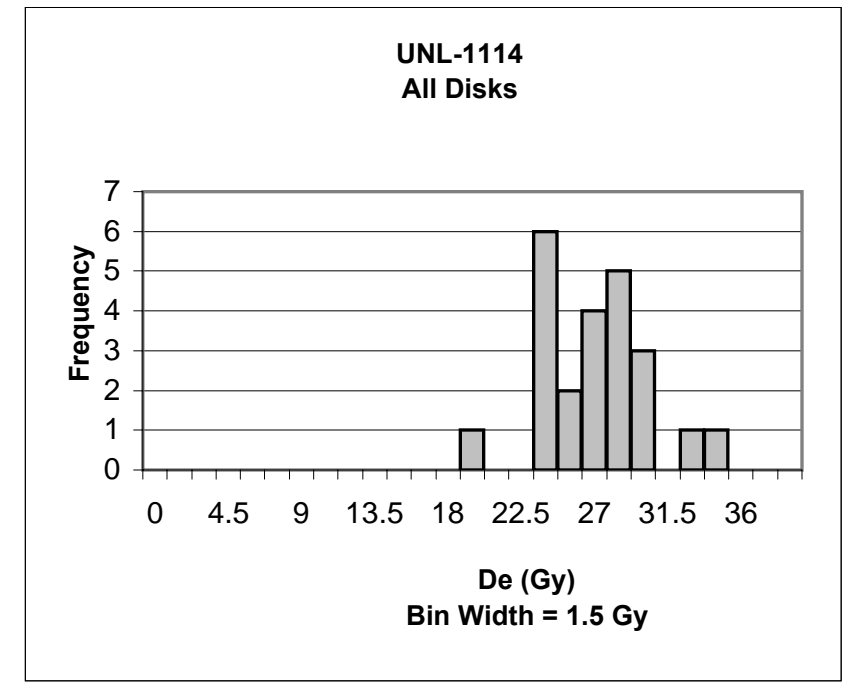

$\begin{array}{lcll}\text { All Disks } & & & \\ & \text { De (Gy) } & & \\ \text { Mean }= & \mathbf{2 6 . 4 1} & \text { S.D. }(\mathbf{1 \sigma})= & 3.27 \\ \text { Median }= & 26.34 & \text { Std. Err }= & 0.68 \\ \text { Min }= & 19.28 & \text { Disks }(\mathbf{n})= & 23 \\ \text { Max }= & 33.26 & & \end{array}$

\begin{tabular}{|c|c|c|c|c|}
\hline Disk & De & Err & Disc & De \\
\hline 1 & 19.28 & 0.31 & 28 & \\
\hline 2 & 22.98 & 0.12 & 29 & \\
\hline 3 & 23.00 & 0.40 & 30 & \\
\hline 4 & 23.40 & 0.00 & 31 & \\
\hline 5 & 23.61 & 0.38 & 32 & \\
\hline 6 & 23.78 & 0.06 & 33 & \\
\hline 7 & 23.98 & 0.25 & 34 & \\
\hline 8 & 24.78 & 0.36 & 35 & \\
\hline 9 & 25.02 & 0.44 & 36 & \\
\hline 10 & 25.76 & 0.85 & 37 & \\
\hline 11 & 25.97 & 0.01 & 38 & \\
\hline 12 & 26.34 & 0.26 & 39 & \\
\hline 13 & 26.54 & 0.40 & 40 & \\
\hline 14 & 27.06 & 0.29 & 41 & \\
\hline 15 & 27.34 & 0.17 & 42 & \\
\hline 16 & 27.55 & 0.13 & 43 & \\
\hline 17 & 27.85 & 0.72 & 44 & \\
\hline 18 & 28.44 & 0.07 & 45 & \\
\hline 19 & 29.08 & 0.15 & 46 & \\
\hline 20 & 29.75 & 0.32 & 47 & \\
\hline 21 & 29.84 & 0.04 & 48 & \\
\hline 22 & 32.74 & 0.45 & 49 & \\
\hline 23 & 33.26 & 0.10 & 50 & \\
\hline 24 & & & 51 & \\
\hline 25 & & & 52 & \\
\hline 26 & & & 53 & \\
\hline 27 & & & 54 & \\
\hline
\end{tabular}

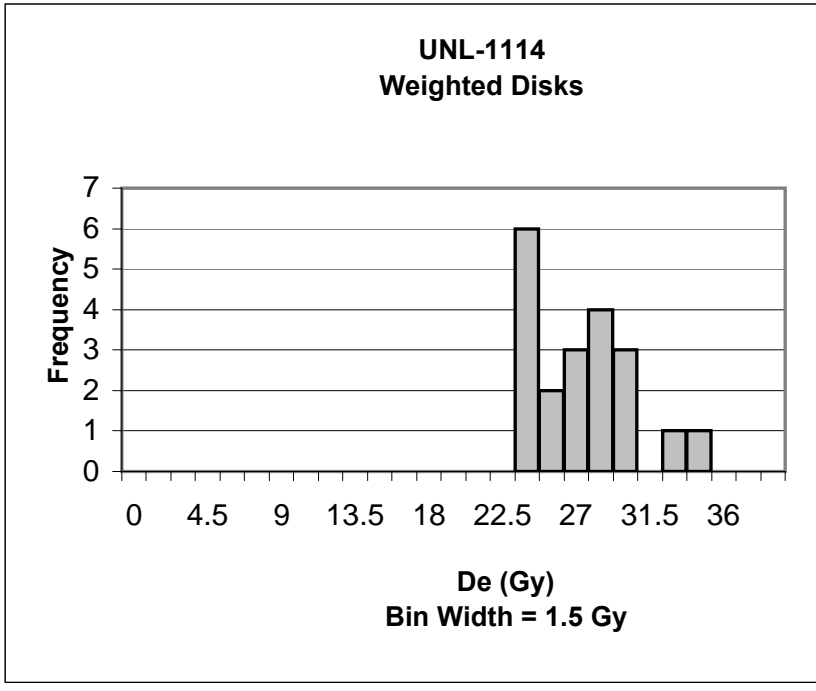

Weighted Disks

De (Gy)

Mean $=\quad 26.71$

Median $=\quad 26.25$

Min $=\quad 22.98$

Max $=\quad 33.26$

$\begin{array}{cccccc}\text { Disk } & \text { De } & \text { Err } & \text { Disc } & \text { De } & \text { Err } \\ \mathbf{1} & 22.98 & 0.12 & \mathbf{2 8} & & \\ \mathbf{2} & 23.00 & 0.40 & \mathbf{2 9} & \\ \mathbf{3} & 23.40 & 0.00 & \mathbf{3 0} & \\ \mathbf{4} & 23.61 & 0.38 & \mathbf{3 1} & \\ \mathbf{5} & 23.78 & 0.06 & \mathbf{3 2} & \\ \mathbf{6} & 23.98 & 0.25 & \mathbf{3 3} & \\ \mathbf{7} & 24.78 & 0.36 & \mathbf{3 4} & \\ \mathbf{8} & 25.02 & 0.44 & \mathbf{3 5} & \\ \mathbf{9} & 25.76 & 0.85 & \mathbf{3 6} & \\ \mathbf{1 0} & 25.97 & 0.01 & \mathbf{3 7} & \\ \mathbf{1 1} & 26.54 & 0.40 & \mathbf{3 8} & \\ \mathbf{1 2} & 27.06 & 0.29 & \mathbf{3 9} & \\ \mathbf{1 3} & 27.34 & 0.17 & \mathbf{4 0} & \\ \mathbf{1 4} & 27.85 & 0.72 & \mathbf{4 1} & \\ \mathbf{1 5} & 28.44 & 0.07 & \mathbf{4 2} & \\ \mathbf{1 6} & 29.08 & 0.15 & \mathbf{4 3} \\ \mathbf{1 7} & 29.75 & 0.32 & \mathbf{4 4} & \\ \mathbf{1 8} & 29.84 & 0.04 & \mathbf{4 5} & \\ \mathbf{1 9} & 32.74 & 0.45 & \mathbf{4 6} & \\ \mathbf{2 0} & 33.26 & 0.10 & \mathbf{4 7} \\ \mathbf{2 1} & & & \mathbf{4 8} & \\ \mathbf{2 2} & & & \mathbf{4 9} \\ \mathbf{2 3} & & & \mathbf{5 0} \\ \mathbf{2 4} & & & \mathbf{5 1} \\ \mathbf{2 5} & & & \mathbf{5 2} \\ \mathbf{2 6} & & & \mathbf{5 3} \\ \mathbf{2 7} & & & \mathbf{5 4}\end{array}$




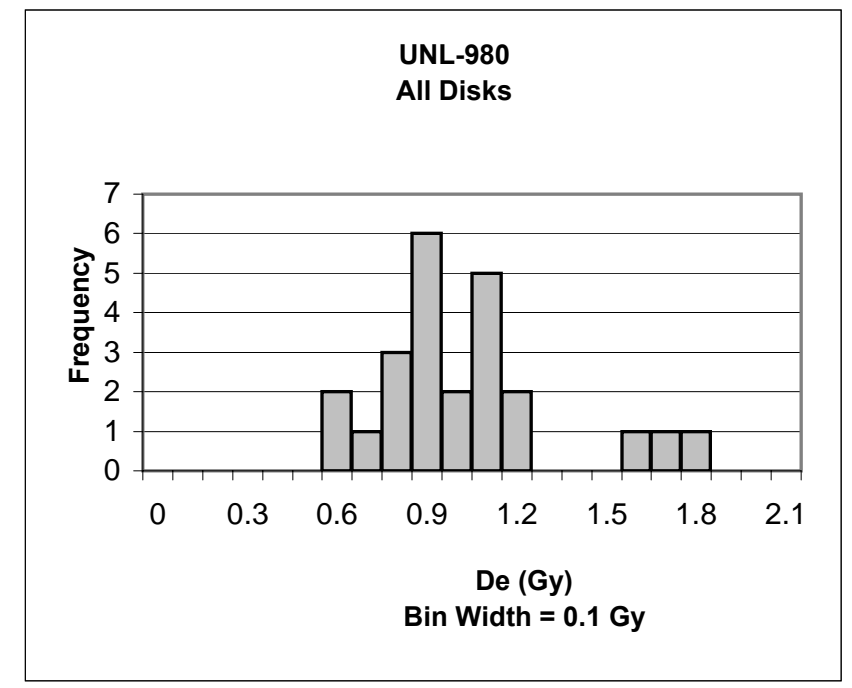

$\begin{array}{lcll}\text { All Disks } & & & \\ & \text { De }(G y) & & \\ \text { Mean }= & \mathbf{0 . 9 8} & \text { S.D. }(\mathbf{1} \sigma)= & 0.30 \\ \text { Median }= & 0.91 & \text { Std. Err }= & 0.06 \\ \text { Min }= & 0.57 & \text { Disks }(\mathbf{n})= & 24 \\ \text { Max }= & 1.77 & & \end{array}$

\begin{tabular}{|c|c|c|c|c|}
\hline Disk & De & Err & Disc & De \\
\hline 1 & 1.77 & 0.15 & 28 & \\
\hline 2 & 0.88 & 0.17 & 29 & \\
\hline 3 & 0.88 & 0.30 & 30 & \\
\hline 4 & 0.57 & 0.53 & 31 & \\
\hline 5 & 1.05 & 0.37 & 32 & \\
\hline 6 & 1.01 & 0.14 & 33 & \\
\hline 7 & 0.95 & 0.18 & 34 & \\
\hline 8 & 0.66 & 0.10 & 35 & \\
\hline 9 & 1.08 & 0.02 & 36 & \\
\hline 10 & 1.01 & 0.10 & 37 & \\
\hline 11 & 0.79 & 0.05 & 38 & \\
\hline 12 & 0.71 & 0.06 & 39 & \\
\hline 13 & 1.14 & 0.10 & 40 & \\
\hline 14 & 0.88 & 0.04 & 41 & \\
\hline 15 & 1.62 & 0.51 & 42 & \\
\hline 16 & 0.75 & 0.08 & 43 & \\
\hline 17 & 0.92 & 0.21 & 44 & \\
\hline 18 & 0.59 & 0.02 & 45 & \\
\hline 19 & 0.83 & 0.06 & 46 & \\
\hline 20 & 1.13 & 0.12 & 47 & \\
\hline 21 & 1.05 & 0.17 & 48 & \\
\hline 22 & 1.51 & 0.23 & 49 & \\
\hline 23 & 0.84 & 0.24 & 50 & \\
\hline 24 & 0.90 & 0.10 & 51 & \\
\hline 25 & & & 52 & \\
\hline 26 & & & 53 & \\
\hline 27 & & & 54 & \\
\hline
\end{tabular}

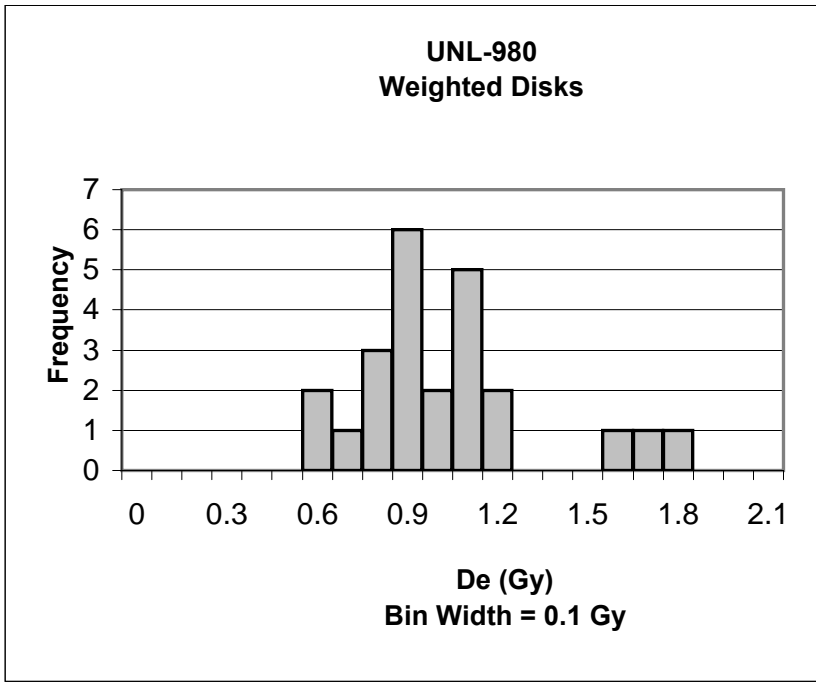

Weighted Disks

$\begin{array}{lc}\text { Mean }= & \text { De }(\text { Gy }) \\ \text { Median }= & 0.98 \\ \text { Min }= & 0.91 \\ \text { Max }= & 0.57 \\ & 1.77\end{array}$

$\begin{array}{cccccc}\text { Disk } & \text { De } & \text { Err } & \text { Disc } & \text { De } & \text { Err } \\ \mathbf{1} & 1.77 & 0.15 & \mathbf{2 8} & \\ \mathbf{2} & 0.88 & 0.17 & \mathbf{2 9} & \\ \mathbf{3} & 0.88 & 0.30 & \mathbf{3 0} & \\ \mathbf{4} & 0.57 & 0.53 & \mathbf{3 1} & \\ \mathbf{5} & 1.05 & 0.37 & \mathbf{3 2} & \\ \mathbf{6} & 1.01 & 0.14 & \mathbf{3 3} & \\ \mathbf{7} & 0.95 & 0.18 & \mathbf{3 4} & \\ \mathbf{8} & 0.66 & 0.10 & \mathbf{3 5} & \\ \mathbf{9} & 1.08 & 0.02 & \mathbf{3 6} & \\ \mathbf{1 0} & 1.01 & 0.10 & \mathbf{3 7} & \\ \mathbf{1 1} & 0.79 & 0.05 & \mathbf{3 8} & \\ \mathbf{1 2} & 0.71 & 0.06 & \mathbf{3 9} & \\ \mathbf{1 3} & 1.14 & 0.10 & \mathbf{4 0} & \\ \mathbf{1 4} & 0.88 & 0.04 & \mathbf{4 1} & \\ \mathbf{1 5} & 1.62 & 0.51 & \mathbf{4 2} & \\ \mathbf{1 6} & 0.75 & 0.08 & \mathbf{4 3} \\ \mathbf{1 7} & 0.92 & 0.21 & \mathbf{4 4} & \\ \mathbf{1 8} & 0.59 & 0.02 & \mathbf{4 5} & \\ \mathbf{1 9} & 0.83 & 0.06 & \mathbf{4 6} & \\ \mathbf{2 0} & 1.13 & 0.12 & \mathbf{4 7} \\ \mathbf{2 1} & 1.05 & 0.17 & \mathbf{4 8} \\ \mathbf{2 2} & 1.51 & 0.23 & \mathbf{4 9} \\ \mathbf{2 3} & 0.84 & 0.24 & \mathbf{5 0} \\ \mathbf{2 4} & 0.90 & 0.10 & \mathbf{5 1} \\ \mathbf{2 5} & & & \mathbf{5 2} \\ \mathbf{2 6} & & & \mathbf{5 3} \\ \mathbf{2 7} & & & \mathbf{5 4}\end{array}$




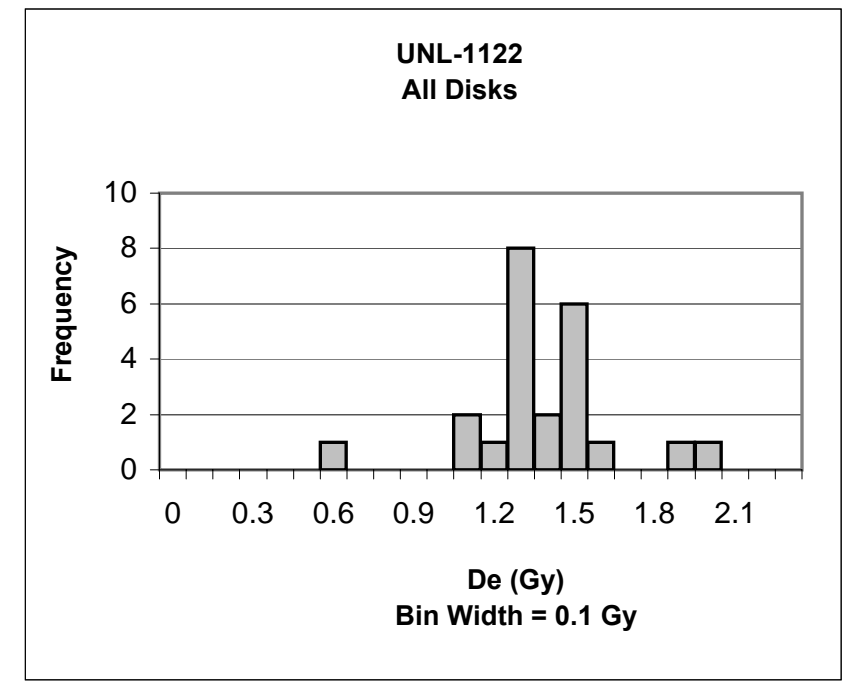

$\begin{array}{lcll}\text { All Disks } & & & \\ & \text { De }(\text { Gy) } & & \\ \text { Mean }= & 1.45 & \text { S.D. }(\mathbf{1 \sigma})= & 0.64 \\ \text { Median }= & 1.30 & \text { Std. Err }= & 0.13 \\ \text { Min }= & 0.59 & \text { Disks }(\mathbf{n})= & 24 \\ \text { Max }= & 4.20 & & \end{array}$

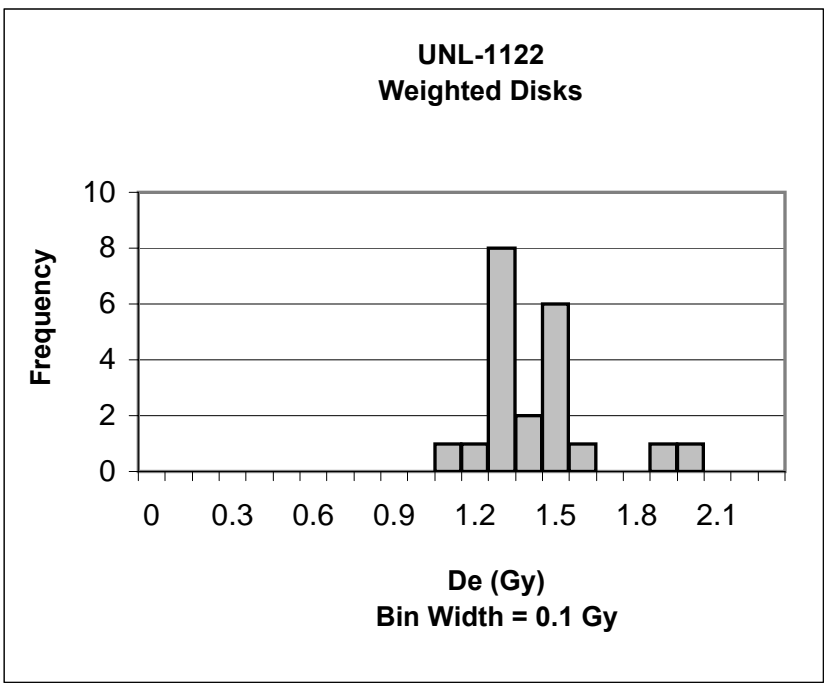

Weighted Disks

De (Gy)

$\begin{array}{lllc}\text { Mean }= & 1.38 & \text { S.D. }(\mathbf{1} \sigma)= & 0.22 \\ \text { Median }= & 1.31 & \text { Std. } \text { Err }= & 0.05 \\ \text { Min }= & 1.07 & \text { Disks }(\mathbf{n})= & 21 \\ \text { Max }= & 1.98 & & \end{array}$

\begin{tabular}{|c|c|c|c|c|c|c|c|c|c|c|}
\hline Disk & $\mathrm{De}$ & Err & Disc & $\mathrm{De}$ & Err & Disk & $\mathrm{De}$ & Err & Disc & De \\
\hline 1 & 0.59 & 0.36 & 28 & & & 1 & 1.07 & 0.02 & 28 & \\
\hline 2 & 1.02 & 0.26 & 29 & & & 2 & 1.12 & 0.27 & 29 & \\
\hline 3 & 1.07 & 0.02 & 30 & & & 3 & 1.21 & 0.06 & 30 & \\
\hline 4 & 1.12 & 0.27 & 31 & & & 4 & 1.22 & 0.08 & 31 & \\
\hline 5 & 1.21 & 0.06 & 32 & & & 5 & 1.24 & 0.15 & 32 & \\
\hline 6 & 1.22 & 0.08 & 33 & & & 6 & 1.25 & 0.10 & 33 & \\
\hline 7 & 1.24 & 0.15 & 34 & & & 7 & 1.26 & 0.03 & 34 & \\
\hline 8 & 1.25 & 0.10 & 35 & & & 8 & 1.26 & 0.11 & 35 & \\
\hline 9 & 1.26 & 0.03 & 36 & & & 9 & 1.27 & 0.04 & 36 & \\
\hline 10 & 1.26 & 0.11 & 37 & & & 10 & 1.29 & 0.07 & 37 & \\
\hline 11 & 1.27 & 0.04 & 38 & & & 11 & 1.31 & 0.04 & 38 & \\
\hline 12 & 1.29 & 0.07 & 39 & & & 12 & 1.39 & 0.11 & 39 & \\
\hline 13 & 1.31 & 0.04 & 40 & & & 13 & 1.40 & 0.05 & 40 & \\
\hline 14 & 1.39 & 0.11 & 41 & & & 14 & 1.43 & 0.13 & 41 & \\
\hline 15 & 1.40 & 0.05 & 42 & & & 15 & 1.44 & 0.02 & 42 & \\
\hline 16 & 1.43 & 0.13 & 43 & & & 16 & 1.45 & 0.03 & 43 & \\
\hline 17 & 1.44 & 0.02 & 44 & & & 17 & 1.45 & 0.05 & 44 & \\
\hline 18 & 1.45 & 0.03 & 45 & & & 18 & 1.50 & 0.05 & 45 & \\
\hline 19 & 1.45 & 0.05 & 46 & & & 19 & 1.57 & 0.44 & 46 & \\
\hline 20 & 1.50 & 0.05 & 47 & & & 20 & 1.82 & 0.09 & 47 & \\
\hline 21 & 1.57 & 0.44 & 48 & & & 21 & 1.98 & 0.30 & 48 & \\
\hline 22 & 1.82 & 0.09 & 49 & & & 22 & & & 49 & \\
\hline 23 & 1.98 & 0.30 & 50 & & & 23 & & & 50 & \\
\hline 24 & 4.20 & 0.11 & 51 & & & 24 & & & 51 & \\
\hline 25 & & & 52 & & & 25 & & & 52 & \\
\hline 26 & & & 53 & & & 26 & & & 53 & \\
\hline 27 & & & 54 & & & 27 & & & 54 & \\
\hline
\end{tabular}




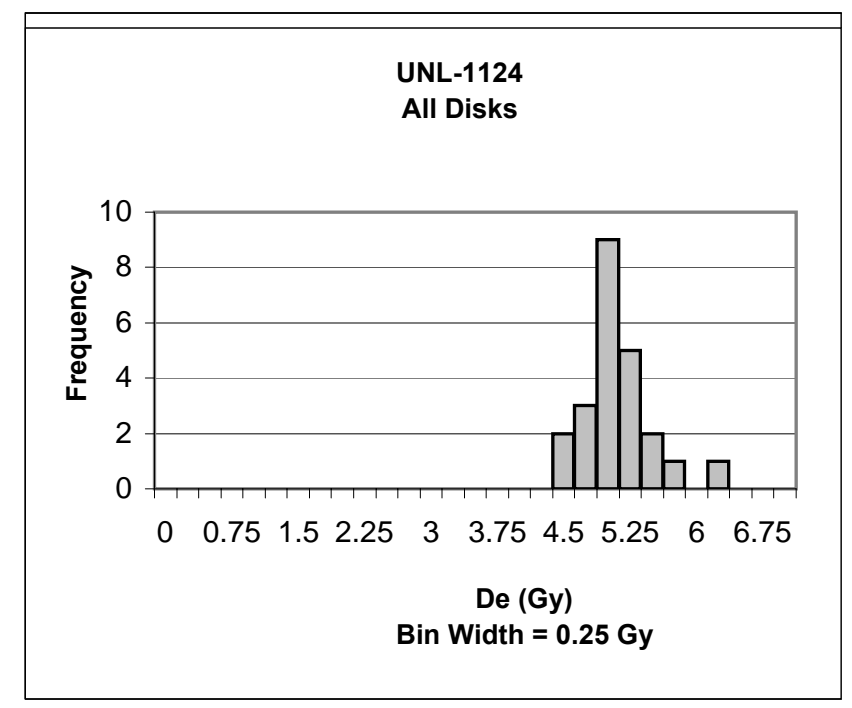

$\begin{array}{lcll}\text { All Disks } & & & \\ & \text { De }(\text { Gy) } & & \\ \text { Mean }= & 4.97 & \text { S.D. }(\mathbf{1 \sigma})= & 0.40 \\ \text { Median }= & 4.94 & \text { Std. Err }= & 0.08 \\ \text { Min }= & 4.36 & \text { Disks }(\mathbf{n})= & 23 \\ \text { Max }= & 6.17 & & \end{array}$

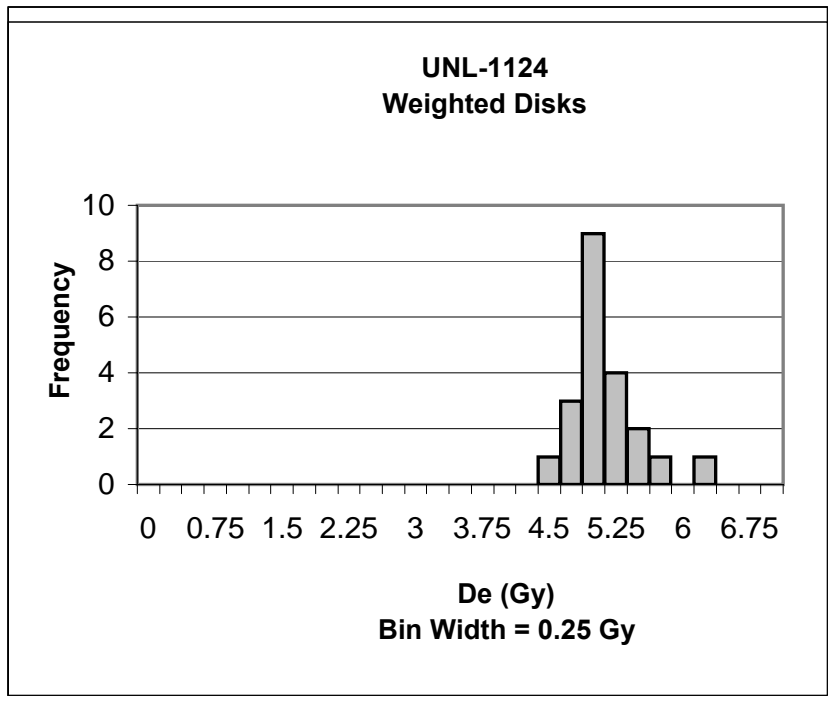

Weighted Disks De (Gy)

$\begin{array}{lllc}\text { Mean }= & 4.99 & \text { S.D. }(1 \sigma)= & 0.40 \\ \text { Median }= & 4.94 & \text { Std. } \text { Err }= & 0.09 \\ \text { Min }= & 4.36 & \text { Disks }(\mathbf{n})= & 21 \\ \text { Max }= & 6.17 & & \end{array}$

\begin{tabular}{|c|c|c|c|c|c|c|c|c|c|c|}
\hline Disk & De & Err & Disc & De & Err & Disk & De & Err & Disc & De \\
\hline 1 & 4.36 & 0.06 & 28 & & & 1 & 4.36 & 0.06 & 28 & \\
\hline 2 & 4.39 & 0.20 & 29 & & & 2 & 4.56 & 0.06 & 29 & \\
\hline 3 & 4.56 & 0.06 & 30 & & & 3 & 4.60 & 0.85 & 30 & \\
\hline 4 & 4.60 & 0.85 & 31 & & & 4 & 4.66 & 0.07 & 31 & \\
\hline 5 & 4.66 & 0.07 & 32 & & & 5 & 4.77 & 0.08 & 32 & \\
\hline 6 & 4.77 & 0.08 & 33 & & & 6 & 4.78 & 0.17 & 33 & \\
\hline 7 & 4.78 & 0.17 & 34 & & & 7 & 4.80 & 0.00 & 34 & \\
\hline 8 & 4.80 & 0.00 & 35 & & & 8 & 4.80 & 0.03 & 35 & \\
\hline 9 & 4.80 & 0.03 & 36 & & & 9 & 4.81 & 0.02 & 36 & \\
\hline 10 & 4.81 & 0.02 & 37 & & & 10 & 4.92 & 0.03 & 37 & \\
\hline 11 & 4.92 & 0.03 & 38 & & & 11 & 4.94 & 0.10 & 38 & \\
\hline 12 & 4.94 & 0.10 & 39 & & & 12 & 4.95 & 0.12 & 39 & \\
\hline 13 & 4.95 & 0.12 & 40 & & & 13 & 4.95 & 0.76 & 40 & \\
\hline 14 & 4.95 & 0.76 & 41 & & & 14 & 5.03 & 0.02 & 41 & \\
\hline 15 & 5.03 & 0.02 & 42 & & & 15 & 5.03 & 0.06 & 42 & \\
\hline 16 & 5.03 & 0.06 & 43 & & & 16 & 5.04 & 0.02 & 43 & \\
\hline 17 & 5.04 & 0.02 & 44 & & & 17 & 5.11 & 0.05 & 44 & \\
\hline 18 & 5.10 & 0.13 & 45 & & & 18 & 5.34 & 0.08 & 45 & \\
\hline 19 & 5.11 & 0.05 & 46 & & & 19 & 5.40 & 0.03 & 46 & \\
\hline 20 & 5.34 & 0.08 & 47 & & & 20 & 5.70 & 0.06 & 47 & \\
\hline 21 & 5.40 & 0.03 & 48 & & & 21 & 6.17 & 0.03 & 48 & \\
\hline 22 & 5.70 & 0.06 & 49 & & & 22 & & & 49 & \\
\hline 23 & 6.17 & 0.03 & 50 & & & 23 & & & 50 & \\
\hline 24 & & & 51 & & & 24 & & & 51 & \\
\hline 25 & & & 52 & & & 25 & & & 52 & \\
\hline 26 & & & 53 & & & 26 & & & 53 & \\
\hline 27 & & & 54 & & & 27 & & & 54 & \\
\hline
\end{tabular}




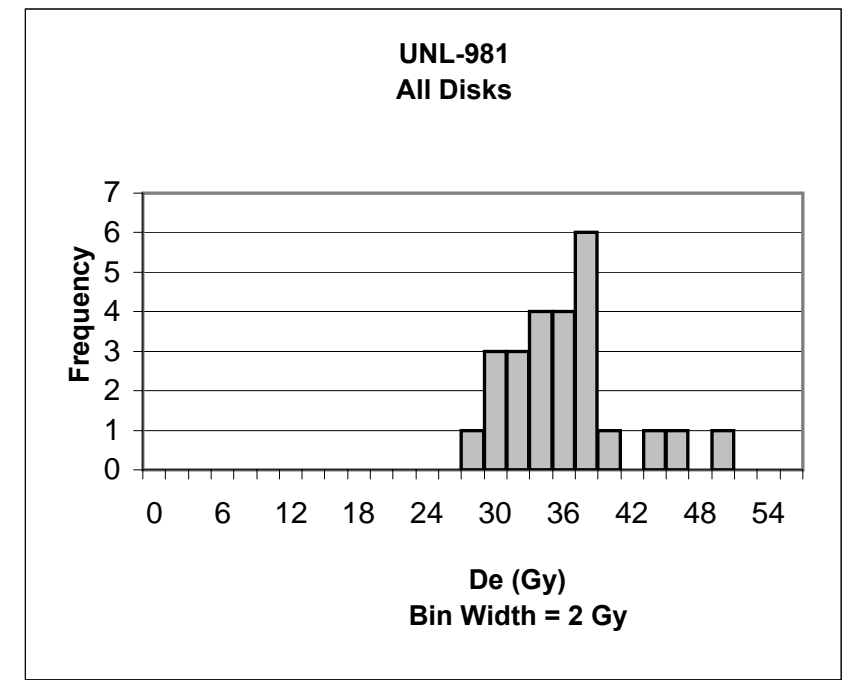

$\begin{array}{lcll}\text { All Disks } & & & \\ & \text { De }(\mathrm{Gy}) & & \\ \text { Mean }= & \mathbf{3 4 . 9 8} & \text { S.D. }(\mathbf{1} \boldsymbol{\sigma})= & 5.12 \\ \text { Median }= & 35.18 & \text { Std. Err }= & 1.02 \\ \text { Min }= & 26.61 & \text { Disks }(\mathbf{n})= & 25 \\ \text { Max }= & 49.10 & & \end{array}$

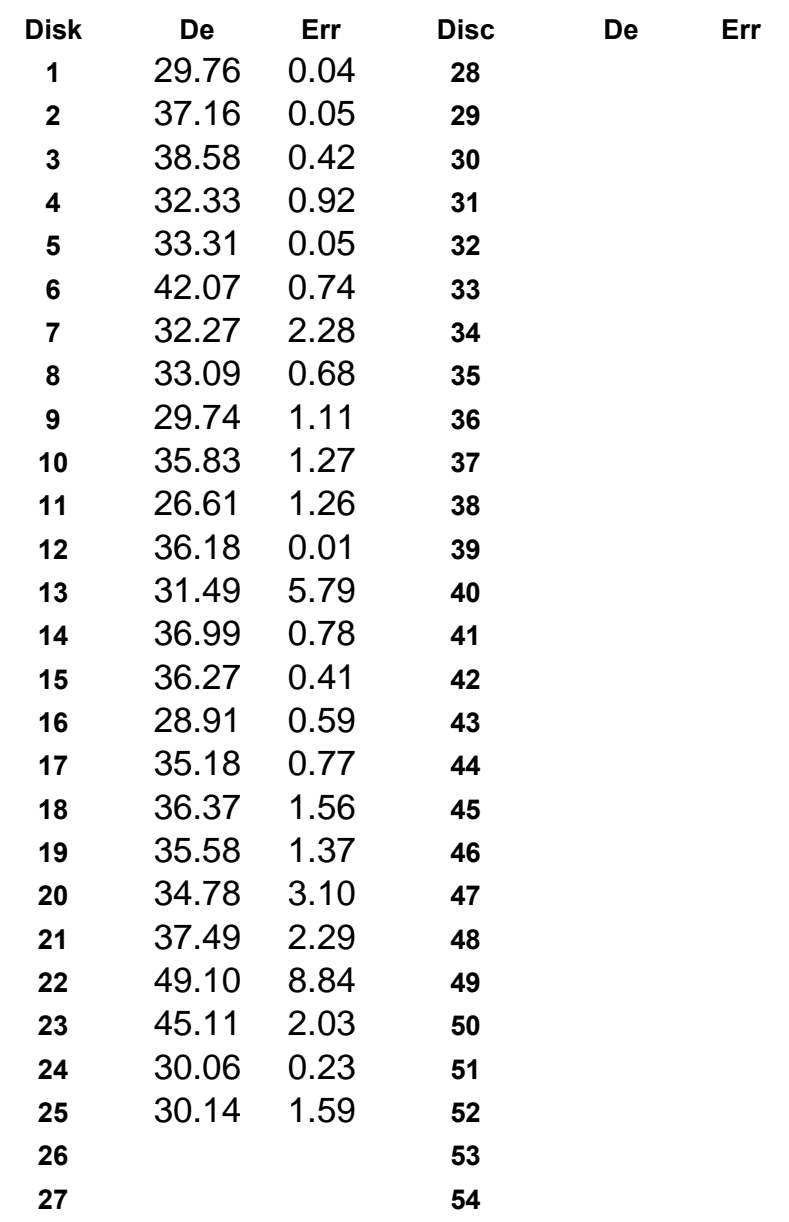

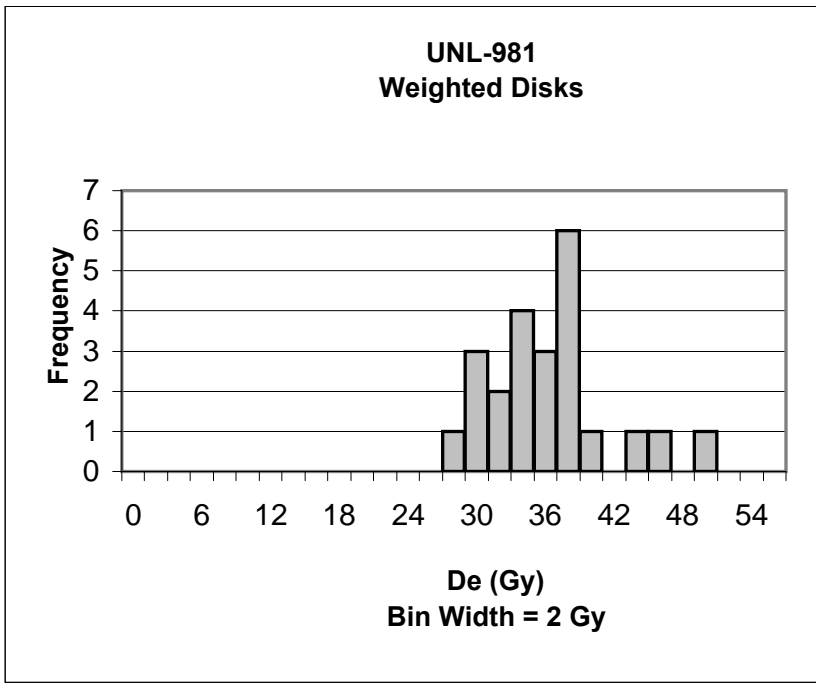

Weighted Disks

De (Gy)

Mean $=\quad 35.14$

Median $=\quad 35.58$

Min $=\quad 26.61$

Max $=\quad 49.10$
S.D. $(1 \sigma)=\quad 5.29$

Std. Err $=\quad 1.10$

Disks $(\mathbf{n})=23$

$\begin{array}{cccccc}\text { Disk } & \text { De } & \text { Err } & \text { Disc } & \text { De } & \text { Err } \\ \mathbf{1} & 29.76 & 0.04 & \mathbf{2 8} & & \\ \mathbf{2} & 37.16 & 0.05 & \mathbf{2 9} & \\ \mathbf{3} & 38.58 & 0.42 & \mathbf{3 0} & \\ \mathbf{4} & 32.33 & 0.92 & \mathbf{3 1} & \\ \mathbf{5} & 33.31 & 0.05 & \mathbf{3 2} & \\ \mathbf{6} & 42.07 & 0.74 & \mathbf{3 3} & \\ \mathbf{7} & 32.27 & 2.28 & \mathbf{3 4} & \\ \mathbf{8} & 33.09 & 0.68 & \mathbf{3 5} & \\ \mathbf{9} & 29.74 & 1.11 & \mathbf{3 6} & \\ \mathbf{1 0} & 35.83 & 1.27 & \mathbf{3 7} & \\ \mathbf{1 1} & 26.61 & 1.26 & \mathbf{3 8} & \\ \mathbf{1 2} & 36.18 & 0.01 & \mathbf{3 9} & \\ \mathbf{1 3} & 36.99 & 0.78 & \mathbf{4 0} & \\ \mathbf{1 4} & 36.27 & 0.41 & \mathbf{4 1} & \\ \mathbf{1 5} & 28.91 & 0.59 & \mathbf{4 2} & \\ \mathbf{1 6} & 35.18 & 0.77 & \mathbf{4 3} & \\ \mathbf{1 7} & 36.37 & 1.56 & \mathbf{4 4} & \\ \mathbf{1 8} & 35.58 & 1.37 & \mathbf{4 5} & \\ \mathbf{1 9} & 37.49 & 2.29 & \mathbf{4 6} & \\ \mathbf{2 0} & \mathbf{4 9 . 1 0} & 8.84 & \mathbf{4 7} \\ \mathbf{2 1} & \mathbf{4 5 . 1 1} & 2.03 & \mathbf{4 8} & \\ \mathbf{2 2} & 30.06 & 0.23 & \mathbf{4 9} \\ \mathbf{2 3} & 30.14 & 1.59 & \mathbf{5 0} \\ \mathbf{2 4} & & & \mathbf{5 1} \\ \mathbf{2 5} & & & \mathbf{5 2} \\ \mathbf{2 6} & & & \mathbf{5 3} \\ \mathbf{2 7} & & & \mathbf{5 4} & \end{array}$




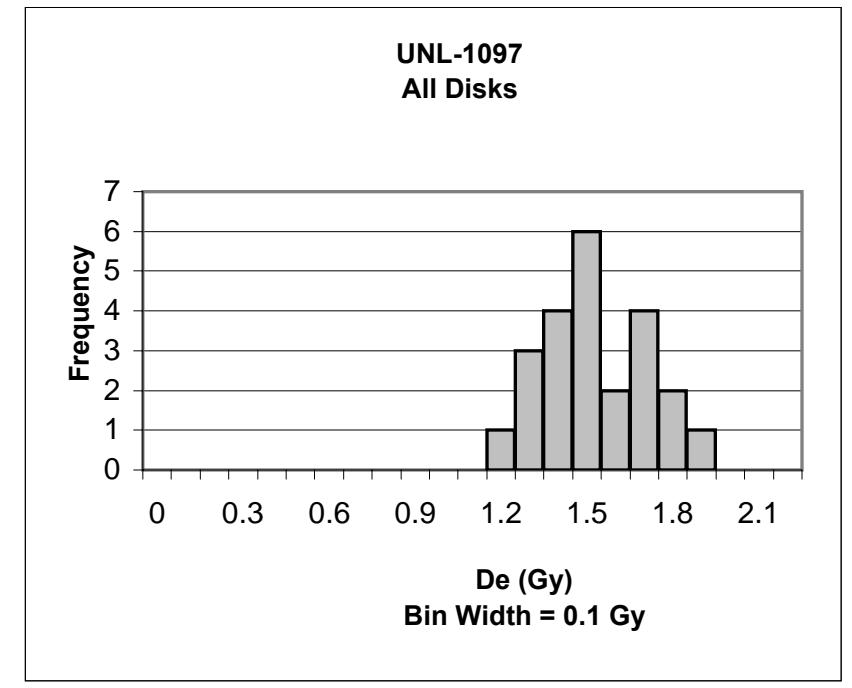

$\begin{array}{lcll}\text { All Disks } & & & \\ & \text { De (Gy) } & & \\ \text { Mean }= & 1.49 & \text { S.D. }(\mathbf{1 \sigma})= & 0.18 \\ \text { Median }= & 1.48 & \text { Std. Err }= & 0.04 \\ \text { Min }= & 1.17 & \text { Disks }(\mathbf{n})= & 23 \\ \text { Max }= & 1.82 & & \end{array}$

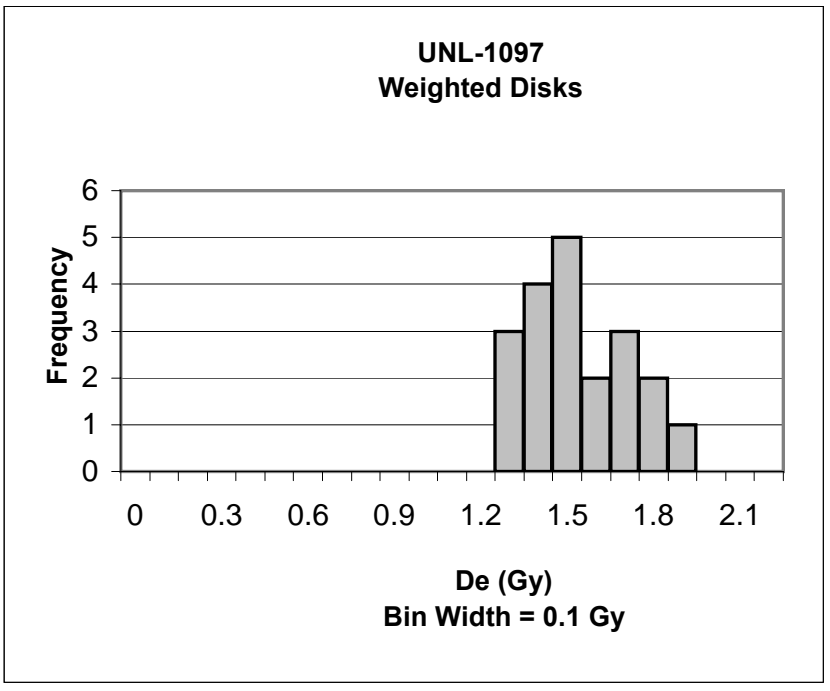

Weighted Disks

De (Gy)

$\begin{array}{lllc}\text { Mean }= & 1.50 & \text { S.D. }(\mathbf{1 \sigma})= & 0.18 \\ \text { Median }= & 1.48 & \text { Std. } \text { Err }= & 0.04 \\ \text { Min }= & 1.22 & \text { Disks }(\mathbf{n})= & 20\end{array}$

Max $=1.82$

$\begin{array}{cccccc}\text { Disk } & \text { De } & \text { Err } & \text { Disc } & \text { De } & \text { Err } \\ \mathbf{1} & 1.22 & 0.08 & \mathbf{2 8} & & \\ \mathbf{2} & 1.29 & 0.28 & \mathbf{2 9} & \\ \mathbf{3} & 1.29 & 0.23 & \mathbf{3 0} & & \\ \mathbf{4} & 1.30 & 0.06 & \mathbf{3 1} & \\ \mathbf{5} & 1.35 & 0.02 & \mathbf{3 2} & \\ \mathbf{6} & 1.36 & 0.06 & \mathbf{3 3} & \\ \mathbf{7} & 1.39 & 0.02 & \mathbf{3 4} & \\ \mathbf{8} & 1.43 & 0.03 & \mathbf{3 5} & \\ \mathbf{9} & 1.47 & 0.02 & \mathbf{3 6} & \\ \mathbf{1 0} & 1.48 & 0.03 & \mathbf{3 7} & \\ \mathbf{1 1} & 1.49 & 0.01 & \mathbf{3 8} & \\ \mathbf{1 2} & 1.49 & 0.01 & \mathbf{3 9} & \\ \mathbf{1 3} & 1.52 & 0.07 & \mathbf{4 0} & \\ \mathbf{1 4} & 1.59 & 0.08 & \mathbf{4 1} & \\ \mathbf{1 5} & 1.65 & 0.03 & \mathbf{4 2} & \\ \mathbf{1 6} & 1.66 & 0.04 & \mathbf{4 3} & \\ \mathbf{1 7} & 1.69 & 0.02 & \mathbf{4 4} & \\ \mathbf{1 8} & 1.74 & 0.07 & \mathbf{4 5} & \\ \mathbf{1 9} & 1.77 & 0.03 & \mathbf{4 6} & \\ \mathbf{2 0} & 1.82 & 0.02 & \mathbf{4 7} \\ \mathbf{2 1} & & & \mathbf{4 8} & \\ \mathbf{2 2} & & & \mathbf{4 9} \\ \mathbf{2 3} & & & \mathbf{5 0} \\ \mathbf{2 4} & & & \mathbf{5 1} \\ \mathbf{2 5} & & & \mathbf{5 2} \\ \mathbf{2 6} & & & \mathbf{5 3} \\ \mathbf{2 7} & & & \mathbf{5 4} & \end{array}$




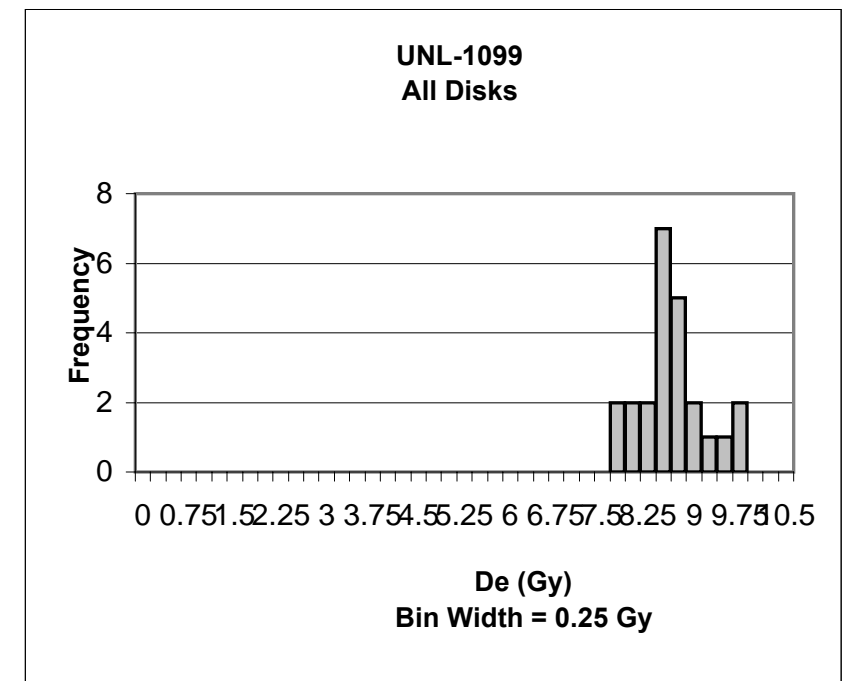

$\begin{array}{lcll}\text { All Disks } & & & \\ & \text { De }(G y) & & \\ \text { Mean }= & \mathbf{8 . 5 1} & \text { S.D. }(\mathbf{1 \sigma})= & 0.52 \\ \text { Median }= & 8.49 & \text { Std. Err }= & 0.11 \\ \text { Min }= & 7.65 & \text { Disks }(\mathbf{n})= & 24 \\ \text { Max }= & 9.62 & & \end{array}$

\begin{tabular}{|c|c|c|c|c|}
\hline Disk & De & Err & Disc & De \\
\hline 1 & 7.65 & 0.41 & 28 & \\
\hline 2 & 7.69 & 0.05 & 29 & \\
\hline 3 & 7.84 & 0.07 & 30 & \\
\hline 4 & 7.96 & 0.04 & 31 & \\
\hline 5 & 8.01 & 0.84 & 32 & \\
\hline 6 & 8.17 & 0.06 & 33 & \\
\hline 7 & 8.31 & 0.15 & 34 & \\
\hline 8 & 8.32 & 0.02 & 35 & \\
\hline 9 & 8.34 & 0.07 & 36 & \\
\hline 10 & 8.36 & 0.07 & 37 & \\
\hline 11 & 8.42 & 0.06 & 38 & \\
\hline 12 & 8.48 & 0.04 & 39 & \\
\hline 13 & 8.49 & 0.06 & 40 & \\
\hline 14 & 8.51 & 0.09 & 41 & \\
\hline 15 & 8.54 & 0.00 & 42 & \\
\hline 16 & 8.58 & 0.06 & 43 & \\
\hline 17 & 8.68 & 0.01 & 44 & \\
\hline 18 & 8.73 & 0.09 & 45 & \\
\hline 19 & 8.82 & 0.43 & 46 & \\
\hline 20 & 8.82 & 0.04 & 47 & \\
\hline 21 & 9.18 & 0.07 & 48 & \\
\hline 22 & 9.28 & 0.04 & 49 & \\
\hline 23 & 9.53 & 0.68 & 50 & \\
\hline 24 & 9.62 & 0.10 & 51 & \\
\hline 25 & & & 52 & \\
\hline 26 & & & 53 & \\
\hline 27 & & & 54 & \\
\hline
\end{tabular}

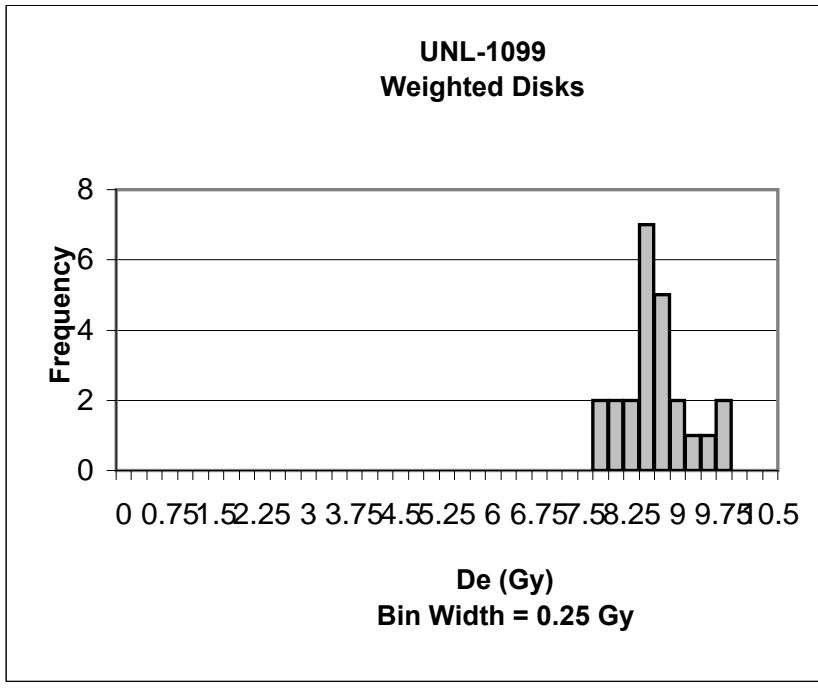

Weighted Disks

De (Gy)

Mean $=\quad 8.51$

Median $=\quad 8.49$

Min $=\quad 7.65$

Max $=9.62$
Weighted Disks

\begin{tabular}{|c|c|c|c|c|}
\hline Disk & $\mathrm{De}$ & Err & Disc & De \\
\hline 1 & 7.65 & 0.41 & 28 & \\
\hline 2 & 7.69 & 0.05 & 29 & \\
\hline 3 & 7.84 & 0.07 & 30 & \\
\hline 4 & 7.96 & 0.04 & 31 & \\
\hline 5 & 8.01 & 0.84 & 32 & \\
\hline 6 & 8.17 & 0.06 & 33 & \\
\hline 7 & 8.31 & 0.15 & 34 & \\
\hline 8 & 8.32 & 0.02 & 35 & \\
\hline 9 & 8.34 & 0.07 & 36 & \\
\hline 10 & 8.36 & 0.07 & 37 & \\
\hline 11 & 8.42 & 0.06 & 38 & \\
\hline 12 & 8.48 & 0.04 & 39 & \\
\hline 13 & 8.49 & 0.06 & 40 & \\
\hline 14 & 8.51 & 0.09 & 41 & \\
\hline 15 & 8.54 & 0.00 & 42 & \\
\hline 16 & 8.58 & 0.06 & 43 & \\
\hline 17 & 8.68 & 0.01 & 44 & \\
\hline 18 & 8.73 & 0.09 & 45 & \\
\hline 19 & 8.82 & 0.43 & 46 & \\
\hline 20 & 8.82 & 0.04 & 47 & \\
\hline 21 & 9.18 & 0.07 & 48 & \\
\hline 22 & 9.28 & 0.04 & 49 & \\
\hline 23 & 9.53 & 0.68 & 50 & \\
\hline 24 & 9.62 & 0.10 & 51 & \\
\hline 25 & & & 52 & \\
\hline 26 & & & 53 & \\
\hline 27 & & & 54 & \\
\hline
\end{tabular}




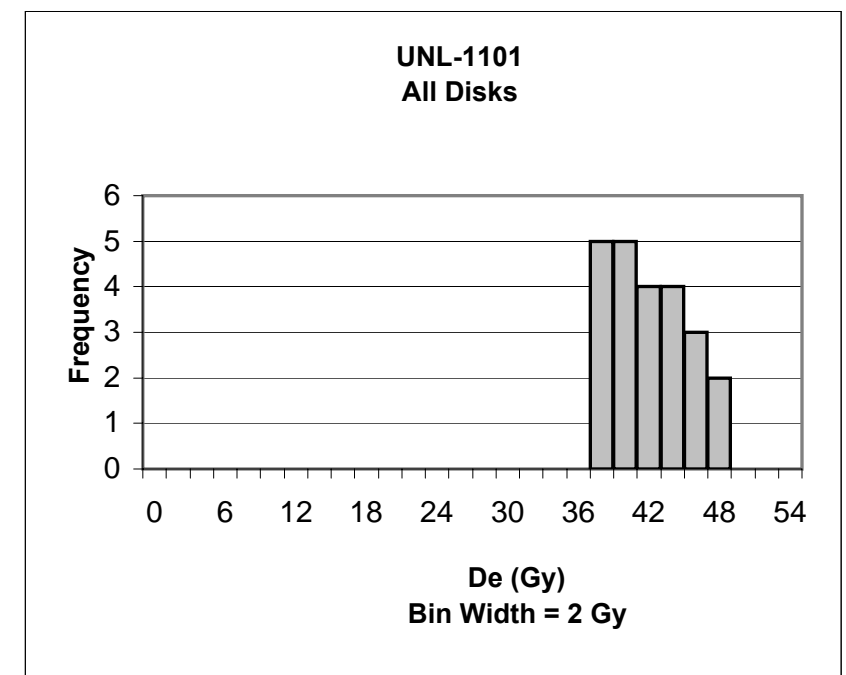

\section{All Disks}

De (Gy)

$\begin{array}{lllc}\text { Mean }= & \mathbf{4 1 . 0 0} & \text { S.D. }(\mathbf{1} \boldsymbol{\sigma})= & 3.22 \\ \text { Median }= & 40.65 & \text { Std. } \text { Err }= & 0.67 \\ \text { Min }= & 36.55 & \text { Disks }(\mathbf{n})= & 23 \\ \text { Max }= & 47.06 & & \end{array}$

\begin{tabular}{|c|c|c|c|c|}
\hline Disk & $\mathrm{De}$ & Err & Disc & De \\
\hline 1 & 36.55 & 0.39 & 28 & \\
\hline 2 & 36.68 & 0.13 & 29 & \\
\hline 3 & 36.83 & 0.26 & 30 & \\
\hline 4 & 37.68 & 0.06 & 31 & \\
\hline 5 & 37.98 & 0.46 & 32 & \\
\hline 6 & 38.03 & 0.20 & 33 & \\
\hline 7 & 38.37 & 0.32 & 34 & \\
\hline 8 & 38.92 & 0.27 & 35 & \\
\hline 9 & 39.58 & 0.15 & 36 & \\
\hline 10 & 39.60 & 0.22 & 37 & \\
\hline 11 & 40.34 & 0.22 & 38 & \\
\hline 12 & 40.65 & 0.01 & 39 & \\
\hline 13 & 40.95 & 0.27 & 40 & \\
\hline 14 & 41.85 & 0.20 & 41 & \\
\hline 15 & 42.05 & 0.02 & 42 & \\
\hline 16 & 42.36 & 0.16 & 43 & \\
\hline 17 & 43.05 & 0.08 & 44 & \\
\hline 18 & 43.55 & 0.46 & 45 & \\
\hline 19 & 44.32 & 0.07 & 46 & \\
\hline 20 & 44.58 & 0.09 & 47 & \\
\hline 21 & 45.17 & 0.28 & 48 & \\
\hline 22 & 46.89 & 0.28 & 49 & \\
\hline 23 & 47.06 & 0.33 & 50 & \\
\hline 24 & & & 51 & \\
\hline 25 & & & 52 & \\
\hline 26 & & & 53 & \\
\hline 27 & & & 54 & \\
\hline
\end{tabular}

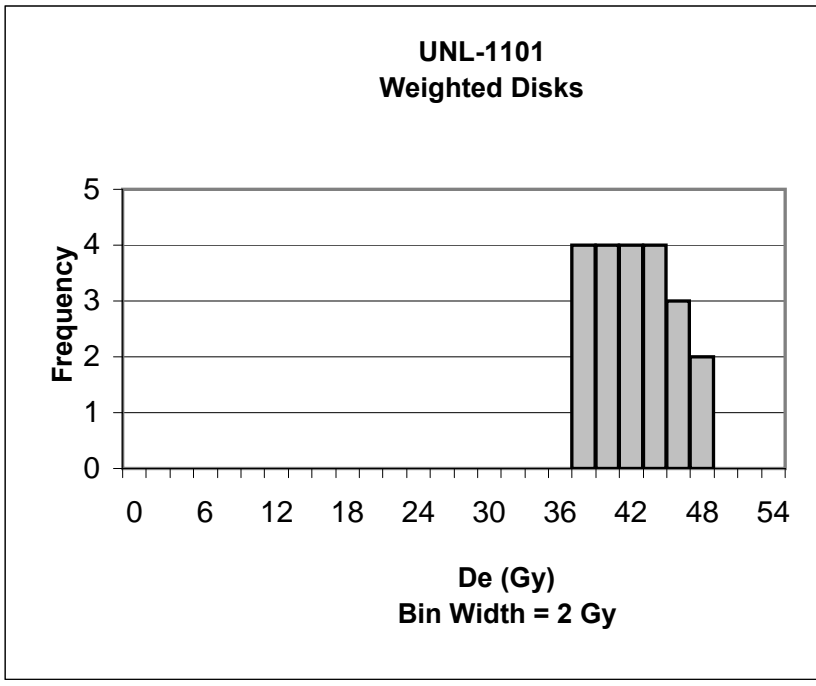

Weighted Disks De (Gy)

$\begin{array}{lllc}\text { Mean }= & \mathbf{4 1 . 3 3} & \text { S.D. }(\mathbf{1} \sigma)= & 3.17 \\ \text { Median }= & 40.95 & \text { Std. } \text { Err }= & 0.69 \\ \text { Min }= & 36.55 & \text { Disks }(\mathbf{n})= & 21 \\ \text { Max }= & 47.06 & & \end{array}$

Max $=\quad 47.06$

$\begin{array}{cccccc}\text { Disk } & \text { De } & \text { Err } & \text { Disc } & \text { De } & \text { Err } \\ \mathbf{1} & 36.55 & 0.39 & \mathbf{2 8} & & \\ \mathbf{2} & 36.68 & 0.13 & \mathbf{2 9} & \\ \mathbf{3} & 37.68 & 0.06 & \mathbf{3 0} & \\ \mathbf{4} & 37.98 & 0.46 & \mathbf{3 1} & \\ \mathbf{5} & 38.03 & 0.20 & \mathbf{3 2} & \\ \mathbf{6} & 38.92 & 0.27 & \mathbf{3 3} & \\ \mathbf{7} & 39.58 & 0.15 & \mathbf{3 4} & \\ \mathbf{8} & 39.60 & 0.22 & \mathbf{3 5} & \\ \mathbf{9} & 40.34 & 0.22 & \mathbf{3 6} & \\ \mathbf{1 0} & 40.65 & 0.01 & \mathbf{3 7} & \\ \mathbf{1 1} & 40.95 & 0.27 & \mathbf{3 8} & \\ \mathbf{1 2} & 41.85 & 0.20 & \mathbf{3 9} & \\ \mathbf{1 3} & \mathbf{4 2 . 0 5} & 0.02 & \mathbf{4 0} & \\ \mathbf{1 4} & \mathbf{4 2 . 3 6} & 0.16 & \mathbf{4 1} & \\ \mathbf{1 5} & 43.05 & 0.08 & \mathbf{4 2} & \\ \mathbf{1 6} & \mathbf{4 3 . 5 5} & 0.46 & \mathbf{4 3} & \\ \mathbf{1 7} & \mathbf{4 4 . 3 2} & 0.07 & \mathbf{4 4} & \\ \mathbf{1 8} & \mathbf{4 4 . 5 8} & 0.09 & \mathbf{4 5} & \\ \mathbf{1 9} & \mathbf{4 5 . 1 7} & 0.28 & \mathbf{4 6} & \\ \mathbf{2 0} & \mathbf{4 6 . 8 9} & 0.28 & \mathbf{4 7} \\ \mathbf{2 1} & \mathbf{4 7 . 0 6} & 0.33 & \mathbf{4 8} & \\ \mathbf{2 2} & & & \mathbf{4 9} \\ \mathbf{2 3} & & & \mathbf{5 0} \\ \mathbf{2 4} & & & \mathbf{5 1} \\ \mathbf{2 5} & & & \mathbf{5 2} \\ \mathbf{2 6} & & & \mathbf{5 3} \\ \mathbf{2 7} & & & \mathbf{5 4} & \end{array}$




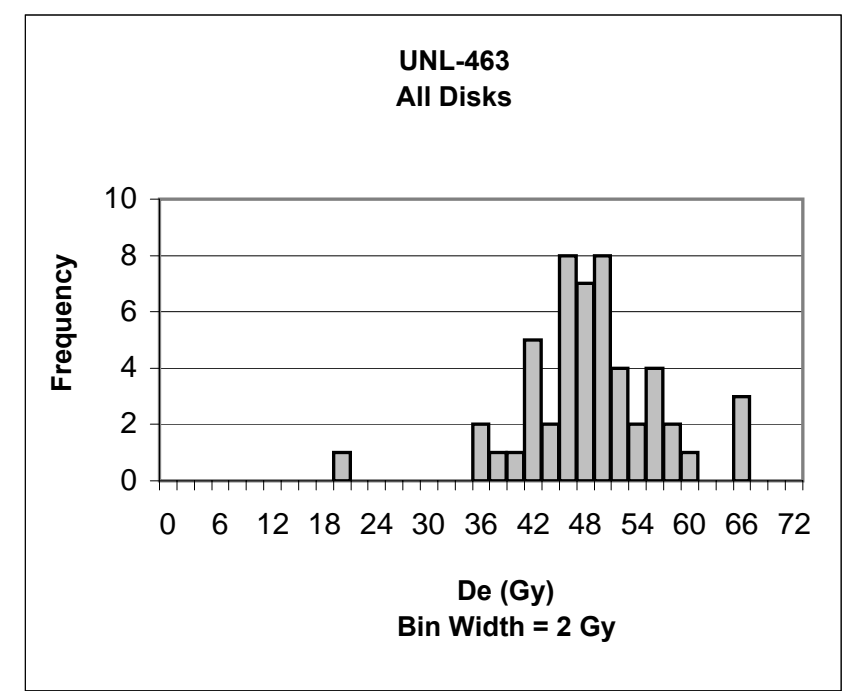

All Disks $\quad$ De (Gy)

$\begin{array}{lclc}\text { Mean }= & \mathbf{4 7 . 6 9} & \text { S.D. }(\mathbf{1 \sigma})= & 7.87 \\ \text { Median }= & 47.23 & \text { Std. Err }= & 1.10 \\ \text { Min }= & 19.91 & \text { Disks }(\mathbf{n})= & 51 \\ \text { Max }= & 65.17 & & \end{array}$

$\begin{array}{cccccc}\text { Disk } & \text { De } & \text { Err } & \text { Disc } & \text { De } & \text { Err } \\ \mathbf{1} & 46.19 & 1.07 & \mathbf{2 8} & 44.53 & 3.36 \\ \mathbf{2} & 54.45 & 1.58 & \mathbf{2 9} & 48.55 & 3.86 \\ \mathbf{3} & 50.87 & 0.47 & \mathbf{3 0} & 43.57 & 4.32 \\ \mathbf{4} & 64.76 & 9.03 & \mathbf{3 1} & 47.15 & 2.60 \\ \mathbf{5} & 48.95 & 0.25 & \mathbf{3 2} & 47.23 & 0.18 \\ \mathbf{6} & 49.67 & 3.90 & \mathbf{3 3} & 46.58 & 2.25 \\ \mathbf{7} & 44.29 & 1.36 & \mathbf{3 4} & 41.09 & 1.88 \\ \mathbf{8} & 44.72 & 3.15 & \mathbf{3 5} & 65.17 & 39.97 \\ \mathbf{9} & 50.29 & 1.73 & \mathbf{3 6} & 40.11 & 3.10 \\ \mathbf{1 0} & 56.69 & 0.52 & \mathbf{3 7} & 48.14 & 3.45 \\ \mathbf{1 1} & 55.66 & 9.37 & \mathbf{3 8} & 35.53 & 3.38 \\ \mathbf{1 2} & 50.88 & 1.99 & \mathbf{3 9} & 54.46 & 5.95 \\ \mathbf{1 3} & 50.77 & 0.60 & \mathbf{4 0} & 35.34 & 0.48 \\ \mathbf{1 4} & 53.71 & 0.30 & \mathbf{4 1} & 44.32 & 4.39 \\ \mathbf{1 5} & 46.38 & 2.94 & \mathbf{4 2} & 49.01 & 2.70 \\ \mathbf{1 6} & 42.23 & 0.32 & \mathbf{4 3} & 48.35 & 0.89 \\ \mathbf{1 7} & 48.63 & 1.86 & \mathbf{4 4} & 45.14 & 2.07 \\ \mathbf{1 8} & 19.91 & 0.81 & \mathbf{4 5} & 46.06 & 1.69 \\ \mathbf{1 9} & 52.72 & 0.48 & \mathbf{4 6} & 57.28 & 0.72 \\ \mathbf{2 0} & 41.44 & 0.40 & \mathbf{4 7} & 45.24 & 4.08 \\ \mathbf{2 1} & 38.72 & 1.55 & \mathbf{4 8} & 37.98 & 0.82 \\ \mathbf{2 2} & 45.86 & 0.41 & \mathbf{4 9} & 41.05 & 0.67 \\ \mathbf{2 3} & 45.65 & 0.67 & \mathbf{5 0} & 49.05 & 0.49 \\ \mathbf{2 4} & 41.25 & 0.96 & \mathbf{5 1} & 47.69 & 2.02 \\ \mathbf{2 5} & 64.86 & 1.15 & \mathbf{5 2} & & \\ \mathbf{2 6} & 58.76 & 2.82 & \mathbf{5 3} & & \\ \mathbf{2 7} & 55.42 & 4.89 & \mathbf{5 4} & & \\ & & & & & \end{array}$

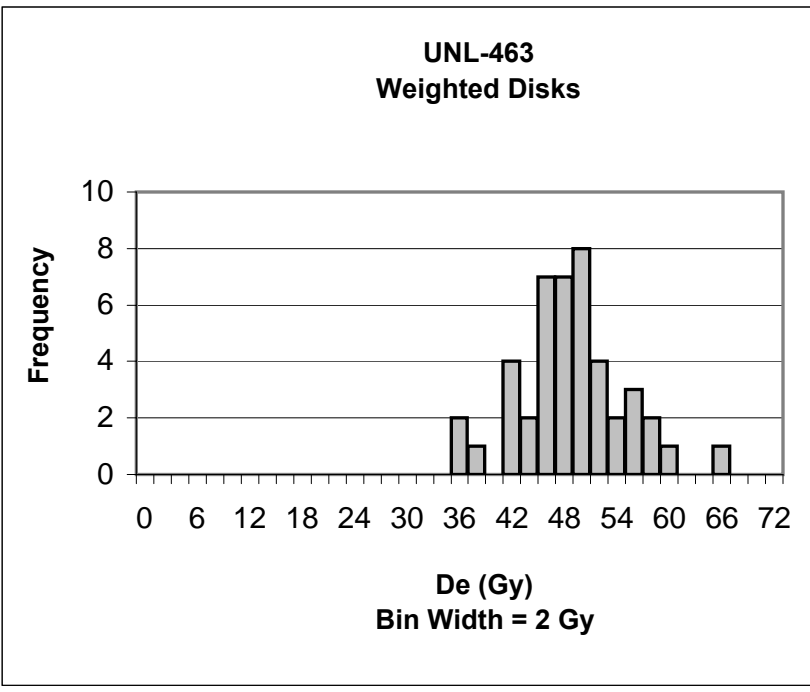

\section{Weighted Disks}

$\begin{array}{lc}\text { Mean }= & \mathbf{D e}(\mathrm{Gy}) \\ \text { Median }= & 47.46 \\ \text { Min }= & 35.34 \\ \text { Max }= & 65.17\end{array}$

S.D. $(1 \sigma)=\quad 6.01$ Std. Err $=\quad 0.91$

Disks $(n)=44$

\begin{tabular}{|c|c|c|c|c|c|}
\hline Disk & De & Err & Disc & De & Err \\
\hline 1 & 46.19 & 1.07 & 28 & 46.58 & 2.25 \\
\hline 2 & 54.45 & 1.58 & 29 & 41.09 & 1.88 \\
\hline 3 & 50.87 & 0.47 & 30 & 65.17 & 39.97 \\
\hline 4 & 48.95 & 0.25 & 31 & 40.11 & 3.10 \\
\hline 5 & 49.67 & 3.90 & 32 & 48.14 & 3.45 \\
\hline 6 & 44.29 & 1.36 & 33 & 35.53 & 3.38 \\
\hline 7 & 44.72 & 3.15 & 34 & 54.46 & 5.95 \\
\hline 8 & 50.29 & 1.73 & 35 & 35.34 & 0.48 \\
\hline 9 & 56.69 & 0.52 & 36 & 44.32 & 4.39 \\
\hline 10 & 55.66 & 9.37 & 37 & 49.01 & 2.70 \\
\hline 11 & 50.88 & 1.99 & 38 & 48.35 & 0.89 \\
\hline 12 & 50.77 & 0.60 & 39 & 45.14 & 2.07 \\
\hline 13 & 53.71 & 0.30 & 40 & 46.06 & 1.69 \\
\hline 14 & 46.38 & 2.94 & 41 & 57.28 & 0.72 \\
\hline 15 & 42.23 & 0.32 & 42 & 37.98 & 0.82 \\
\hline 16 & 48.63 & 1.86 & 43 & 49.05 & 0.49 \\
\hline 17 & 52.72 & 0.48 & 44 & 47.69 & 2.02 \\
\hline 18 & 41.44 & 0.40 & 45 & & \\
\hline 19 & 45.86 & 0.41 & 46 & & \\
\hline 20 & 45.65 & 0.67 & 47 & & \\
\hline 21 & 41.25 & 0.96 & 48 & & \\
\hline 22 & 58.76 & 2.82 & 49 & & \\
\hline 23 & 44.53 & 3.36 & 50 & & \\
\hline 24 & 48.55 & 3.86 & 51 & & \\
\hline 25 & 43.57 & 4.32 & 52 & & \\
\hline 26 & 47.15 & 2.60 & 53 & & \\
\hline 27 & 47.23 & 0.18 & 54 & & \\
\hline
\end{tabular}




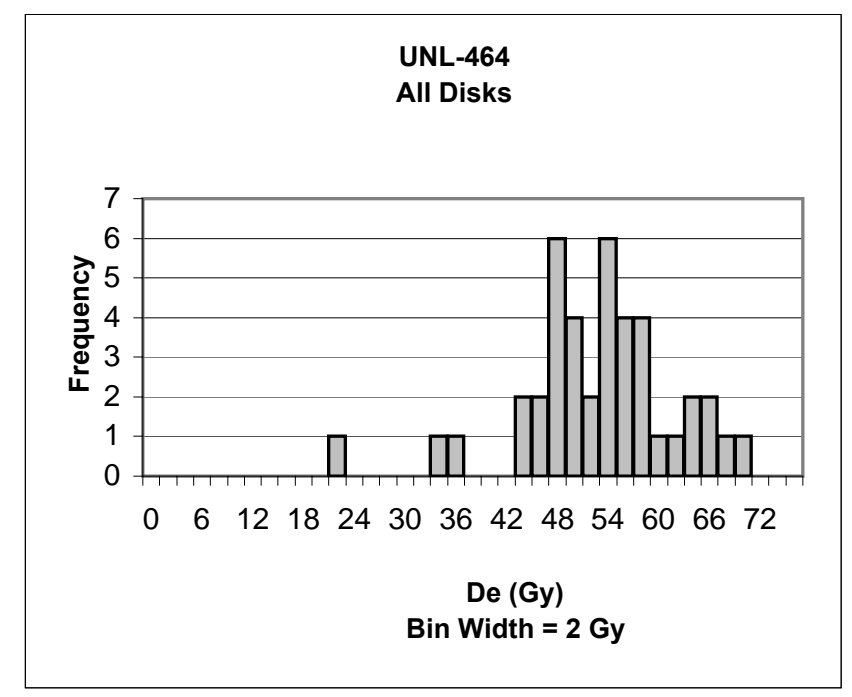

$\begin{array}{lcll}\text { All Disks } & & & \\ & \text { De (Gy) } & & \\ \text { Mean }= & \mathbf{5 1 . 7 6} & \text { S.D. }(\mathbf{1} \boldsymbol{\sigma})= & 9.31 \\ \text { Median }= & 52.41 & \text { Std. Err }= & 1.45 \\ \text { Min }= & 20.65 & \text { Disks }(\mathbf{n})= & 41 \\ \text { Max }= & 69.72 & & \end{array}$

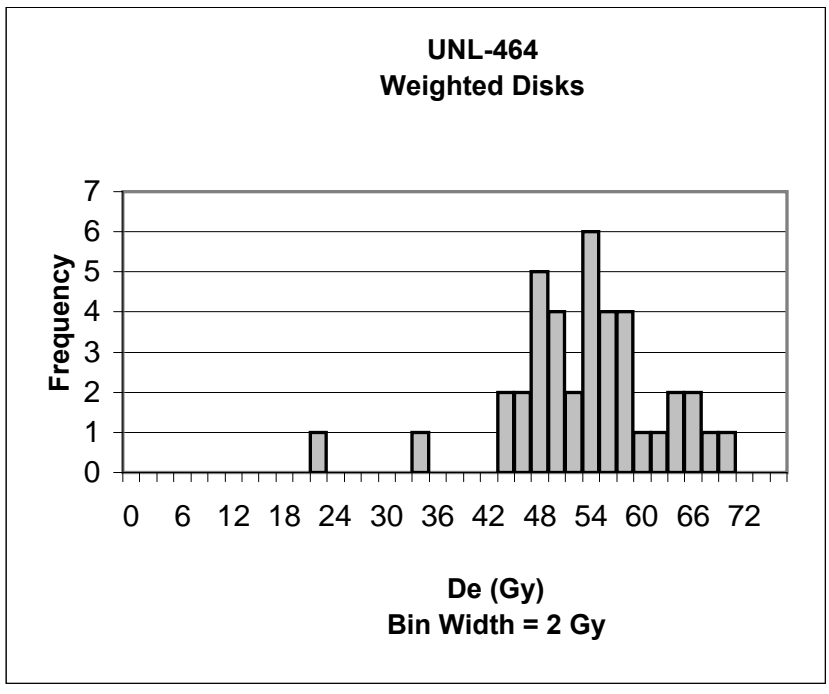

\section{Weighted Disks} De (Gy)

Mean $=\quad \mathbf{5 2 . 3 4}$ Median $=\quad 52.63$ Min $=\quad 20.65$ Max $=\quad 69.72$

$\begin{array}{lc}\text { S.D. }(\mathbf{1} \boldsymbol{\sigma})= & 9.08 \\ \text { Std. } \text { Err }= & 1.45 \\ \text { Disks }(\mathbf{n})= & 39\end{array}$

\begin{tabular}{|c|c|c|c|c|c|c|c|c|c|c|c|}
\hline Disk & De & Err & Disc & De & Err & Disk & $\mathrm{De}$ & Err & Disc & De & Err \\
\hline 1 & 63.92 & 1.35 & 28 & 57.32 & 1.46 & 1 & 63.92 & 1.35 & 28 & 50.55 & 1.24 \\
\hline 2 & 64.01 & 1.91 & 29 & 54.27 & 2.04 & 2 & 64.01 & 1.91 & 29 & 56.14 & 0.72 \\
\hline 3 & 57.20 & 0.95 & 30 & 50.55 & 1.24 & 3 & 57.20 & 0.95 & 30 & 52.23 & 1.16 \\
\hline 4 & 43.84 & 37.93 & 31 & 56.14 & 0.72 & 4 & 43.84 & 37.93 & 31 & 53.60 & 1.27 \\
\hline 5 & 46.19 & 3.13 & 32 & 52.23 & 1.16 & 5 & 51.39 & 3.09 & 32 & 69.72 & 0.76 \\
\hline 6 & 51.39 & 3.09 & 33 & 53.60 & 1.27 & 6 & 61.91 & 1.36 & 33 & 58.75 & 1.02 \\
\hline 7 & 61.91 & 1.36 & 34 & 69.72 & 0.76 & 7 & 62.63 & 1.45 & 34 & 47.80 & 3.26 \\
\hline 8 & 62.63 & 1.45 & 35 & 58.75 & 1.02 & 8 & 65.37 & 1.24 & 35 & 49.31 & 1.64 \\
\hline 9 & 65.37 & 1.24 & 36 & 47.80 & 3.26 & 9 & 53.94 & 1.05 & 36 & 52.78 & 1.45 \\
\hline 10 & 53.94 & 1.05 & 37 & 49.31 & 1.64 & 10 & 54.27 & 6.35 & 37 & 55.18 & 1.08 \\
\hline 11 & 54.27 & 6.35 & 38 & 52.78 & 1.45 & 11 & 48.52 & 1.26 & 38 & 52.63 & 2.86 \\
\hline 12 & 48.52 & 1.26 & 39 & 55.18 & 1.08 & 12 & 44.74 & 2.64 & 39 & 66.60 & 2.58 \\
\hline 13 & 44.74 & 2.64 & 40 & 52.63 & 2.86 & 13 & 20.65 & 1.70 & 40 & & \\
\hline 14 & 20.65 & 1.70 & 41 & 66.60 & 2.58 & 14 & 47.74 & 4.18 & 41 & & \\
\hline 15 & 47.74 & 4.18 & 42 & & & 15 & 33.80 & 1.69 & 42 & & \\
\hline 16 & 33.80 & 1.69 & 43 & & & 16 & 48.16 & 2.23 & 43 & & \\
\hline 17 & 48.16 & 2.23 & 44 & & & 17 & 46.82 & 1.92 & 44 & & \\
\hline 18 & 46.82 & 1.92 & 45 & & & 18 & 45.48 & 3.70 & 45 & & \\
\hline 19 & 45.48 & 3.70 & 46 & & & 19 & 46.24 & 3.25 & 46 & & \\
\hline 20 & 46.24 & 3.25 & 47 & & & 20 & 42.87 & 2.78 & 47 & & \\
\hline 21 & 34.75 & 31.62 & 48 & & & 21 & 46.68 & 1.42 & 48 & & \\
\hline 22 & 42.87 & 2.78 & 49 & & & 22 & 52.41 & 2.90 & 49 & & \\
\hline 23 & 46.68 & 1.42 & 50 & & & 23 & 48.03 & 2.66 & 50 & & \\
\hline 24 & 52.41 & 2.90 & 51 & & & 24 & 55.97 & 1.46 & 51 & & \\
\hline 25 & 48.03 & 2.66 & 52 & & & 25 & 57.92 & 1.58 & 52 & & \\
\hline 26 & 55.97 & 1.46 & 53 & & & 26 & 57.32 & 1.46 & 53 & & \\
\hline 27 & 57.92 & 1.58 & 54 & & & 27 & 54.27 & 2.04 & 54 & & \\
\hline
\end{tabular}




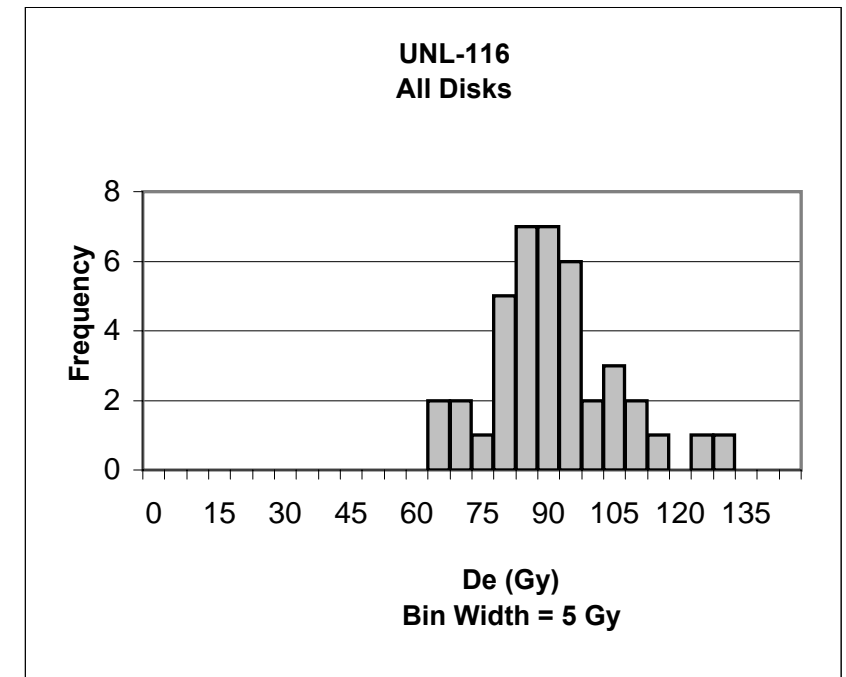

$\begin{array}{lclc}\text { All Disks } & & & \\ & \text { De (Gy) } & & \\ \text { Mean = } & \mathbf{8 8 . 8 7} & \text { S.D. (1 } \boldsymbol{\sigma})= & 14.70 \\ \text { Median }= & 86.95 & \text { Std. Err }= & 2.32 \\ \text { Min }= & 63.40 & \text { Disks }(\mathbf{n})= & 40 \\ \text { Max }= & 125.10 & & \end{array}$

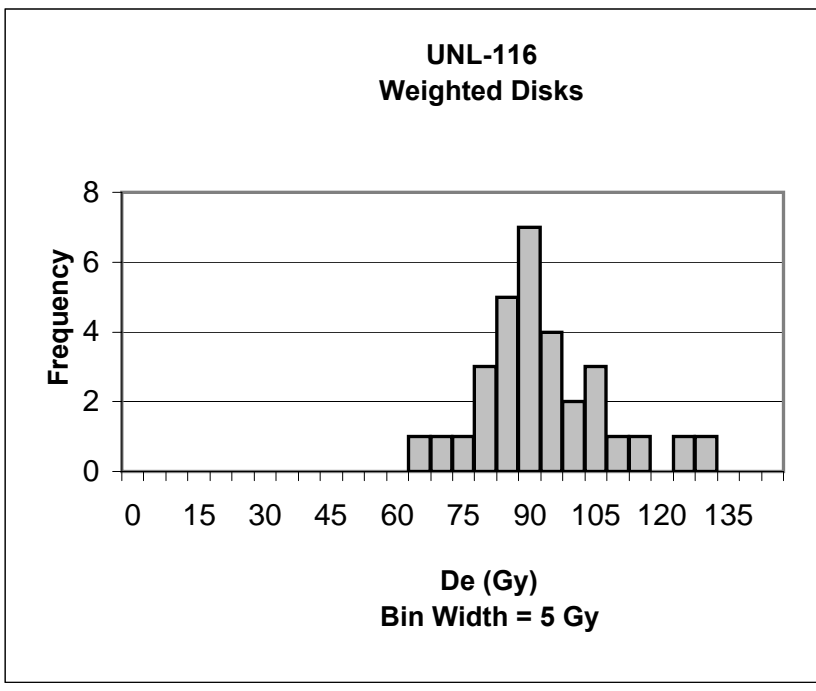

Weighted Disks De (Gy)

$\begin{array}{lllc}\text { Mean }= & \mathbf{9 0 . 6 3} & \text { S.D. }(\mathbf{1} \boldsymbol{\sigma})= & 14.66 \\ \text { Median }= & 88.14 & \text { Std. } \text { Err }= & 2.63 \\ \text { Min }= & 64.46 & \text { Disks }(\mathbf{n})= & 31\end{array}$

Max $=\quad 125.10$

$\begin{array}{cccccc}\text { Disk } & \text { De } & \text { Err } & \text { Disc } & \text { De } & \text { Err } \\ \mathbf{1} & 108.31 & 14.80 & \mathbf{2 8} & 71.97 & 6.87 \\ \mathbf{2} & 94.87 & 9.98 & \mathbf{2 9} & 86.26 & 7.41 \\ \mathbf{3} & 87.14 & 1.81 & \mathbf{3 0} & 84.85 & 3.98 \\ \mathbf{4} & 75.83 & 6.84 & \mathbf{3 1} & 83.57 & 9.31 \\ \mathbf{5} & 92.55 & 16.95 & \mathbf{3 2} & & \\ \mathbf{6} & 82.92 & 2.29 & \mathbf{3 3} & & \\ \mathbf{7} & 90.07 & 7.22 & \mathbf{3 4} & & \\ \mathbf{8} & 78.04 & 11.29 & \mathbf{3 5} & & \\ \mathbf{9} & 104.49 & 7.51 & \mathbf{3 6} & & \\ \mathbf{1 0} & 125.10 & 2.10 & \mathbf{3 7} & & \\ \mathbf{1 1} & 95.52 & 3.16 & \mathbf{3 8} & & \\ \mathbf{1 2} & 122.71 & 6.27 & \mathbf{3 9} & & \\ \mathbf{1 3} & 98.09 & 9.21 & \mathbf{4 0} & & \\ \mathbf{1 4} & 114.79 & 3.25 & \mathbf{4 1} & & \\ \mathbf{1 5} & 83.88 & 6.60 & \mathbf{4 2} & & \\ \mathbf{1 6} & 104.32 & 6.36 & \mathbf{4 3} & & \\ \mathbf{1 7} & 104.89 & 5.06 & \mathbf{4 4} & & \\ \mathbf{1 8} & 94.51 & 6.79 & \mathbf{4 5} & & \\ \mathbf{1 9} & 85.63 & 6.66 & \mathbf{4 6} & & \\ \mathbf{2 0} & 88.14 & 25.58 & \mathbf{4 7} & & \\ \mathbf{2 1} & 75.09 & 10.87 & \mathbf{4 8} & & \\ \mathbf{2 2} & 81.74 & 7.85 & \mathbf{4 9} & & \\ \mathbf{2 3} & 64.46 & 4.23 & \mathbf{5 0} & & \\ \mathbf{2 4} & 88.33 & 27.03 & \mathbf{5 1} & & \\ \mathbf{2 5} & 86.77 & 6.80 & \mathbf{5 2} & & \\ \mathbf{2 6} & 89.10 & 9.89 & \mathbf{5 3} & & \\ \mathbf{2 7} & 65.45 & 2.13 & \mathbf{5 4} & & \end{array}$




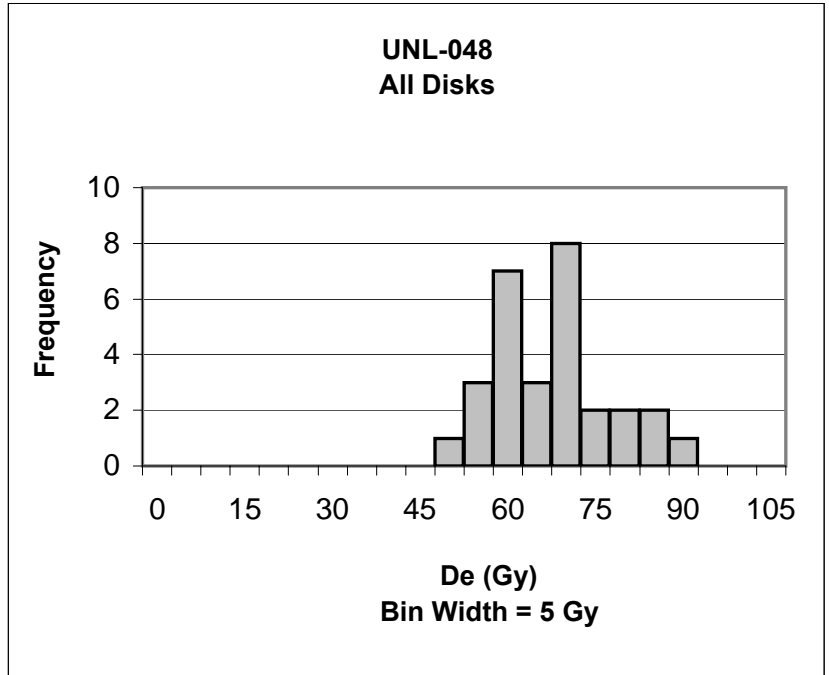

$\begin{array}{lcll}\text { All Disks } & & & \\ & \text { De (Gy) } & & \\ \text { Mean }= & \mathbf{6 5 . 2 4} & \text { S.D. }(\mathbf{1} \sigma)= & 10.16 \\ \text { Median }= & 65.42 & \text { Std. Err }= & 1.89 \\ \text { Min }= & 48.04 & \text { Disks }(\mathbf{n})= & 29 \\ \text { Max }= & 89.14 & & \end{array}$

\begin{tabular}{|c|c|c|c|c|c|}
\hline Disk & $\mathrm{De}$ & Err & Disc & $\mathrm{De}$ & Err \\
\hline 1 & 52.24 & 1.28 & 28 & 69.26 & 0.68 \\
\hline 2 & 58.46 & 1.68 & 29 & 80.38 & 1.09 \\
\hline 3 & 57.26 & 3.73 & 30 & & \\
\hline 4 & 69.60 & 0.87 & 31 & & \\
\hline 5 & 73.87 & 0.92 & 32 & & \\
\hline 6 & 68.40 & 1.15 & 33 & & \\
\hline 7 & 75.89 & 3.25 & 34 & & \\
\hline 8 & 63.66 & 0.55 & 35 & & \\
\hline 9 & 84.78 & 4.54 & 36 & & \\
\hline 10 & 78.74 & 3.04 & 37 & & \\
\hline 11 & 59.12 & 3.05 & 38 & & \\
\hline 12 & 67.98 & 3.12 & 39 & & \\
\hline 13 & 89.14 & 2.45 & 40 & & \\
\hline 14 & 65.42 & 3.02 & 41 & & \\
\hline 15 & 48.04 & 3.74 & 42 & & \\
\hline 16 & 69.26 & 4.50 & 43 & & \\
\hline 17 & 55.43 & 0.97 & 44 & & \\
\hline 18 & 59.46 & 4.25 & 45 & & \\
\hline 19 & 51.73 & 0.44 & 46 & & \\
\hline 20 & 71.07 & 0.89 & 47 & & \\
\hline 21 & 60.10 & 0.97 & 48 & & \\
\hline 22 & 65.42 & 0.63 & 49 & & \\
\hline 23 & 62.74 & 0.09 & 50 & & \\
\hline 24 & 51.27 & 3.00 & 51 & & \\
\hline 25 & 65.46 & 2.42 & 52 & & \\
\hline 26 & 58.20 & 1.98 & 53 & & \\
\hline 27 & 59.65 & 2.90 & 54 & & \\
\hline
\end{tabular}

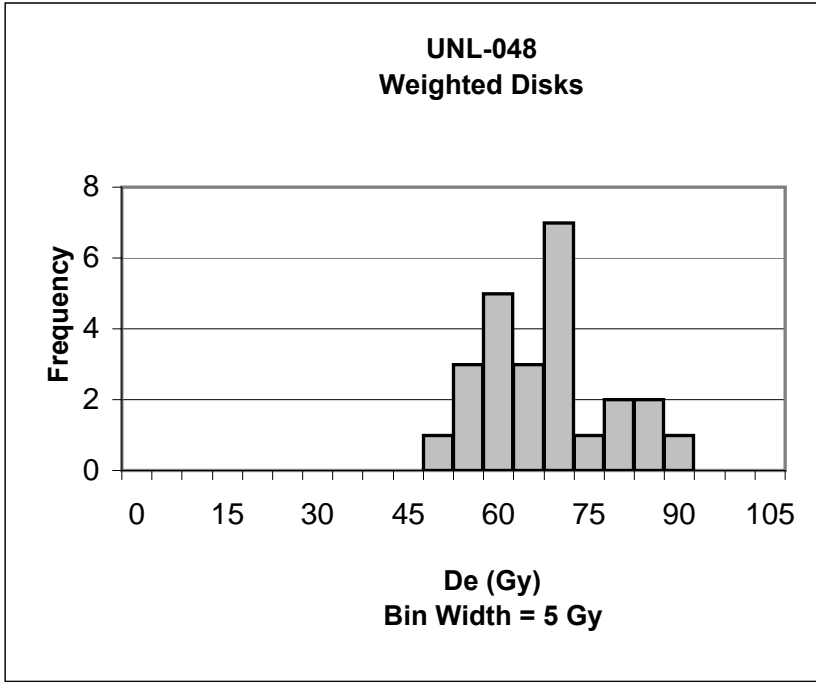

Weighted Disks De (Gy)

Mean $=\quad 65.52$

Median $=\quad 65.42$

Min $=\quad 48.04$

Max $=\quad 89.14$
UNL-048

Weighted Disks

$\begin{array}{ccccc}\text { Disk } & \text { De } & \text { Err } & \text { Disc } & \text { De } \\ \mathbf{1} & 52.24 & 1.28 & \mathbf{2 8} \\ \mathbf{2} & 58.46 & 1.68 & \mathbf{2 9} \\ \mathbf{3} & 57.26 & 3.73 & \mathbf{3 0} \\ \mathbf{4} & 69.60 & 0.87 & \mathbf{3 1} \\ \mathbf{5} & 73.87 & 0.92 & \mathbf{3 2} \\ \mathbf{6} & 68.40 & 1.15 & \mathbf{3 3} \\ \mathbf{7} & 75.89 & 3.25 & \mathbf{3 4} \\ \mathbf{8} & 63.66 & 0.55 & \mathbf{3 5} \\ \mathbf{9} & 84.78 & 4.54 & \mathbf{3 6} \\ \mathbf{1 0} & 78.74 & 3.04 & \mathbf{3 7} \\ \mathbf{1 1} & 59.12 & 3.05 & \mathbf{3 8} \\ \mathbf{1 2} & 89.14 & 2.45 & \mathbf{3 9} \\ \mathbf{1 3} & 65.42 & 3.02 & \mathbf{4 0} \\ \mathbf{1 4} & 48.04 & 3.74 & \mathbf{4 1} \\ \mathbf{1 5} & 69.26 & 4.50 & \mathbf{4 2} \\ \mathbf{1 6} & 51.73 & 0.44 & \mathbf{4 3} \\ \mathbf{1 7} & 60.10 & 0.97 & \mathbf{4 4} \\ \mathbf{1 8} & 65.42 & 0.63 & \mathbf{4 5} \\ \mathbf{1 9} & 62.74 & 0.09 & \mathbf{4 6} \\ \mathbf{2 0} & 51.27 & 3.00 & \mathbf{4 7} \\ \mathbf{2 1} & 65.46 & 2.42 & \mathbf{4 8} \\ \mathbf{2 2} & 58.20 & 1.98 & \mathbf{4 9} \\ \mathbf{2 3} & 59.65 & 2.90 & \mathbf{5 0} \\ \mathbf{2 4} & 69.26 & 0.68 & \mathbf{5 1} \\ \mathbf{2 5} & 80.38 & 1.09 & \mathbf{5 2} \\ \mathbf{2 6} & & & \mathbf{5 3} \\ \mathbf{2 7} & & & \mathbf{5 4}\end{array}$




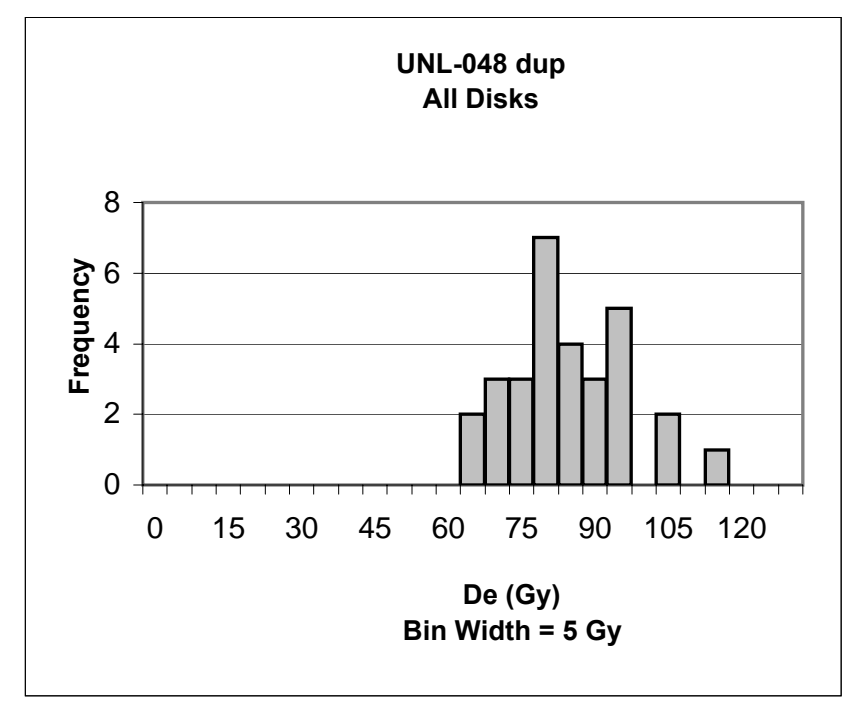

$\begin{array}{lcll}\text { All Disks } & & & \\ & \text { De }(\text { Gy) } & & \\ \text { Mean }= & \mathbf{8 2 . 2 7} & \text { S.D. }(\mathbf{1 \sigma})= & 11.90 \\ \text { Median }= & 80.37 & \text { Std. Err }= & 2.17 \\ \text { Min }= & 62.65 & \text { Disks }(\mathbf{n})= & 30 \\ \text { Max }= & 112.25 & & \end{array}$

\begin{tabular}{|c|c|c|c|c|c|}
\hline Disk & $\mathrm{De}$ & Err & Disc & $\mathrm{De}$ & Err \\
\hline 1 & 74.83 & 5.90 & 28 & 80.94 & 4.20 \\
\hline 2 & 62.65 & 5.89 & 29 & 72.58 & 1.65 \\
\hline 3 & 79.80 & 1.02 & 30 & 86.17 & 3.66 \\
\hline 4 & 69.76 & 7.80 & 31 & & \\
\hline 5 & 64.75 & 5.56 & 32 & & \\
\hline 6 & 94.74 & 5.58 & 33 & & \\
\hline 7 & 76.37 & 5.62 & 34 & & \\
\hline 8 & 72.59 & 3.01 & 35 & & \\
\hline 9 & 76.74 & 8.16 & 36 & & \\
\hline 10 & 81.73 & 6.87 & 37 & & \\
\hline 11 & 94.70 & 5.43 & 38 & & \\
\hline 12 & 79.64 & 16.37 & 39 & & \\
\hline 13 & 94.03 & 3.37 & 40 & & \\
\hline 14 & 89.08 & 14.47 & 41 & & \\
\hline 15 & 91.75 & 7.85 & 42 & & \\
\hline 16 & 67.84 & 5.43 & 43 & & \\
\hline 17 & 101.06 & 3.84 & 44 & & \\
\hline 18 & 79.28 & 2.43 & 45 & & \\
\hline 19 & 76.42 & 7.11 & 46 & & \\
\hline 20 & 87.24 & 3.85 & 47 & & \\
\hline 21 & 82.80 & 7.16 & 48 & & \\
\hline 22 & 65.21 & 4.18 & 49 & & \\
\hline 23 & 102.33 & 5.14 & 50 & & \\
\hline 24 & 112.25 & 1.09 & 51 & & \\
\hline 25 & 91.23 & 3.50 & 52 & & \\
\hline 26 & 76.35 & 2.35 & 53 & & \\
\hline 27 & 83.32 & 8.59 & 54 & & \\
\hline
\end{tabular}

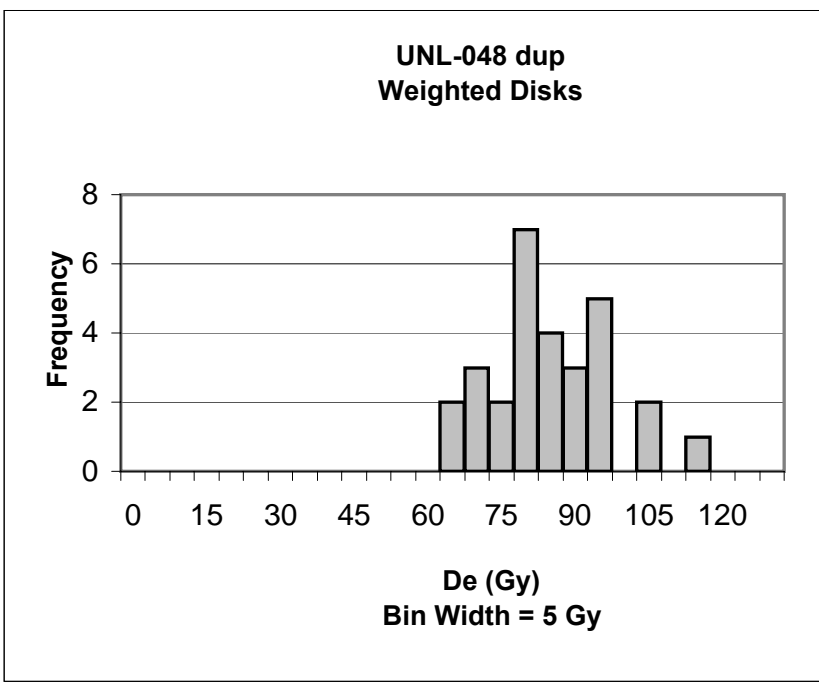

Weighted Disks

De (Gy)

Mean $=\quad \mathbf{8 2 . 6 1}$

Median $=\quad 80.94$

Min $=\quad 62.65$

Max $=\quad 112.25$

$\begin{array}{cccccc}\text { Disk } & \text { De } & \text { Err } & \text { Disc } & \text { De } & \text { Err } \\ \mathbf{1} & 74.83 & 5.90 & \mathbf{2 8} & 80.94 & 4.20 \\ \mathbf{2} & 62.65 & 5.89 & \mathbf{2 9} & 86.17 & 3.66 \\ \mathbf{3} & 79.80 & 1.02 & \mathbf{3 0} & & \\ \mathbf{4} & 69.76 & 7.80 & \mathbf{3 1} & & \\ \mathbf{5} & 64.75 & 5.56 & \mathbf{3 2} & & \\ \mathbf{6} & 94.74 & 5.58 & \mathbf{3 3} & & \\ \mathbf{7} & 76.37 & 5.62 & \mathbf{3 4} & & \\ \mathbf{8} & 72.59 & 3.01 & \mathbf{3 5} & & \\ \mathbf{9} & 76.74 & 8.16 & \mathbf{3 6} & & \\ \mathbf{1 0} & 81.73 & 6.87 & \mathbf{3 7} & & \\ \mathbf{1 1} & 94.70 & 5.43 & \mathbf{3 8} & & \\ \mathbf{1 2} & 79.64 & 16.37 & \mathbf{3 9} & & \\ \mathbf{1 3} & 94.03 & 3.37 & \mathbf{4 0} & & \\ \mathbf{1 4} & 89.08 & 14.47 & \mathbf{4 1} & & \\ \mathbf{1 5} & 91.75 & 7.85 & \mathbf{4 2} & & \\ \mathbf{1 6} & 67.84 & 5.43 & \mathbf{4 3} & & \\ \mathbf{1 7} & 101.06 & 3.84 & \mathbf{4 4} & & \\ \mathbf{1 8} & 79.28 & 2.43 & \mathbf{4 5} & & \\ \mathbf{1 9} & 76.42 & 7.11 & \mathbf{4 6} & & \\ \mathbf{2 0} & 87.24 & 3.85 & \mathbf{4 7} & \\ \mathbf{2 1} & 82.80 & 7.16 & \mathbf{4 8} & \\ \mathbf{2 2} & 65.21 & 4.18 & \mathbf{4 9} & \\ \mathbf{2 3} & 102.33 & 5.14 & \mathbf{5 0} & \\ \mathbf{2 4} & 112.25 & 1.09 & \mathbf{5 1} & \\ \mathbf{2 5} & 91.23 & 3.50 & \mathbf{5 2} & \\ \mathbf{2 6} & 76.35 & 2.35 & \mathbf{5 3} & \\ \mathbf{2 7} & 83.32 & 8.59 & \mathbf{5 4} & & \end{array}$

S.D. $(1 \sigma)=11.97$

Std. Err $=2.22$

Disks $(\mathbf{n})=29$ 


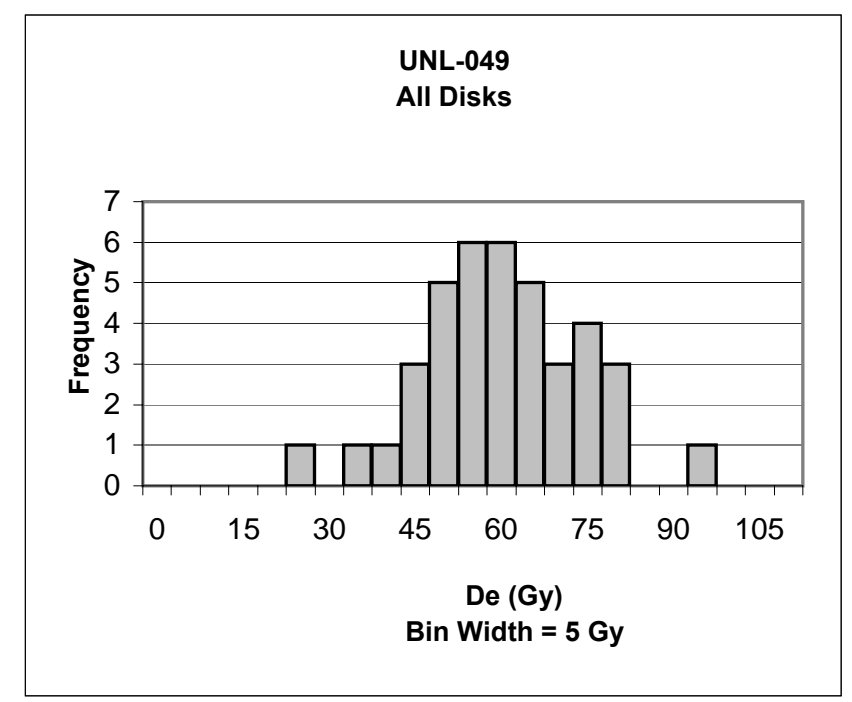

$\begin{array}{lclc}\text { All Disks } & & & \\ & \text { De (Gy) } & & \\ \text { Mean }= & \mathbf{5 7 . 6 2} & \text { S.D. }(\mathbf{1 \sigma})= & 13.57 \\ \text { Median }= & 57.23 & \text { Std. Err }= & 2.17 \\ \text { Min }= & 22.51 & \text { Disks }(\mathbf{n})= & 39 \\ \text { Max }= & 91.79 & & \end{array}$

$\begin{array}{cccccc}\text { Disk } & \text { De } & \text { Err } & \text { Disc } & \text { De } & \text { Err } \\ \mathbf{1} & 64.39 & 19.33 & \mathbf{2 8} & 46.61 & 8.02 \\ \mathbf{2} & 66.75 & 4.73 & \mathbf{2 9} & 52.74 & 8.88 \\ \mathbf{3} & 76.86 & 6.26 & \mathbf{3 0} & 67.37 & 1.27 \\ \mathbf{4} & 46.68 & 4.21 & \mathbf{3 1} & 63.67 & 4.12 \\ \mathbf{5} & 73.13 & 10.93 & \mathbf{3 2} & 46.84 & 2.74 \\ \mathbf{6} & 58.45 & 12.41 & \mathbf{3 3} & 60.99 & 5.16 \\ \mathbf{7} & 61.32 & 1.39 & \mathbf{3 4} & 76.27 & 7.49 \\ \mathbf{8} & 42.93 & 12.07 & \mathbf{3 5} & 57.23 & 1.76 \\ \mathbf{9} & 57.46 & 15.74 & \mathbf{3 6} & 65.34 & 2.15 \\ \mathbf{1 0} & 32.78 & 7.62 & \mathbf{3 7} & 48.47 & 4.16 \\ \mathbf{1 1} & 70.20 & 6.54 & \mathbf{3 8} & 22.51 & 0.61 \\ \mathbf{1 2} & 54.18 & 4.06 & \mathbf{3 9} & 63.69 & 4.74 \\ \mathbf{1 3} & 53.44 & 3.32 & \mathbf{4 0} & & \\ \mathbf{1 4} & 55.23 & 5.42 & \mathbf{4 1} & & \\ \mathbf{1 5} & 57.05 & 2.09 & \mathbf{4 2} & & \\ \mathbf{1 6} & 44.82 & 3.48 & \mathbf{4 3} & & \\ \mathbf{1 7} & 75.94 & 3.51 & \mathbf{4 4} & & \\ \mathbf{1 8} & 59.39 & 2.14 & \mathbf{4 5} & & \\ \mathbf{1 9} & 53.20 & 7.07 & \mathbf{4 6} & & \\ \mathbf{2 0} & 46.96 & 10.88 & \mathbf{4 7} & & \\ \mathbf{2 1} & 91.79 & 14.05 & \mathbf{4 8} & & \\ \mathbf{2 2} & 74.93 & 14.79 & \mathbf{4 9} & & \\ \mathbf{2 3} & 71.36 & 49.26 & \mathbf{5 0} & & \\ \mathbf{2 4} & 37.76 & 10.27 & \mathbf{5 1} & & \\ \mathbf{2 5} & 50.87 & 13.81 & \mathbf{5 2} & & \\ \mathbf{2 6} & 44.13 & 4.32 & \mathbf{5 3} & & \\ \mathbf{2 7} & 53.45 & 4.61 & \mathbf{5 4} & & \\ & & & & & \end{array}$

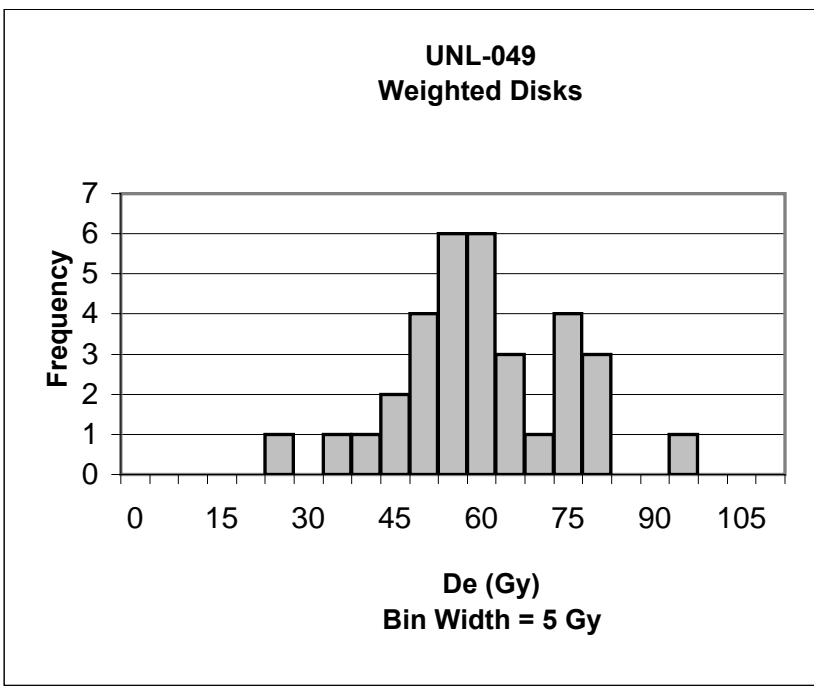

Weighted Disks

De (Gy)

Mean $=\quad 57.53$

Median $=\quad 57.05$

Min $=\quad 22.51$

Max $=\quad 91.79$
S.D. $(1 \sigma)=14.25$

Std. Err $=\quad 2.48$

$\operatorname{Disks}(\mathbf{n})=\quad 33$

\begin{tabular}{|c|c|c|c|c|c|}
\hline Disk & $\mathrm{De}$ & Err & Disc & De & Err \\
\hline 1 & 64.39 & 19.33 & 28 & 52.74 & 8.88 \\
\hline 2 & 66.75 & 4.73 & 29 & 63.67 & 4.12 \\
\hline 3 & 76.86 & 6.26 & 30 & 46.84 & 2.74 \\
\hline 4 & 46.68 & 4.21 & 31 & 76.27 & 7.49 \\
\hline 5 & 73.13 & 10.93 & 32 & 57.23 & 1.76 \\
\hline 6 & 58.45 & 12.41 & 33 & 22.51 & 0.61 \\
\hline 7 & 61.32 & 1.39 & 34 & & \\
\hline 8 & 57.46 & 15.74 & 35 & & \\
\hline 9 & 32.78 & 7.62 & 36 & & \\
\hline 10 & 70.20 & 6.54 & 37 & & \\
\hline 11 & 54.18 & 4.06 & 38 & & \\
\hline 12 & 53.44 & 3.32 & 39 & & \\
\hline 13 & 55.23 & 5.42 & 40 & & \\
\hline 14 & 57.05 & 2.09 & 41 & & \\
\hline 15 & 44.82 & 3.48 & 42 & & \\
\hline 16 & 75.94 & 3.51 & 43 & & \\
\hline 17 & 59.39 & 2.14 & 44 & & \\
\hline 18 & 53.20 & 7.07 & 45 & & \\
\hline 19 & 46.96 & 10.88 & 46 & & \\
\hline 20 & 91.79 & 14.05 & 47 & & \\
\hline 21 & 74.93 & 14.79 & 48 & & \\
\hline 22 & 71.36 & 49.26 & 49 & & \\
\hline 23 & 37.76 & 10.27 & 50 & & \\
\hline 24 & 50.87 & 13.81 & 51 & & \\
\hline 25 & 44.13 & 4.32 & 52 & & \\
\hline 26 & 53.45 & 4.61 & 53 & & \\
\hline 27 & 46.61 & 8.02 & 54 & & \\
\hline
\end{tabular}




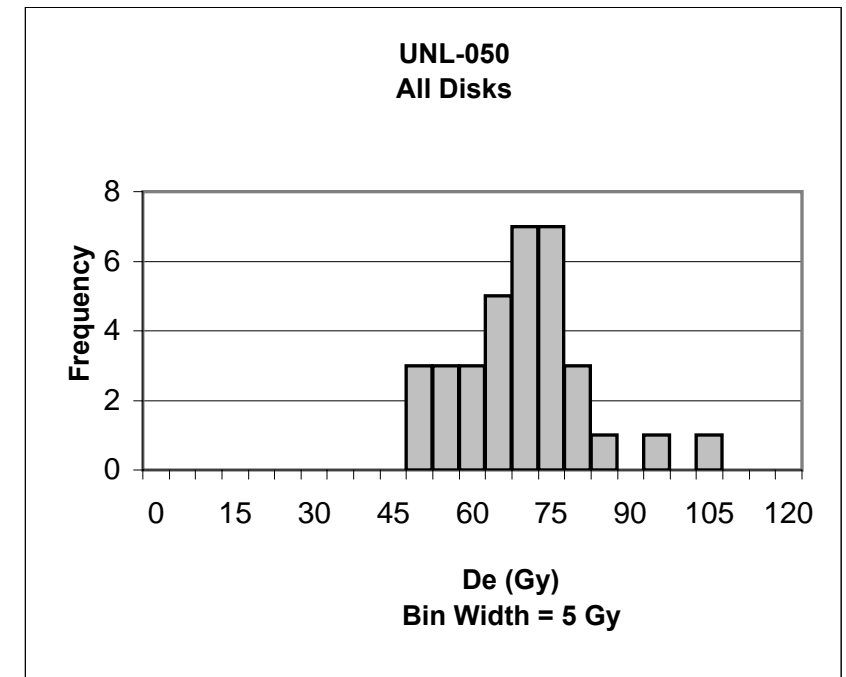

All Disks $\quad$ De (Gy)

$\begin{array}{lclc}\text { Mean }= & \mathbf{6 6 . 5 2} & \text { S.D. }(\mathbf{1} \boldsymbol{\sigma})= & 11.97 \\ \text { Median }= & 66.85 & \text { Std. Err }= & 2.05 \\ \text { Min }= & 46.15 & \text { Disks }(\mathbf{n})= & 34 \\ \text { Max }= & 101.58 & & \end{array}$

\begin{tabular}{|c|c|c|c|c|c|}
\hline Disk & $\mathrm{De}$ & Err & Disc & $\mathrm{De}$ & Err \\
\hline 1 & 62.44 & 5.15 & 28 & 76.57 & 2.38 \\
\hline 2 & 61.29 & 3.07 & 29 & 71.84 & 8.23 \\
\hline 3 & 70.06 & 6.22 & 30 & 54.04 & 4.58 \\
\hline 4 & 62.85 & 3.58 & 31 & 64.39 & 19.33 \\
\hline 5 & 46.15 & 10.37 & 32 & 66.75 & 4.73 \\
\hline 6 & 61.54 & 3.08 & 33 & 76.86 & 6.26 \\
\hline 7 & 101.58 & 2.03 & 34 & 46.68 & 4.21 \\
\hline 8 & 68.74 & 2.70 & 35 & & \\
\hline 9 & 69.54 & 5.25 & 36 & & \\
\hline 10 & 66.87 & 5.02 & 37 & & \\
\hline 11 & 57.95 & 3.80 & 38 & & \\
\hline 12 & 80.90 & 4.16 & 39 & & \\
\hline 13 & 72.04 & 9.16 & 40 & & \\
\hline 14 & 93.22 & 6.96 & 41 & & \\
\hline 15 & 50.43 & 5.09 & 42 & & \\
\hline 16 & 57.53 & 4.38 & 43 & & \\
\hline 17 & 72.23 & 6.01 & 44 & & \\
\hline 18 & 68.16 & 3.66 & 45 & & \\
\hline 19 & 50.52 & 2.00 & 46 & & \\
\hline 20 & 71.07 & 6.29 & 47 & & \\
\hline 21 & 66.02 & 5.04 & 48 & & \\
\hline 22 & 58.93 & 4.93 & 49 & & \\
\hline 23 & 48.96 & 4.58 & 50 & & \\
\hline 24 & 70.35 & 4.80 & 51 & & \\
\hline 25 & 66.82 & 7.71 & 52 & & \\
\hline 26 & 72.30 & 6.41 & 53 & & \\
\hline 27 & 76.21 & 6.47 & 54 & & \\
\hline
\end{tabular}

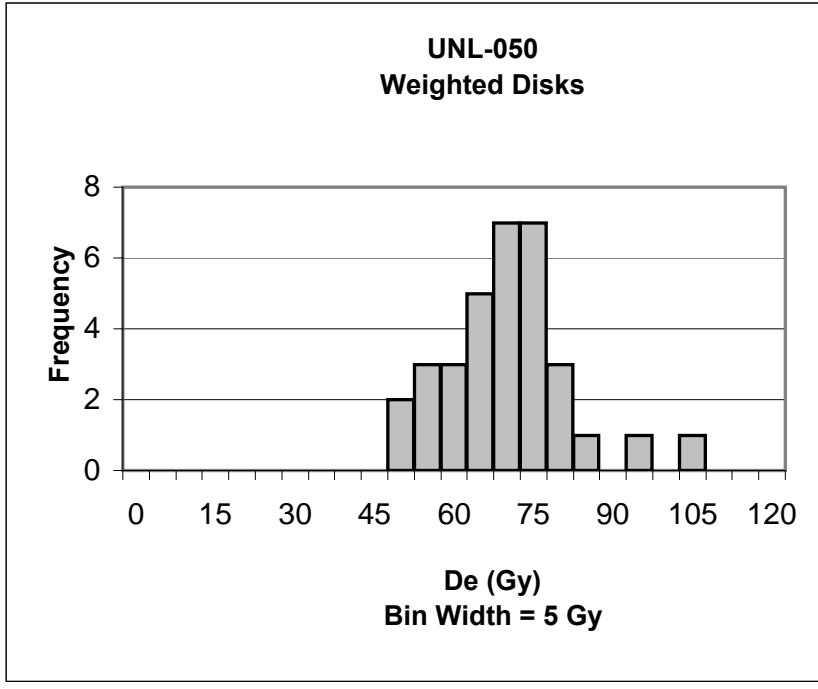

Weighted Disks

De (Gy)

Mean $=\quad 67.14$

Median $=\quad 66.87$

Min $=\quad 46.68$

Max $=\quad 101.58$
S.D. $(1 \sigma)=11.59$

Std. Err = 2.02

Disks $(\mathbf{n})=33$

\begin{tabular}{|c|c|c|c|c|c|}
\hline Disk & De & Err & Disc & De & Err \\
\hline 1 & 62.44 & 5.15 & 28 & 71.84 & 8.23 \\
\hline 2 & 61.29 & 3.07 & 29 & 54.04 & 4.58 \\
\hline 3 & 70.06 & 6.22 & 30 & 64.39 & 19.33 \\
\hline 4 & 62.85 & 3.58 & 31 & 66.75 & 4.73 \\
\hline 5 & 61.54 & 3.08 & 32 & 76.86 & 6.26 \\
\hline 6 & 101.58 & 2.03 & 33 & 46.68 & 4.21 \\
\hline 7 & 68.74 & 2.70 & 34 & & \\
\hline 8 & 69.54 & 5.25 & 35 & & \\
\hline 9 & 66.87 & 5.02 & 36 & & \\
\hline 10 & 57.95 & 3.80 & 37 & & \\
\hline 11 & 80.90 & 4.16 & 38 & & \\
\hline 12 & 72.04 & 9.16 & 39 & & \\
\hline 13 & 93.22 & 6.96 & 40 & & \\
\hline 14 & 50.43 & 5.09 & 41 & & \\
\hline 15 & 57.53 & 4.38 & 42 & & \\
\hline 16 & 72.23 & 6.01 & 43 & & \\
\hline 17 & 68.16 & 3.66 & 44 & & \\
\hline 18 & 50.52 & 2.00 & 45 & & \\
\hline 19 & 71.07 & 6.29 & 46 & & \\
\hline 20 & 66.02 & 5.04 & 47 & & \\
\hline 21 & 58.93 & 4.93 & 48 & & \\
\hline 22 & 48.96 & 4.58 & 49 & & \\
\hline 23 & 70.35 & 4.80 & 50 & & \\
\hline 24 & 66.82 & 7.71 & 51 & & \\
\hline 25 & 72.30 & 6.41 & 52 & & \\
\hline 26 & 76.21 & 6.47 & 53 & & \\
\hline 27 & 76.57 & 2.38 & 54 & & \\
\hline
\end{tabular}




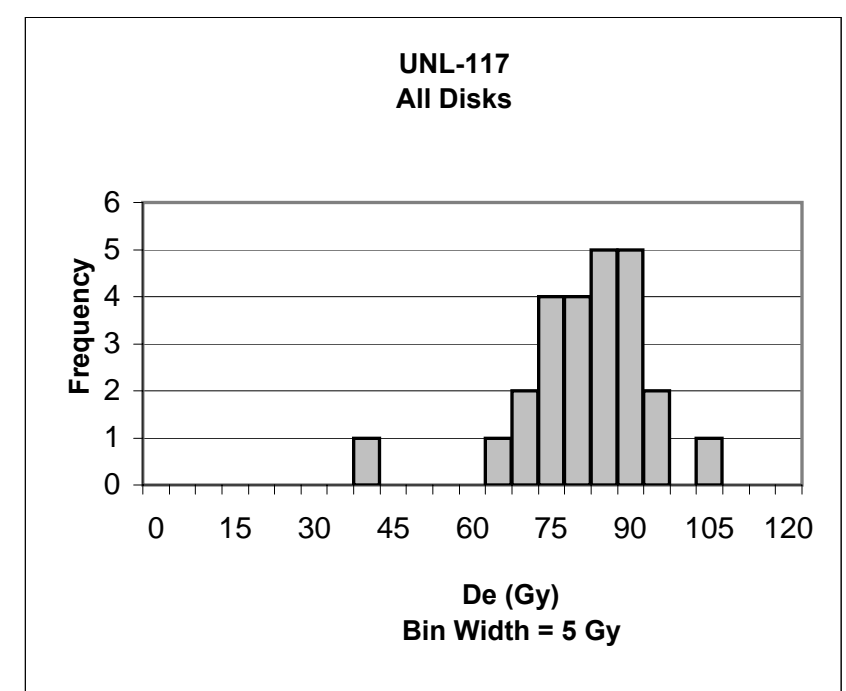

$\begin{array}{lcll}\text { All Disks } & & & \\ & \text { De (Gy) } & & \\ \text { Mean }= & \mathbf{7 8 . 4 4} & \text { S.D. }(\mathbf{1 \sigma})= & 12.40 \\ \text { Median }= & 80.43 & \text { Std. Err }= & 2.48 \\ \text { Min }= & 36.44 & \text { Disks }(\mathbf{n})= & 25 \\ \text { Max }= & 101.69 & & \end{array}$

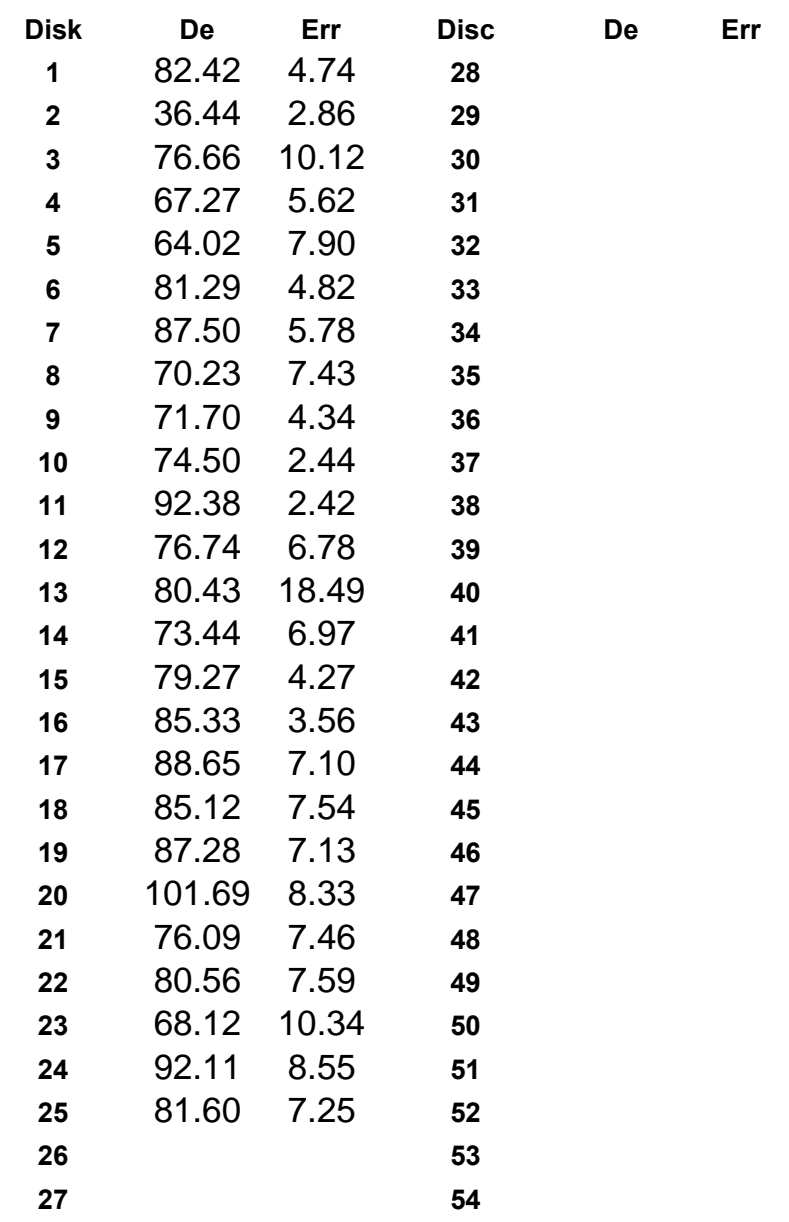

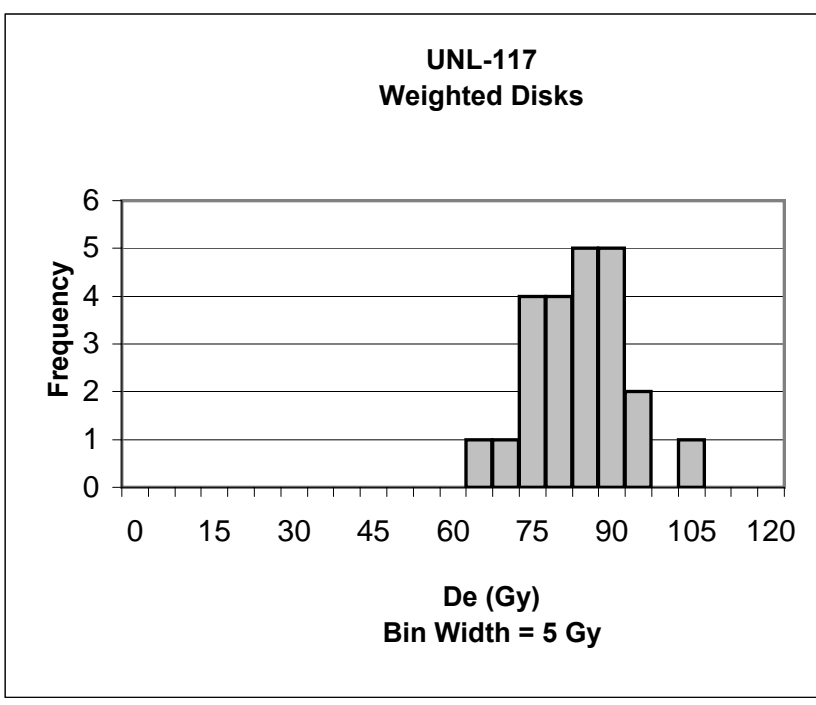

Weighted Disks De (Gy)

Mean $=\quad \mathbf{8 0 . 7 1}$

Median $=\quad 80.56$

Min $=\quad 64.02$

Max $=\quad 101.69$

$$
\begin{array}{lc}
\text { S.D. }(\mathbf{1 \sigma})= & 8.79 \\
\text { Std. } \text { Err }= & 1.83 \\
\text { Disks }(\mathbf{n})= & 23
\end{array}
$$

$\begin{array}{cccccc}\text { Disk } & \text { De } & \text { Err } & \text { Disc } & \text { De } & \text { Err } \\ \mathbf{1} & 82.42 & 4.74 & \mathbf{2 8} & & \\ \mathbf{2} & 76.66 & 10.12 & \mathbf{2 9} & \\ \mathbf{3} & 67.27 & 5.62 & \mathbf{3 0} & \\ \mathbf{4} & 64.02 & 7.90 & \mathbf{3 1} & \\ \mathbf{5} & 81.29 & 4.82 & \mathbf{3 2} & \\ \mathbf{6} & 87.50 & 5.78 & \mathbf{3 3} & \\ \mathbf{7} & 70.23 & 7.43 & \mathbf{3 4} & \\ \mathbf{8} & 71.70 & 4.34 & \mathbf{3 5} & \\ \mathbf{9} & 74.50 & 2.44 & \mathbf{3 6} & \\ \mathbf{1 0} & 92.38 & 2.42 & \mathbf{3 7} & \\ \mathbf{1 1} & 76.74 & 6.78 & \mathbf{3 8} & \\ \mathbf{1 2} & 80.43 & 18.49 & \mathbf{3 9} & \\ \mathbf{1 3} & 73.44 & 6.97 & \mathbf{4 0} & \\ \mathbf{1 4} & 79.27 & 4.27 & \mathbf{4 1} & \\ \mathbf{1 5} & 85.33 & 3.56 & \mathbf{4 2} & \\ \mathbf{1 6} & 88.65 & 7.10 & \mathbf{4 3} & \\ \mathbf{1 7} & 85.12 & 7.54 & \mathbf{4 4} & \\ \mathbf{1 8} & 87.28 & 7.13 & \mathbf{4 5} & \\ \mathbf{1 9} & 101.69 & 8.33 & \mathbf{4 6} & \\ \mathbf{2 0} & 76.09 & 7.46 & \mathbf{4 7} & \\ \mathbf{2 1} & 80.56 & 7.59 & \mathbf{4 8} & \\ \mathbf{2 2} & 92.11 & 8.55 & \mathbf{4 9} \\ \mathbf{2 3} & 81.60 & 7.25 & \mathbf{5 0} \\ \mathbf{2 4} & & & \mathbf{5 1} \\ \mathbf{2 5} & & & \mathbf{5 2} & \\ \mathbf{2 6} & & & \mathbf{5 3} & \\ \mathbf{2 7} & & & \mathbf{5 4} & \end{array}$




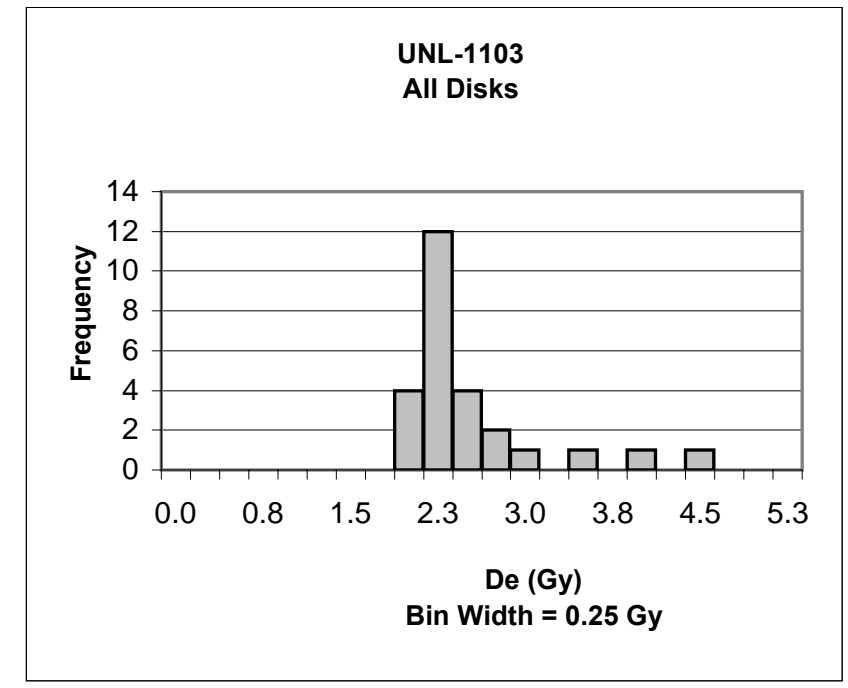

$\begin{array}{lcll}\text { All Disks } & & & \\ & \text { De (Gy) } & & \\ \text { Mean }= & \mathbf{2 . 3 9} & \text { S.D. }(\mathbf{1 \sigma})= & 0.63 \\ \text { Median }= & 2.17 & \text { Std. Err }= & 0.12 \\ \text { Min }= & 1.76 & \text { Disks }(\mathbf{n})= & 26 \\ \text { Max }= & 4.47 & & \end{array}$

\begin{tabular}{|c|c|c|c|c|}
\hline Disk & $\mathrm{De}$ & Err & Disc & De \\
\hline 1 & 1.76 & 0.66 & 28 & \\
\hline 2 & 1.91 & 0.16 & 29 & \\
\hline 3 & 1.92 & 0.12 & 30 & \\
\hline 4 & 1.95 & 0.06 & 31 & \\
\hline 5 & 2.01 & 0.19 & 32 & \\
\hline 6 & 2.02 & 0.14 & 33 & \\
\hline 7 & 2.03 & 0.08 & 34 & \\
\hline 8 & 2.04 & 0.04 & 35 & \\
\hline 9 & 2.07 & 0.09 & 36 & \\
\hline 10 & 2.09 & 0.02 & 37 & \\
\hline 11 & 2.13 & 0.03 & 38 & \\
\hline 12 & 2.15 & 0.05 & 39 & \\
\hline 13 & 2.15 & 0.04 & 40 & \\
\hline 14 & 2.19 & 0.12 & 41 & \\
\hline 15 & 2.23 & 0.22 & 42 & \\
\hline 16 & 2.23 & 0.02 & 43 & \\
\hline 17 & 2.29 & 0.03 & 44 & \\
\hline 18 & 2.30 & 0.08 & 45 & \\
\hline 19 & 2.35 & 0.12 & 46 & \\
\hline 20 & 2.47 & 0.03 & 47 & \\
\hline 21 & 2.52 & 0.17 & 48 & \\
\hline 22 & 2.66 & 0.09 & 49 & \\
\hline 23 & 2.86 & 0.02 & 50 & \\
\hline 24 & 3.45 & 0.23 & 51 & \\
\hline 25 & 3.89 & 0.15 & 52 & \\
\hline 26 & 4.47 & 0.23 & 53 & \\
\hline 27 & & & 54 & \\
\hline
\end{tabular}

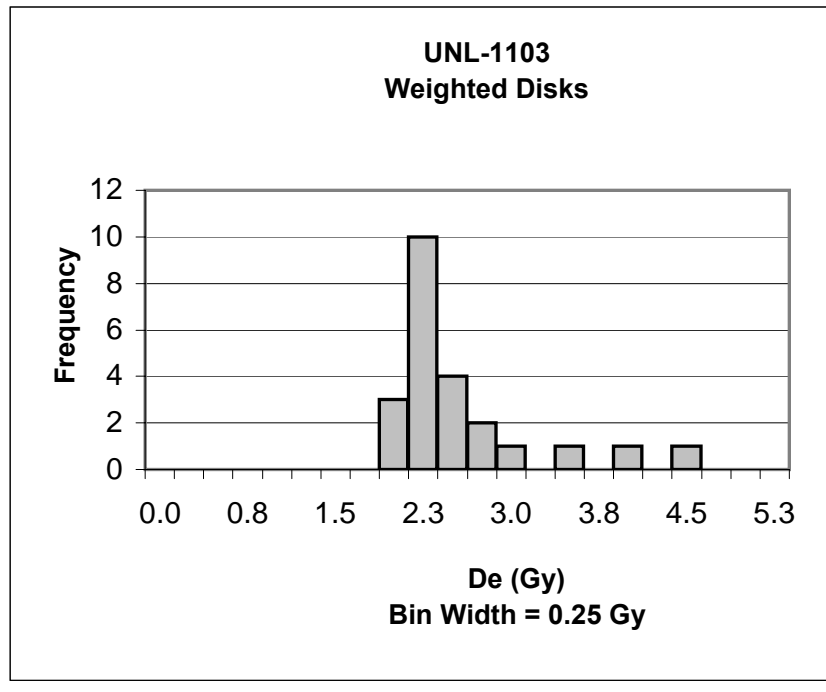

Weighted Disks

De (Gy)

Mean $=\quad 2.43$

Median $=\quad 2.15$

Min = $\quad 1.91$

Max $=\quad 4.47$

$\begin{array}{cccccc}\text { Disk } & \text { De } & \text { Err } & \text { Disc } & \text { De } & \text { Err } \\ \mathbf{1} & 1.91 & 0.16 & \mathbf{2 8} & & \\ \mathbf{2} & 1.92 & 0.12 & \mathbf{2 9} & \\ \mathbf{3} & 1.95 & 0.06 & \mathbf{3 0} & & \\ \mathbf{4} & 2.01 & 0.19 & \mathbf{3 1} & \\ \mathbf{5} & 2.02 & 0.14 & \mathbf{3 2} & \\ \mathbf{6} & 2.03 & 0.08 & \mathbf{3 3} & \\ \mathbf{7} & 2.04 & 0.04 & \mathbf{3 4} & \\ \mathbf{8} & 2.07 & 0.09 & \mathbf{3 5} & \\ \mathbf{9} & 2.09 & 0.02 & \mathbf{3 6} & \\ \mathbf{1 0} & 2.13 & 0.03 & \mathbf{3 7} & \\ \mathbf{1 1} & 2.15 & 0.05 & \mathbf{3 8} & \\ \mathbf{1 2} & 2.15 & 0.04 & \mathbf{3 9} & \\ \mathbf{1 3} & 2.23 & 0.02 & \mathbf{4 0} & \\ \mathbf{1 4} & 2.29 & 0.03 & \mathbf{4 1} & \\ \mathbf{1 5} & 2.30 & 0.08 & \mathbf{4 2} & \\ \mathbf{1 6} & 2.35 & 0.12 & \mathbf{4 3} & \\ \mathbf{1 7} & 2.47 & 0.03 & \mathbf{4 4} & \\ \mathbf{1 8} & 2.52 & 0.17 & \mathbf{4 5} & \\ \mathbf{1 9} & 2.66 & 0.09 & \mathbf{4 6} & \\ \mathbf{2 0} & 2.86 & 0.02 & \mathbf{4 7} & \\ \mathbf{2 1} & 3.45 & 0.23 & \mathbf{4 8} & \\ \mathbf{2 2} & 3.89 & 0.15 & \mathbf{4 9} & \\ \mathbf{2 3} & 4.47 & 0.23 & \mathbf{5 0} \\ \mathbf{2 4} & & & \mathbf{5 1} \\ \mathbf{2 5} & & & \mathbf{5 2} \\ \mathbf{2 6} & & & \mathbf{5 3} & \\ \mathbf{2 7} & & & \mathbf{5 4} & \end{array}$




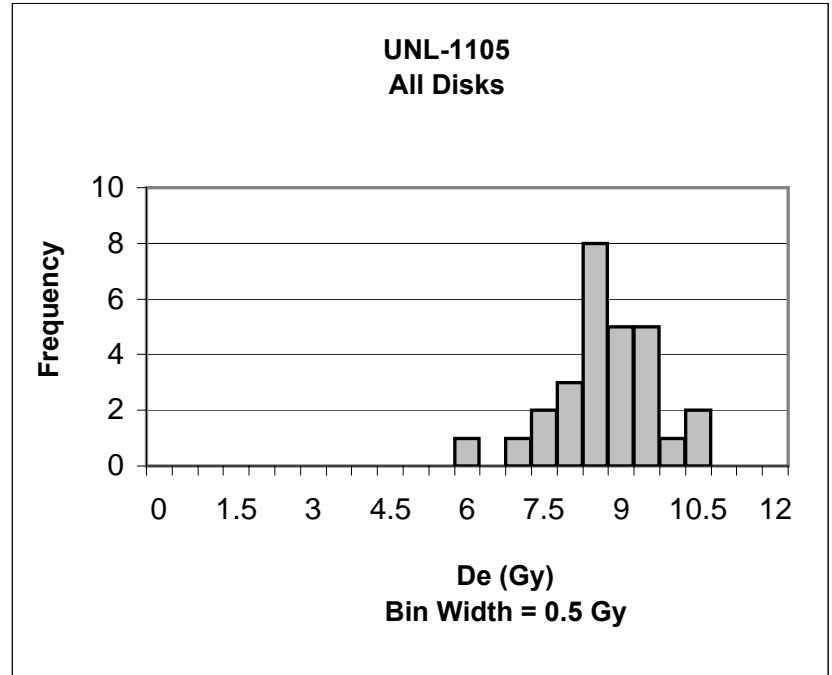

All Disks

$\begin{array}{lcll} & \text { De }(G y) & & \\ \text { Mean }= & \mathbf{8 . 4 2} & \text { S.D. }(\mathbf{1 \sigma})= & 0.94 \\ \text { Median }= & 8.43 & \text { Std. Err }= & 0.18 \\ \text { Min }= & 5.85 & \text { Disks }(\mathbf{n})= & 28 \\ \text { Max }= & 10.27 & & \end{array}$

\begin{tabular}{|c|c|c|c|c|c|}
\hline Disk & De & Err & Disc & De & Err \\
\hline 1 & 5.85 & 0.12 & 28 & 10.27 & 0.58 \\
\hline 2 & 6.90 & 0.29 & 29 & & \\
\hline 3 & 7.43 & 0.04 & 30 & & \\
\hline 4 & 7.44 & 0.41 & 31 & & \\
\hline 5 & 7.59 & 0.06 & 32 & & \\
\hline 6 & 7.85 & 0.60 & 33 & & \\
\hline 7 & 7.99 & 0.42 & 34 & & \\
\hline 8 & 8.00 & 0.07 & 35 & & \\
\hline 9 & 8.02 & 0.27 & 36 & & \\
\hline 10 & 8.02 & 0.25 & 37 & & \\
\hline 11 & 8.08 & 0.23 & 38 & & \\
\hline 12 & 8.09 & 0.57 & 39 & & \\
\hline 13 & 8.40 & 0.30 & 40 & & \\
\hline 14 & 8.42 & 0.20 & 41 & & \\
\hline 15 & 8.43 & 0.18 & 42 & & \\
\hline 16 & 8.55 & 1.10 & 43 & & \\
\hline 17 & 8.60 & 0.61 & 44 & & \\
\hline 18 & 8.66 & 0.10 & 45 & & \\
\hline 19 & 8.68 & 0.37 & 46 & & \\
\hline 20 & 8.86 & 0.11 & 47 & & \\
\hline 21 & 9.11 & 0.08 & 48 & & \\
\hline 22 & 9.15 & 0.19 & 49 & & \\
\hline 23 & 9.16 & 0.26 & 50 & & \\
\hline 24 & 9.24 & 0.11 & 51 & & \\
\hline 25 & 9.32 & 0.02 & 52 & & \\
\hline 26 & 9.60 & 0.09 & 53 & & \\
\hline 27 & 10.14 & 0.38 & 54 & & \\
\hline
\end{tabular}

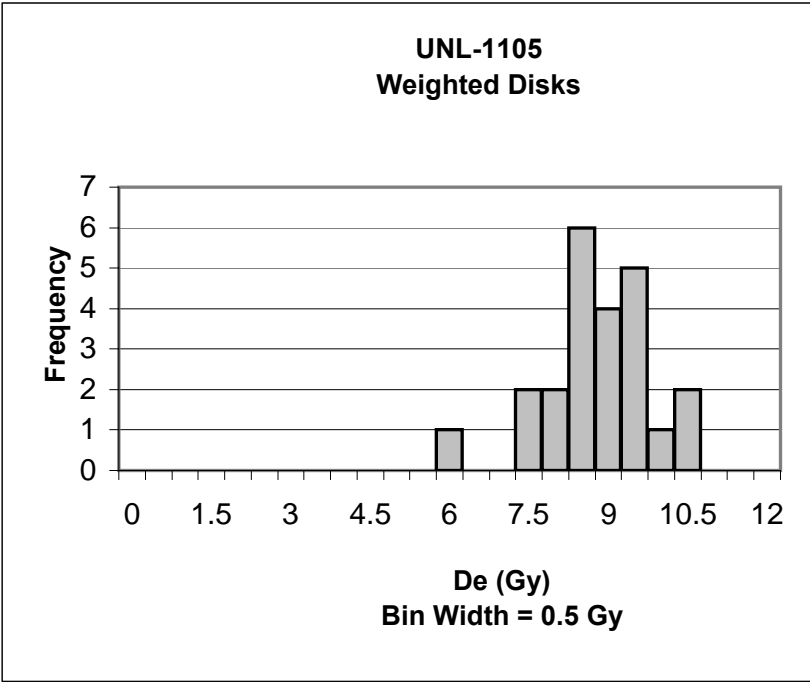

Weighted Disks

De (Gy)

Mean $=\quad 8.54$

Median $=\quad 8.60$

Min $=\quad 5.85$

Max $=\quad 10.27$

$\begin{array}{cccccc}\text { Disk } & \text { De } & \text { Err } & \text { Disc } & \text { De } & \text { Err } \\ \mathbf{1} & 5.85 & 0.12 & \mathbf{2 8} & & \\ \mathbf{2} & 7.43 & 0.04 & \mathbf{2 9} & \\ \mathbf{3} & 7.44 & 0.41 & \mathbf{3 0} & \\ \mathbf{4} & 7.59 & 0.06 & \mathbf{3 1} & \\ \mathbf{5} & 7.99 & 0.42 & \mathbf{3 2} & \\ \mathbf{6} & 8.00 & 0.07 & \mathbf{3 3} & \\ \mathbf{7} & 8.02 & 0.27 & \mathbf{3 4} & \\ \mathbf{8} & 8.08 & 0.23 & \mathbf{3 5} & \\ \mathbf{9} & 8.40 & 0.30 & \mathbf{3 6} & \\ \mathbf{1 0} & 8.42 & 0.20 & \mathbf{3 7} & \\ \mathbf{1 1} & 8.43 & 0.18 & \mathbf{3 8} & \\ \mathbf{1 2} & 8.60 & 0.61 & \mathbf{3 9} & \\ \mathbf{1 3} & 8.66 & 0.10 & \mathbf{4 0} & \\ \mathbf{1 4} & 8.68 & 0.37 & \mathbf{4 1} & \\ \mathbf{1 5} & 8.86 & 0.11 & \mathbf{4 2} & \\ \mathbf{1 6} & 9.11 & 0.08 & \mathbf{4 3} & \\ \mathbf{1 7} & 9.15 & 0.19 & \mathbf{4 4} & \\ \mathbf{1 8} & 9.16 & 0.26 & \mathbf{4 5} & \\ \mathbf{1 9} & 9.24 & 0.11 & \mathbf{4 6} & \\ \mathbf{2 0} & 9.32 & 0.02 & \mathbf{4 7} & \\ \mathbf{2 1} & 9.60 & 0.09 & \mathbf{4 8} & \\ \mathbf{2 2} & 10.14 & 0.38 & \mathbf{4 9} \\ \mathbf{2 3} & 10.27 & 0.58 & \mathbf{5 0} & \\ \mathbf{2 4} & & & \mathbf{5 1} \\ \mathbf{2 5} & & & \mathbf{5 2} \\ \mathbf{2 6} & & & \mathbf{5 3} \\ \mathbf{2 7} & & & \mathbf{5 4} & \end{array}$




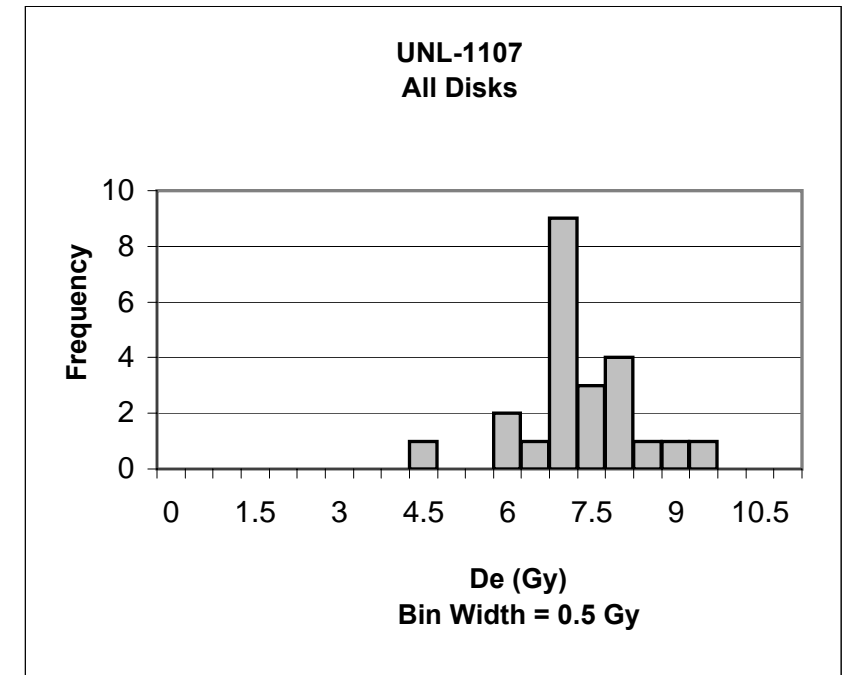

\section{All Disks}

De (Gy)

$\begin{array}{lllc}\text { Mean }= & \mathbf{7 . 0 5} & \text { S.D. }(\mathbf{1} \boldsymbol{\sigma})= & 1.07 \\ \text { Median }= & 6.90 & \text { Std. } \text { Err }= & 0.22 \\ \text { Min }= & 4.16 & \text { Disks }(\mathbf{n})= & 23 \\ \text { Max }= & 9.47 & & \end{array}$

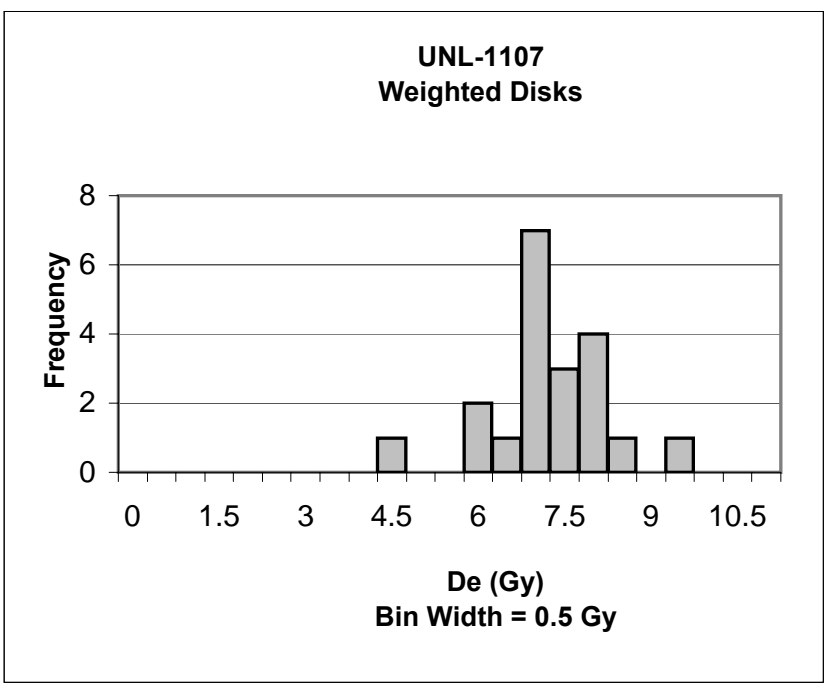

Weighted Disks De (Gy)

Mean $=\quad 6.98$

Median $=\quad 6.92$

Min $=\quad 4.16$

Max $=\quad 9.47$

\begin{tabular}{|c|c|c|c|c|c|c|c|c|c|c|}
\hline Disk & $\mathrm{De}$ & Err & Disc & $\mathrm{De}$ & Err & Disk & $\mathrm{De}$ & Err & Disc & $\mathrm{De}$ \\
\hline 1 & 4.16 & 0.18 & 28 & & & 1 & 4.16 & 0.18 & 28 & \\
\hline 2 & 5.74 & 0.08 & 29 & & & 2 & 5.74 & 0.08 & 29 & \\
\hline 3 & 5.88 & 0.12 & 30 & & & 3 & 5.88 & 0.12 & 30 & \\
\hline 4 & 6.27 & 0.10 & 31 & & & 4 & 6.27 & 0.10 & 31 & \\
\hline 5 & 6.55 & 0.06 & 32 & & & 5 & 6.55 & 0.06 & 32 & \\
\hline 6 & 6.66 & 0.02 & 33 & & & 6 & 6.66 & 0.02 & 33 & \\
\hline 7 & 6.79 & 0.11 & 34 & & & 7 & 6.79 & 0.11 & 34 & \\
\hline 8 & 6.82 & 0.32 & 35 & & & 8 & 6.87 & 0.12 & 35 & \\
\hline 9 & 6.87 & 0.12 & 36 & & & 9 & 6.90 & 0.11 & 36 & \\
\hline 10 & 6.88 & 0.39 & 37 & & & 10 & 6.90 & 0.09 & 37 & \\
\hline 11 & 6.90 & 0.11 & 38 & & & 11 & 6.93 & 0.22 & 38 & \\
\hline 12 & 6.90 & 0.09 & 39 & & & 12 & 7.03 & 0.18 & 39 & \\
\hline 13 & 6.93 & 0.22 & 40 & & & 13 & 7.13 & 0.10 & 40 & \\
\hline 14 & 7.03 & 0.18 & 41 & & & 14 & 7.26 & 0.17 & 41 & \\
\hline 15 & 7.13 & 0.10 & 42 & & & 15 & 7.59 & 0.08 & 42 & \\
\hline 16 & 7.26 & 0.17 & 43 & & & 16 & 7.63 & 0.05 & 43 & \\
\hline 17 & 7.59 & 0.08 & 44 & & & 17 & 7.75 & 0.18 & 44 & \\
\hline 18 & 7.63 & 0.05 & 45 & & & 18 & 7.97 & 0.12 & 45 & \\
\hline 19 & 7.75 & 0.18 & 46 & & & 19 & 8.07 & 0.13 & 46 & \\
\hline 20 & 7.97 & 0.12 & 47 & & & 20 & 9.47 & 0.03 & 47 & \\
\hline 21 & 8.07 & 0.13 & 48 & & & 21 & & & 48 & \\
\hline 22 & 8.89 & 0.38 & 49 & & & 22 & & & 49 & \\
\hline 23 & 9.47 & 0.03 & 50 & & & 23 & & & 50 & \\
\hline 24 & & & 51 & & & 24 & & & 51 & \\
\hline 25 & & & 52 & & & 25 & & & 52 & \\
\hline 26 & & & 53 & & & 26 & & & 53 & \\
\hline 27 & & & 54 & & & 27 & & & 54 & \\
\hline
\end{tabular}




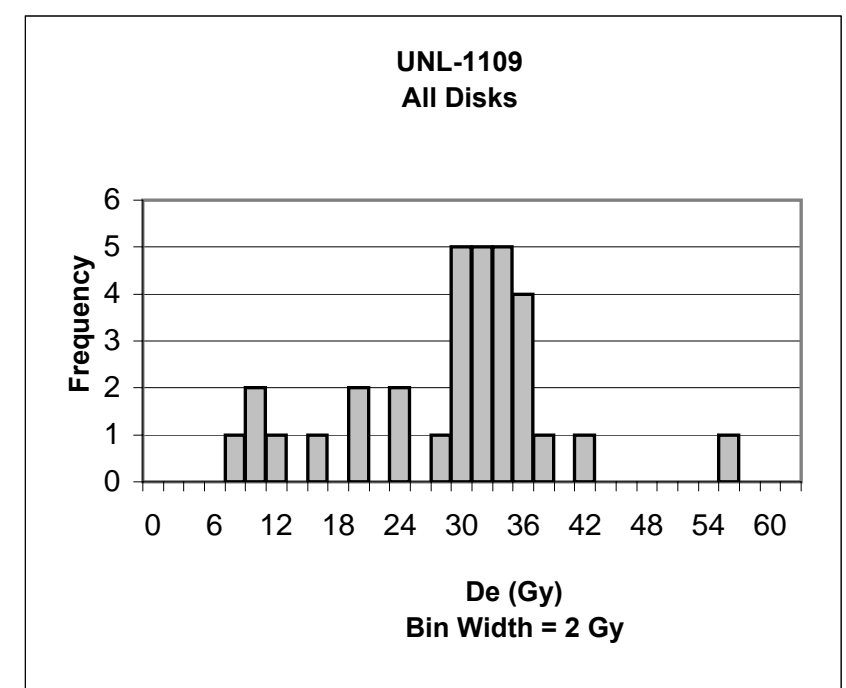

$\begin{array}{lcll}\text { All Disks } & & & \\ & \text { De }(G y) & & \\ \text { Mean }= & \mathbf{2 8 . 0 1} & \text { S.D. }(\mathbf{1 \sigma})= & 10.11 \\ \text { Median }= & 30.83 & \text { Std. Err }= & 1.79 \\ \text { Min }= & 7.48 & \text { Disks }(\mathbf{n})= & 32 \\ \text { Max }= & 55.03 & & \end{array}$

\begin{tabular}{|c|c|c|c|c|c|}
\hline Disk & $\mathrm{De}$ & Err & Disc & $\mathrm{De}$ & Err \\
\hline 1 & 7.48 & 0.60 & 28 & 34.91 & 0.37 \\
\hline 2 & 8.69 & 0.48 & 29 & 35.73 & 0.43 \\
\hline 3 & 9.52 & 0.46 & 30 & 36.91 & 0.02 \\
\hline 4 & 10.73 & 0.09 & 31 & 40.68 & 0.30 \\
\hline 5 & 14.61 & 0.02 & 32 & 55.03 & 0.34 \\
\hline 6 & 19.25 & 0.06 & 33 & & \\
\hline 7 & 19.43 & 0.24 & 34 & & \\
\hline 8 & 22.19 & 0.31 & 35 & & \\
\hline 9 & 23.52 & 1.19 & 36 & & \\
\hline 10 & 26.07 & 0.61 & 37 & & \\
\hline 11 & 28.06 & 0.15 & 38 & & \\
\hline 12 & 28.13 & 0.18 & 39 & & \\
\hline 13 & 28.22 & 0.09 & 40 & & \\
\hline 14 & 28.37 & 0.76 & 41 & & \\
\hline 15 & 28.54 & 0.45 & 42 & & \\
\hline 16 & 30.73 & 0.29 & 43 & & \\
\hline 17 & 30.92 & 1.03 & 44 & & \\
\hline 18 & 31.15 & 0.85 & 45 & & \\
\hline 19 & 31.17 & 0.21 & 46 & & \\
\hline 20 & 31.68 & 0.63 & 47 & & \\
\hline 21 & 32.35 & 0.01 & 48 & & \\
\hline 22 & 32.53 & 0.12 & 49 & & \\
\hline 23 & 33.46 & 0.45 & 50 & & \\
\hline 24 & 33.63 & 0.52 & 51 & & \\
\hline 25 & 33.98 & 0.36 & 52 & & \\
\hline 26 & 34.24 & 0.53 & 53 & & \\
\hline 27 & 34.46 & 0.39 & 54 & & \\
\hline
\end{tabular}

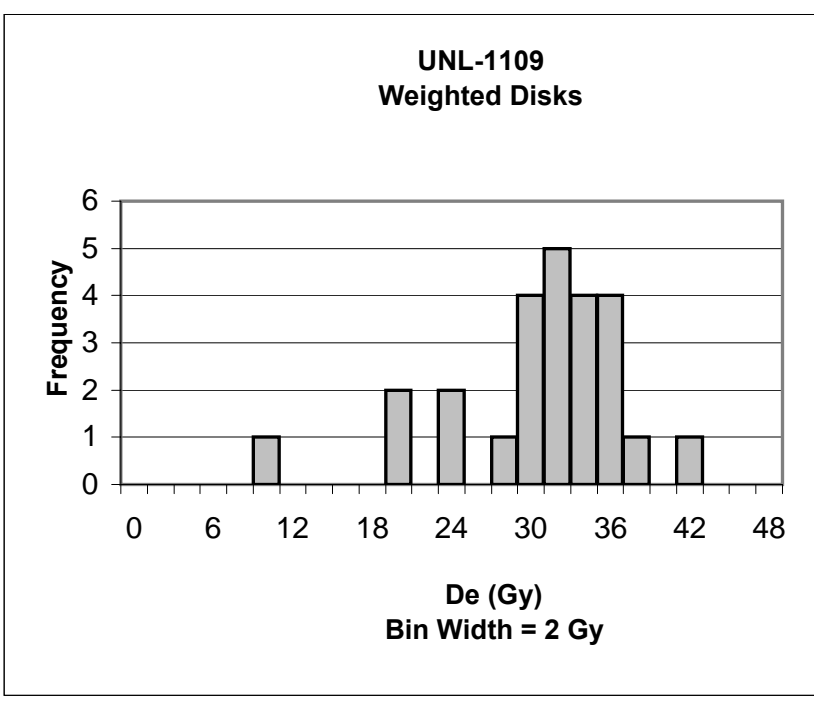

Weighted Disks De (Gy)

Mean $=\quad 29.50$

Median $=\quad 31.15$

Min $=\quad 8.69$

Max $=\quad 40.68$
S.D. $(1 \sigma)=\quad 6.80$

Std. Err $=\quad 1.36$

Disks $(\mathbf{n})=25$

$\begin{array}{ccccc}\text { Disk } & \text { De } & \text { Err } & \text { Disc } & \text { De } \\ \mathbf{1} & 8.69 & 0.48 & \mathbf{2 8} & \\ \mathbf{2} & 19.25 & 0.06 & \mathbf{2 9} & \\ \mathbf{3} & 19.43 & 0.24 & \mathbf{3 0} \\ \mathbf{4} & 22.19 & 0.31 & \mathbf{3 1} \\ \mathbf{5} & 23.52 & 1.19 & \mathbf{3 2} \\ \mathbf{6} & 26.07 & 0.61 & \mathbf{3 3} \\ \mathbf{7} & 28.13 & 0.18 & \mathbf{3 4} \\ \mathbf{8} & 28.22 & 0.09 & \mathbf{3 5} \\ \mathbf{9} & 28.37 & 0.76 & \mathbf{3 6} \\ \mathbf{1 0} & 28.54 & 0.45 & \mathbf{3 7} \\ \mathbf{1 1} & 30.73 & 0.29 & \mathbf{3 8} \\ \mathbf{1 2} & 30.92 & 1.03 & \mathbf{3 9} \\ \mathbf{1 3} & 31.15 & 0.85 & \mathbf{4 0} \\ \mathbf{1 4} & 31.17 & 0.21 & \mathbf{4 1} \\ \mathbf{1 5} & 31.68 & 0.63 & \mathbf{4 2} \\ \mathbf{1 6} & 32.35 & 0.01 & \mathbf{4 3} \\ \mathbf{1 7} & 32.53 & 0.12 & \mathbf{4 4} \\ \mathbf{1 8} & 33.63 & 0.52 & \mathbf{4 5} \\ \mathbf{1 9} & 33.98 & 0.36 & \mathbf{4 6} \\ \mathbf{2 0} & 34.24 & 0.53 & \mathbf{4 7} \\ \mathbf{2 1} & 34.46 & 0.39 & \mathbf{4 8} \\ \mathbf{2 2} & 34.91 & 0.37 & \mathbf{4 9} \\ \mathbf{2 3} & 35.73 & 0.43 & \mathbf{5 0} \\ \mathbf{2 4} & 36.91 & 0.02 & \mathbf{5 1} \\ \mathbf{2 5} & 40.68 & 0.30 & \mathbf{5 2} \\ \mathbf{2 6} & & & \mathbf{5 3} \\ \mathbf{2 7} & & & \mathbf{5 4}\end{array}$




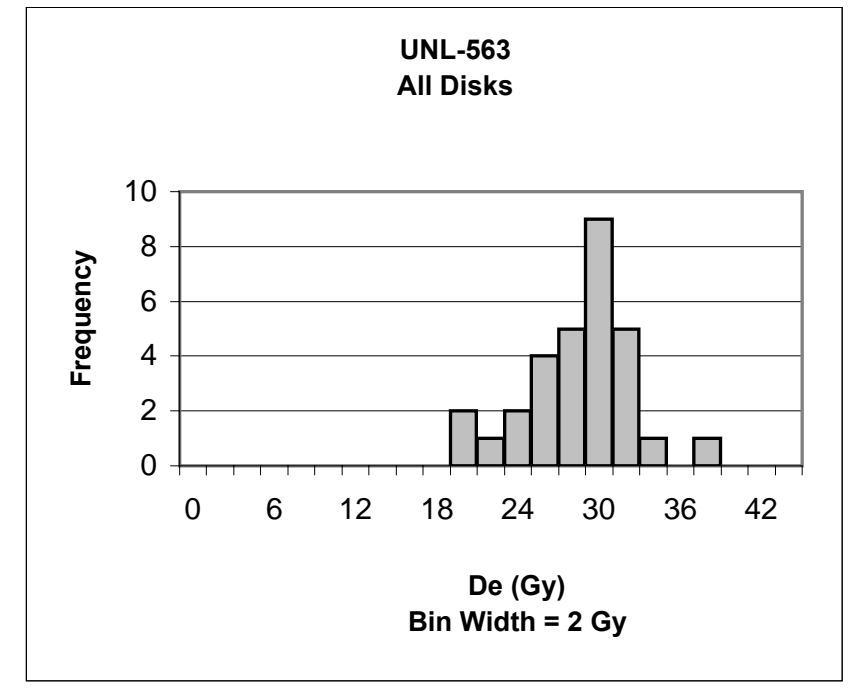

$\begin{array}{lcll}\text { All Disks } & & & \\ & \text { De (Gy) } & & \\ \text { Mean }= & \mathbf{2 7 . 5 5} & \text { S.D. }(\mathbf{1 \sigma})= & 3.90 \\ \text { Median }= & 28.25 & \text { Std. Err }= & 0.71 \\ \text { Min }= & 18.83 & \text { Disks }(\mathbf{n})= & 30 \\ \text { Max }= & 36.46 & & \end{array}$

\begin{tabular}{|c|c|c|c|c|c|}
\hline Disk & De & Err & Disc & De & Err \\
\hline 1 & 29.63 & 0.19 & 28 & 22.11 & 0.28 \\
\hline 2 & 28.14 & 0.14 & 29 & 21.12 & 0.16 \\
\hline 3 & 31.96 & 0.24 & 30 & 25.95 & 0.16 \\
\hline 4 & 29.94 & 0.14 & 31 & & \\
\hline 5 & 26.89 & 0.30 & 32 & & \\
\hline 6 & 26.22 & 0.45 & 33 & & \\
\hline 7 & 28.36 & 0.01 & 34 & & \\
\hline 8 & 28.91 & 0.40 & 35 & & \\
\hline 9 & 31.73 & 0.13 & 36 & & \\
\hline 10 & 28.39 & 0.02 & 37 & & \\
\hline 11 & 18.83 & 0.02 & 38 & & \\
\hline 12 & 29.29 & 0.26 & 39 & & \\
\hline 13 & 30.52 & 0.11 & 40 & & \\
\hline 14 & 28.45 & 0.13 & 41 & & \\
\hline 15 & 30.55 & 0.36 & 42 & & \\
\hline 16 & 32.93 & 1.32 & 43 & & \\
\hline 17 & 19.15 & 0.34 & 44 & & \\
\hline 18 & 25.84 & 1.31 & 45 & & \\
\hline 19 & 23.89 & 0.07 & 46 & & \\
\hline 20 & 30.93 & 0.51 & 47 & & \\
\hline 21 & 36.46 & 3.07 & 48 & & \\
\hline 22 & 26.63 & 0.80 & 49 & & \\
\hline 23 & 25.45 & 0.09 & 50 & & \\
\hline 24 & 25.72 & 0.25 & 51 & & \\
\hline 25 & 28.65 & 0.82 & 52 & & \\
\hline 26 & 27.68 & 1.75 & 53 & & \\
\hline 27 & 26.34 & 0.50 & 54 & & \\
\hline
\end{tabular}

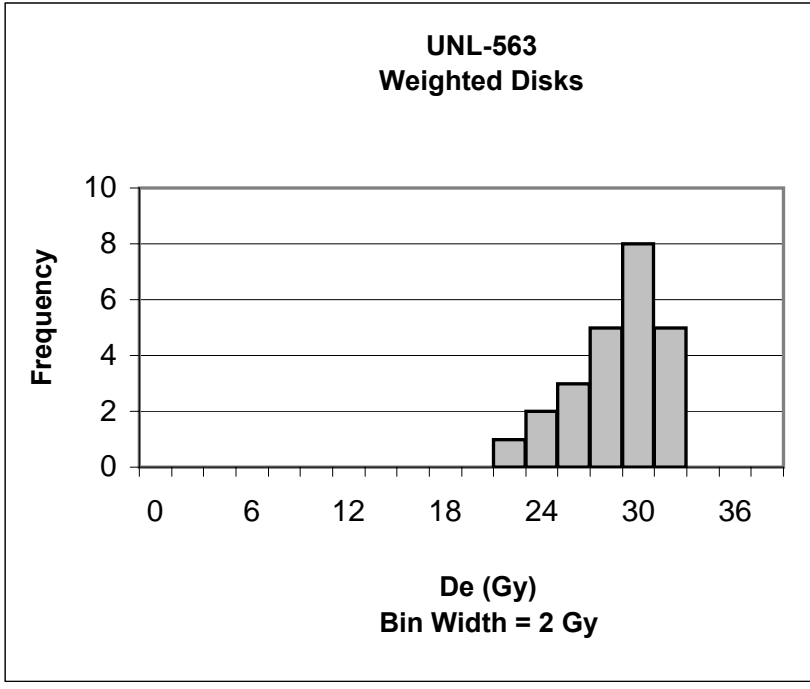

Weighted Disks

$\begin{array}{ll}\text { Mean }= & \mathbf{2 7 . 7 2} \\ \text { Median }= & 28.37 \\ \text { Min }= & 21.12 \\ \text { Max }= & 31.96\end{array}$

$\begin{array}{ccccc}\text { Disk } & \text { De } & \text { Err } & \text { Disc } & \text { De } \\ 1 & 29.63 & 0.19 & \mathbf{2 8} \\ 2 & 31.96 & 0.24 & \mathbf{2 9} & \\ \mathbf{3} & 29.94 & 0.14 & \mathbf{3 0} \\ \mathbf{4} & 26.89 & 0.30 & \mathbf{3 1} \\ \mathbf{5} & 26.22 & 0.45 & \mathbf{3 2} \\ \mathbf{6} & 28.36 & 0.01 & \mathbf{3 3} \\ \mathbf{7} & 28.91 & 0.40 & \mathbf{3 4} \\ \mathbf{8} & 31.73 & 0.13 & \mathbf{3 5} \\ \mathbf{9} & 28.39 & 0.02 & \mathbf{3 6} \\ \mathbf{1 0} & 29.29 & 0.26 & \mathbf{3 7} \\ \mathbf{1 1} & 30.52 & 0.11 & \mathbf{3 8} \\ \mathbf{1 2} & 28.45 & 0.13 & \mathbf{3 9} \\ \mathbf{1 3} & 30.55 & 0.36 & \mathbf{4 0} \\ \mathbf{1 4} & 23.89 & 0.07 & \mathbf{4 1} \\ \mathbf{1 5} & 30.93 & 0.51 & \mathbf{4 2} \\ \mathbf{1 6} & 26.63 & 0.80 & \mathbf{4 3} \\ \mathbf{1 7} & 25.45 & 0.09 & \mathbf{4 4} \\ \mathbf{1 8} & 25.72 & 0.25 & \mathbf{4 5} \\ \mathbf{1 9} & 28.65 & 0.82 & \mathbf{4 6} \\ \mathbf{2 0} & 27.68 & 1.75 & \mathbf{4 7} \\ \mathbf{2 1} & 26.34 & 0.50 & \mathbf{4 8} \\ \mathbf{2 2} & 22.11 & 0.28 & \mathbf{4 9} \\ \mathbf{2 3} & 21.12 & 0.16 & \mathbf{5 0} \\ \mathbf{2 4} & 25.95 & 0.16 & \mathbf{5 1} \\ \mathbf{2 5} & & & \mathbf{5 2} \\ \mathbf{2 6} & & & \mathbf{5 3} \\ \mathbf{2 7} & & & \mathbf{5 4}\end{array}$




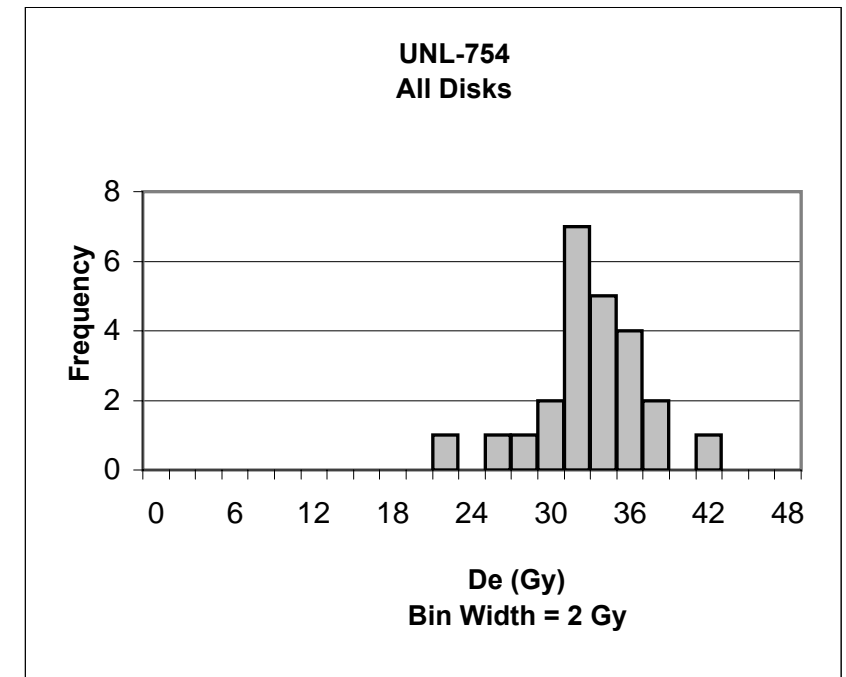

\section{All Disks}

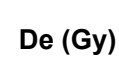

$\begin{array}{ll}\text { Mean }= & \mathbf{3 2 . 1 0} \\ \text { Median }= & 32.09 \\ \text { Min }= & 21.14 \\ \text { Max }= & 41.75\end{array}$

$\begin{array}{cccccc}\text { Disk } & \text { De } & \text { Err } & \text { Disc } & \text { De } & \text { Err } \\ 1 & 29.43 & 0.57 & 28 & & \\ 2 & 33.00 & 0.02 & 29 & & \\ 3 & 30.79 & 0.49 & 30 & & \end{array}$

S.D. $(1 \sigma)=\quad 4.08$

Std. Err $=\quad 0.83$

Disks $(n)=\quad 24$

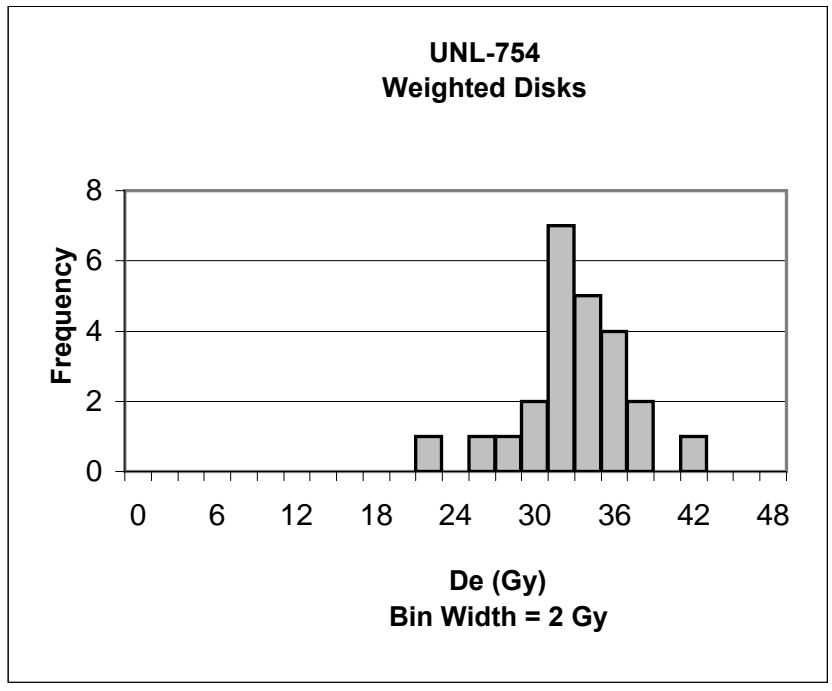

Weighted Disks

De (Gy)

$\begin{array}{lllc}\text { Mean }= & \mathbf{3 2 . 1 0} & \text { S.D. }(\mathbf{1} \boldsymbol{\sigma})= & 4.08 \\ \text { Median }= & 32.09 & \text { Std. } \text { Err }= & 0.83 \\ \text { Min }= & 21.14 & \text { Disks }(\mathbf{n})= & 24 \\ \text { Max }= & 41.75 & \end{array}$

Max $=\quad 41.75$

$\begin{array}{cccccc}\text { Disk } & \text { De } & \text { Err } & \text { Disc } & \text { De } & \text { Err } \\ \mathbf{1} & 29.43 & 0.57 & \mathbf{2 8} & & \\ \mathbf{2} & 33.00 & 0.02 & \mathbf{2 9} & \\ \mathbf{3} & 30.79 & 0.49 & \mathbf{3 0} & \\ \mathbf{4} & 31.55 & 0.13 & \mathbf{3 1} & \\ \mathbf{5} & 41.75 & 0.14 & \mathbf{3 2} & \\ \mathbf{6} & 31.61 & 0.67 & \mathbf{3 3} & \\ \mathbf{7} & 32.91 & 0.67 & \mathbf{3 4} & \\ \mathbf{8} & 30.83 & 0.49 & \mathbf{3 5} & \\ \mathbf{9} & 37.25 & 0.55 & \mathbf{3 6} & \\ \mathbf{1 0} & 30.04 & 0.43 & \mathbf{3 7} & \\ \mathbf{1 1} & 29.62 & 0.51 & \mathbf{3 8} & \\ \mathbf{1 2} & 35.29 & 0.50 & \mathbf{3 9} & \\ \mathbf{1 3} & 36.86 & 0.27 & \mathbf{4 0} & \\ \mathbf{1 4} & 30.60 & 0.33 & \mathbf{4 1} & \\ \mathbf{1 5} & 34.86 & 0.31 & \mathbf{4 2} & \\ \mathbf{1 6} & 27.28 & 0.11 & \mathbf{4 3} & \\ \mathbf{1 7} & 34.55 & 0.20 & \mathbf{4 4} & \\ \mathbf{1 8} & 33.85 & 0.24 & \mathbf{4 5} & \\ \mathbf{1 9} & 32.51 & 0.42 & \mathbf{4 6} & \\ \mathbf{2 0} & 32.98 & 0.90 & \mathbf{4 7} & \\ \mathbf{2 1} & 25.79 & 1.59 & \mathbf{4 8} & \\ \mathbf{2 2} & 21.14 & 0.11 & \mathbf{4 9} \\ \mathbf{2 3} & 34.24 & 0.27 & \mathbf{5 0} \\ \mathbf{2 4} & 31.67 & 0.17 & \mathbf{5 1} \\ \mathbf{2 5} & & & \mathbf{5 2} \\ \mathbf{2 6} & & & \mathbf{5 3} \\ \mathbf{2 7} & & & \mathbf{5 4} & \end{array}$




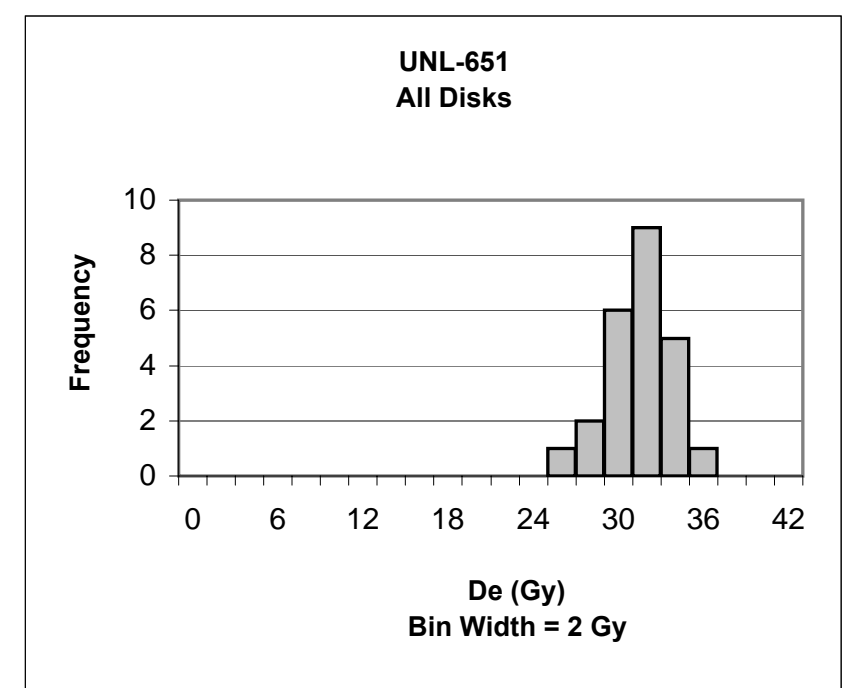

$\begin{array}{lr}\text { All Disks } & \\ & \text { De }(\mathbf{G} y) \\ \text { Mean }= & \mathbf{3 0 . 5 2} \\ \text { Median }= & 30.89 \\ \text { Min }= & 25.87 \\ \text { Max }= & 35.92\end{array}$

\begin{tabular}{|c|c|c|c|c|}
\hline Disk & $\mathrm{De}$ & Err & Disc & De \\
\hline 1 & 31.70 & 0.26 & 28 & \\
\hline 2 & 30.57 & 0.39 & 29 & \\
\hline 3 & 31.50 & 0.03 & 30 & \\
\hline 4 & 32.13 & 0.89 & 31 & \\
\hline 5 & 28.93 & 0.60 & 32 & \\
\hline 6 & 31.41 & 0.61 & 33 & \\
\hline 7 & 32.02 & 0.11 & 34 & \\
\hline 8 & 35.92 & 0.07 & 35 & \\
\hline 9 & 31.48 & 0.32 & 36 & \\
\hline 10 & 33.32 & 0.67 & 37 & \\
\hline 11 & 29.89 & 0.43 & 38 & \\
\hline 12 & 30.79 & 0.42 & 39 & \\
\hline 13 & 32.14 & 0.08 & 40 & \\
\hline 14 & 28.62 & 0.03 & 41 & \\
\hline 15 & 30.03 & 0.10 & 42 & \\
\hline 16 & 25.87 & 0.66 & 43 & \\
\hline 17 & 26.19 & 0.01 & 44 & \\
\hline 18 & 27.17 & 1.08 & 45 & \\
\hline 19 & 30.99 & 0.36 & 46 & \\
\hline 20 & 29.57 & 0.10 & 47 & \\
\hline 21 & 31.55 & 0.39 & 48 & \\
\hline 22 & 28.81 & 0.05 & 49 & \\
\hline 23 & 29.22 & 0.16 & 50 & \\
\hline 24 & 32.58 & 0.74 & 51 & \\
\hline 25 & & & 52 & \\
\hline 26 & & & 53 & \\
\hline 27 & & & 54 & \\
\hline
\end{tabular}

S.D. $(1 \sigma)=2.27$

Std. Err $=\quad 0.46$

$\operatorname{Disks}(\mathbf{n})=\quad 24$

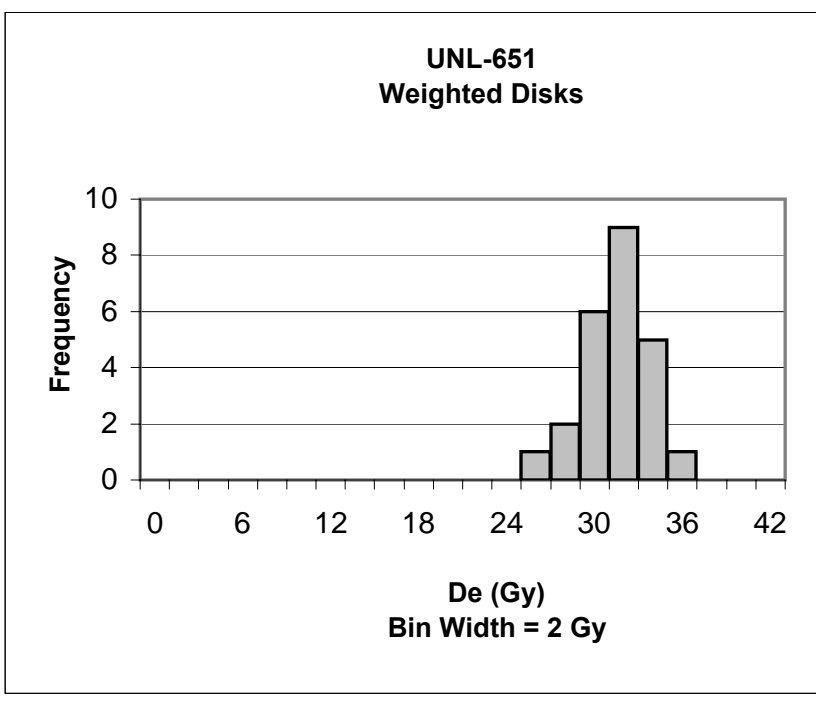

Weighted Disks

De (Gy)

$\begin{array}{lll}\text { Mean }= & 30.52 & \text { S.D. }(1 \sigma)=\quad 2.27\end{array}$

$\begin{array}{lll}\text { Median }= & 30.89 & \text { Std. } \text { Err }= \\ 2 & 0.46\end{array}$

$\begin{array}{lll}\text { Min }= & 25.87 & \text { Disks }(n)=\end{array}$

Max $=\quad 35.92$

$\begin{array}{ccccc}\text { Disk } & \text { De } & \text { Err } & \text { Disc } & \text { De } \\ 1 & 31.70 & 0.26 & \mathbf{2 8} & \\ 2 & 30.57 & 0.39 & \mathbf{2 9} \\ \mathbf{3} & 31.50 & 0.03 & \mathbf{3 0} \\ \mathbf{4} & 32.13 & 0.89 & \mathbf{3 1} \\ \mathbf{5} & 28.93 & 0.60 & \mathbf{3 2} \\ \mathbf{6} & 31.41 & 0.61 & \mathbf{3 3} \\ \mathbf{7} & 32.02 & 0.11 & \mathbf{3 4} \\ \mathbf{8} & 35.92 & 0.07 & \mathbf{3 5} \\ \mathbf{9} & 31.48 & 0.32 & \mathbf{3 6} \\ \mathbf{1 0} & 33.32 & 0.67 & \mathbf{3 7} \\ \mathbf{1 1} & 29.89 & 0.43 & \mathbf{3 8} \\ \mathbf{1 2} & 30.79 & 0.42 & \mathbf{3 9} \\ \mathbf{1 3} & 32.14 & 0.08 & \mathbf{4 0} \\ \mathbf{1 4} & 28.62 & 0.03 & \mathbf{4 1} \\ \mathbf{1 5} & 30.03 & 0.10 & \mathbf{4 2} \\ \mathbf{1 6} & 25.87 & 0.66 & \mathbf{4 3} \\ \mathbf{1 7} & 26.19 & 0.01 & \mathbf{4 4} \\ \mathbf{1 8} & 27.17 & 1.08 & \mathbf{4 5} \\ \mathbf{1 9} & 30.99 & 0.36 & \mathbf{4 6} \\ \mathbf{2 0} & 29.57 & 0.10 & \mathbf{4 7} \\ \mathbf{2 1} & 31.55 & 0.39 & \mathbf{4 8} \\ \mathbf{2 2} & 28.81 & 0.05 & \mathbf{4 9} \\ \mathbf{2 3} & 29.22 & 0.16 & \mathbf{5 0} \\ \mathbf{2 4} & 32.58 & 0.74 & \mathbf{5 1} \\ \mathbf{2 5} & & & \mathbf{5 2} \\ \mathbf{2 6} & & & \mathbf{5 3} \\ \mathbf{2 7} & & & \mathbf{5 4}\end{array}$




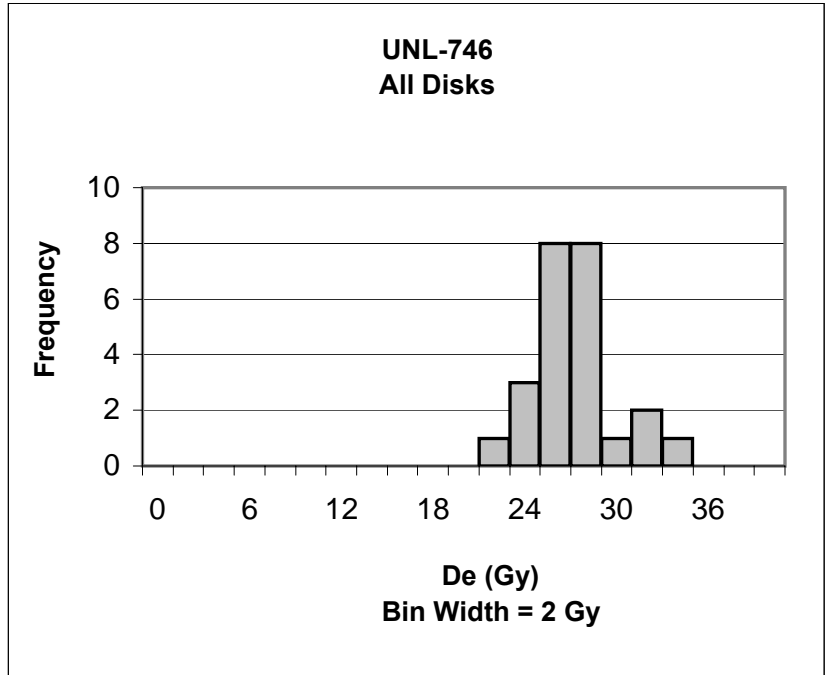

$\begin{array}{lc}\text { All Disks } & \\ & \text { De }(\text { Gy }) \\ \text { Mean }= & \mathbf{2 6 . 3 1} \\ \text { Median }= & 26.19 \\ \text { Min }= & 20.81 \\ \text { Max }= & 33.62\end{array}$

\begin{tabular}{|c|c|c|c|c|}
\hline Disk & De & Err & Disc & De \\
\hline 1 & 27.32 & 0.30 & 28 & \\
\hline 2 & 22.87 & 0.71 & 29 & \\
\hline 3 & 30.89 & 0.42 & 30 & \\
\hline 4 & 20.81 & 0.84 & 31 & \\
\hline 5 & 25.72 & 0.32 & 32 & \\
\hline 6 & 27.82 & 0.22 & 33 & \\
\hline 7 & 30.62 & 0.32 & 34 & \\
\hline 8 & 25.12 & 0.19 & 35 & \\
\hline 9 & 27.02 & 0.19 & 36 & \\
\hline 10 & 26.41 & 0.20 & 37 & \\
\hline 11 & 23.47 & 0.26 & 38 & \\
\hline 12 & 23.48 & 0.30 & 39 & \\
\hline 13 & 25.88 & 0.11 & 40 & \\
\hline 14 & 25.03 & 0.18 & 41 & \\
\hline 15 & 24.41 & 1.03 & 42 & \\
\hline 16 & 27.66 & 0.87 & 43 & \\
\hline 17 & 25.97 & 0.15 & 44 & \\
\hline 18 & 24.45 & 0.67 & 45 & \\
\hline 19 & 33.62 & 0.21 & 46 & \\
\hline 20 & 26.48 & 0.33 & 47 & \\
\hline 21 & 26.60 & 0.17 & 48 & \\
\hline 22 & 28.11 & 0.47 & 49 & \\
\hline 23 & 26.55 & 0.12 & 50 & \\
\hline 24 & 25.14 & 0.27 & 51 & \\
\hline 25 & & & 52 & \\
\hline 26 & & & 53 & \\
\hline 27 & & & 54 & \\
\hline
\end{tabular}

S.D. $(1 \sigma)=\quad 2.74$

Std. Err $=\quad 0.56$

Disks $(n)=24$

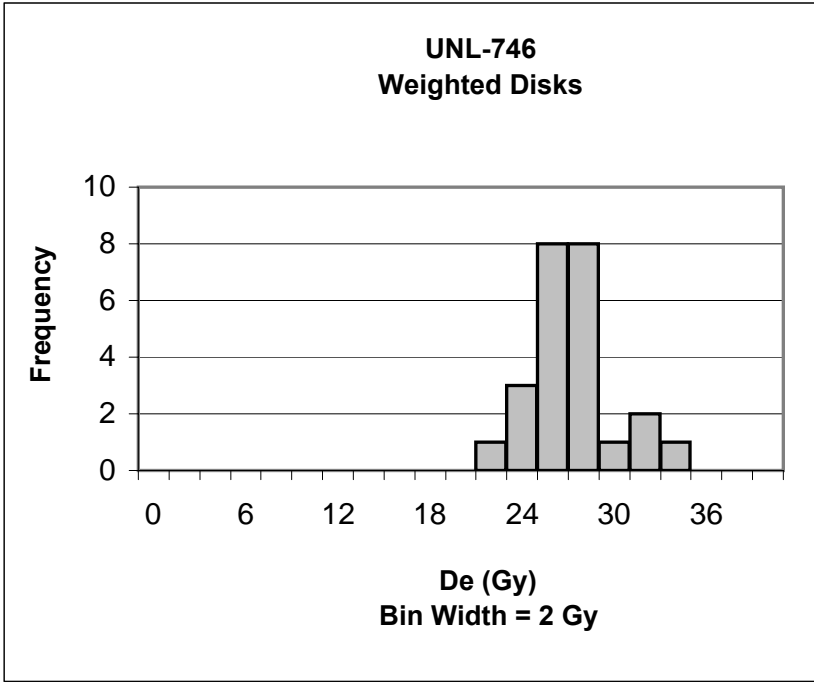

Weighted Disks

De (Gy)

Mean $=\quad 26.31$

Median $=26.19$

Min $=\quad 20.81$

Max $=\quad 33.62$

S.D. $(1 \sigma)=2.74$

Std. Err $=\quad 0.56$

Disks $(n)=24$

$\begin{array}{ccccc}\text { Disk } & \text { De } & \text { Err } & \text { Disc } & \text { De } \\ \mathbf{1} & 27.32 & 0.30 & \mathbf{2 8} & \\ 2 & 22.87 & 0.71 & \mathbf{2 9} \\ \mathbf{3} & 30.89 & 0.42 & \mathbf{3 0} \\ \mathbf{4} & 20.81 & 0.84 & \mathbf{3 1} \\ \mathbf{5} & 25.72 & 0.32 & \mathbf{3 2} \\ \mathbf{6} & 27.82 & 0.22 & \mathbf{3 3} \\ \mathbf{7} & 30.62 & 0.32 & \mathbf{3 4} \\ \mathbf{8} & 25.12 & 0.19 & \mathbf{3 5} \\ \mathbf{9} & 27.02 & 0.19 & \mathbf{3 6} \\ \mathbf{1 0} & 26.41 & 0.20 & \mathbf{3 7} \\ \mathbf{1 1} & 23.47 & 0.26 & \mathbf{3 8} \\ \mathbf{1 2} & 23.48 & 0.30 & \mathbf{3 9} \\ \mathbf{1 3} & 25.88 & 0.11 & \mathbf{4 0} \\ \mathbf{1 4} & 25.03 & 0.18 & \mathbf{4 1} \\ \mathbf{1 5} & 24.41 & 1.03 & \mathbf{4 2} \\ \mathbf{1 6} & 27.66 & 0.87 & \mathbf{4 3} \\ \mathbf{1 7} & 25.97 & 0.15 & \mathbf{4 4} \\ \mathbf{1 8} & 24.45 & 0.67 & \mathbf{4 5} \\ \mathbf{1 9} & 33.62 & 0.21 & \mathbf{4 6} \\ \mathbf{2 0} & 26.48 & 0.33 & \mathbf{4 7} \\ \mathbf{2 1} & 26.60 & 0.17 & \mathbf{4 8} \\ \mathbf{2 2} & 28.11 & 0.47 & \mathbf{4 9} \\ \mathbf{2 3} & 26.55 & 0.12 & \mathbf{5 0} \\ \mathbf{2 4} & 25.14 & 0.27 & \mathbf{5 1} \\ \mathbf{2 5} & & & \mathbf{5 2} \\ \mathbf{2 6} & & & \mathbf{5 3} \\ \mathbf{2 7} & & & \mathbf{5 4}\end{array}$



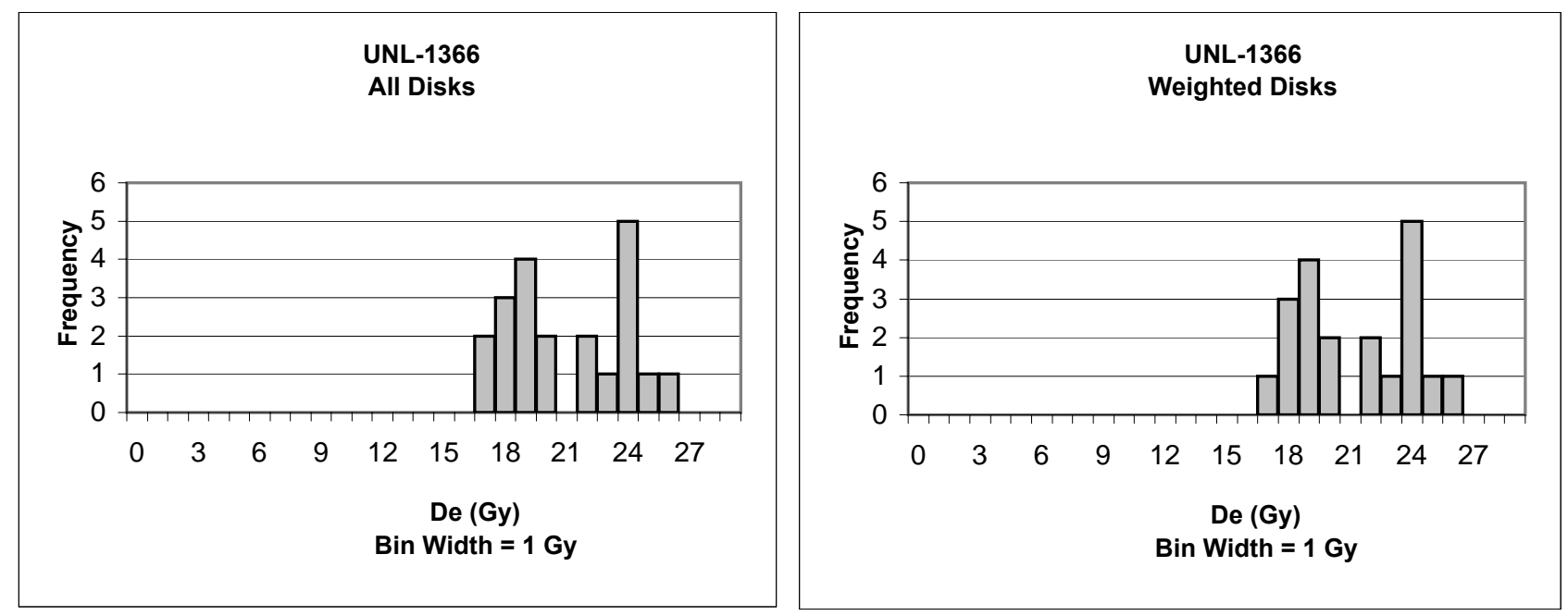

\begin{tabular}{|c|c|c|c|c|c|}
\hline \multicolumn{6}{|l|}{ All Disks } \\
\hline & De (Gy) & & & & \\
\hline Mean = & 20.54 & & S.D. $(1 \sigma)=$ & 2.99 & \\
\hline Median = & 19.64 & & Std. Err = & 0.65 & \\
\hline Min = & 16.43 & & Disks $(n)=$ & 21 & \\
\hline Max = & 25.99 & & & & \\
\hline Disk & De & Err & Disc & $\mathrm{De}$ & Err \\
\hline 1 & 16.57 & 0.32 & 28 & & \\
\hline 2 & 17.65 & 0.53 & 29 & & \\
\hline 3 & 17.78 & 0.41 & 30 & & \\
\hline 4 & 17.83 & 1.05 & 31 & & \\
\hline 5 & 18.07 & 1.40 & 32 & & \\
\hline 6 & 18.13 & 2.78 & 33 & & \\
\hline 7 & 18.13 & 1.34 & 34 & & \\
\hline 8 & 18.35 & 0.51 & 35 & & \\
\hline 9 & 19.09 & 0.90 & 36 & & \\
\hline 10 & 19.64 & 0.53 & 37 & & \\
\hline 11 & 21.18 & 0.54 & 38 & & \\
\hline 12 & 21.79 & 0.90 & 39 & & \\
\hline 13 & 22.40 & 0.99 & 40 & & \\
\hline 14 & 23.19 & 0.77 & 41 & & \\
\hline 15 & 23.33 & 0.07 & 42 & & \\
\hline 16 & 23.49 & 2.38 & 43 & & \\
\hline 17 & 23.63 & 0.26 & 44 & & \\
\hline 18 & 23.72 & 0.94 & 45 & & \\
\hline 19 & 24.86 & 0.45 & 46 & & \\
\hline 20 & 25.99 & 0.13 & 47 & & \\
\hline 21 & 16.43 & 1.57 & 48 & & \\
\hline 22 & & & 49 & & \\
\hline 23 & & & 50 & & \\
\hline 24 & & & 51 & & \\
\hline 25 & & & 52 & & \\
\hline 26 & & & 53 & & \\
\hline 27 & & & 54 & & \\
\hline
\end{tabular}

Weighted Disks

$\begin{array}{lr} & \text { De }(\text { Gy }) \\ \text { Mean }= & \mathbf{2 0 . 7 4} \\ \text { Median = } & 20.41 \\ \text { Min = } & 16.57 \\ \text { Max }= & 25.99\end{array}$

$\begin{array}{cccccc}\text { Disk } & \text { De } & \text { Err } & \text { Disc } & \text { De } & \text { Err } \\ \mathbf{1} & 16.57 & 0.32 & \mathbf{2 8} & & \\ \mathbf{2} & 17.65 & 0.53 & \mathbf{2 9} & \\ \mathbf{3} & 17.78 & 0.41 & \mathbf{3 0} & \\ \mathbf{4} & 17.83 & 1.05 & \mathbf{3 1} & \\ \mathbf{5} & 18.07 & 1.40 & \mathbf{3 2} & \\ \mathbf{6} & 18.13 & 2.78 & \mathbf{3 3} & \\ \mathbf{7} & 18.13 & 1.34 & \mathbf{3 4} & \\ \mathbf{8} & 18.35 & 0.51 & \mathbf{3 5} & \\ \mathbf{9} & 19.09 & 0.90 & \mathbf{3 6} & \\ \mathbf{1 0} & 19.64 & 0.53 & \mathbf{3 7} & \\ \mathbf{1 1} & 21.18 & 0.54 & \mathbf{3 8} & \\ \mathbf{1 2} & 21.79 & 0.90 & \mathbf{3 9} & \\ \mathbf{1 3} & 22.40 & 0.99 & \mathbf{4 0} & \\ \mathbf{1 4} & 23.19 & 0.77 & \mathbf{4 1} & \\ \mathbf{1 5} & 23.33 & 0.07 & \mathbf{4 2} & \\ \mathbf{1 6} & 23.49 & 2.38 & \mathbf{4 3} \\ \mathbf{1 7} & 23.63 & 0.26 & \mathbf{4 4} & \\ \mathbf{1 8} & 23.72 & 0.94 & \mathbf{4 5} & \\ \mathbf{1 9} & 24.86 & 0.45 & \mathbf{4 6} & \\ \mathbf{2 0} & 25.99 & 0.13 & \mathbf{4 7} \\ \mathbf{2 1} & & & \mathbf{4 8} \\ \mathbf{2 2} & & & \mathbf{4 9} \\ \mathbf{2 3} & & & \mathbf{5 0} \\ \mathbf{2 4} & & & \mathbf{5 1} \\ \mathbf{2 5} & & & \mathbf{5 2} \\ \mathbf{2 6} & & & \mathbf{5 3} \\ \mathbf{2 7} & & & \mathbf{5 4}\end{array}$



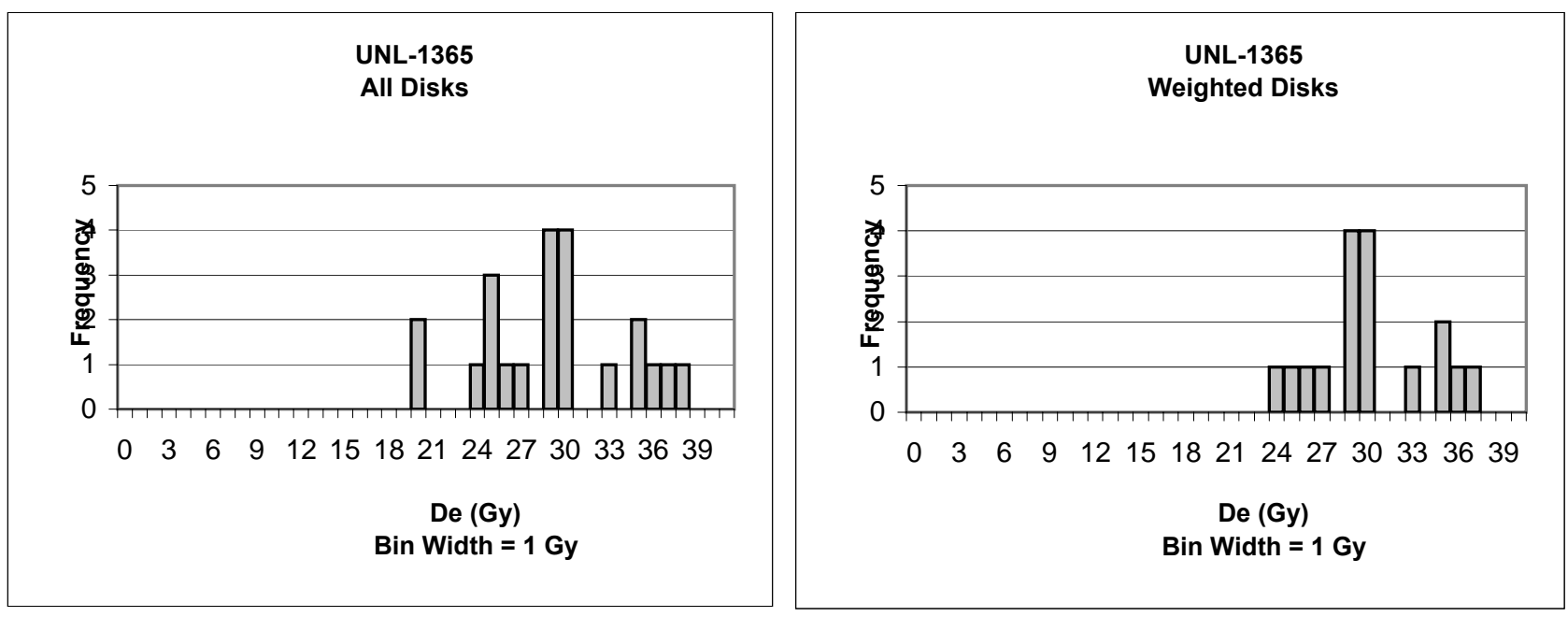

\begin{tabular}{|c|c|c|c|c|c|}
\hline \multicolumn{6}{|l|}{ All Disks } \\
\hline & $\mathrm{De}(\mathrm{Gy})$ & & & & \\
\hline Mean = & 28.67 & & S.D. $(1 \sigma)=$ & 5.02 & \\
\hline Median = & 28.46 & & Std. Err = & 1.07 & \\
\hline Min = & 19.30 & & Disks $(n)=$ & 22 & \\
\hline Max = & 37.74 & & & & \\
\hline Disk & De & Err & Disc & $\mathrm{De}$ & Err \\
\hline 1 & 23.05 & 1.76 & 28 & & \\
\hline 2 & 24.87 & 1.24 & 29 & & \\
\hline 3 & 25.70 & 1.45 & 30 & & \\
\hline 4 & 26.50 & 0.93 & 31 & & \\
\hline 5 & 28.14 & 1.07 & 32 & & \\
\hline 6 & 28.16 & 1.46 & 33 & & \\
\hline 7 & 28.27 & 1.14 & 34 & & \\
\hline 8 & 28.64 & 0.78 & 35 & & \\
\hline 9 & 29.34 & 1.01 & 36 & & \\
\hline 10 & 29.38 & 1.22 & 37 & & \\
\hline 11 & 29.78 & 0.96 & 38 & & \\
\hline 12 & 29.87 & 0.65 & 39 & & \\
\hline 13 & 32.38 & 0.90 & 40 & & \\
\hline 14 & 34.20 & 1.42 & 41 & & \\
\hline 15 & 34.55 & 1.43 & 42 & & \\
\hline 16 & 35.48 & 0.24 & 43 & & \\
\hline 17 & 36.32 & 2.58 & 44 & & \\
\hline 18 & 37.74 & 3.45 & 45 & & \\
\hline 19 & 24.84 & 2.61 & 46 & & \\
\hline 20 & 19.30 & 1.92 & 47 & & \\
\hline 21 & 19.77 & 1.92 & 48 & & \\
\hline 22 & 24.48 & 3.14 & 49 & & \\
\hline 23 & & & 50 & & \\
\hline 24 & & & 51 & & \\
\hline 25 & & & 52 & & \\
\hline 26 & & & 53 & & \\
\hline 27 & & & 54 & & \\
\hline
\end{tabular}

Weighted Disks

$\begin{array}{lclc}\text { Mean }= & \mathbf{2 9 . 6 8} & \text { S.D. }(\mathbf{1 \sigma})= & 3.79 \\ \text { Median }= & 29.34 & \text { Std. } \text { Err }= & 0.92 \\ \text { Min }= & 23.05 & \text { Disks }(\mathbf{n})= & 17 \\ \text { Max }= & 36.32 & & \end{array}$

\begin{tabular}{|c|c|c|c|c|}
\hline Disk & $\mathrm{De}$ & Err & Disc & De \\
\hline 1 & 23.05 & 1.76 & 28 & \\
\hline 2 & 24.87 & 1.24 & 29 & \\
\hline 3 & 25.70 & 1.45 & 30 & \\
\hline 4 & 26.50 & 0.93 & 31 & \\
\hline 5 & 28.14 & 1.07 & 32 & \\
\hline 6 & 28.16 & 1.46 & 33 & \\
\hline 7 & 28.27 & 1.14 & 34 & \\
\hline 8 & 28.64 & 0.78 & 35 & \\
\hline 9 & 29.34 & 1.01 & 36 & \\
\hline 10 & 29.38 & 1.22 & 37 & \\
\hline 11 & 29.78 & 0.96 & 38 & \\
\hline 12 & 29.87 & 0.65 & 39 & \\
\hline 13 & 32.38 & 0.90 & 40 & \\
\hline 14 & 34.20 & 1.42 & 41 & \\
\hline 15 & 34.55 & 1.43 & 42 & \\
\hline 16 & 35.48 & 0.24 & 43 & \\
\hline 17 & 36.32 & 2.58 & 44 & \\
\hline 18 & & & 45 & \\
\hline 19 & & & 46 & \\
\hline 20 & & & 47 & \\
\hline 21 & & & 48 & \\
\hline 22 & & & 49 & \\
\hline 23 & & & 50 & \\
\hline 24 & & & 51 & \\
\hline 25 & & & 52 & \\
\hline 26 & & & 53 & \\
\hline 27 & & & 54 & \\
\hline
\end{tabular}



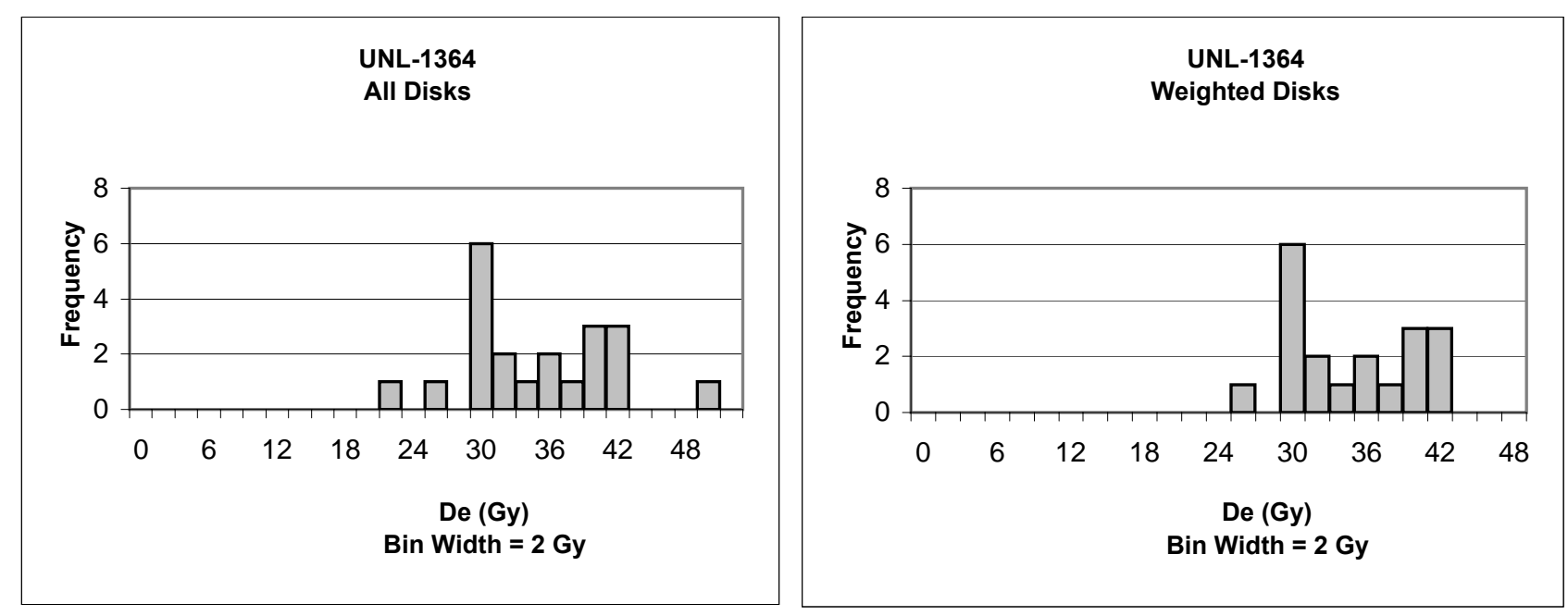

$\begin{array}{lcll}\text { All Disks } & & & \\ & \text { De }(G y) & & \\ \text { Mean }= & \mathbf{3 3 . 9 2} & \text { S.D. }(\mathbf{1} \boldsymbol{\sigma})= & 6.62 \\ \text { Median }= & 32.77 & \text { Std. Err }= & 1.45 \\ \text { Min }= & 21.07 & \text { Disks }(\mathbf{n})= & 21 \\ \text { Max }= & 48.60 & & \end{array}$

Weighted Disks

$\begin{array}{lc} & \text { De }(G y) \\ \text { Mean }= & \mathbf{3 3 . 8 2} \\ \text { Median }= & 32.77 \\ \text { Min }= & 25.19 \\ \text { Max }= & 41.76\end{array}$

$\begin{array}{cccccc}\text { Disk } & \text { De } & \text { Err } & \text { Disc } & \text { De } & \text { Err } \\ \mathbf{1} & 25.19 & 1.70 & \mathbf{2 8} & & \\ \mathbf{2} & 28.45 & 3.46 & \mathbf{2 9} & \\ \mathbf{3} & 28.57 & 0.30 & \mathbf{3 0} & \\ \mathbf{4} & 28.64 & 0.10 & \mathbf{3 1} & \\ \mathbf{5} & 29.13 & 0.85 & \mathbf{3 2} & \\ \mathbf{6} & 29.29 & 1.76 & \mathbf{3 3} & \\ \mathbf{7} & 29.60 & 1.75 & \mathbf{3 4} & \\ \mathbf{8} & 31.13 & 0.74 & \mathbf{3 5} & \\ \mathbf{9} & 31.71 & 0.13 & \mathbf{3 6} & \\ \mathbf{1 0} & 32.77 & 0.58 & \mathbf{3 7} & \\ \mathbf{1 1} & 34.15 & 5.16 & \mathbf{3 8} & \\ \mathbf{1 2} & 35.19 & 0.75 & \mathbf{3 9} & \\ \mathbf{1 3} & 37.74 & 0.90 & \mathbf{4 0} & \\ \mathbf{1 4} & 38.46 & 0.89 & \mathbf{4 1} & \\ \mathbf{1 5} & 39.45 & 0.52 & \mathbf{4 2} & \\ \mathbf{1 6} & 39.99 & 0.67 & \mathbf{4 3} \\ \mathbf{1 7} & 40.52 & 0.43 & \mathbf{4 4} & \\ \mathbf{1 8} & 40.86 & 0.68 & \mathbf{4 5} & \\ \mathbf{1 9} & 41.76 & 1.21 & \mathbf{4 6} & \\ \mathbf{2 0} & & & \mathbf{4 7} \\ \mathbf{2 1} & & & \mathbf{4 8} \\ \mathbf{2 2} & & & \mathbf{4 9} \\ \mathbf{2 3} & & & \mathbf{5 0} \\ \mathbf{2 4} & & & \mathbf{5 1} \\ \mathbf{2 5} & & & \mathbf{5 2} \\ \mathbf{2 6} & & & \mathbf{5 3} \\ \mathbf{2 7} & & & \mathbf{5 4}\end{array}$




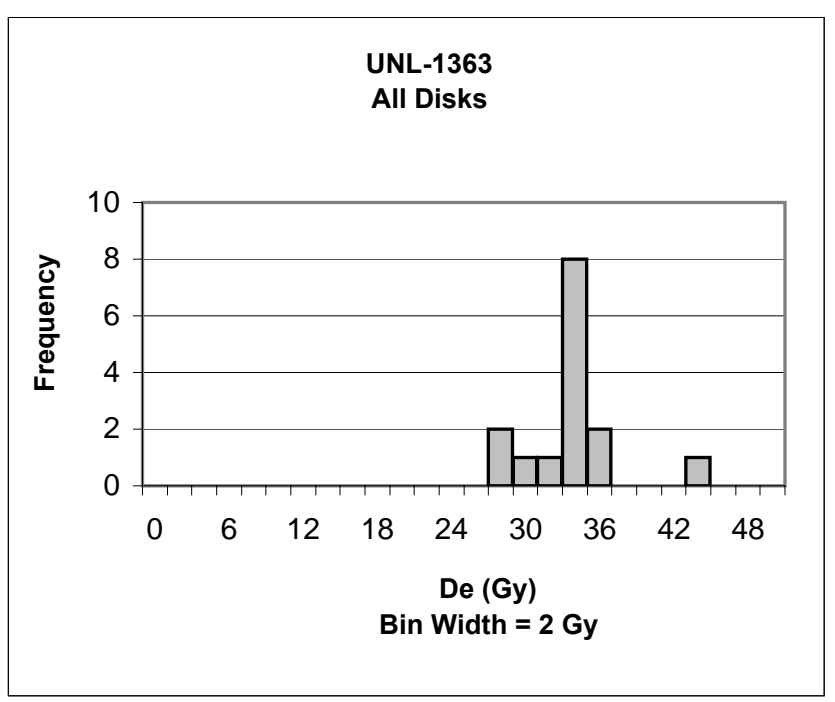

All Disks

$\begin{array}{lcll} & \text { De (Gy) } & & \\ \text { Mean }= & 33.04 & \text { S.D. }(1 \sigma)= & 3.86 \\ \text { Median }= & 33.38 & \text { Std. Err }= & 1.00 \\ \text { Min }= & 26.77 & \text { Disks }(\mathbf{n})= & 15 \\ \text { Max }= & 43.82 & & \end{array}$

\begin{tabular}{|c|c|c|c|c|}
\hline Disk & De & Err & Disc & $\mathrm{De}$ \\
\hline 1 & 43.82 & 2.38 & 28 & \\
\hline 2 & 27.50 & 1.72 & 29 & \\
\hline 3 & 34.23 & 1.71 & 30 & \\
\hline 4 & 33.81 & 1.98 & 31 & \\
\hline 5 & 33.38 & 2.25 & 32 & \\
\hline 6 & 33.36 & 5.10 & 33 & \\
\hline 7 & 32.52 & 0.40 & 34 & \\
\hline 8 & 32.53 & 1.17 & 35 & \\
\hline 9 & 31.19 & 1.19 & 36 & \\
\hline 10 & 33.97 & 0.37 & 37 & \\
\hline 11 & 33.64 & 0.93 & 38 & \\
\hline 12 & 26.77 & 0.82 & 39 & \\
\hline 13 & 33.77 & 1.11 & 40 & \\
\hline 14 & 29.89 & 0.20 & 41 & \\
\hline 15 & 35.27 & 0.54 & 42 & \\
\hline 16 & & & 43 & \\
\hline 17 & & & 44 & \\
\hline 18 & & & 45 & \\
\hline 19 & & & 46 & \\
\hline 20 & & & 47 & \\
\hline 21 & & & 48 & \\
\hline 22 & & & 49 & \\
\hline 23 & & & 50 & \\
\hline 24 & & & 51 & \\
\hline 25 & & & 52 & \\
\hline 26 & & & 53 & \\
\hline 27 & & & 54 & \\
\hline
\end{tabular}

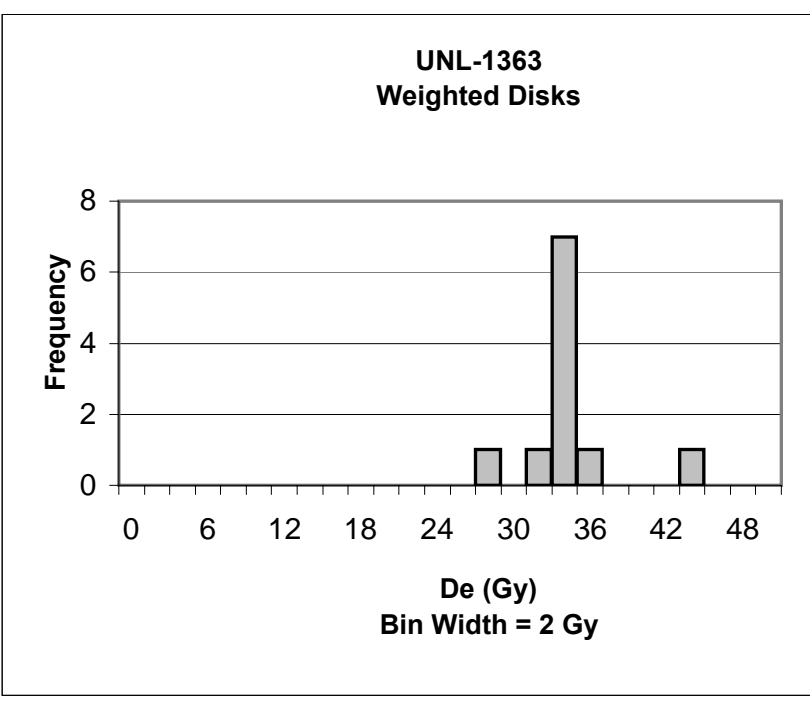

Weighted Disks

De (Gy)

Mean $=\quad 33.63$

Median $=\quad 33.38$

Min $=\quad 27.50$

Max $=\quad 43.82$

\begin{tabular}{|c|c|c|c|c|}
\hline Disk & $\mathrm{De}$ & Err & Disc & De \\
\hline 1 & 43.82 & 2.38 & 28 & \\
\hline 2 & 27.50 & 1.72 & 29 & \\
\hline 3 & 34.23 & 1.71 & 30 & \\
\hline 4 & 33.81 & 1.98 & 31 & \\
\hline 5 & 33.38 & 2.25 & 32 & \\
\hline 6 & 33.36 & 5.10 & 33 & \\
\hline 7 & 32.52 & 0.40 & 34 & \\
\hline 8 & 32.53 & 1.17 & 35 & \\
\hline 9 & 31.19 & 1.19 & 36 & \\
\hline 10 & 33.97 & 0.37 & 37 & \\
\hline 11 & 33.64 & 0.93 & 38 & \\
\hline 12 & & & 39 & \\
\hline 13 & & & 40 & \\
\hline 14 & & & 41 & \\
\hline 15 & & & 42 & \\
\hline 16 & & & 43 & \\
\hline 17 & & & 44 & \\
\hline 18 & & & 45 & \\
\hline 19 & & & 46 & \\
\hline 20 & & & 47 & \\
\hline 21 & & & 48 & \\
\hline 22 & & & 49 & \\
\hline 23 & & & 50 & \\
\hline 24 & & & 51 & \\
\hline 25 & & & 52 & \\
\hline 26 & & & 53 & \\
\hline 27 & & & 54 & \\
\hline
\end{tabular}




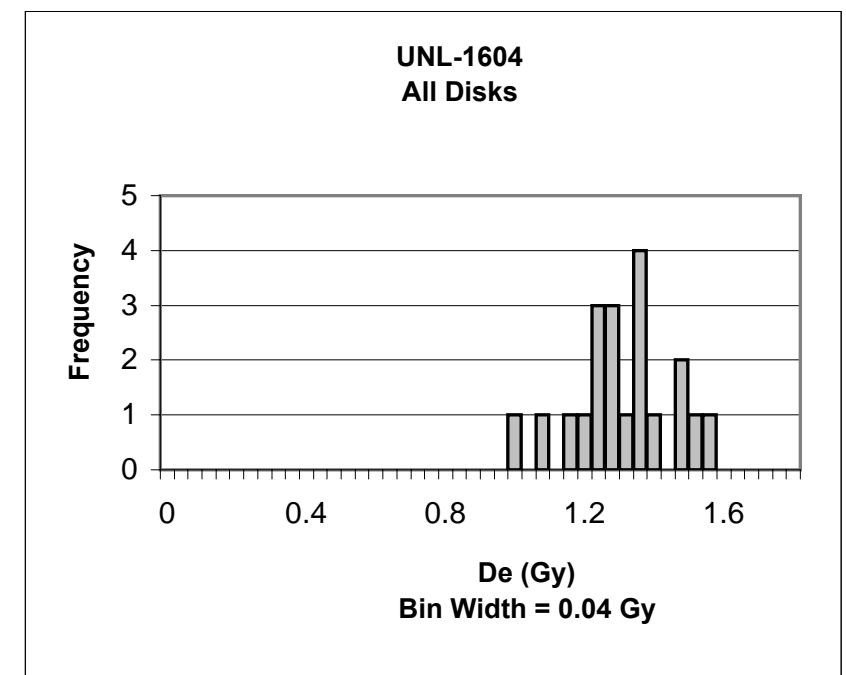

\section{All Disks}

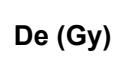

$\begin{array}{ll}\text { Mean }= & \mathbf{1 . 2 9} \\ \text { Median }= & 1.29 \\ \text { Min }= & 1.00 \\ \text { Max }= & 1.52\end{array}$

$\begin{array}{cccccc}\text { Disk } & \text { De } & \text { Err } & \text { Disc } & \text { De } & \text { Err } \\ 1 & 1.29 & 0.06 & \mathbf{2 8} & & \\ 2 & 1.44 & 0.12 & \mathbf{2 9} & & \\ 3 & 1.37 & 0.19 & 30 & & \end{array}$

S.D. $(1 \sigma)=0.13$

Std. Err $=\quad 0.03$

Disks $(\mathbf{n})=\quad 20$

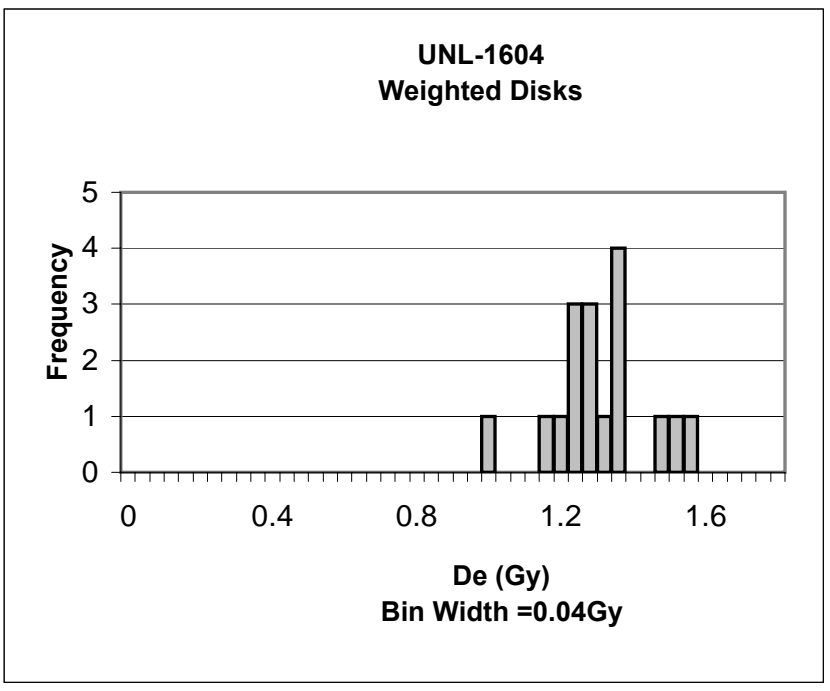

Weighted Disks

$\begin{array}{lll}1.37 & 0.19 & 30\end{array}$

$\begin{array}{lll}1.36 & 0.02 & 31\end{array}$

$\begin{array}{lll}1.20 & 0.11 & 32\end{array}$

$\begin{array}{lll}1.07 & 0.18 & 33\end{array}$

$\begin{array}{lll}1.15 & 0.05 & 34\end{array}$

$\begin{array}{lll}1.22 & 0.05 & 35\end{array}$

$\begin{array}{lll}1.27 & 0.05 & 36\end{array}$

$\begin{array}{lll}1.18 & 0.15 & 37\end{array}$

$\begin{array}{lll}1.34 & 0.15 & 38\end{array}$

$\begin{array}{lll}1.25 & 0.05 & 39\end{array}$

$\begin{array}{lll}1.00 & 0.13 & 40\end{array}$

$\begin{array}{lll}1.24 & 0.03 & 41\end{array}$

$\begin{array}{lll}1.33 & 0.07 & 42\end{array}$

$\begin{array}{lll}1.52 & 0.06 & 43\end{array}$

$\begin{array}{lll}1.46 & 0.09 & 44\end{array}$

$\begin{array}{lll}1.49 & 0.07 & 45\end{array}$

$\begin{array}{lll}1.34 & 0.08 & 46\end{array}$

$\begin{array}{lll}1.28 & 0.09 & 47\end{array}$

48

49

50

51

52

53

54
De (Gy)

$\begin{array}{ll}\text { Mean }= & \mathbf{1 . 2 9} \\ \text { Median }= & 1.28 \\ \text { Min }= & 1.00 \\ \text { Max }= & 1.52\end{array}$

S.D. $(1 \sigma)=0.13$

Std. Err $=\quad 0.03$

$\operatorname{Disks}(\mathbf{n})=17$

$\begin{array}{ccccc}\text { Disk } & \text { De } & \text { Err } & \text { Disc } & \text { De } \\ 1 & 1.29 & 0.06 & \mathbf{2 8} & \\ 2 & 1.36 & 0.02 & \mathbf{2 9} \\ 3 & 1.20 & 0.11 & \mathbf{3 0} \\ \mathbf{4} & 1.15 & 0.05 & \mathbf{3 1} \\ \mathbf{5} & 1.22 & 0.05 & \mathbf{3 2} \\ \mathbf{6} & 1.27 & 0.05 & \mathbf{3 3} \\ \mathbf{7} & 1.18 & 0.15 & \mathbf{3 4} \\ \mathbf{8} & 1.34 & 0.15 & \mathbf{3 5} \\ \mathbf{9} & 1.25 & 0.05 & \mathbf{3 6} \\ 10 & 1.00 & 0.13 & \mathbf{3 7} \\ \mathbf{1 1} & 1.24 & 0.03 & \mathbf{3 8} \\ \mathbf{1 2} & 1.33 & 0.07 & \mathbf{3 9} \\ \mathbf{1 3} & 1.52 & 0.06 & \mathbf{4 0} \\ \mathbf{1 4} & 1.46 & 0.09 & \mathbf{4 1} \\ \mathbf{1 5} & 1.49 & 0.07 & \mathbf{4 2} \\ \mathbf{1 6} & 1.34 & 0.08 & \mathbf{4 3} \\ \mathbf{1 7} & 1.28 & 0.09 & \mathbf{4 4} \\ \mathbf{1 8} & & & \mathbf{4 5} \\ \mathbf{1 9} & & & \mathbf{4 6} \\ \mathbf{2 0} & & & \mathbf{4 7} \\ \mathbf{2 1} & & & \mathbf{4 8} \\ \mathbf{2 2} & & & \mathbf{4 9} \\ \mathbf{2 3} & & & \mathbf{5 0} \\ \mathbf{2 4} & & & \mathbf{5 1} \\ \mathbf{2 5} & & & \mathbf{5 2} \\ \mathbf{2 6} & & & \mathbf{5 3} \\ \mathbf{2 7} & & & \mathbf{5 4}\end{array}$




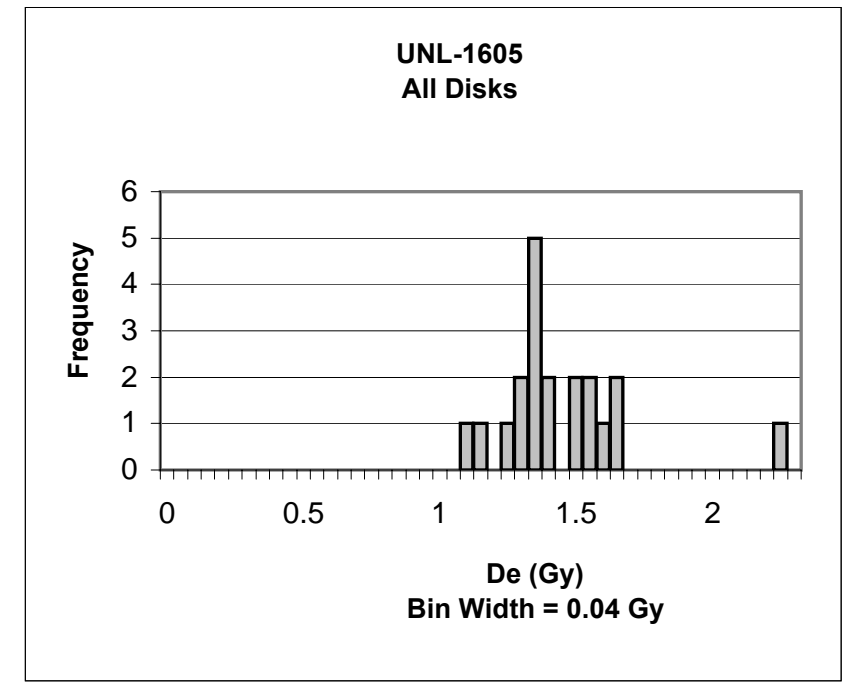

$\begin{array}{lcll}\text { All Disks } & & & \\ & \text { De }(G y) & & \\ \text { Mean }= & \mathbf{1 . 4 2} & \text { S.D. }(\mathbf{1 \sigma})= & 0.24 \\ \text { Median }= & 1.36 & \text { Std. Err }= & 0.05 \\ \text { Min }= & 1.07 & \text { Disks }(\mathbf{n})= & 20 \\ \text { Max }= & 2.22 & & \end{array}$

\begin{tabular}{|c|c|c|c|c|}
\hline Disk & $\mathrm{De}$ & Err & Disc & De \\
\hline 1 & 1.14 & 0.11 & 28 & \\
\hline 2 & 1.40 & 0.05 & 29 & \\
\hline 3 & 1.29 & 0.07 & 30 & \\
\hline 4 & 2.22 & 0.13 & 31 & \\
\hline 5 & 1.31 & 0.08 & 32 & \\
\hline 6 & 1.34 & 0.09 & 33 & \\
\hline 7 & 1.23 & 0.02 & 34 & \\
\hline 8 & 1.33 & 0.12 & 35 & \\
\hline 9 & 1.31 & 0.02 & 36 & \\
\hline 10 & 1.07 & 0.10 & 37 & \\
\hline 11 & 1.27 & 0.05 & 38 & \\
\hline 12 & 1.47 & 0.07 & 39 & \\
\hline 13 & 1.60 & 0.09 & 40 & \\
\hline 14 & 1.59 & 0.04 & 41 & \\
\hline 15 & 1.31 & 0.05 & 42 & \\
\hline 16 & 1.39 & 0.09 & 43 & \\
\hline 17 & 1.64 & 0.14 & 44 & \\
\hline 18 & 1.52 & 0.02 & 45 & \\
\hline 19 & 1.51 & 0.05 & 46 & \\
\hline 20 & 1.46 & 0.06 & 47 & \\
\hline 21 & & & 48 & \\
\hline 22 & & & 49 & \\
\hline 23 & & & 50 & \\
\hline 24 & & & 51 & \\
\hline 25 & & & 52 & \\
\hline 26 & & & 53 & \\
\hline 27 & & & 54 & \\
\hline
\end{tabular}

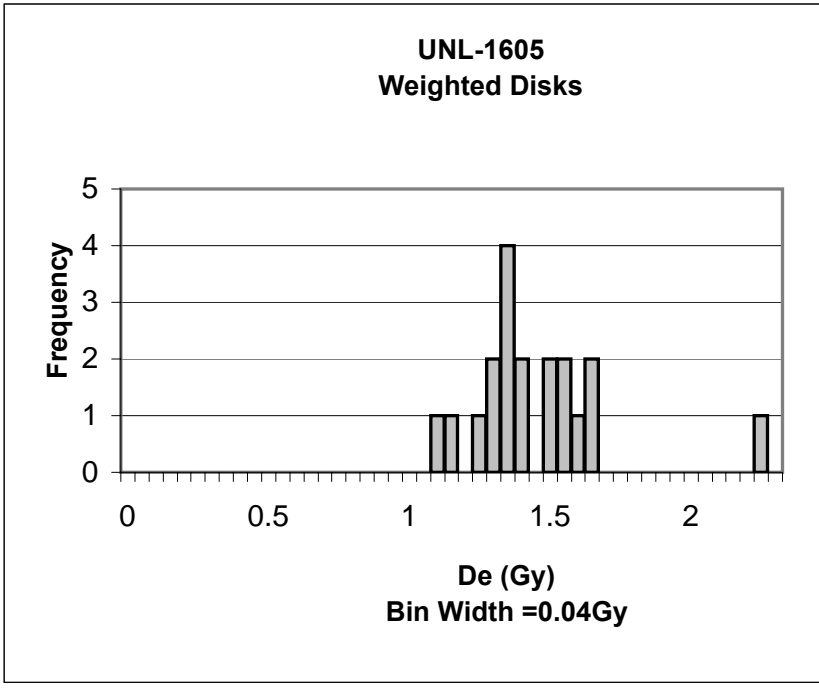

Weighted Disks De (Gy)

Mean $=\quad 1.43$

Median $=\quad 1.39$

Min $=\quad 1.07$

Max $=2.22$
Weighted Disks

$\begin{array}{ccccc}\text { Disk } & \text { De } & \text { Err } & \text { Disc } & \text { De } \\ \mathbf{1} & 1.14 & 0.11 & \mathbf{2 8} & \\ \mathbf{2} & 1.40 & 0.05 & \mathbf{2 9} \\ \mathbf{3} & 1.29 & 0.07 & \mathbf{3 0} \\ \mathbf{4} & 2.22 & 0.13 & \mathbf{3 1} \\ \mathbf{5} & 1.31 & 0.08 & \mathbf{3 2} \\ \mathbf{6} & 1.23 & 0.02 & \mathbf{3 3} \\ \mathbf{7} & 1.33 & 0.12 & \mathbf{3 4} \\ \mathbf{8} & 1.31 & 0.02 & \mathbf{3 5} \\ \mathbf{9} & 1.07 & 0.10 & \mathbf{3 6} \\ \mathbf{1 0} & 1.27 & 0.05 & \mathbf{3 7} \\ \mathbf{1 1} & 1.47 & 0.07 & \mathbf{3 8} \\ \mathbf{1 2} & 1.60 & 0.09 & \mathbf{3 9} \\ \mathbf{1 3} & 1.59 & 0.04 & \mathbf{4 0} \\ \mathbf{1 4} & 1.31 & 0.05 & \mathbf{4 1} \\ \mathbf{1 5} & 1.39 & 0.09 & \mathbf{4 2} \\ \mathbf{1 6} & 1.64 & 0.14 & \mathbf{4 3} \\ \mathbf{1 7} & 1.52 & 0.02 & \mathbf{4 4} \\ \mathbf{1 8} & 1.51 & 0.05 & \mathbf{4 5} \\ \mathbf{1 9} & 1.46 & 0.06 & \mathbf{4 6} \\ \mathbf{2 0} & & & \mathbf{4 7} \\ \mathbf{2 1} & & & \mathbf{4 8} \\ \mathbf{2 2} & & & \mathbf{4 9} \\ \mathbf{2 3} & & & \mathbf{5 0} \\ \mathbf{2 4} & & & \mathbf{5 1} \\ \mathbf{2 5} & & & \mathbf{5 2} \\ \mathbf{2 6} & & & \mathbf{5 3} \\ \mathbf{2 7} & & & \mathbf{5 4}\end{array}$




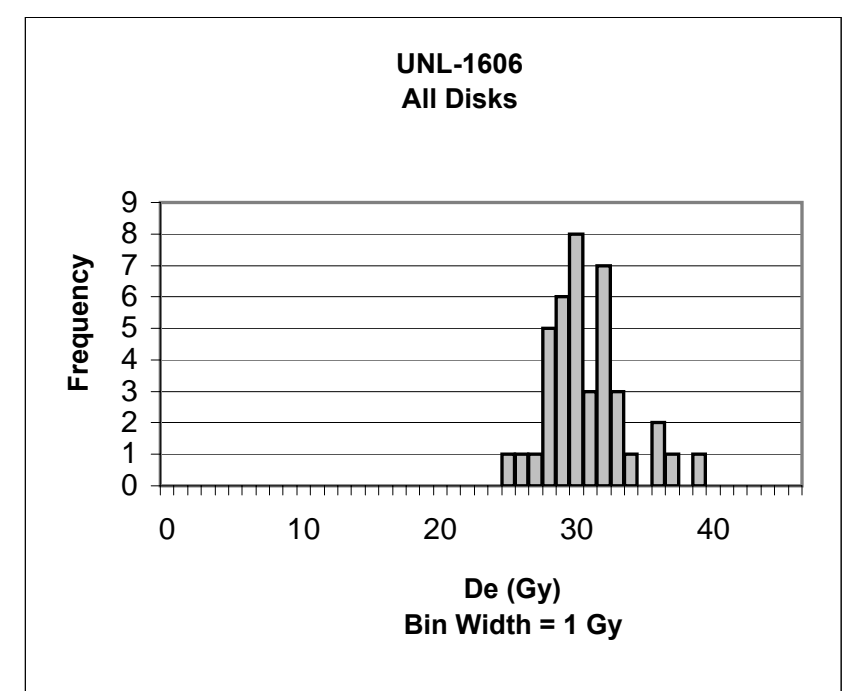

$\begin{array}{lc}\text { All Disks } & \\ & \text { De }(\text { Gy }) \\ \text { Mean }= & \mathbf{3 0 . 2 2} \\ \text { Median }= & 29.63 \\ \text { Min }= & 24.42 \\ \text { Max }= & 38.76\end{array}$

$\begin{array}{cccccc}\text { Disk } & \text { De } & \text { Err } & \text { Disc } & \text { De } & \text { Err } \\ \mathbf{1} & 26.84 & 1.75 & \mathbf{2 8} & 32.91 & 0.68 \\ \mathbf{2} & 38.76 & 0.97 & \mathbf{2 9} & 31.43 & 0.99 \\ \mathbf{3} & 28.18 & 1.31 & \mathbf{3 0} & 35.04 & 0.23 \\ \mathbf{4} & 27.88 & 0.83 & \mathbf{3 1} & 29.58 & 1.21 \\ \mathbf{5} & 25.24 & 1.36 & \mathbf{3 2} & 31.68 & 0.60 \\ \mathbf{6} & 28.44 & 0.36 & \mathbf{3 3} & 27.12 & 0.31 \\ \mathbf{7} & 29.11 & 0.93 & \mathbf{3 4} & 33.06 & 1.33 \\ \mathbf{8} & 29.97 & 1.11 & \mathbf{3 5} & 27.64 & 1.11 \\ \mathbf{9} & 31.07 & 0.43 & \mathbf{3 6} & 36.28 & 2.73 \\ \mathbf{1 0} & 31.70 & 0.48 & \mathbf{3 7} & 29.00 & 0.17 \\ \mathbf{1 1} & 31.69 & 0.93 & \mathbf{3 8} & 30.39 & 0.32 \\ \mathbf{1 2} & 31.06 & 0.36 & \mathbf{3 9} & 27.76 & 1.57 \\ \mathbf{1 3} & 35.05 & 0.59 & \mathbf{4 0} & 28.25 & 0.52 \\ \mathbf{1 4} & 32.12 & 0.58 & \mathbf{4 1} & & \\ \mathbf{1 5} & 30.39 & 0.71 & \mathbf{4 2} & & \\ \mathbf{1 6} & 32.33 & 0.86 & \mathbf{4 3} & & \\ \mathbf{1 7} & 29.58 & 0.59 & \mathbf{4 4} & & \\ \mathbf{1 8} & 28.68 & 1.33 & \mathbf{4 5} & & \\ \mathbf{1 9} & 31.89 & 0.49 & \mathbf{4 6} & & \\ \mathbf{2 0} & 27.87 & 0.87 & \mathbf{4 7} & & \\ \mathbf{2 1} & 28.04 & 0.29 & \mathbf{4 8} & & \\ \mathbf{2 2} & 24.42 & 1.27 & \mathbf{4 9} & & \\ \mathbf{2 3} & 29.67 & 0.54 & \mathbf{5 0} & & \\ \mathbf{2 4} & 28.66 & 0.16 & \mathbf{5 1} & & \\ \mathbf{2 5} & 30.71 & 0.48 & \mathbf{5 2} & & \\ \mathbf{2 6} & 29.57 & 0.16 & \mathbf{5 3} & & \\ \mathbf{2 7} & 29.59 & 1.89 & \mathbf{5 4} & & \\ & & & & & \end{array}$

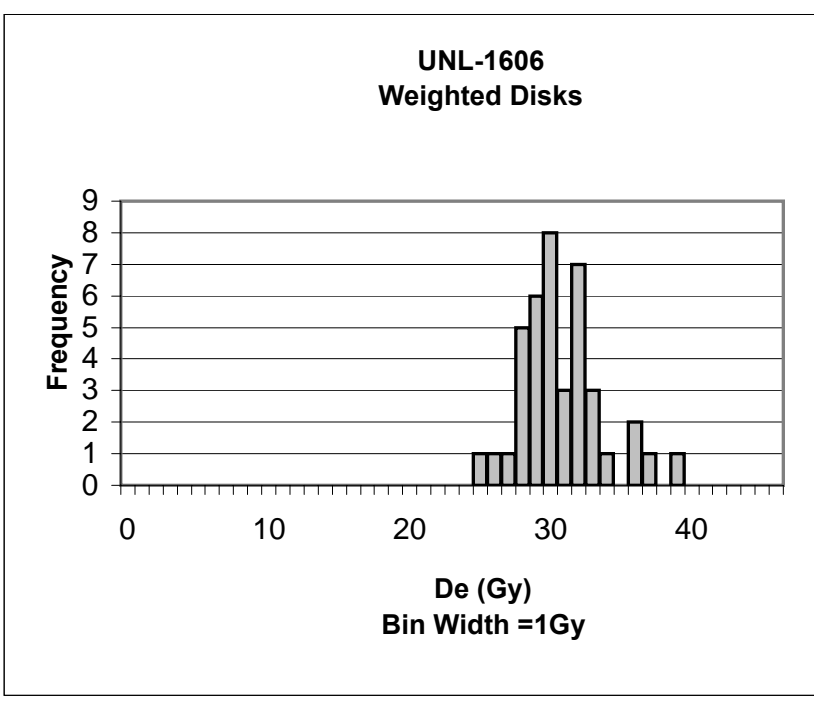

Weighted Disks

S.D. $(1 \sigma)=2.87$

Std. Err $=\quad 0.46$

Disks $(\mathbf{n})=\quad 40$
De (Gy)

Mean $=\quad 30.22$

Median $=29.63$

Min $=\quad 24.42$

Max $=\quad 38.76$
S.D. $(1 \sigma)=2.87$

Std. Err $=\quad 0.46$

Disks $(\mathbf{n})=\quad 40$

\begin{tabular}{|c|c|c|c|c|c|}
\hline Disk & $\mathrm{De}$ & Err & Disc & De & Err \\
\hline 1 & 26.84 & 1.75 & 28 & 32.91 & 0.68 \\
\hline 2 & 38.76 & 0.97 & 29 & 31.43 & 0.99 \\
\hline 3 & 28.18 & 1.31 & 30 & 35.04 & 0.23 \\
\hline 4 & 27.88 & 0.83 & 31 & 29.58 & 1.21 \\
\hline 5 & 25.24 & 1.36 & 32 & 31.68 & 0.60 \\
\hline 6 & 28.44 & 0.36 & 33 & 27.12 & 0.31 \\
\hline 7 & 29.11 & 0.93 & 34 & 33.06 & 1.33 \\
\hline 8 & 29.97 & 1.11 & 35 & 27.64 & 1.11 \\
\hline 9 & 31.07 & 0.43 & 36 & 36.28 & 2.73 \\
\hline 10 & 31.70 & 0.48 & 37 & 29.00 & 0.17 \\
\hline 11 & 31.69 & 0.93 & 38 & 30.39 & 0.32 \\
\hline 12 & 31.06 & 0.36 & 39 & 27.76 & 1.57 \\
\hline 13 & 35.05 & 0.59 & 40 & 28.25 & 0.52 \\
\hline 14 & 32.12 & 0.58 & 41 & & \\
\hline 15 & 30.39 & 0.71 & 42 & & \\
\hline 16 & 32.33 & 0.86 & 43 & & \\
\hline 17 & 29.58 & 0.59 & 44 & & \\
\hline 18 & 28.68 & 1.33 & 45 & & \\
\hline 19 & 31.89 & 0.49 & 46 & & \\
\hline 20 & 27.87 & 0.87 & 47 & & \\
\hline 21 & 28.04 & 0.29 & 48 & & \\
\hline 22 & 24.42 & 1.27 & 49 & & \\
\hline 23 & 29.67 & 0.54 & 50 & & \\
\hline 24 & 28.66 & 0.16 & 51 & & \\
\hline 25 & 30.71 & 0.48 & 52 & & \\
\hline 26 & 29.57 & 0.16 & 53 & & \\
\hline 27 & 29.59 & 1.89 & 54 & & \\
\hline
\end{tabular}




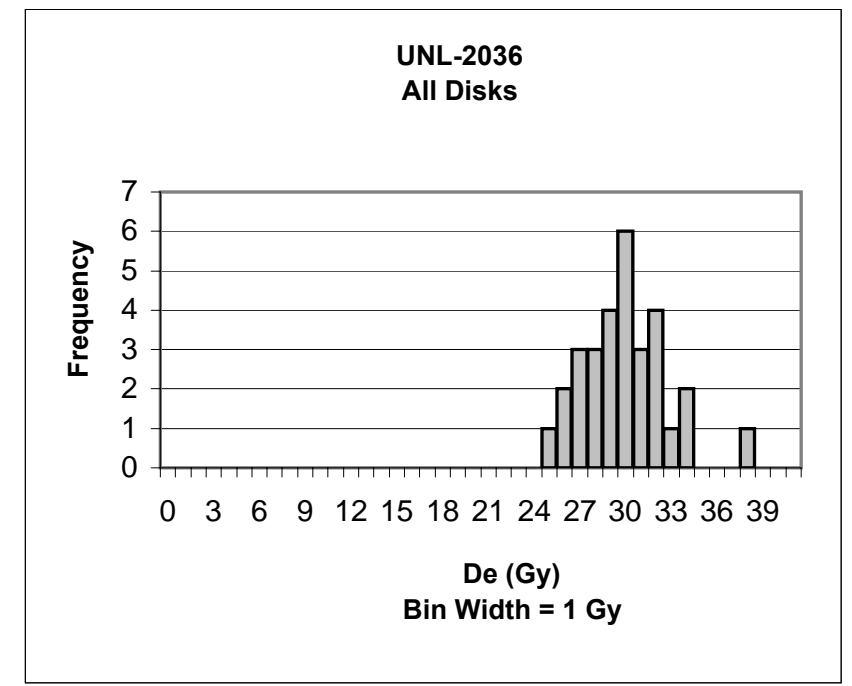

$\begin{array}{lc}\text { All Disks } & \\ \text { Mean = } & \text { De }(G y) \\ \text { Median }= & 29.38 \\ \text { Min }= & 24.25 \\ \text { Max }= & 37.44\end{array}$

\begin{tabular}{|c|c|c|c|c|c|}
\hline Disk & De & Err & Disc & $\mathrm{De}$ & Err \\
\hline 1 & 24.54 & 1.11 & 28 & 33.28 & 1.67 \\
\hline 2 & 25.29 & 0.70 & 29 & 28.83 & 0.95 \\
\hline 3 & 25.30 & 0.79 & 30 & 37.44 & 1.41 \\
\hline 4 & 26.15 & 0.83 & 31 & & \\
\hline 5 & 26.38 & 0.91 & 32 & & \\
\hline 6 & 26.87 & 0.82 & 33 & & \\
\hline 7 & 27.38 & 0.64 & 34 & & \\
\hline 8 & 27.55 & 1.08 & 35 & & \\
\hline 9 & 27.55 & 1.22 & 36 & & \\
\hline 10 & 28.23 & 0.98 & 37 & & \\
\hline 11 & 28.52 & 0.63 & 38 & & \\
\hline 12 & 28.58 & 0.73 & 39 & & \\
\hline 13 & 29.08 & 1.08 & 40 & & \\
\hline 14 & 29.25 & 1.33 & 41 & & \\
\hline 15 & 29.26 & 0.64 & 42 & & \\
\hline 16 & 29.39 & 0.75 & 43 & & \\
\hline 17 & 29.73 & 0.81 & 44 & & \\
\hline 18 & 29.78 & 0.71 & 45 & & \\
\hline 19 & 30.27 & 0.68 & 46 & & \\
\hline 20 & 30.36 & 0.64 & 47 & & \\
\hline 21 & 30.92 & 0.86 & 48 & & \\
\hline 22 & 31.27 & 1.15 & 49 & & \\
\hline 23 & 31.39 & 1.00 & 50 & & \\
\hline 24 & 31.54 & 0.77 & 51 & & \\
\hline 25 & 31.79 & 0.97 & 52 & & \\
\hline 26 & 32.40 & 0.81 & 53 & & \\
\hline 27 & 33.10 & 0.83 & 54 & & \\
\hline
\end{tabular}

S.D. $(1 \sigma)=\quad 2.77$

Std. Err $=\quad 0.51$

Disks $(\mathbf{n})=\quad 30$

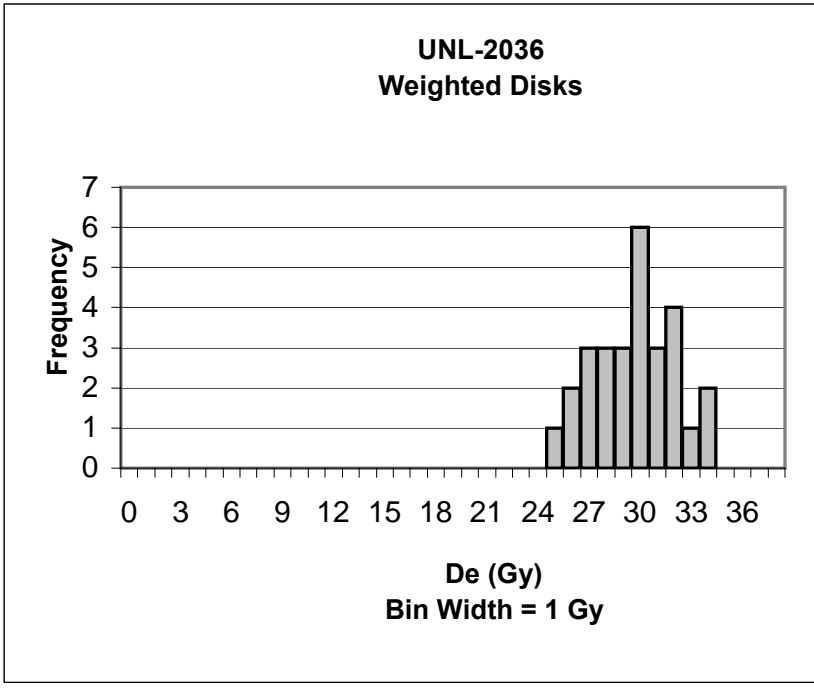

Weighted Disks

Mean $=\quad 29.11$

Median $=29.25$

Min $=\quad 24.54$

Max $=\quad 33.28$

$\begin{array}{cccccc}\text { Disk } & \text { De } & \text { Err } & \text { Disc } & \text { De } & \text { Err } \\ 1 & 24.54 & 1.11 & \mathbf{2 8} & 33.28 & 1.67 \\ 2 & 25.29 & 0.70 & \mathbf{2 9} & & \\ 3 & 25.30 & 0.79 & \mathbf{3 0} & & \\ \mathbf{4} & 26.15 & 0.83 & \mathbf{3 1} & & \\ \mathbf{5} & 26.38 & 0.91 & \mathbf{3 2} & & \\ \mathbf{6} & 26.87 & 0.82 & \mathbf{3 3} & & \\ \mathbf{7} & 27.38 & 0.64 & \mathbf{3 4} & \\ \mathbf{8} & 27.55 & 1.08 & \mathbf{3 5} & \\ \mathbf{9} & 27.55 & 1.22 & \mathbf{3 6} & \\ \mathbf{1 0} & 28.23 & 0.98 & \mathbf{3 7} & \\ \mathbf{1 1} & 28.52 & 0.63 & \mathbf{3 8} & \\ \mathbf{1 2} & 28.58 & 0.73 & \mathbf{3 9} & \\ 13 & 29.08 & 1.08 & \mathbf{4 0} & \\ 14 & 29.25 & 1.33 & \mathbf{4 1} & \\ 15 & 29.26 & 0.64 & \mathbf{4 2} & \\ 16 & 29.39 & 0.75 & \mathbf{4 3} & \\ 17 & 29.73 & 0.81 & \mathbf{4 4} & \\ 18 & 29.78 & 0.71 & \mathbf{4 5} & \\ 19 & 30.27 & 0.68 & \mathbf{4 6} & \\ \mathbf{2 0} & 30.36 & 0.64 & \mathbf{4 7} & \\ \mathbf{2 1} & 30.92 & 0.86 & \mathbf{4 8} & \\ \mathbf{2 2} & 31.27 & 1.15 & \mathbf{4 9} & \\ \mathbf{2 3} & 31.39 & 1.00 & \mathbf{5 0} & \\ \mathbf{2 4} & 31.54 & 0.77 & \mathbf{5 1} & \\ \mathbf{2 5} & 31.79 & 0.97 & \mathbf{5 2} & \\ \mathbf{2 6} & 32.40 & 0.81 & \mathbf{5 3} & \\ \mathbf{2 7} & 33.10 & 0.83 & \mathbf{5 4} & \\ \end{array}$

S.D. $(1 \sigma)=2.39$

Std. Err $=\quad 0.45$

Disks $(n)=28$ 